\title{
Geophysical Database of the East Coast of the United States: Southern Atlantic Margin - Stratigraphy and Velocity from Multichannel Seismic Profiles
}

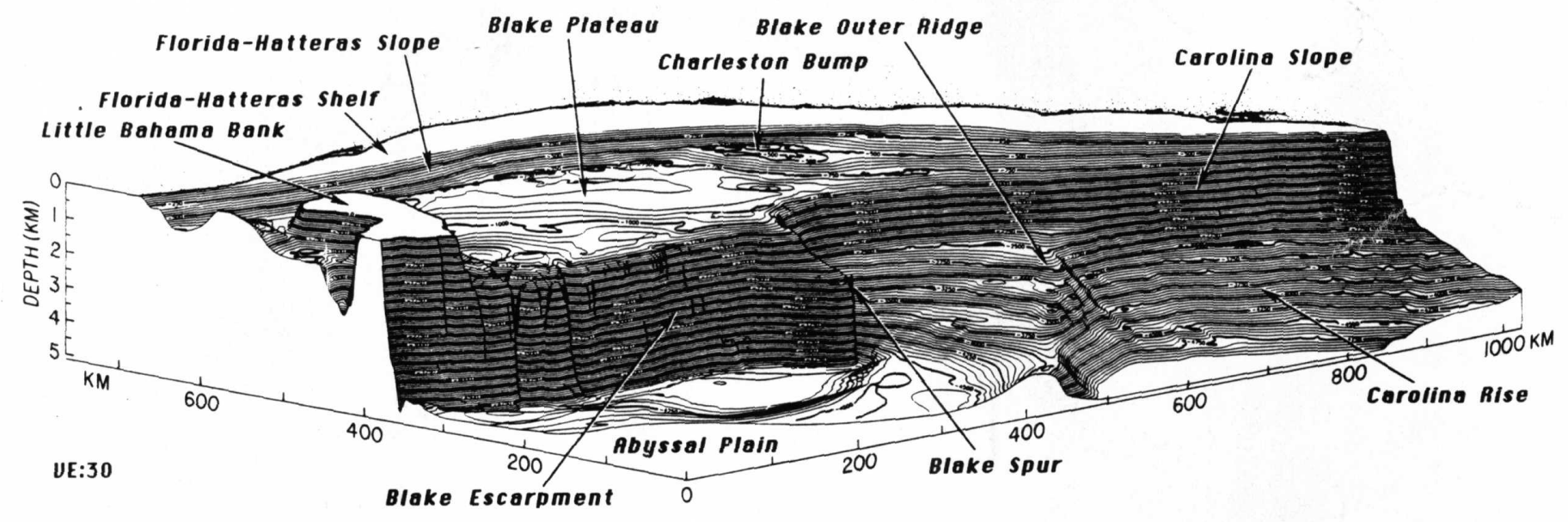

D.R. Hutchinson, C.W. Poag, and P. Popenoe

U.S. Geological Survey

Woods Hole, MA 02543

U.S. Geological Survey

Open File Report 95-27 


\title{
Geophysical Database of the East Coast of the United States: \\ Southern Atlantic Margin - Stratigraphy and Velocity from Multichannel Seismic Profiles
}

\author{
by \\ D.R. Hutchinson, C.W. Poag, and P. Popenoe \\ U.S. Geological Survey \\ Woods Hole, MA 02543
}

U.S. Geological Survey

Open File Report 95-27

1995

This report is preliminary and has not been reviewed for conformity with U.S. Geological Survey editorial standards and nomenclature. Use of trade names is for the purposes of identification only and does not contitute endorsement by the U.S. Geological Survey. 


\section{TABLE OF CONTENTS}

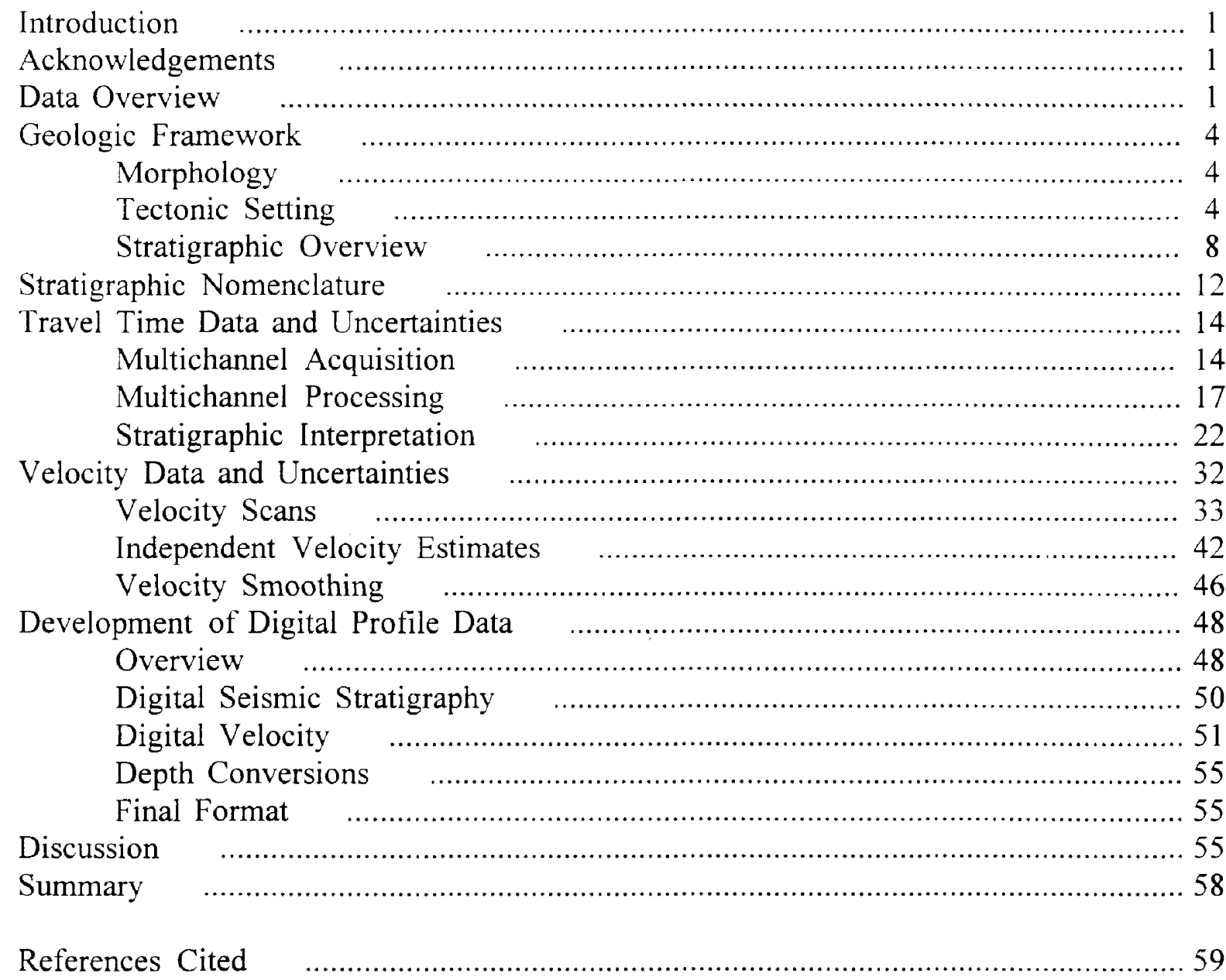

APPENDICES (Note these are a separate document on 11 in. $\times 17$ in. paper)

Appendix 1 Travel Time and Depth Profiles ……............................................ 67

Appendix 2 Initial and Final RMS Velocity Plots _......................................... 96

Appendix 3 Initial and Final Interval Velocity Plots ….................................... 126

Appendix 4 Independent Refraction Velocities …….......................................... 156 


\section{LIST OF TABLES}

Table 1 Multichannel Line Segments 6

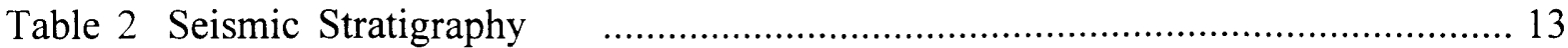

Table 3 Description of Information about Multichannel Profiles ….................... 16

Table 4 Locations of Well and Other Samples ……......................................... 31

\section{LIST OF FIGURES}

Figure 1A: Location of Multichannel Profiles

Figure 1B: Physiography of the U.S. Continental Margin $\quad$............................... 3

Figure 2: Simplified Tectonic Map of the Study Area …………….................... 5

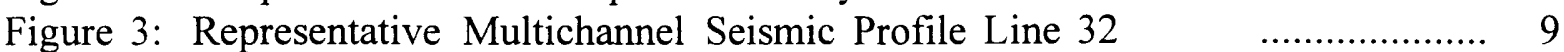

Figure 4: Representative Multichannel Seismic Profile Line TD-4 ……............ 11

Figure 5: Hypothetical Stratigraphy with Terminology and Labelling Conventions 15

Figure 6A: MCS Profiles at crossing of Lines 32 and TD-1 …........................ 19

Figure 6B: MCS Profiles at crossing of Lines BT-8 and FC-7 .......................... 20

Figure 6C: MCS Profiles at crossing of Lines TD-1 and FC-7 ........................... 21

Figure 7: Map showing Location of Zone of Multichannel Mute $\quad$..................... 23

Figure 8: Map showing Location of Profiles and Sample Information .................... 25

Figure 9A: Stratigraphic tie from COST GE-1 to Line TD-5 ……..................... 27

Figure 9B: Stratigraphic tie from DSDP 390 to TD-5 ………............................ 28

Figure 9C: Stratigraphic tie from DSDP 391 to TD-3 ………............................. 29

Figure 9D: Stratigraphic tie from Great Isaac 1 to TD-1 _............................ 30

Figure 10: Poag (1991) and Dillon and Popenoe (1988) Stratigraphy on TD-3 33

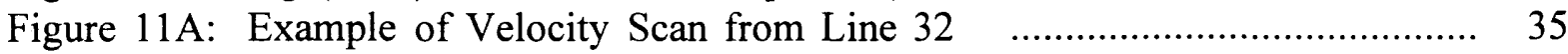

Figure 11B: Example of Velocity Scan from Line IPOD $\quad$.............................. 36

Figure 11C: Example of Velocity Scan from Line BT-1 $\quad$.............................. 37

Figure 11D: Example of Velocity Scan from Line TD-4 …………............ 38

Figure 11E: Example of Velocity Scan from Line FC-3 _........................... 39

Figure 12: Plots of Initial RMS Velocity for Lines 32 and TD-4 .................. 41

Figure 13: Map showing Locations of Profiles and Independent Refraction Stations 43

Figure 14: Compilation of Velocities for COST GE-1 well and DSDP $391 \quad$......... 45

Figure 15: Compilation of Velocities from Recent Refraction Experiments $\quad$......... 47

Figure 16: Flow Chart of Digitizing Strategy ……........................................... 49

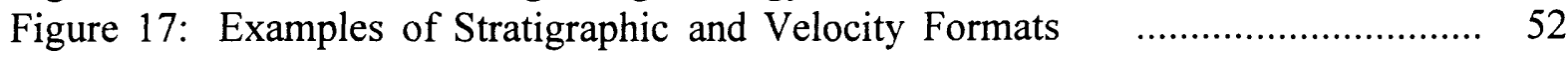

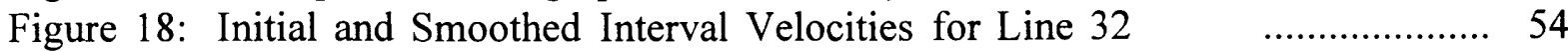

Figure 19: Initial and Smoothed Depth Sections for Line TD-4 ……............ 56 


\section{INTRODUCTION}

During the middle and late 1970's, the U.S. Geological Survey acquired approximately $25,000 \mathrm{~km}$ of then state-of-the-art marine multichannel seismic-reflection data along the U.S. Atlantic Continental Margin, primarily to address hydrocarbon resource potential and stratigraphic history (e.g., Sheridan et al., 1988). Despite the many advances in our understanding of the geologic evolution of the margin (e.g., Klitgord et al., 1988; Poag, 1991), most of the interpretations of the data were based on stratigraphic and structural interpretations of individual analog records. The derivative information contained in the original digital seismic field data remained archived in rather inaccessible 9-track tapes. In 1990, the Naval Oceanographic Office and the U.S. Geological Survey agreed to develop a digital data base for the U.S. Atlantic Continental Margin that would be built upon the stratigraphic interpretations of the seismic reflection data and the velocity information derived from processing the multichannel data. The goal of compiling the data base was to assign acoustic properties to the continental margin postrift sediments in an internally consistent, geologically meaningful, regionally extensive, digital form. The acoustic properties of interest include layer thickness, depth, compressional- and shear-wave velocity, compressional and shear-wave attenuation, density, and lithology.

This report describes the first part of developing the data base for the continental margin between Florida and North Carolina: stratigraphic interpretation and velocity analysis of the multichannel seismic-reflection data. The stratigraphic and velocity information form the basic observational inputs to the data base and both are based on the multichannel seismic-reflection data (Figure 1A). A knowledge of the resolution, uncertainty, calibration, and quality control of these data is therefore essential to understanding the validity and significance of the rest of the data base. A second report (Hutchinson et al., 1996) describes the methods of spatial gridding of the data, calculation of secondary acoustic properties (e.g., shear-wave parameters), and format of the final data base.

\section{ACKNOWLEDGEMENTS}

Funding for this project was provided by the U.S. Naval Oceanographic Office. We gratefully thank Dr. Rudi Markl, project manager from the Naval Oceanographic Office during most of this work, for his technical advice, discussions, and support. We also thank Peggy Schexnayder and Gus Michel of the U.S. Naval Oceanographic Office, for their encouragement. Discussions with and reviews by Kim Klitgord and Bill Dillon have resulted in significant improvements to this work. We thank D. Coleman, S. Harrison, A. Johnson, L. North, E. Schmuck, C. Schneider, A. Swift, D. Unger, and E. Wright for technical assistance in digitizing and displaying the data, and P. Wengler for assistance in preparing the manuscript.

\section{DATA OVERVIEW}

Approximately 7,600 km of 48-fold multichannel seismic-reflection profiles were used in the data compilation (Figure 1A, Plate 1). These lines were collected in 1974, 1975, and 1978 , by private companies under contract to, or in cooperation with, the U.S. Geological Survey. The profiles are designated by 18 separate line numbers, but because many of the 
Multichannel Profile Locations

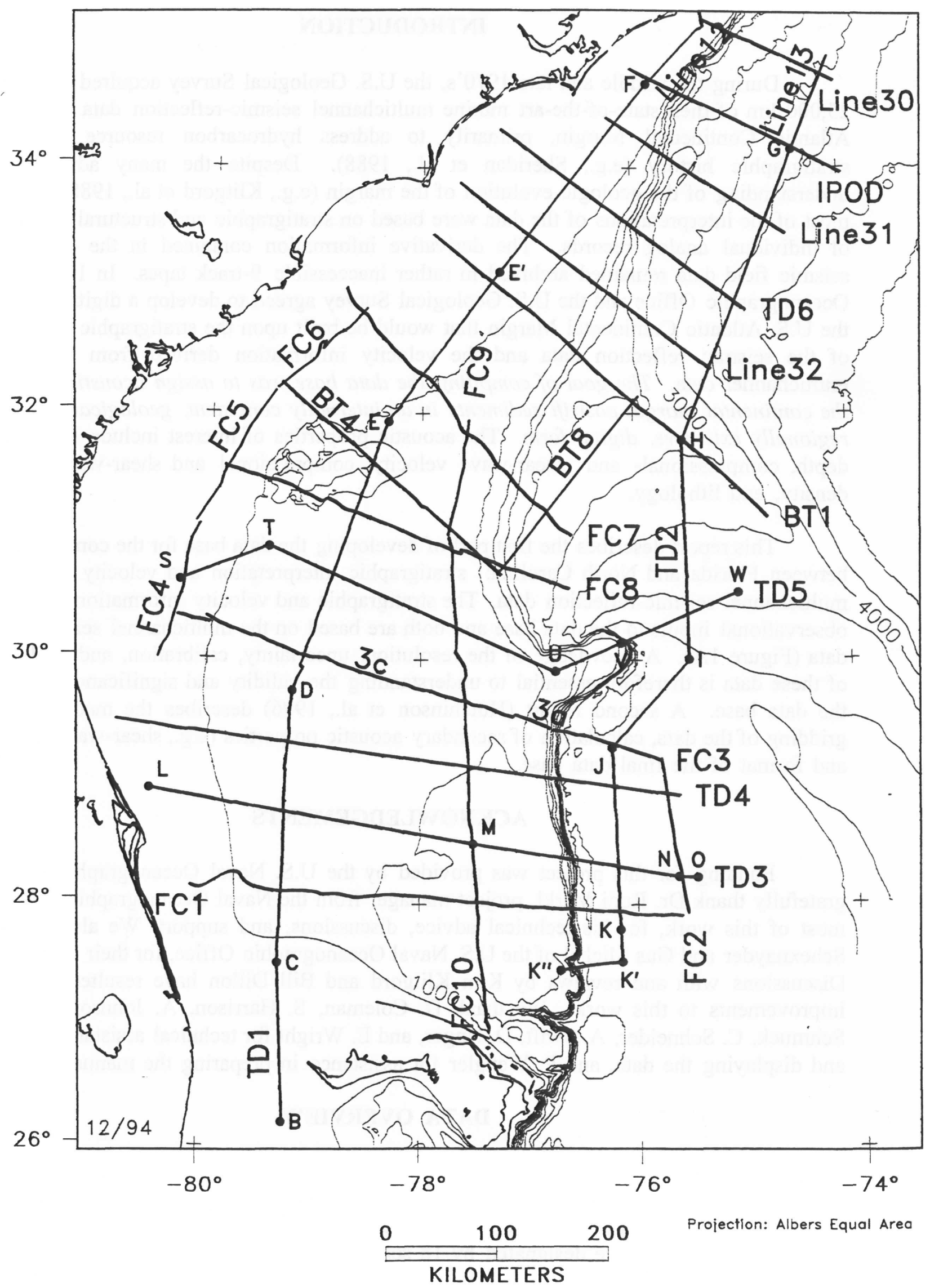




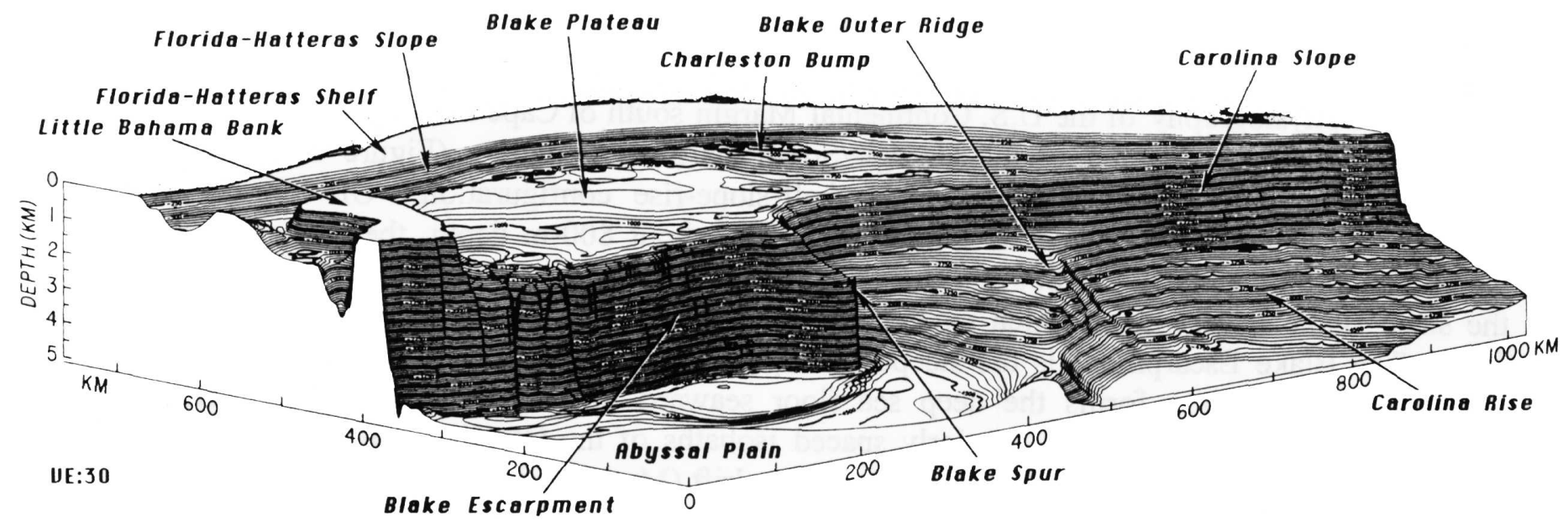

Figure 1: (A) Location of multichannel seismic profiles used in this study. Shot point locations and line number designations are shown in Plate 1. (B) Physiography of the U.S. continental margin between Cape Hatteras (right) and the Bahamas (left). In the physiographic diagram, the coast line for the U.S. is shown, but not that for the Bahamas. 
lines were shot in segments, the number of discreet profiles used is 42 (Table 1). The original seismic profiles and velocity scans supplied by the contractor or collaborator were used for the interpretation of stratigraphy and root-mean-square (RMS) velocity, except for lines 12, 13, TD-6, and TD-2 north of the Blake Outer Ridge. Lines 12 and 13 at the extreme northern end of the study area were reprocessed and redisplayed by USGS (Wise and Oliver, 1988). Line TD-6 and the northern half of line TD-2 were originally processed by USGS in 1979.

All of the digital data are presented in graphical form in the appendices that accompany this report. All profiles are plotted at the same scales to facilitate comparison; each segment of a line is plotted separately. Time and depth sections are shown in Appendix 1. Initial and final RMS velocity plots are shown in Appendix 2. Initial and final interval velocity plots are shown in Appendix 3. Independent refraction velocities compared to the multichannel interval velocities are illustrated in Appendix 4.

\section{Morphology}

\section{GEOLOGIC FRAMEWORK}

The physiography of the U.S. Continental Margin south of Cape Hatteras can be divided along the offshore extension of the Georgia/South Carolina boundary (Figure 1B). Off the Carolinas, the margin consists of a typical shelf-slope-rise configuration. Off Florida and Georgia, the slope is interrupted by a large plateau at about $800-\mathrm{m}$ depth, the Blake Plateau, which is approximately $350 \times 800 \mathrm{~km}$ in extent. The Blake Plateau abruptly terminates along the steep Blake Escarpment, which extends north-south between the Bahamas and the Blake Spur. The Blake Escarpment is the steepest morphologic feature along the U.S. East Coast. Hatteras Abyssal Plain forms the deep sea floor seaward of both the Carolina and Blake Plateau regions. The otherwise regularly spaced isobaths of the Carolina continental margin are modified by the Blake Outer Ridge sedimentary drift (Markl et al., 1970; Markl and Bryan, 1983; Mountain and Tucholke, 1985) and the Charleston Bump structure (Pinet et al., 1981).

\section{Tectonic Setting}

Two large sedimentary basins underlie the U.S. continental margin south of Cape Hatteras, the Carolina trough and the Blake Plateau basin (Figure 2); each marks a distinct geological province. These two large basins were formed as the continental margin evolved following the separation of North America and Africa in Middle Jurassic time. The Carolina platform and Florida platform form the landward sides of these basins, respectively.

The Carolina trough and the Blake Plateau basin have the greatest contrasts of any of the large offshore Atlantic basins (Dillon and Popenoe, 1988) and these differences can be seen

Figure 2: Simplified tectonic map of the continental margin south of Cape Hatteras. Abbreviations are H - hinge zone; BMA - Brunswick magnetic anomaly; ECMA - East Coast Magnetic Anomaly; BSMA - Blake Spur magnetic anomaly. The map shows the positions of synrift basins on land, major fracture zones, major magnetic anomalies, the hinge zone, the positions of the deeply subsided offshore sedimentary basins (Carolina trough and Blake Plateau), large faults, and bathymetry in meters (dotted lines). Modified from Klitgord et al. (1988). 


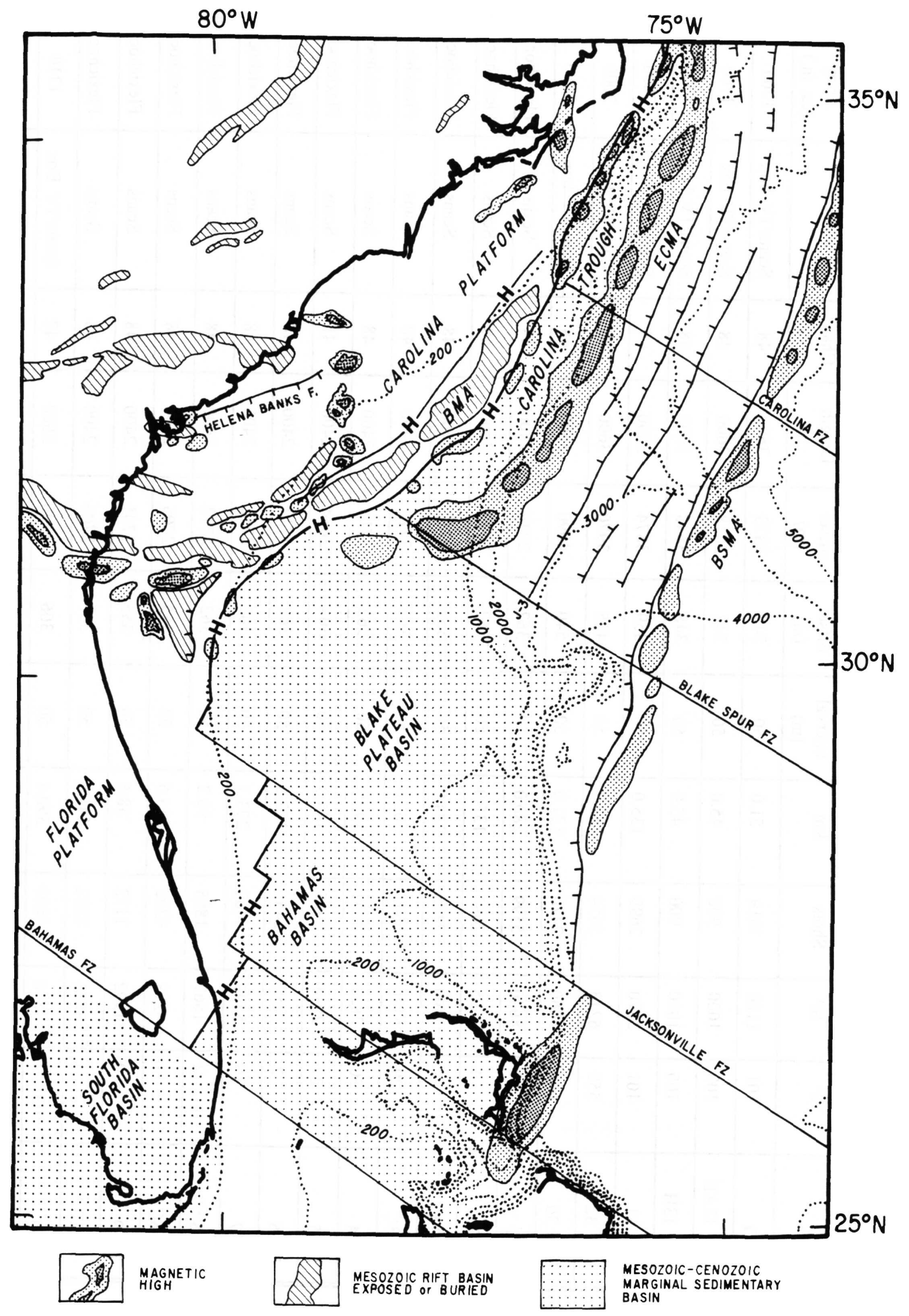


Table 1: Detailed Information about all Multichannel Seismic Profile Segments.

\begin{tabular}{|c|c|c|c|c|c|c|c|c|c|c|c|}
\hline Line No. & $\begin{array}{l}\text { First } \\
\text { SP }\end{array}$ & $\begin{array}{c}\text { Last } \\
\mathrm{SP}\end{array}$ & $\begin{array}{l}\text { Total } \\
\text { Shots }\end{array}$ & $\begin{array}{l}\text { Total } \\
\mathrm{km}\end{array}$ & $\begin{array}{l}\text { Firing } \\
\text { interval } \\
\text { (m) }\end{array}$ & $\begin{array}{c}\text { Near } \\
\text { offset } \\
(\mathrm{m})\end{array}$ & $\begin{array}{c}\text { Far } \\
\text { offset } \\
(\mathrm{m})\end{array}$ & $\begin{array}{l}\text { Streamer } \\
\text { Length } \\
\text { (m) }\end{array}$ & $\begin{array}{l}\text { No. } \\
\text { Chan. }\end{array}$ & $\begin{array}{l}\text { Velocity } \\
\text { source }\end{array}$ & $\begin{array}{c}\text { Source } \\
\text { Array } \\
\text { (cu. in.) }\end{array}$ \\
\hline IPOD & 101 & 1120 & 1019 & 51.0 & 50 & 348 & 3873 & 3600 & 48 & Scans/TV box & 1700 \\
\hline Line $12 \mathrm{AB}$ & 100 & 1000 & 900 & 45.0 & 50 & 348 & 3848 & 3600 & 48 & Scans/TV box & 1700 \\
\hline Line $13 \mathrm{H}$ & 100 & 1000 & 900 & 45.0 & 50 & 348 & 3848 & 3600 & 48 & Scans/TV box & 1700 \\
\hline Line 31 & 101 & 3870 & 2699 & 135.0 & 50 & 359 & 3874 & 3600 & 48 & Scans/TV box & 2000 \\
\hline Line 32 & 559 & 6213 & 5654 & 282.7 & 50 & 425 & 3970 & 3600 & 48 & Scans/TV box & 2000 \\
\hline Line 30 & 640 & 3060 & 2420 & 121.0 & 50 & 540 & 4090 & 3600 & 48 & Scans/TV box & 2000 \\
\hline $\mathrm{FC}-1$ & 1 & 8640 & 5599 & 280.0 & 50 & 362 & 2712 & 2400 & 48 & Scans & Flexichoc \\
\hline FC-2 & 4 & 2695 & 2691 & 135.0 & 50 & 362 & 2712 & 2400 & 48 & Scans & Flexichoc \\
\hline $\mathrm{FC}-3 \mathrm{~A}$ & 1 & 2499 & 2498 & 124.9 & 50 & 362 & 2712 & 2400 & 48 & Scans & Flexichoc \\
\hline $\mathrm{FC}-3 \mathrm{C}$ & 129 & 6170 & 6041 & 302.0 & 50 & 362 & 2712 & 2400 & 48 & Scans & Flexichoc \\
\hline $\mathrm{FC}-4$ & 50 & 2853 & 2803 & 140.2 & 50 & 362 & 2712 & 2400 & 48 & Scans & Flexichoc \\
\hline FC-5 & 29 & 2934 & 2905 & 145.3 & 50 & 304 & 2654 & 2400 & 48 & Scans & Flexichoc \\
\hline FC-6 & 2 & 2453 & 2451 & 122.5 & 50 & 362 & 2712 & 2400 & 48 & Scans & Flexichoc \\
\hline FC-7 & 36 & 5499 & 5463 & 273.1 & 50 & 362 & 2712 & 2400 & 48 & Scans & Flexichoc \\
\hline FC-8A & 2 & 1867 & 1865 & 93.2 & 50 & 362 & 2712 & 2400 & 48 & Scans & Flexichoc \\
\hline $\mathrm{FC}-8 \mathrm{C}$ & 1 & 4293 & 4292 & 214.6 & 50 & 355 & 2705 & 2400 & 48 & Scans & Flexichoc \\
\hline FC-9 & 20 & 1992 & 1172 & 58.6 & 50 & 355 & 2705 & 2400 & 48 & Scans & Flexichoc \\
\hline FC-10 & 1 & 8833 & 8832 & 441.6 & 50 & 355 & 2705 & 2400 & 48 & Scans & Flexichoc \\
\hline $\mathrm{BT}-1$ & 1 & 7810 & 7809 & 390.4 & 50 & 306 & 3906 & 3600 & 48 & Scans/TV Box & 1310 \\
\hline BT-4 & 1181 & 5393 & 4793 & 239.7 & 50 & 306 & 3906 & 3600 & 48 & Scans/TV box & 1310 \\
\hline BT-8 & 1 & 4125 & 4124 & 206.2 & 50 & 306 & 3906 & 3600 & 48 & DISCO & 1310 \\
\hline
\end{tabular}




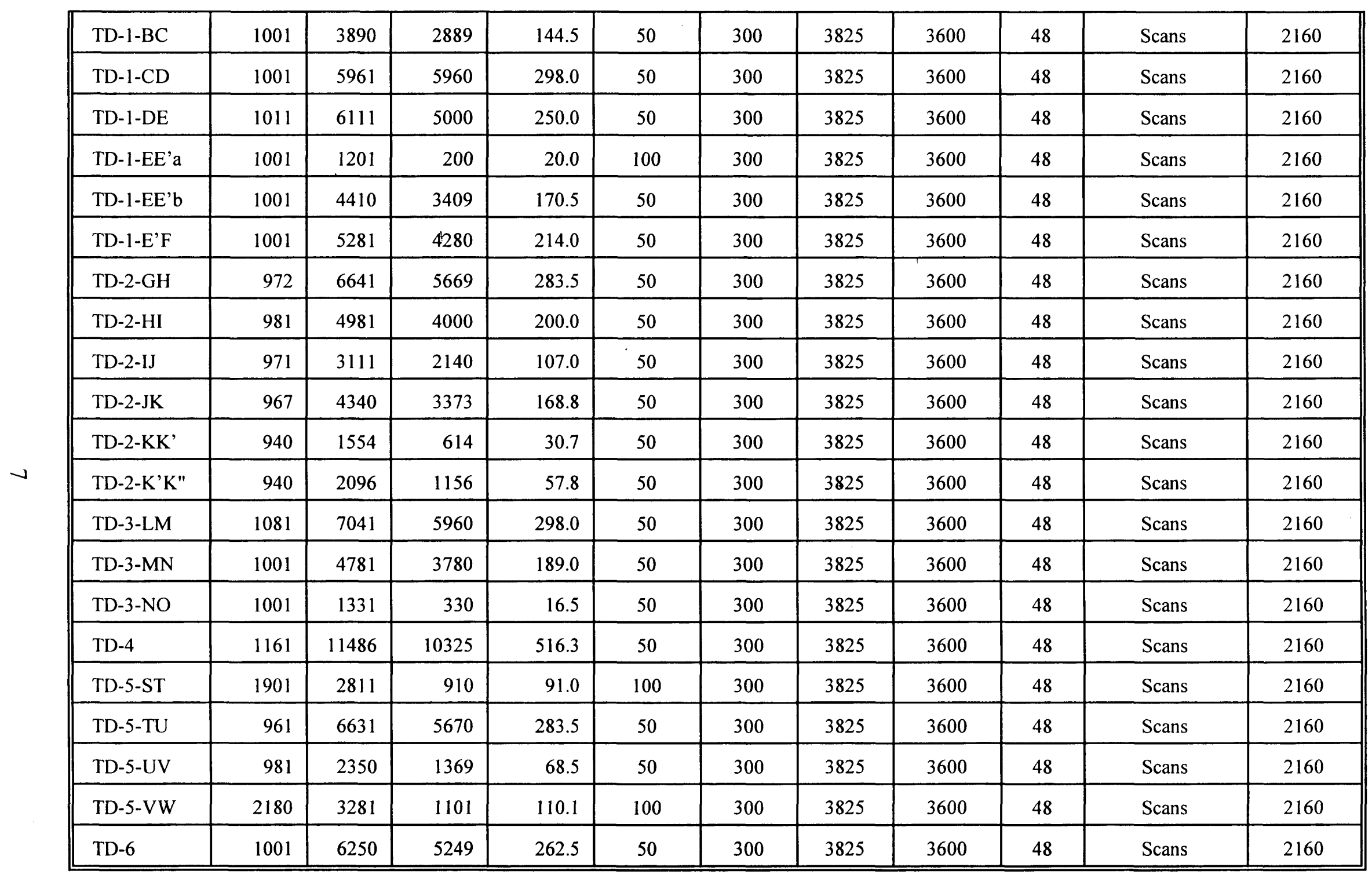


by comparing the representative seismic profiles across each basin (Figures 3 and 4): the Carolina trough is the narrowest and most linear of the basins (Figure 3); the Blake Plateau is the widest and most equidimensional (Figure 4). The Carolina trough is underlain by narrow rift basins and extensive salt deposits (Hutchinson et al., 1983; Dillon et al., 1983) whereas rifting in the Blake Plateau occurred over a much wider zone and no salt deposits are known (Dillon and Popenoe, 1988). The Carolina trough is dominated by a terrigenous-clastic depositional regime; the Blake Plateau is transitional into a carbonate-platform depositional regime best developed in the Bahamas to the south. The continent-ocean transition is well marked by a prominent magnetic anomaly in the Carolina trough, the East Coast Magnetic Anomaly, (see review by Holbrook and Keleman, 1993). No similar geophysical marker exists along the Blake Plateau basin, and the continent-ocean transition is presumed to underlie the Blake Escarpment (e.g., Dillon and Popenoe, 1988).

The break-up history of the Carolina trough and Blake Plateau regions also differed significantly. Sea-floor spreading was initiated in the Carolina trough by $175 \mathrm{Ma}$, but was delayed by about $4 \mathrm{my}$ in the Blake Plateau until $171 \mathrm{Ma}$ (Dillon and Popenoe, 1988). Within a million years, at $170 \mathrm{Ma}$, a spreading-center jump occurred at the position of the Blake Spur magnetic anomaly. Numerous oceanic fracture zones project into the continental margin from oceanic crust (Figure 2); the largest is the Blake Spur fracture zone, which separates the Carolina trough from the Blake Plateau basin (Klitgord and Behrendt, 1979).

\section{Stratigraphic Overview}

The stratigraphy of the Carolina trough and Blake Plateau basin is known primarily from interpretation of seismic-reflection profiles calibrated by limited samples (Dillon and Popenoe, 1988; Poag, 1991). No dated samples older than Early Cretaceous have been recovered from this part of the continental margin in either shallow or deep water (Sheridan and Enos, 1979; Dillon et al., 1985); therefore, the geologic interpretation of the rift and early post-rift formation of the margin is based on seismic character, inference, and comparison with the continental margin to the north. The following paragraphs on the stratigraphy of the Carolina trough and Blake Plateau basin are taken from the summaries in Dillon and Popenoe (1988) and Poag (1991).

Blake Plateau basin: The postrift sedimentary history of the Blake Plateau began in the Jurassic with widespread carbonate deposition and reef building along the eastern portion of the margin. The Blake Plateau did not exist as a deep water environment: the region was characterized by shallow-water, carbonate-bank deposition. Much of this carbonate deposition formed a Jurassic gigaplatform/reef system that extended from the Bahamas to Georges Bank (Poag, 1991). Anhydrite deposits of presumed Jurassic age are recorded in wells from the Bahamas (Tator and Hatfield, 1975a, 1975b). On the western side of the region, deposition was more terrigenous. During the Early Cretaceous, similar depositional patterns persisted,

Figure 3: Representative multichannel seismic reflection profile line 32 across the Carolina trough showing uninterpreted profile data (upper) and the same profile with numbered stratigraphic horizons, ages, faults, major reef structure, and inferred salt deposits (lower). $P R U$ - post rift unconformity. 


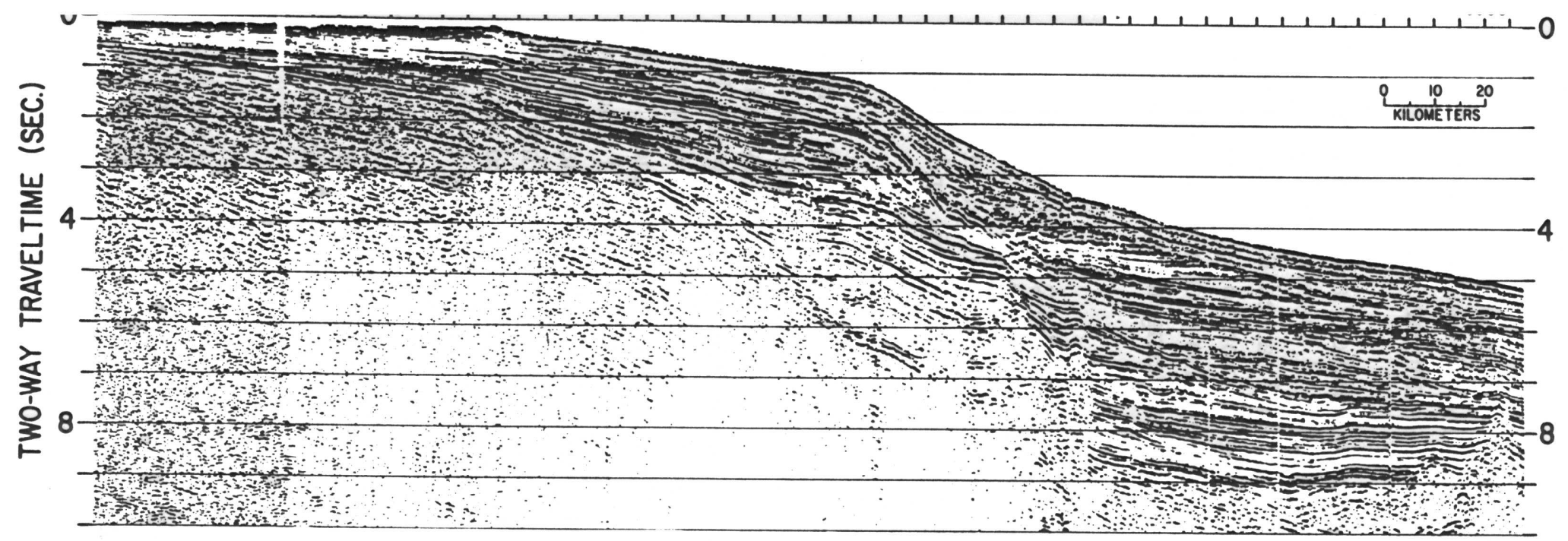

6

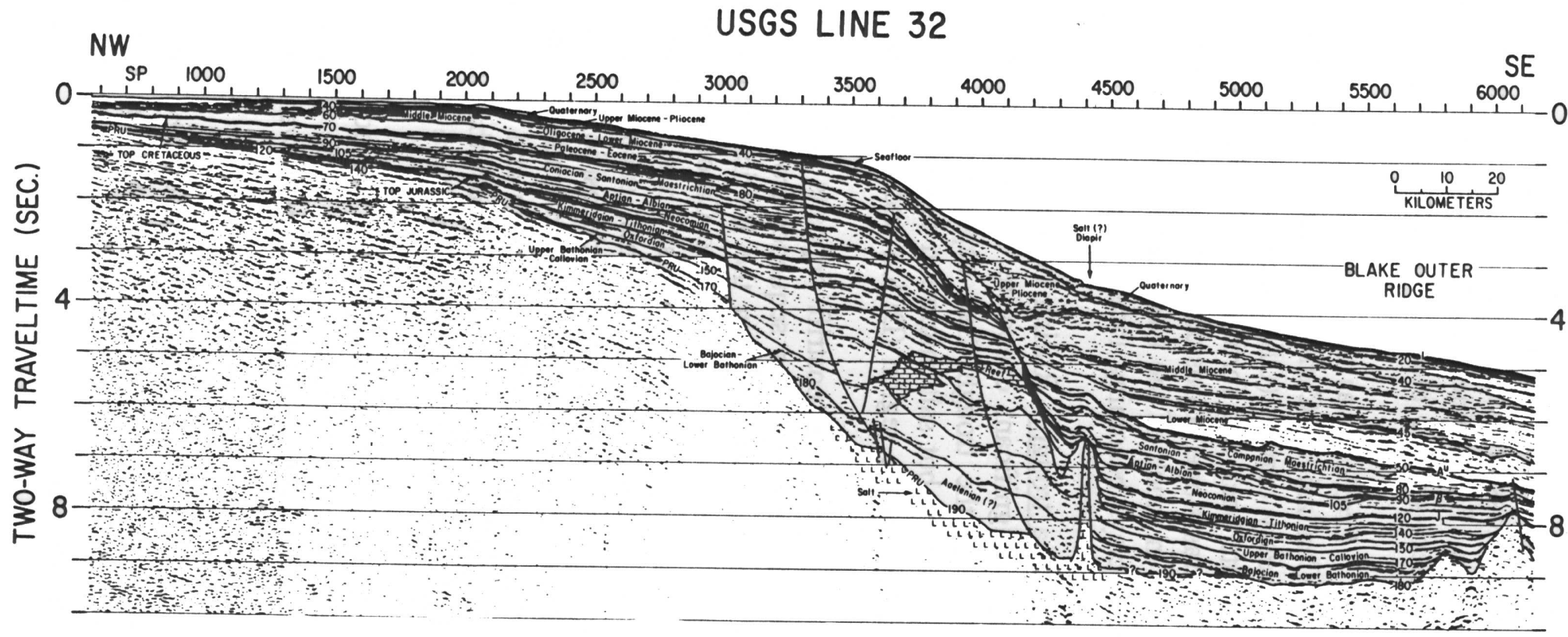




\section{USGS LINE TD-4}
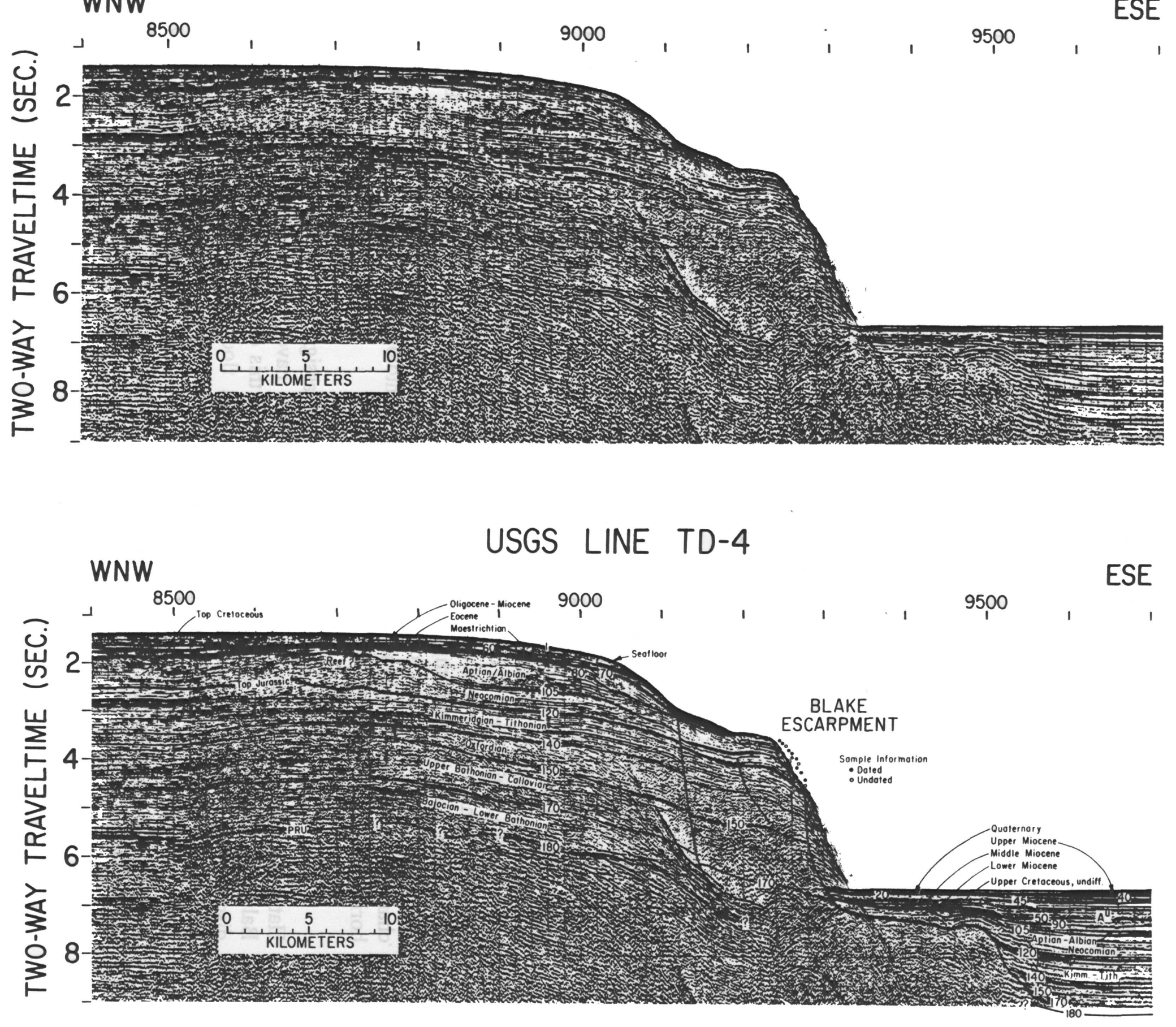
TABLE 2: U.S. Atlantic Margin Seismic Stratigraphy ${ }^{1}$

\begin{tabular}{|c|c|c|}
\hline $\begin{array}{l}\text { Reflector } \\
\text { Number }^{2}\end{array}$ & Geologic Surface & Common Name ${ }^{3}$ \\
\hline 1 & Base water column & Seafloor \\
\hline 20 & Base Quaternary & \\
\hline 30 & Base Pliocene & \\
\hline 40 & Base Upper Miocene & \\
\hline 45 & Base Middle Miocene & Mid-Miocene Unconformity \\
\hline 50 & Base Lower Miocene & \\
\hline 60 & Base Upper Oligocene & Mid-Oligocene Unconformity \\
\hline 70 & Base Paleocene/Eocene & Top Cretaceous \\
\hline 80 & Base Campanian/Maastrichtian & Horizon $\mathrm{A}^{*}$ in Deep Sea \\
\hline 90 & Base Coniacian/Santonian & Late Cenomanian Unconformity \\
\hline 105 & Base Aptian/Albian/Cenomanian/ Turonian & Mid Cretaceous Unconformity \\
\hline 110 & Base Barremian & Horizon $\beta$ in Deep Sea \\
\hline 120 & Base Berriasian/Valanginian/ Hauterivian & Top Jurassic \\
\hline 140 & Base Kimmeridgian/Tithonian & \\
\hline 150 & Base Oxfordian & Top Middle Jurassic \\
\hline 170 & Base Upper Bathonian/Callovian & \\
\hline 180 & Base Bajocian/Lower Bathonian & \\
\hline 190 & Base Aalenian & Postrift Unconformity \\
\hline
\end{tabular}

${ }^{1}$ This is the same stratigraphy used by Klitgord et al. (1994) for the continental margin north of Cape Hatteras, except for horizons 30 (Base Pliocene), 100 (Base Cenomanian/Turonian), and 130 (Base Tithonian). These three horizons were not mapped separately in the area south of Hatteras.

${ }^{2}$ Numbers have no geologic significance and are used only as an identifier in the digital data base. They correspond to the same geologic horizons throughout the data set.

${ }^{3}$ Names commonty encountered in the literature.

Each numbered discontinuity represents the surface at the base of a unit. Properties that characterize a unit (e.g., interval velocity or thickness) refer to the unit immediately above the numbered discontinuity. In this convention, we always refer to material that exists above a reflector, since the original material below a reflector may have been eroded. This is illustrated in Figure 5 which shows an example where the surface represented by reflector 60 (base of Oligocene) merges with reflector 70 (base of Paleocene-Eocene). We call the reflector at the base of Oligocene reflector 60 and assume that the surface represented by reflector 70 is not present in the middle of the profile. Prominent geologic boundaries that form erosional 
unconformities at the tops of units (such as the top of Cretaceous) often consist of several reflectors (reflector 70 at the sides of the figure and reflector 60 in the center of Figure 5). This convention differs from standard reference to the tops of geologic units, but eliminates ambiguity in defining units and bounding horizons as well as simplifying the stratigraphic framework. Representative seismic sections illustrating the stratigraphy are shown in Figures 3 and 4.

The reflectors defined in Table 2 are identical to those used by Klitgord et al. (1994) for the stratigraphic data base north of Cape Hatteras, except for two horizons: 100 (base Cenomanian/Turonian), and 130 (base Tithonian). These two horizons are not regionally extensive and therefore have not been mapped for the area south of Cape Hatteras.

\section{TRAVEL-TIME DATA AND UNCERTAINTIES}

Scaled, stacked multichannel seismic profiles form the basis for interpreting and digitizing allostratigraphic units. This section discusses the acquisition, processing, and interpretation of the multichannel data, which affects the quality of the final digitized travel time data. An assessment of possible sources of error and uncertainties is given for each stage of analysis.

\section{Multichannel Acquisition}

The multichannel reflection profiles used in developing the data base were collected between 1974 and 1978. Details of the source and receiver acquisition parameters for each line are given in Table 1. The lines can be separated into five groups that have slightly different acquisition systems: IPOD line, BT lines, FC lines, TD lines, and GSI lines. The IPOD, BT, TD, and FC lines are labelled by their acquisition letters (e.g., BT-1, TD-6, or FC-7). The GSI lines refer to lines 30, 31, and 32 in the northern Carolina trough (Table 3). Line 12 and 13 are taken from Klitgord et al. (1994); they were acquired by Digicon in 1975 and are similar to the IPOD line in overall quality. Some of the FC and TD lines were collected in segments, designated by letters: for example, line TD-3 consists of the the segments TD-3LM, TD-3MN, and TD-3NO (Figure 1).

The acquisition systems for all seismic data are roughly equivalent; all used a firing interval of $50 \mathrm{~m}$ and $\overline{48}$-channel streamers which were $2.4-$ or $3.6-\mathrm{km}$ long. The 1978 GSI lines probably have the highest resolution, with the longest streamer and largest, tuned air gun source. Teledyne lines, with four large low-frequency air guns as the source (with a total volume of $2,160 \mathrm{in}^{3}$ ), are noticeably ringier and lack the clarity and resolution of the GSI profiles. The IPOD line was shot with a slightly smaller source $\left(1,700 \mathrm{in}^{3}\right)$ than the GSI lines $\left(2,000 \mathrm{in}^{3}\right)$. The BT lines $\left(1,310 \mathrm{in}^{3}\right)$ were shot with a source that was about two-thirds the size of the source used in the GSI lines. The FC lines have the shortest offset and smallest source: the Flexichoc is a large low-pressure airgun equivalent to about 1,000 $\mathrm{in}^{3}$ (Magneville, 1970). The shorter offsets, different source, and generally higher towing speeds (Dillon et al., 1976) probably contributed to the generally lower signal quality and total penetration of the FC lines relative to the others. 
Figure 9: Correlation between drill hole information and seismic stratigraphy. (A) COST GE-1 well tied to line TD-5 at the landward end of TD-5.. Lithology patterns and interpretations are from Poag (1991). (B) DSDP 390 tied to line TD-5 near the top of the Blake Spur. Lithology patterns and descriptions are from Leg 44 Scientific Party (1978). (C) DSDP 391 tied to TD-3 in the Hatteras Abyssal Plain. Lithology patterns and descriptions are from Leg 44 Shipboard Scientific Party (1978). (D) Great Isaac I well tied through Sheridan et al. (1981) to line TD-1. Lithologic descriptions are simplified from Sheridan et al. (1981), Schlager et al. (1988), and Tator and Hatfield (1975a, 1975b). Line TD-1 does not tie directly with either the multichannel data of Sheridan et al. (1981) or the Great Isaacs 1 well, and therefore, the correlations are approximate. 
recovery (usually a spherical divergence correction), edit, deconvolution (generally predictive deconvolution with design and application dependent on water depth), velocity analysis (every 3-7 km), normal moveout correction, stack, time-varying frequency filter, scaling, and display. The BT and TD lines had a second (predictive) deconvolution operator applied after stack and before final scaling and display. For the FC lines, a prestack predictive deconvolution was applied on the shallow water portions of the lines, but no deconvolution was applied for the portions of lines over the Blake Plateau or the abyssal plain.

The primitive processing of these lines, depending on the effectiveness of the deconvolution operators, can compromise the resolution of both the travel-time sections and the velocity analyses. This, in turn, can limit the accuracy and precision of the travel time estimates and velocity values. Detailed discussion of the velocity scans is given in the following section on Velocity Data and Uncertainties. Errors in travel time are impossible to quantify without detailed reprocessing and statistical analysis, and this remains a concern in the overall assessment of uncertainty in the data base. Reprocessing of these data should include F-K filtering (especially in regions of high-velocity carbonates on the Blake Plateau), more extensive deconvolution tests (including spiking, predictive, and wavelet algorithms), and migration.

Nonquantitative assessments of data quality can be made by (1) estimating the duration of the source wavelet at a prominent reflection and (2) comparing record quality at line crossings. The water-bottom reflection is a primary geologic discontinuity that can be used to show how sharp the source is. For the IPOD, GSI, and TD lines, it is a double reflection about $50 \mathrm{~ms}$ long; for the BT lines, it is a single or double wavelet of 30 or $50 \mathrm{~ms}$ respectively; for the FC lines where no deconvolution was applied, it is a triple wavelet about $90 \mathrm{~ms}$ in duration. The duration of the water bottom return is also an indicator of how well units that extend upward to the sea floor can be imaged or detected. For durations of 30, 50, and $90 \mathrm{ms,}$ the resolvable unit thickness is about 10,35, and $65 \mathrm{~m}$ respectively (assuming a subsea-floor velocity of $1500 \mathrm{~m} / \mathrm{s}$ and resolution of $1 / 4$ wavelength). Individual reflection events (i.e., single wavelets) can be resolved in the shallow subbottom on the GSI, TD, BT, and IPOD lines and are about $20-25 \mathrm{~ms}$ duration, indicating a slightly better resolution for individual subbottom events. Subbottom reflections on the FC lines are generally double wavelets and are about $50 \mathrm{~ms}$ duration. Actual resolution within the sedimentary section is difficult to quantify because it depends on several factors that interact, such as frequency content, attenuation, wavelet shape, and rock velocity. Qualitatively, this type of analysis shows that the FC lines have inherently lower resolution than the other lines.

An alternative assessment of data quality can be made by comparing profiles at three line crossings (Figure 6). These displays visually show how different acquisition and processing schemes affect the overall quality and clarity of data from different surveys. GSI line 32 has more clarity and resolution than TD-1 (Fig. 6a); line BT-8 has better resolution

Figure 6: A comparison of multichannel data profiles at line crossings. (A) Line 32 and TD1. (B) Line BT-8 and FC-7. (C) Line TD-I and FC-7. The horizontal scale on the FC-data is somewhat compressed compared to the other lines. 


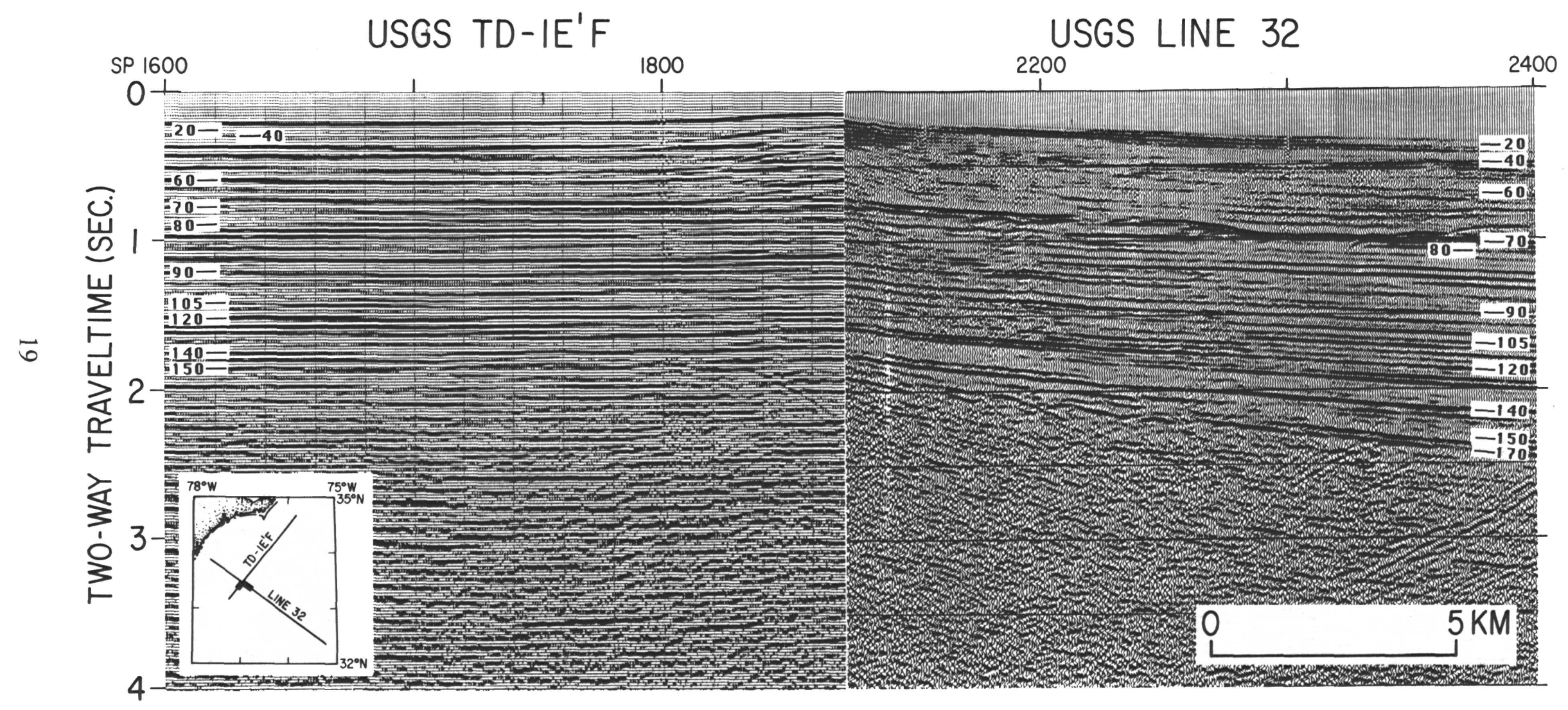




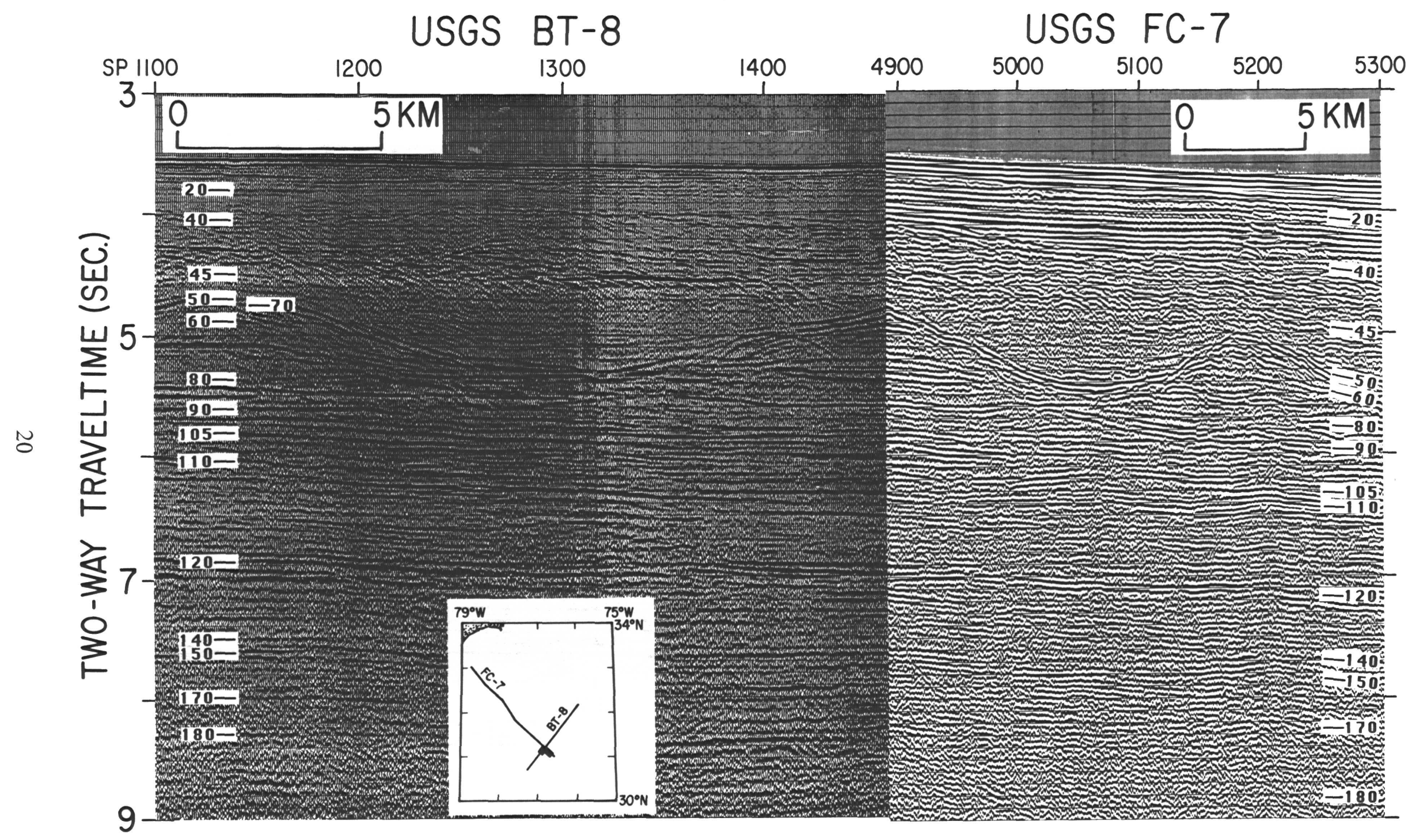




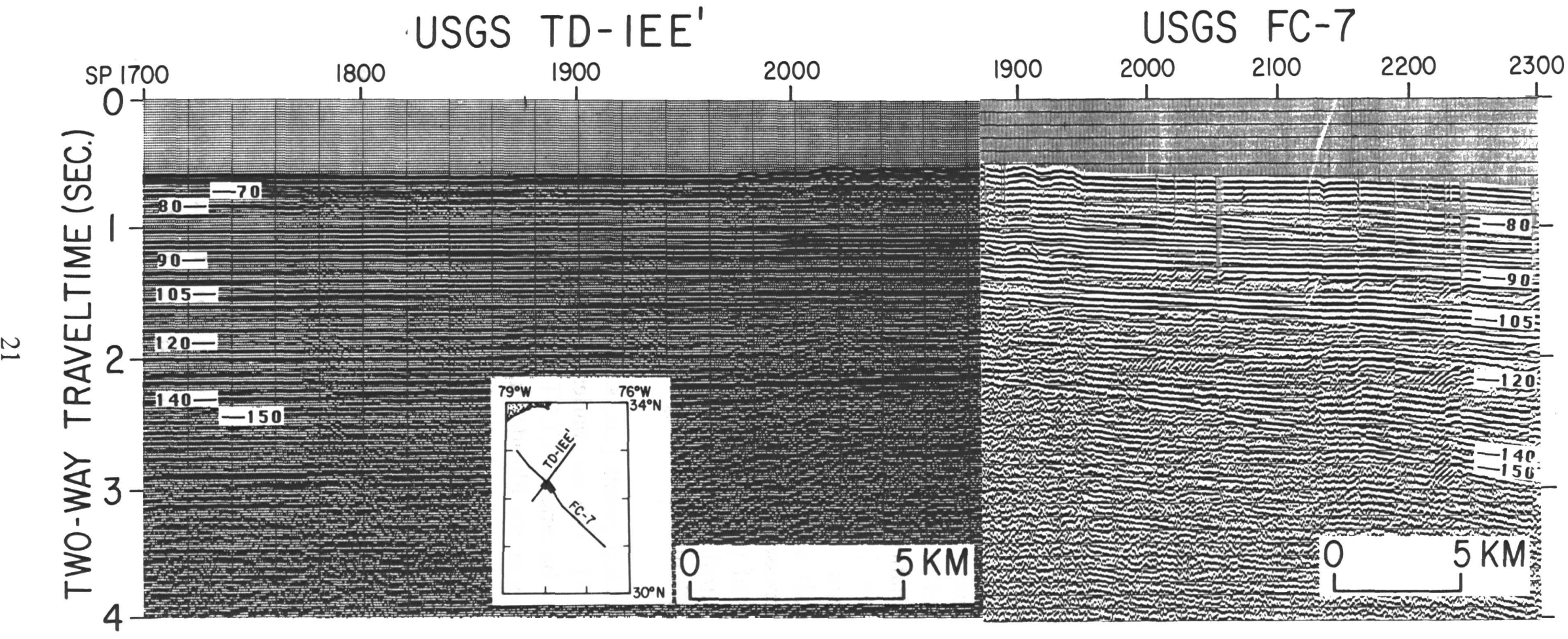


and clarity than line FC-7 (Fig. 6b); and line TD-1 is slightly better than FC-7 (Fig. 6c). The perception of clarity and resolution also depends somewhat on the individual interpreter.

A special problem unique to processing the data occurs in shallow water due to mute patterns. Muting is a prestack processing procedure that removes noise, such as shallow refractions or normal-moveout (NMO) stretch, from common depth point (cdp) gathers by zeroing amplitudes. In shallow water, this noise interferes with the water-bottom and shallow subbottom reflections; the result of muting is to remove the water bottom and shallow reflections from the final stacked data. Careful muting can minimize the effect, but some data are invariably lost along profiles where the geometry of acquisition causes the near offset to be several times longer than the water depth, such as on all the multichannel data used in this compilation where near offsets are $300-400 \mathrm{~m}$, and water depths on the shelf are less than $100 \mathrm{~m}$. The mutes typically affect subbottom reflections for $100-150 \mathrm{~ms}$. Deeper reflections are unaffected. Figure 7 shows the locations where shallow data are lost due to mute patterns. For the landwardmost portions of these affected lines, bathymetry was digitized from NOS (1986) and shallow reflectors were projected through the mute zone based on extrapolated dips or known outcrop geometries (Popenoe, 1993).

\section{Stratigraphic Interpretation}

Stacked, unmigrated multichannel profiles provided by the contractor or collaborator were used in the interpretation. Migrated sections were utilized when available to help constrain the interpretation in areas of complex structure, but were not used when the interpretations were digitized. Scales of the profiles for the IPOD, BT, TD, and GSI lines were 2.5 inches/second (vertical) and about $1.2 \mathrm{~km}$ per inch (horizontal). The FC lines were displayed at a more compressed scale of about 2.0 inches/second (vertical) and $2.5 \mathrm{~km} /$ inch (horizontal). Digital tapes of the FC lines were not available for redisplay of the data at the scale used in the other profiles. The difference in scale between the FC and other lines presented a continuing difficulty in linking stratigraphic horizons at line crossings.

Stratigraphic calibration points (i.e., samples) for the continental margin south of Cape Hatteras are sparse (Table 4). The summaries of Dillon and Popenoe (1988) and Poag (1991) examine the two wells to basement (COST GE-1 and TR 1005-1, Figure 8) that provide Cretaceous and younger ties on the Florida-Hatteras shelf off Georgia. Several shallower wells were drilled by Joint Oceanographic Institutions for Deep Earth Sampling - JOIDES (Bunce et al., 1965; Charm et al., 1969), by the USGS - AMCOR (Hathaway et al., 1981; Poppe, 1981), and by the Atlantic Slope Project - ASP - a consortium of oil companies (Poag, 1978; Poag and Valentine, 1988). Seven Deep Sea Drilling Project (DSDP) holes were drilled on the Blake Spur, the Blake Outer Ridge, and on the Hatteras abyssal plain (Hollister, Ewing et al, 1972; Benson, Sheridan et al., 1978; Sheridan, Gradstein et al., 1983). Dredge samples (Heezen and Sheridan, 1966; Sheridan et al., 1971) and Alvin submersible samples on the

Figure 7: Location of the zone affected by mute along the landward ends of the multichannel profiles. In these zones, the bathymetry was digitized from NOS (1986) and horizons in the first 100-200 milliseconds subbottom were extrapolated from projected dips and outcrop patterns from Paull et al. (1980) and Popenoe (1993). 


\section{Region Affected by Multichannel Mute}

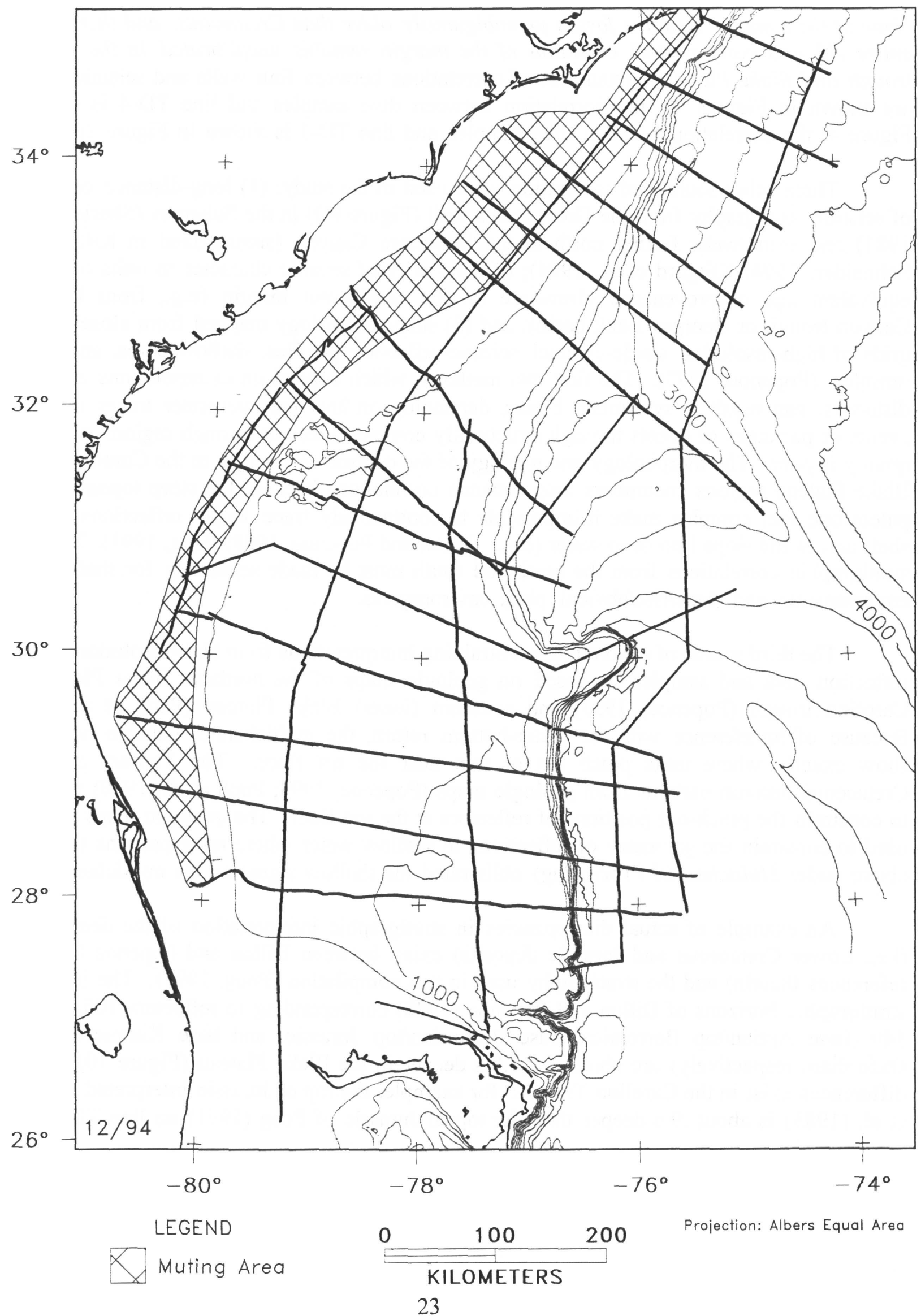


Blake Escarpment (Dillon et al., 1987, 1988) provide additional stratigraphic information. None of the samples contains fossils unambiguously older than Cretaceous, and therefore the entire rift and early postrift evolution of the margin remains uncalibrated in the Carolina trough and Blake Plateau. Examples of correlations between four wells and seismic profiles are shown in Figures 9; the correlation between dive samples and line TD-4 is shown in Figure 4; the correlation between dive samples and line TD-3 is shown in Figure 10.

Three other sources of calibration were used in the study: (1) long-distance correlation of seismic stratigraphy from the Great Isaacs well (Figure 9D) in the Bahamas (Sheridan et al., 1981) and from wells further north in the Baltimore Canyon (summarized in Klitgord and Schneider, 1994; Klitgord et al., 1994); (2) similarity of seismic character to units of inferred equivalent age or provenance elsewhere on the continental margin (e.g., from Baltimore Canyon trough or Georges Bank basin); and (3) surficial geology mapped from closely spaced grids of high-resolution single-channel seismic-reflection profiles, shallow cores, and surface samples. (Popenoe, 1993). The first two methods, which depend on extrapolations over large distances, can result in systematic biases, depending on how the interpreter traces individual events or packages of events through structurally complex areas or through regions where data quality is poor. The morphology and geology of the continental margin in the Carolina troughBlake Plateau regions encumbers long-distance correlations because the steep topography and paleoslope reef complex make it impossible to continuously trace deeper reflections from the shelf across the slope into deep water (e.g., Dillon and Popenoe, 1988; Poag, 1991). Therefore, stratigraphic correlations from the north and south must be made separately for shallow shelf environments and slope/rise/abyssal plain environments.

The third source of calibration, constraining interpretations from high-resolution seismicreflection data and samples, is based on geologic maps of the northern Blake Plateau and Carolina trough (Popenoe, 1993) and southern (inner) Blake Plateau (Paull et al., 1980). Because of interference with the water-bottom return, the multichannel data do not always show exactly where units pinch out or thin near the sea floor. The Tertiary and Early Cretaceous outcrop patterns from geologic maps (Popenoe, 1993; Paull et al., 1980) were used to constrain the pinch-out positions of reflectors at the sea floor. The geologic maps were also used to constrain the geometry of reflections in shallow water where mute patterns (discussed above under Multichannel Processing) obliterated the shallow signal on the multichannel data.

An example of actual discrepancies in stratigraphic interpretation of the deepest units (i.e., Lower Cretaceous and Jurassic deposits) exists between Dillon and Popenoe (1988 and references therein) and the stratigraphy used in this compilation (Poag, 1991). The interpreted stratigraphic horizons of Dillon and Popenoe (1988) corresponding to reflectors 105, 120, and 140 (base Aptian/top Berremian, base Berriasian/top Jurassic, and base Kimmeridgian/top Oxfordian, respectively) are about .7 - $1.0 \mathrm{~s}$ deeper in the Blake Plateau (Figure 10). Similar differences exist in the Carolina Trough: for example, the top of Jurassic interpreted by Dillon et al. (1983) is about .9 s deeper than the top of Jurassic of Poag (1991) on line TD-6.

Figure 8: Locations of multichannel profiles and sample information used to constrain interpretations of the multichannel data. Bathymetry contoured at 500-m intervals. 


\section{Sample and Profile Locations}

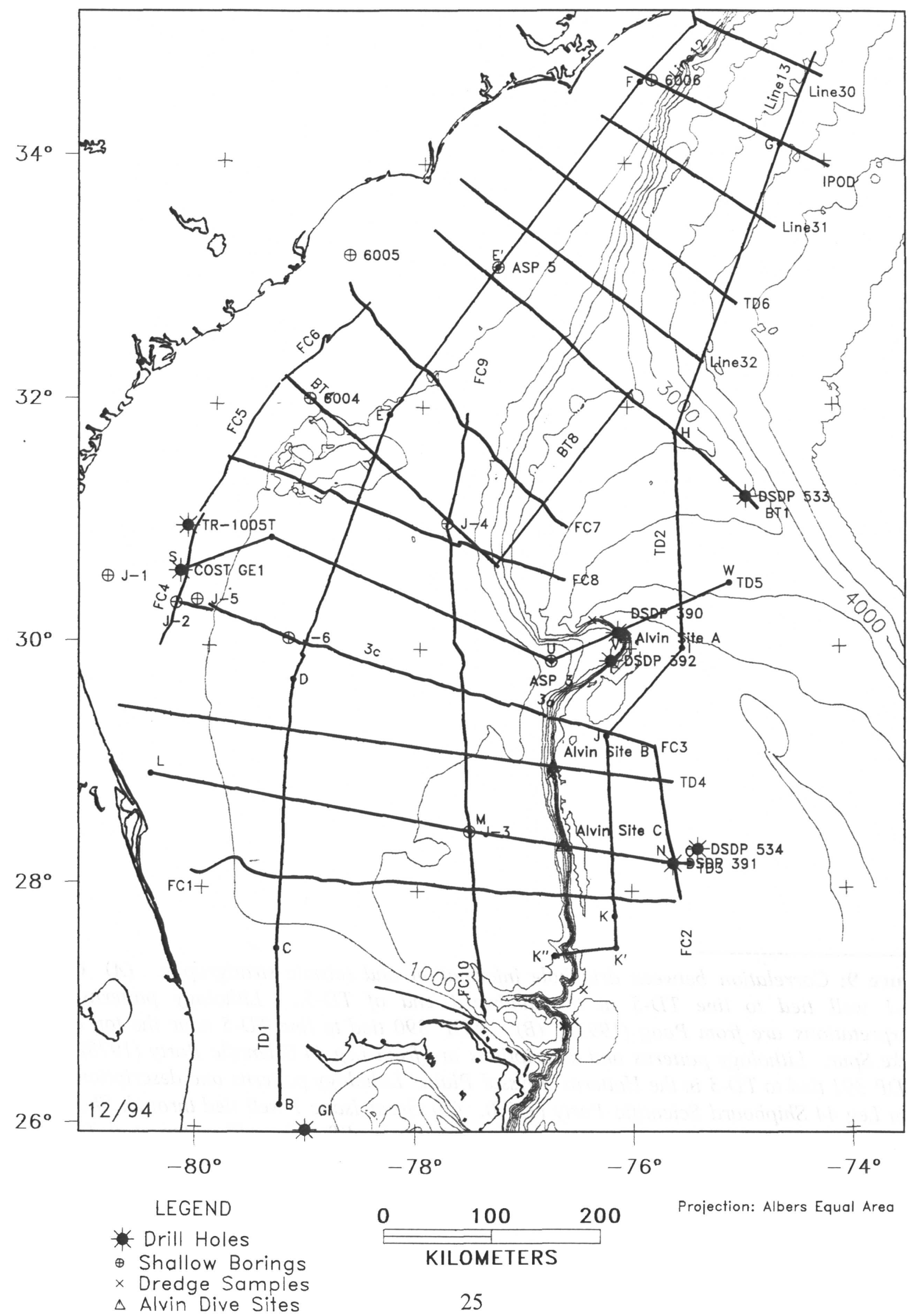


Figure 9: Correlation between drill hole information and seismic stratigraphy. (A) COST GE-1 well tied to line TD-5 at the landward end of TD-5.. Lithology patterns and interpretations are from Poag (1991). (B) DSDP 390 tied to line TD-5 near the top of the Blake Spur. Lithology patterns and descriptions are from Leg 44 Scientific Party (1978). (C) DSDP 391 tied to TD-3 in the Hatteras Abyssal Plain. Lithology patterns and descriptions are from Leg 44 Shipboard Scientific Party (1978). (D) Great Isaac I well tied through Sheridan et al. (1981) to line TD-1. Lithologic descriptions are simplified from Sheridan et al. (1981), Schlager et al. (1988), and Tator and Hatfield (1975a, 1975b). Line TD-1 does not tie directly with either the multichannel data of Sheridan et al. (1981) or the Great Isaacs 1 well, and therefore, the correlations are approximate. 


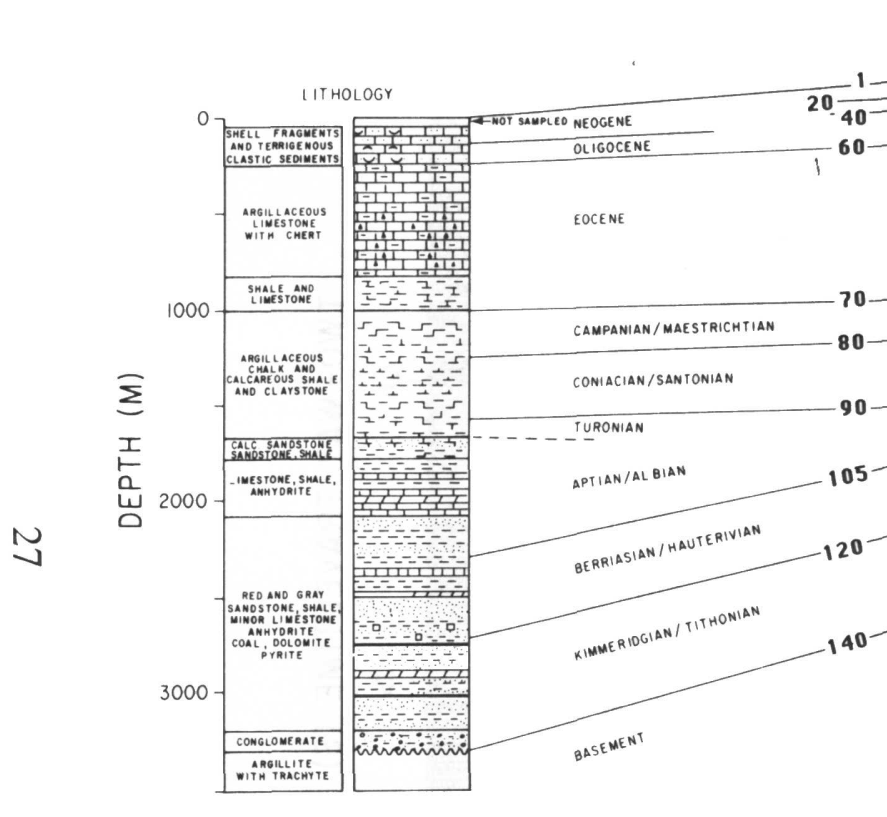

SP 1900

2000

1. $-0$

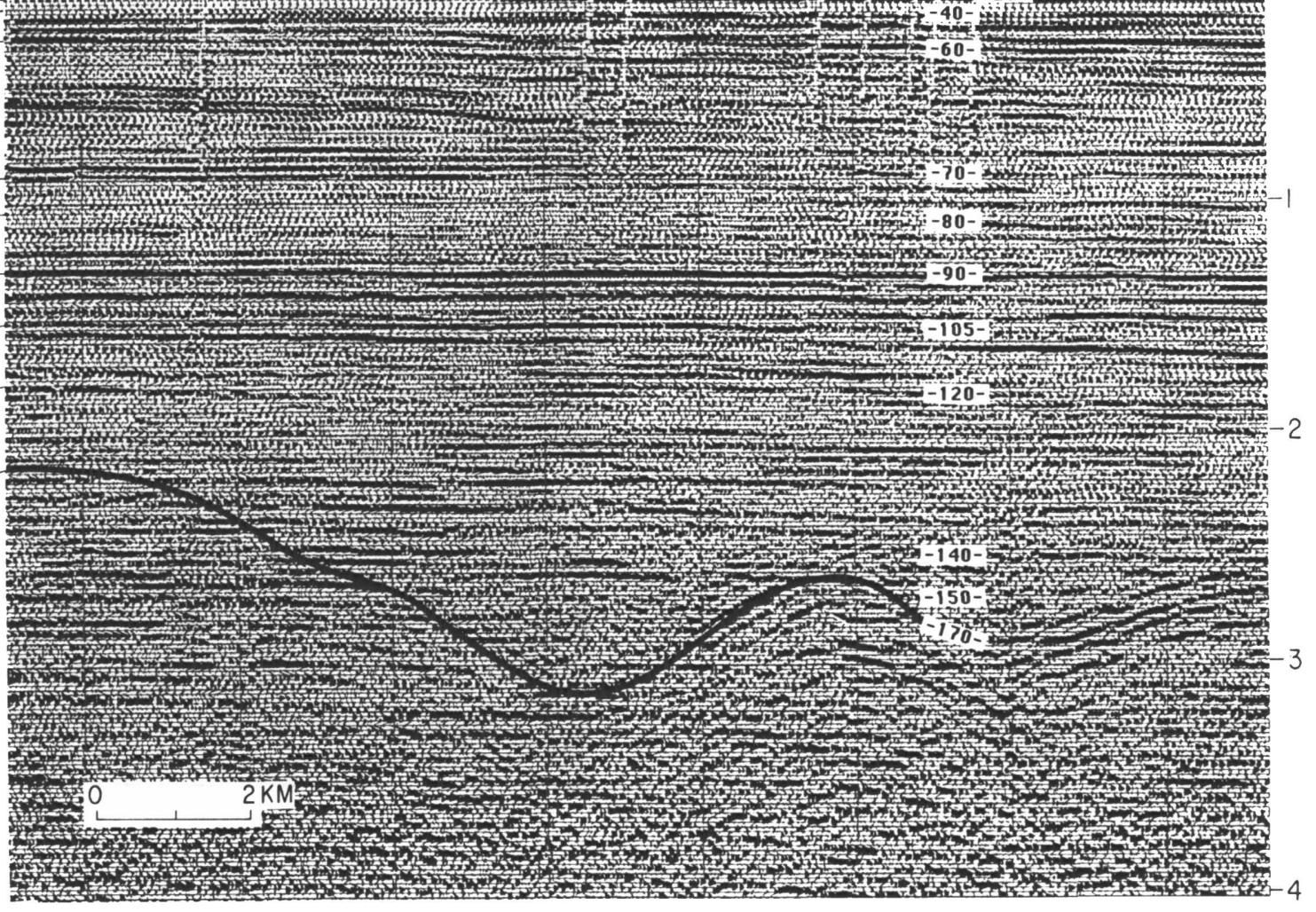


USGS TD-5 UV

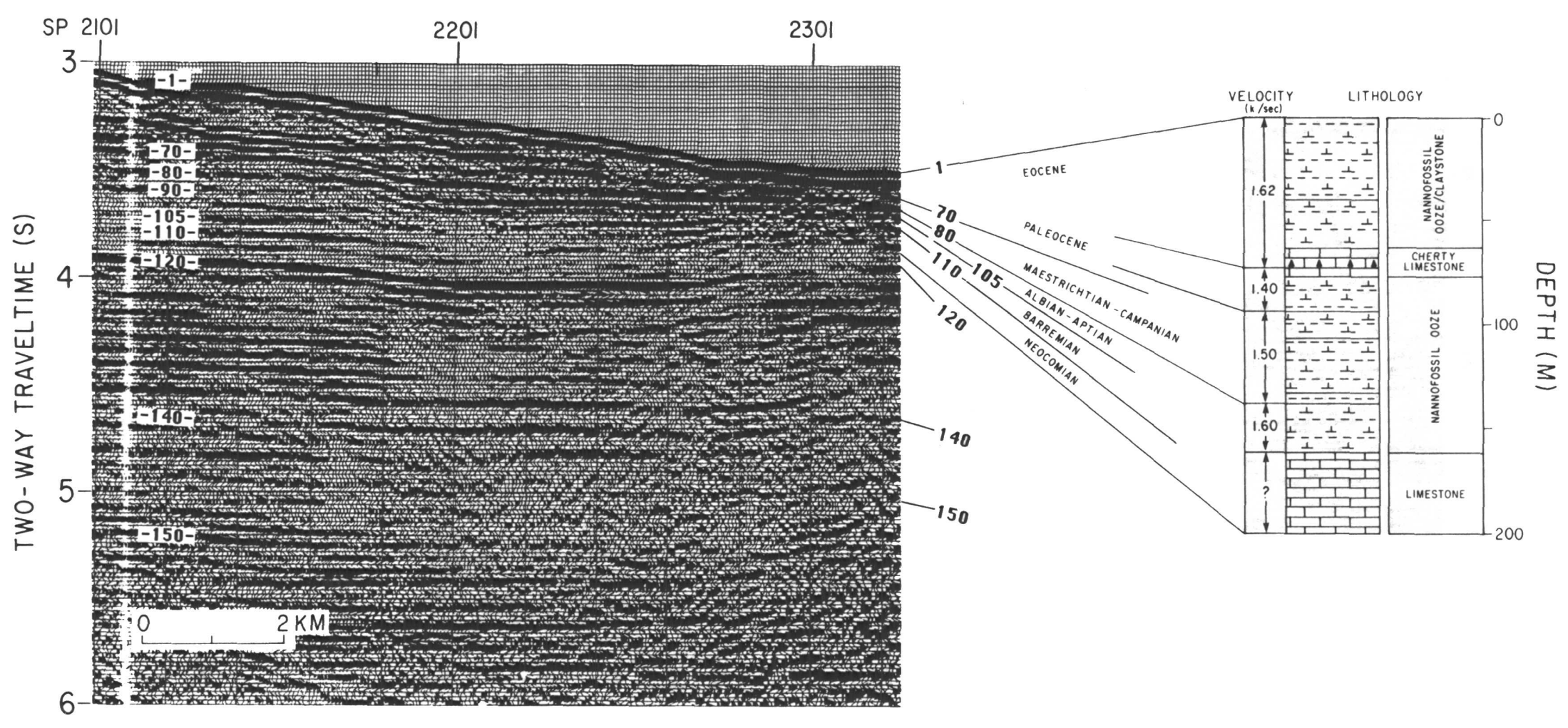


DSDP 39|

USGS TD-3 NO

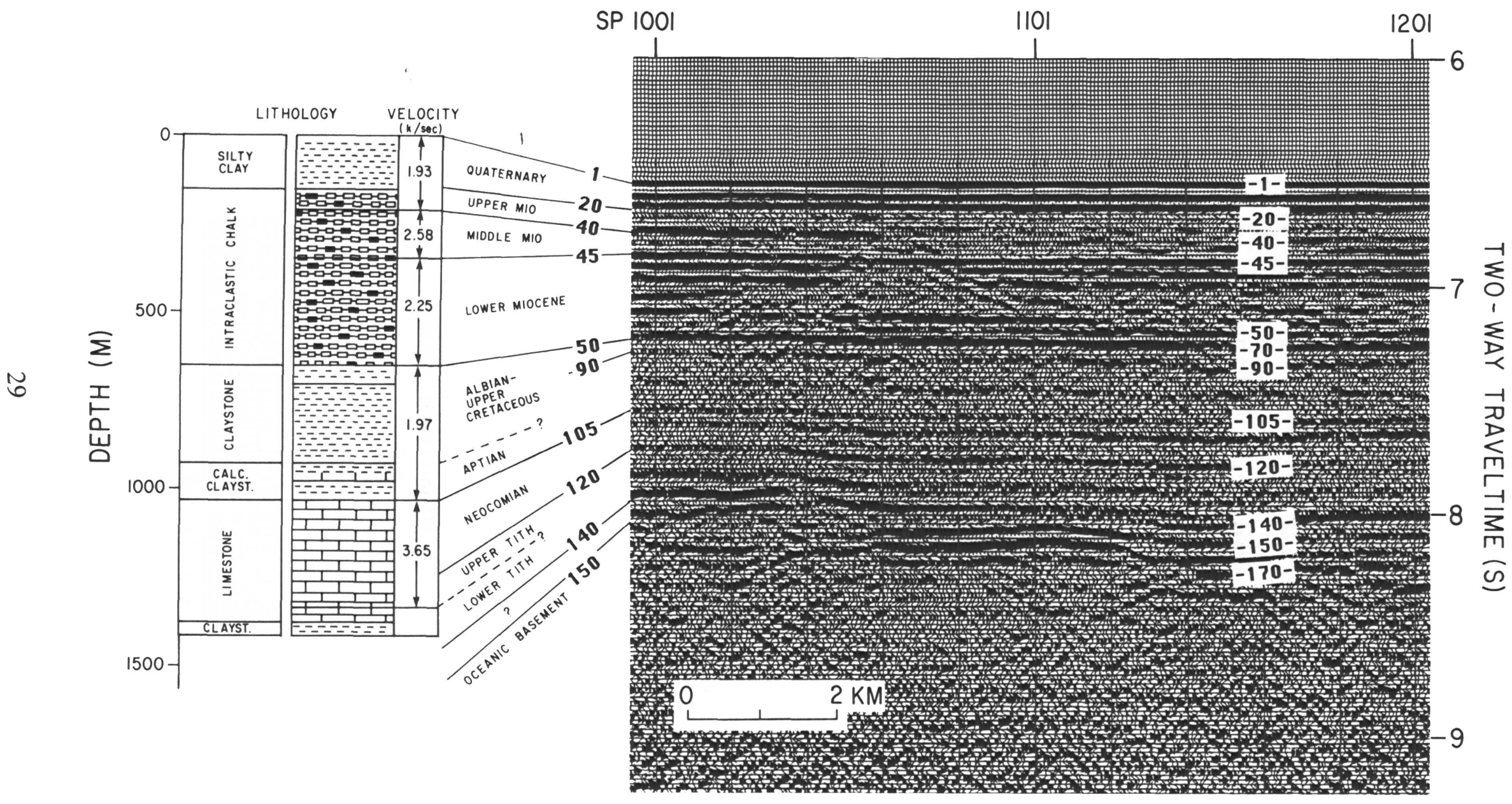




\section{GREAT ISAAC I}

USGS TD-1 BC
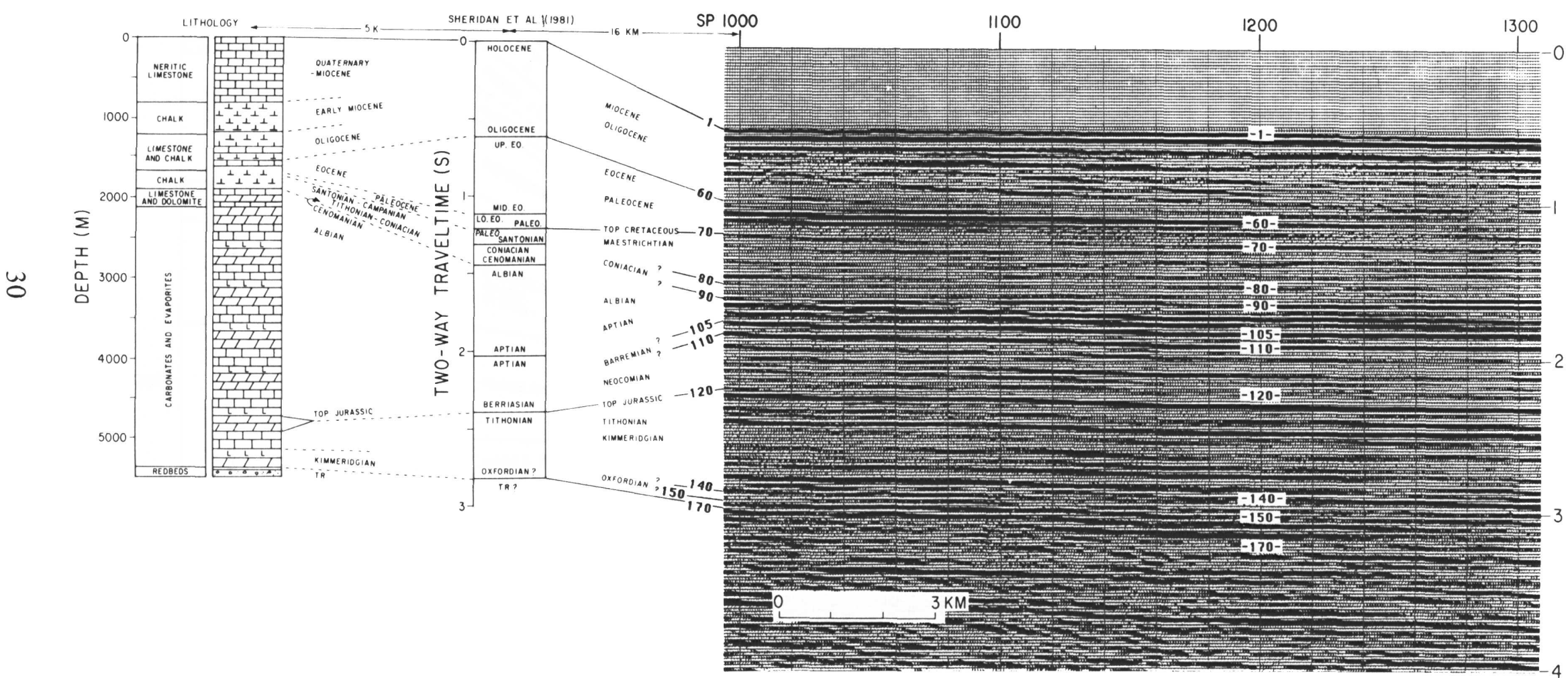
TABLE 4: Locations of Well and Other Samples

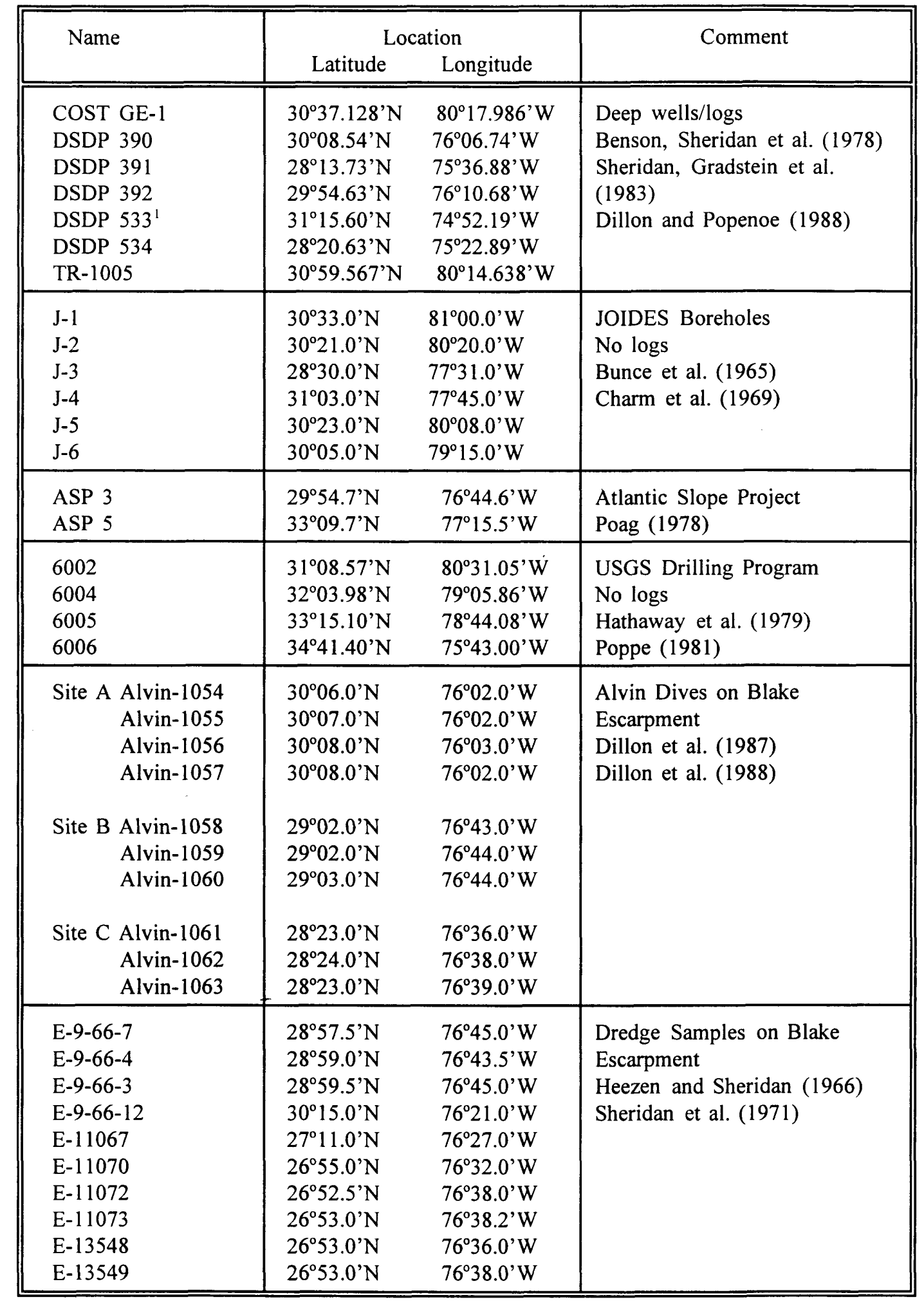

1 Information from DSDP 533 and 534 was used instead of DSDP holes 102, 103, 104 (Hollister, Ewing et al., 1972) because of better line ties to BT-1. 
Differences in the Dillon and Popenoe (1988) and Poag (1991) interpretations can be reduced to differences in (1) how dates on unfossiliferous samples are extrapolated; (2) how the depth stratigraphy of the Great Isaacs 1 well is converted to travel time and extrapolated north to line TD-1; and (3) how structure is interpreted across the Blake Escarpment. Concerning unfossiliferous samples, Poag (1991) assigned Early Cretaceous or Late Jurassic ages to these sections in the COST GE-1 well, DSDP Hole 390, and several of the undated Alvin samples on the Blake Escarpment, whereas Dillon and Popenoe (1988) prefer middle Cretaceous ages. Concerning the Great Isaacs 1 well, sonic velocities are published for the Upper Cretaceous and Tertiary strata of the well (Schlager et al., 1988); but the only published seismic correlation for the deeper units is that of Sheridan et al., (1981), which forms the basis for the Poag (1991) interpretation. The Dillon and Popenoe (1988) interpretation of the Great Isaacs 1 well generally places the Lower Cretaceous and Jurassic section at greater travel times. Concerning the structural interpretation of the Blake Escarpment, Poag (1991) infers the existence of large normal faults ( $>300 \mathrm{~m}$ displacement) near the escarpment edge to explain the positions of dated samples, whereas Dillon and Popenoe (1988) interpreted no structural offsets. Much of the Dillon interpretation uses the premise of constant subsidence throughout the postrift period (Dillon et al., 1985), whereas the Poag interpretation is based on regionally consistent stratigraphic ties between Georges Bank and the Bahamas. Both interpretations are consistent with available sample data, but have different geologic rationales.

Two seismic lines, showing the Poag (1991) interpretation used in this study, are presented as representative sections from the Carolina trough (line 32; Figure 3) and the Blake Plateau basin (line TD-4; Figure 4). Both of these lines have been used extensively as reference sections within each basin (Dillon et al., 1983; Hutchinson et al., 1983; Dillon et al., 1985; Dillon et al., 1988, Poag, 1991).

\section{VELOCITY DATA AND UNCERTAINTIES}

Velocity information derived from stacking the multichannel seismic data form the raw "observations" upon which the depth conversions and some of the secondary acoustic properties of the digital data set are based. This section analyzes the nature of the velocity scans, independent measurements of velocity for calibration, the likely sources of error, and associated uncertainties.

Figure 10: A comparison of the stratigraphy of selected Early Cretaceous and Jurassic horizons interpreted by Poag, 1991 (solid lines) and Dillon and Popenoe, 1988 (dashed lines) together with locations of samples from Alvin dives along the escarpment. The interpretation of Poag (1991) is used in this study. 


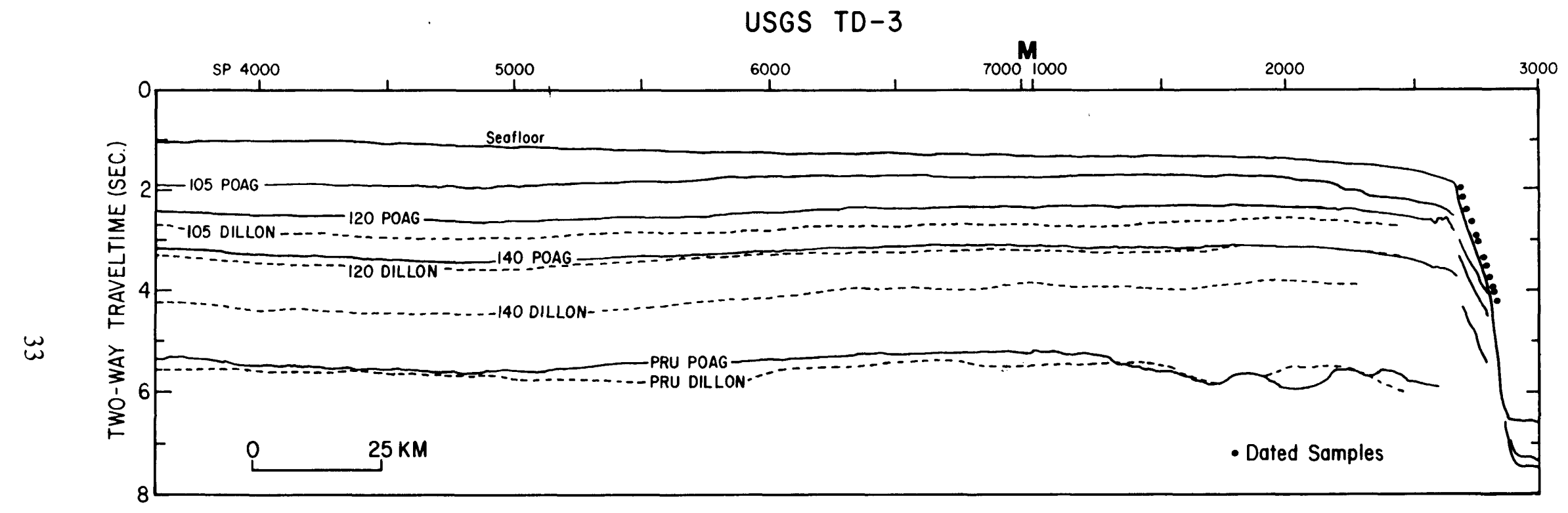




\section{Velocity Scans}

Velocity scans are the displays which processors use to estimate multichannel stacking velocities. These stacking velocities, also called Root-Mean-Square (RMS) velocities, are used to stack traces together and improve signal-to-noise ratios in the final processed record sections. The RMS velocity information contained in the velocity scans determines the accuracy and resolution of the velocity data. Variables such as streamer length, frequency content of the source and wavelet shape contribute to the final velocity display, and therefore their contribution to resolution can be evaluated in the context of the quality of the scan. Examples of the five types of velocity scans used in processing the multichannel data are illustrated in Figure 11. The scans from the GSI, IPOD, and BT lines are representative of the bulk of the data in the Carolina trough; those from the TD and FC lines show the quality of data from the Blake Plateau. The purpose of discussing the velocity scans is not to assign specific error bars or uncertainties to each data set (which is line-dependent, water-depth dependent, and velocity dependent), but to show the magnitude of the differences in the quality of the velocity data between data sets.

Figure 11a (GSI lines) gives the interpreter the most information to evaluate quality of the velocity data. This velocity scan comes from the seaward end of Line 32, where the water depth is about $4.6 \mathrm{~s}$ (two-way travel time). Types of information included in this display are the raw common depth point (cdp) gather, seven normal-moveout corrected examples of the raw cdp using seven different velocity functions (V1 to V7), seven stacks of 9 traces centered on the raw cdp trace using the seven velocity functions, a plot of the seven velocity functions with automatic point estimates of different amplitude strengths, and information about dip. This scan provides many different ways of analyzing the effects of different velocity functions and allows one to choose the optimum function. Unfortunately, this scan also illustrates a limitation of this display which occurs when the optimum picks are at velocities less than any of the seven velocity functions, a situation which occurs from 5.5 to $8.0 \mathrm{~s}$ two-way travel time. At the depth of the strong event at $8.7 \mathrm{~s}$, normal moveout differences on the seven velocity scans can be seen, indicating that the maximum offset of the streamer is enough to make a reasonable velocity pick, even at these large travel times.

Figure $11 \mathrm{~b}$ (IPOD line) shows an earlier generation of the same (GSI) velocity analysis display used in Figure 11a. This scan comes from the continental slope where water depths are about $1.0 \mathrm{~s}$. Despite the similarity of display, the quality of the raw seismic data input to the scan is considerably less than that used for line 32 in Figure 11a. Normal moveout is difficult to distinguish below about $5 \mathrm{~s}$. Because the base of sediments on this portion of IPOD is interpreted just above $5 \mathrm{~s}$, this scan shows that the streamer length and all other variables

Figure 11: Examples of velocity scans used in the 5 multichannel surveys. (A) GSI velocity scan from Line 32, SP 5504. (B) IPOD velocity scan from SP 550. (C) BT velocity scan from line BT-1, SP 2005. (D) TD velocity scan from line TD-4, SP 4001. (E) FC velocity scan from line FC-3, SP 5575. Labels have been added for two-way travel time, RMS velocity, the approximate location of the sea floor and basement, and other relevant information. Very little primary information exists at subbottom depths in excess of $2 \mathrm{~s}$ for the scans from the TD-and FC-lines in the Blake Plateau and southern Carolina trough. 


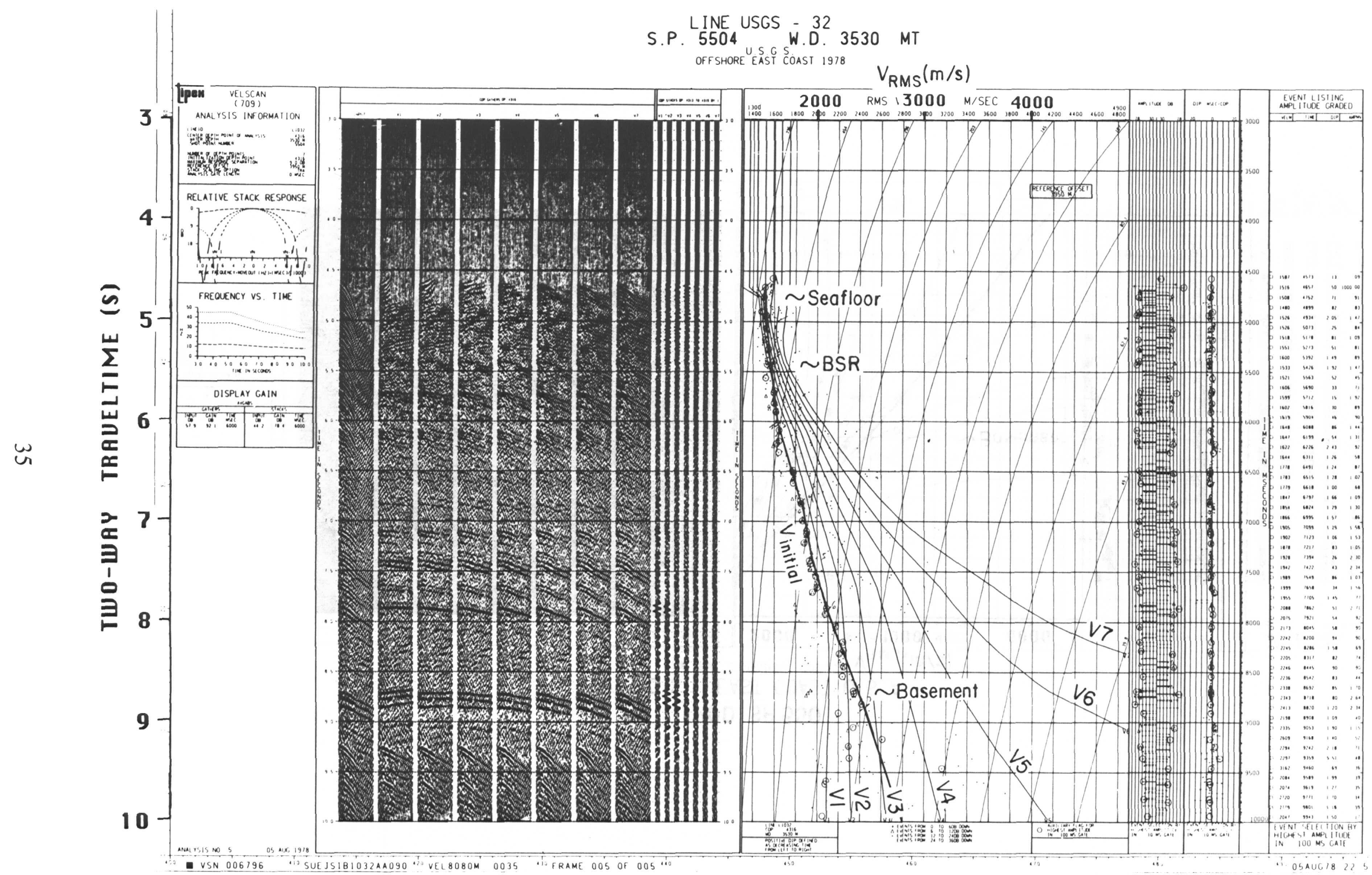




\section{IPOD SP 550}

U.S.G.S. EAST COAST U.S.A.

LINE IPOO SHOTPOINTS $520 \cdot 1023 \mathrm{~V}_{\text {RMS }}(\mathrm{m} / \mathrm{s})$

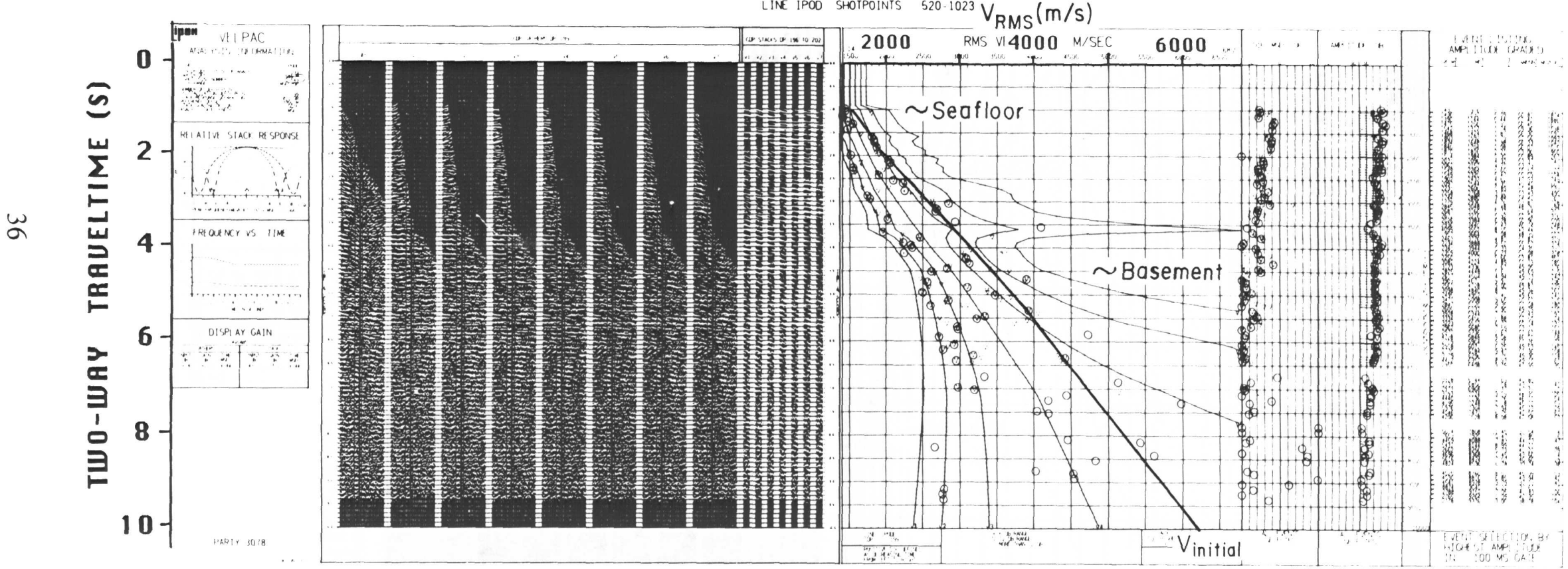




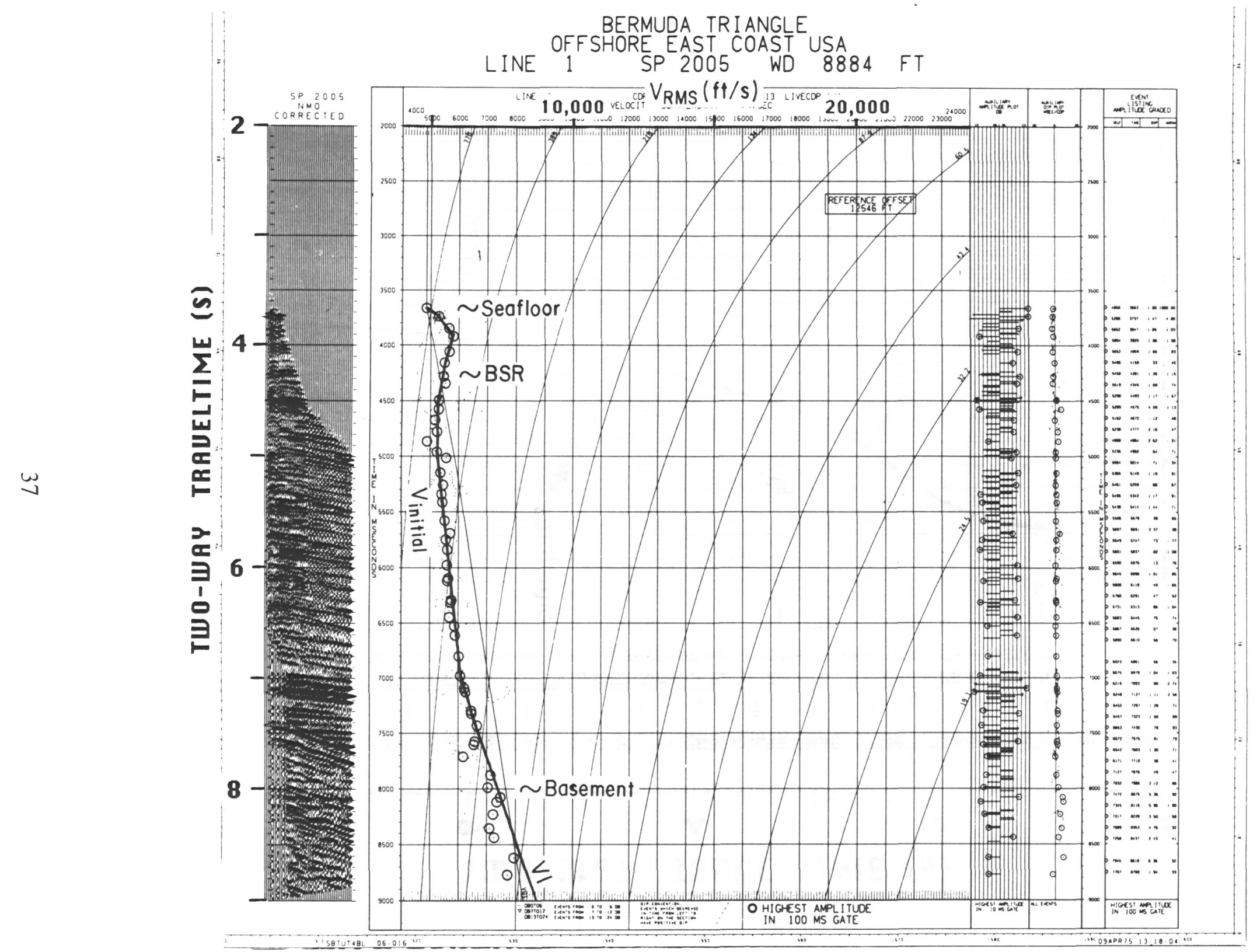




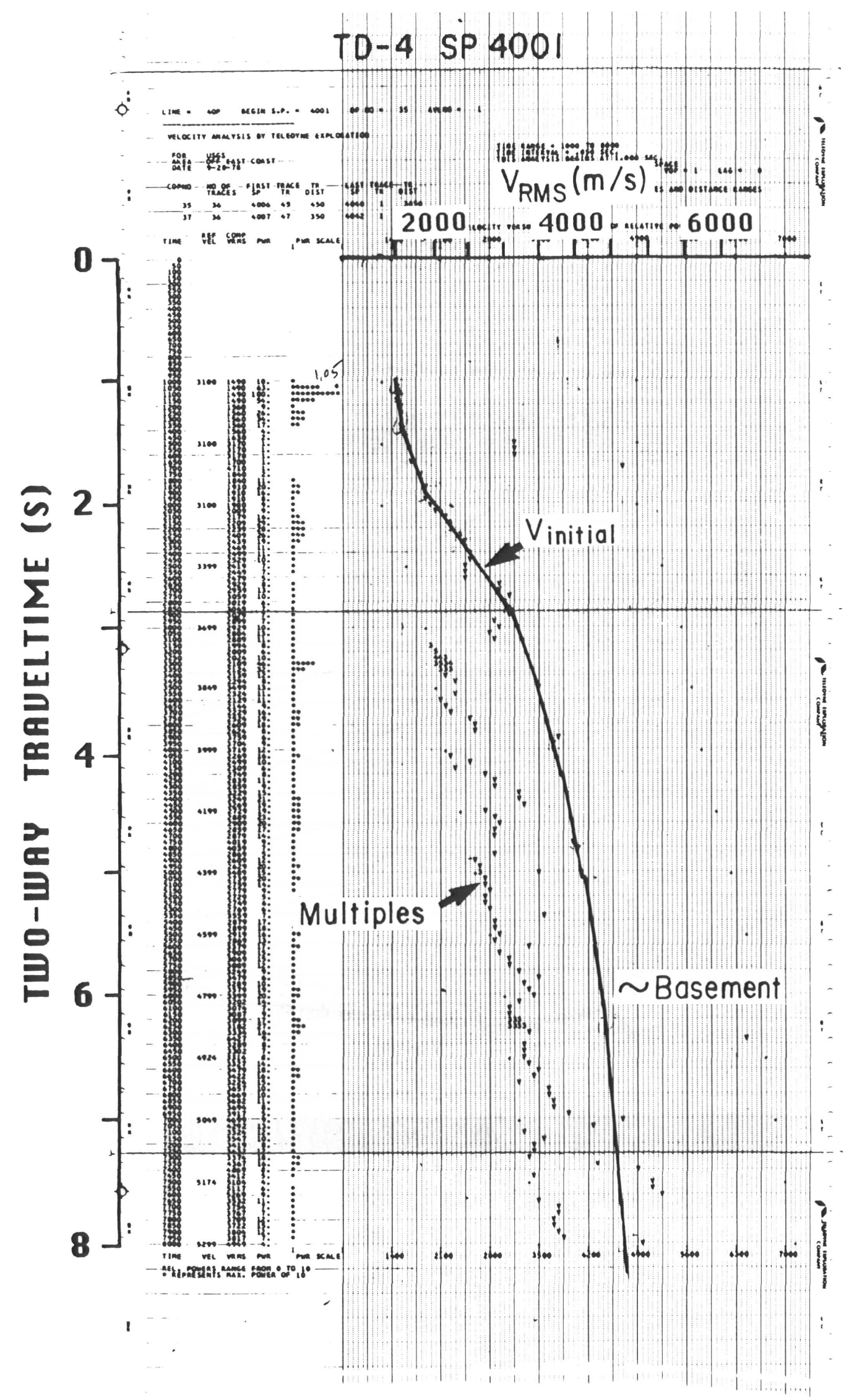




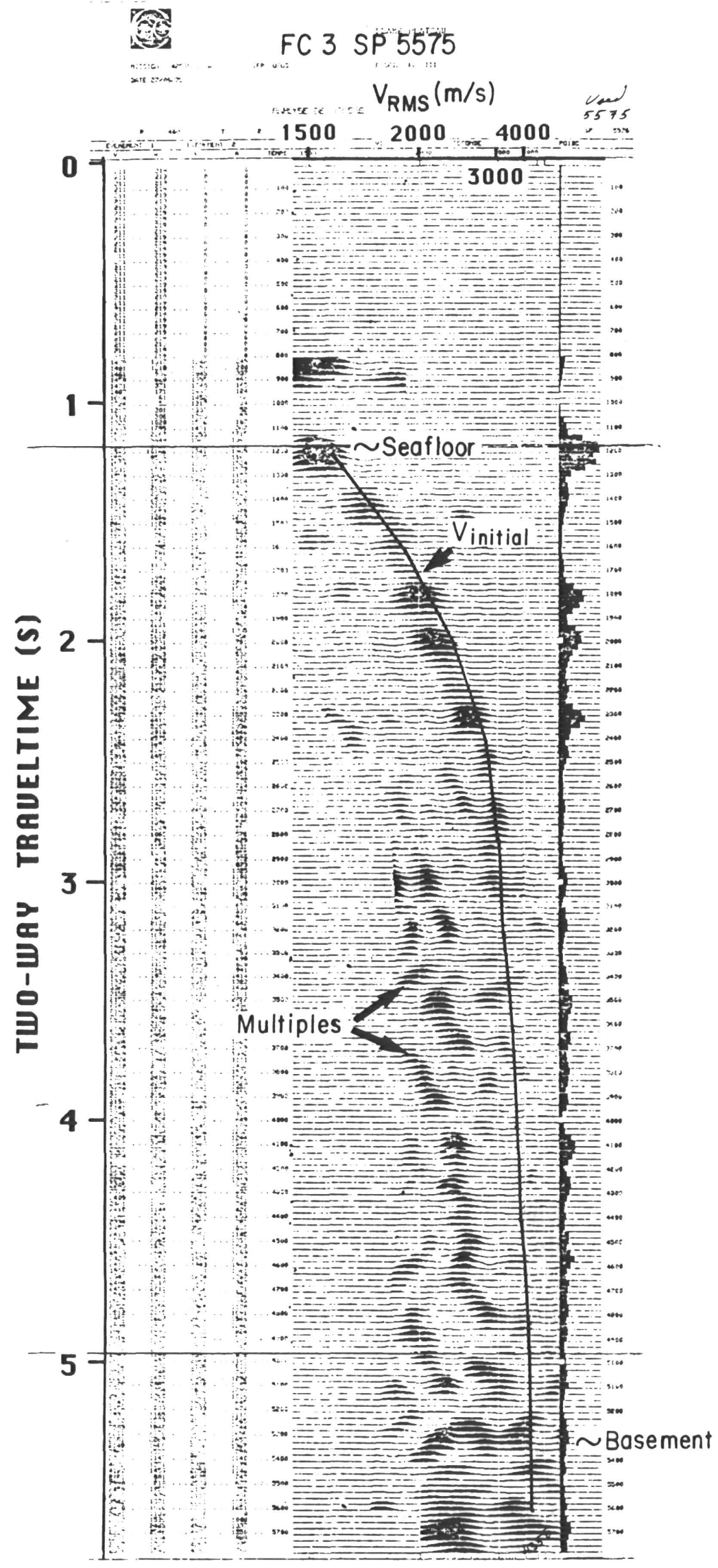


still make velocity resolvable, although the larger scatter in the velocity estimates (presumably related to the lower quality of the input raw cdp) adds uncertainty to the final velocity function.

The velocity scans used for the BT lines (Figure 11c) are still an earlier version of the same program used for the GSI and IPOD lines (each of these data sets was processed by GSI in different years). In this display, for shot 2005 on the axis of the Blake Ridge in water depths of $3.7 \mathrm{~s}$, only the NMO-corrected cdp for a single velocity function is shown, with amplitude picks rated by size; different velocity functions are not applied to the data nor are the displays of multiple normal-moveout-corrected cdps or stacked traces included. The lack of these additional displays means that little information exists in the scan to evaluate whether measurable normal moveout occurs at travel times up to $8 \mathrm{~s}$ (near the basement reflection). It is therefore difficult to evaluate how well the deeper velocities are resolved, or whether this is the optimum velocity function for stacking.

The velocity scans used for the TD lines (Figure 11d) and FC lines (Figure 11e) are extremely primitive. Neither includes displays of the raw or normal-moveout-corrected data (either cdps or stacks); both are printed with low-resolution line printer output; the analysed time gates are coarse (50 ms and $25 \mathrm{~ms}$ for the TD and FC data, respectively); the velocity scales are coarse. An additional difficulty on the FC lines is that the velocity scale is nonlinear, complicating the digitizing process. Both examples are from the inner part of the Blake Plateau. Good primary velocity extimates exist in the uppermost 1-2 s subbottom, although the coarse scales of display make the estimates look better constrained than they probably are; significant multiple energy contaminates the deeper arrivals; and little information exists for primary velocity estimates at travel times greater than about $2 \mathrm{~s}$ subbottom. This is true for all of the TD and FC lines in the Blake Plateau, indicating that velocity information is of consistently very low quality and resolution.

The distance between adjacent velocity scans affects the horizontal or lateral resolution of velocities. For most of the multichannel data, the spacing of velocity scans was $3 \mathrm{~km}$ (Table 4), although lines TD-6 and the northern segments of line TD-2 had velocity analyses at 5-km intervals and the FC-lines had analyses at $10.8-\mathrm{km}$ intervals. This spatial sampling of the velocity data limits the resolution to velocity anomalies that equal or exceed $3-5 \mathrm{~km}$ wavelength along each line (about $10 \mathrm{~km}$ along the FC lines).

Another way of assessing the quality of the scans is to look at the variability and scatter of adjacent estimates along individual lines. This can be misleading, however, because estimates can be remarkably smooth in regions of no data if the interpreter maintains consistent (default) velocity functions. This is shown by an example of the initial $\mathrm{V}_{\mathrm{RMS}}$ picks for line TD4 (Figure 12b). Two reflectors, 120 and 180, are examined; reflector 120 is about $2 \mathrm{~s}$ subbottom, or at about the limit of velocity resolution using the velocity scans; reflector 180

Figure 12: Plots of the initial RMS velocity for lines TD-4 (upper) and 32 (lower). The vertical scale is velocity, enabling the velocity for each horizon to be plotted separately. The larger scatter on the TD-lines can be attributed to the much lower quality of the deeper velocity information compared to line 32. 


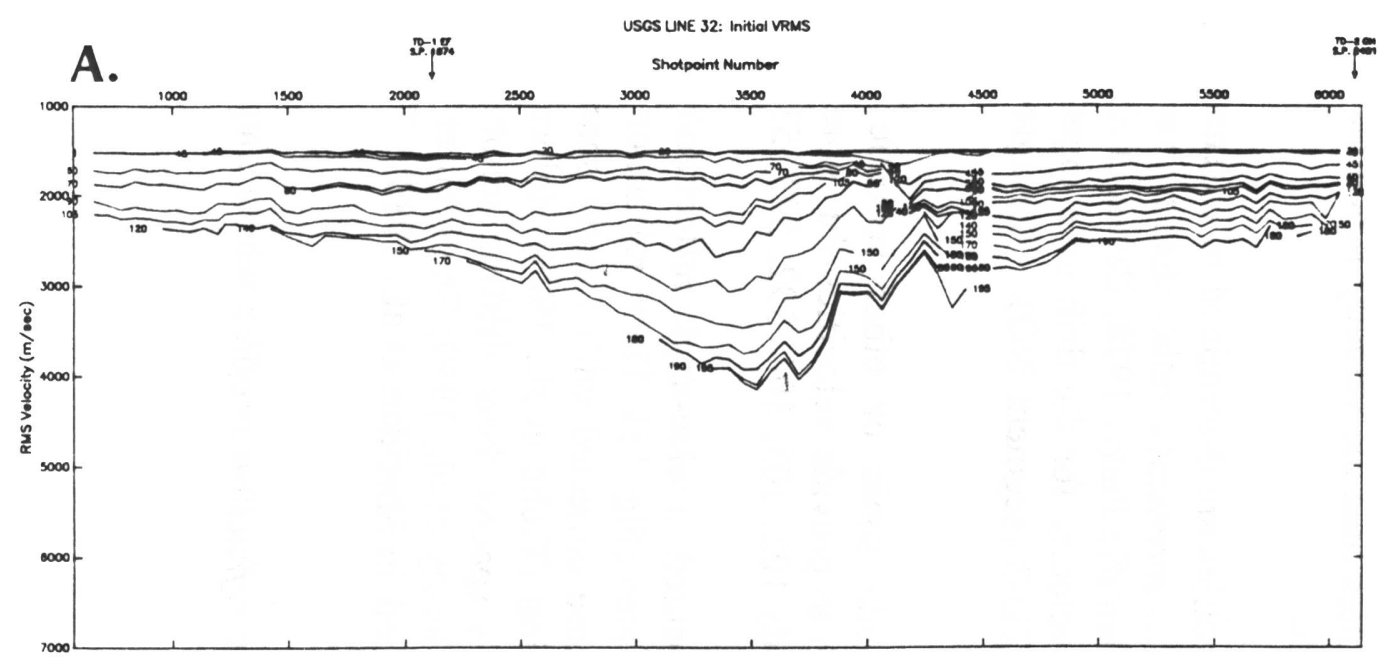

$\pm$

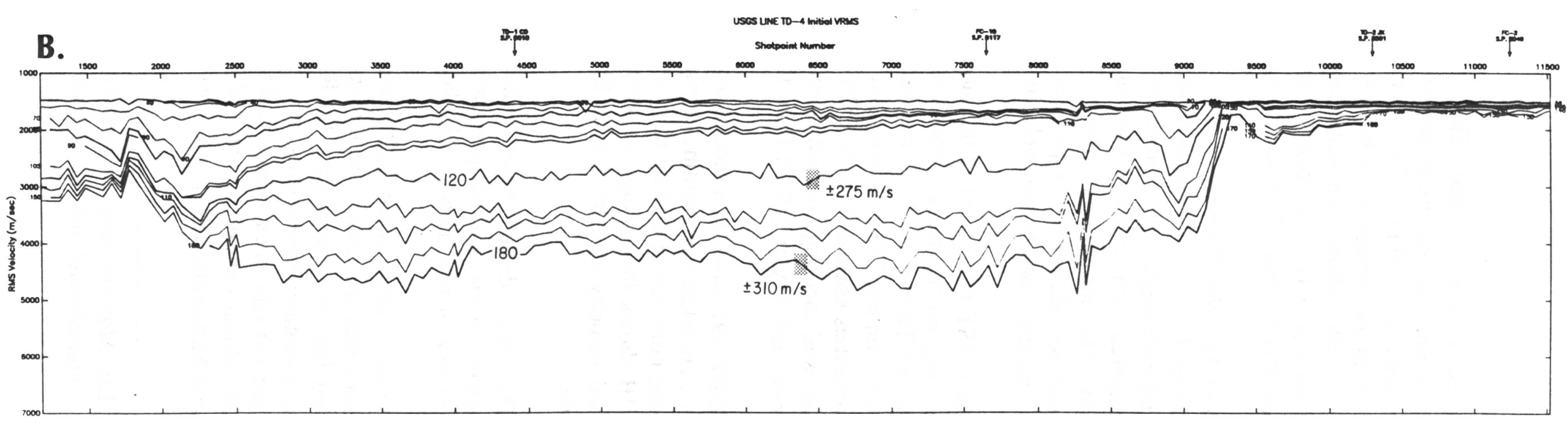


is the deepest reflector picked. The uncertainty for reflector 120 , based on an envelope constructed around the maximum and minimum peaks, is about $275 \mathrm{~m} / \mathrm{s}$, or about $10 \%$ of an average velocity of $2,700 \mathrm{~m} / \mathrm{s}$. The uncertainty in the velocity of reflector 180 is about $310 \mathrm{~m} / \mathrm{s}$, or about $7 \%$ of an average velocity of $4,400 \mathrm{~m} / \mathrm{s}$. These uncertainties are deceptively small, because very little information exists on which to base the velocity values. This figure does show that the scatter (i.e., jaggedness) of the deeper part of the section for line TD-4 is much greater than that for line 32 (Figure 12a).

\section{Independent Velocity Estimates}

Independent velocity measurements have been made in the study area using sonic logs in wells and wide-angle reflection/refraction experiments. These data provide information that can be compared with velocities calculated from the multichannel data in discrete locations on the margin. The locations of these independent velocity experiments that are near the multichannel seismic-reflection profiles are shown in Figure 13; comparisons between these velocities and the multichannel velocities are presented in Appendix 4.

The COST GE-1 well at the landward end of line TD-5 (Figures 8, 9A) contains the only sonic log on the margin south of Cape Hatteras that has been modelled extensively (Anderson and Taylor, 1979). A comparison of the sonic-log velocities with interval velocities from SP 1921 on line TD-5 shows good consistency (Figure 14A). Dillon et al. (1985) pointed out that velocities estimated in the COST GE-1 well by Schlumberger using both sonic log and check shot (well shooting) yielded slightly higher velocities than the velocity functions derived by Anderson and Taylor (1979) from the same data set.

DSDP 391 provides a second well in which velocities are determined to basement. The velocities were taken from routine physical properties measurements, rather than true sonic logs taken in the hole during drilling (Leg 44 Shipboard Scientific Party, 1978; Bryan et al., 1980). Figure 14B shows the average velocity and range in velocity for the drill hole together with the interval velocity calculated from SP 1001 of line TD-3 (segment NO). The agreement is reasonable.

The other drilled holes either did not include sonic or other acoustic velocity measurements or they did not penetrate deeply enough to provide velocities for more than the uppermost one or two units in this database (e.g., wells 102, 103, 104, 392, 533, 534).

Velocity information is also independently measured in wide-angle reflection/refraction experiments that are distributed throughout the study area (Fig. 13). These refraction data can be divided into two categories: (a) Recent lines - those collected with closely spaced shots, fixed ocean-bottom instruments, and satellite navigation (Trehu et al., 1989; Holbrook et al., 1994); and (b) Old lines - those collected with widely spaced shots, drifting sonobuoys, and poor navigational control (Ewing and Ewing, 1959; Hersey et al., 1959; Sheridan et al., 1966; Dillon and McGinnis, 1983; and other lines summarized in Sheridan et al., 1988). The recent

Figure 13: Map showing the locations of the seismic refraction profiles where they intersect with the multichannel seismic reflection tracklines. 


\section{ocations of Refraction Data Sets}

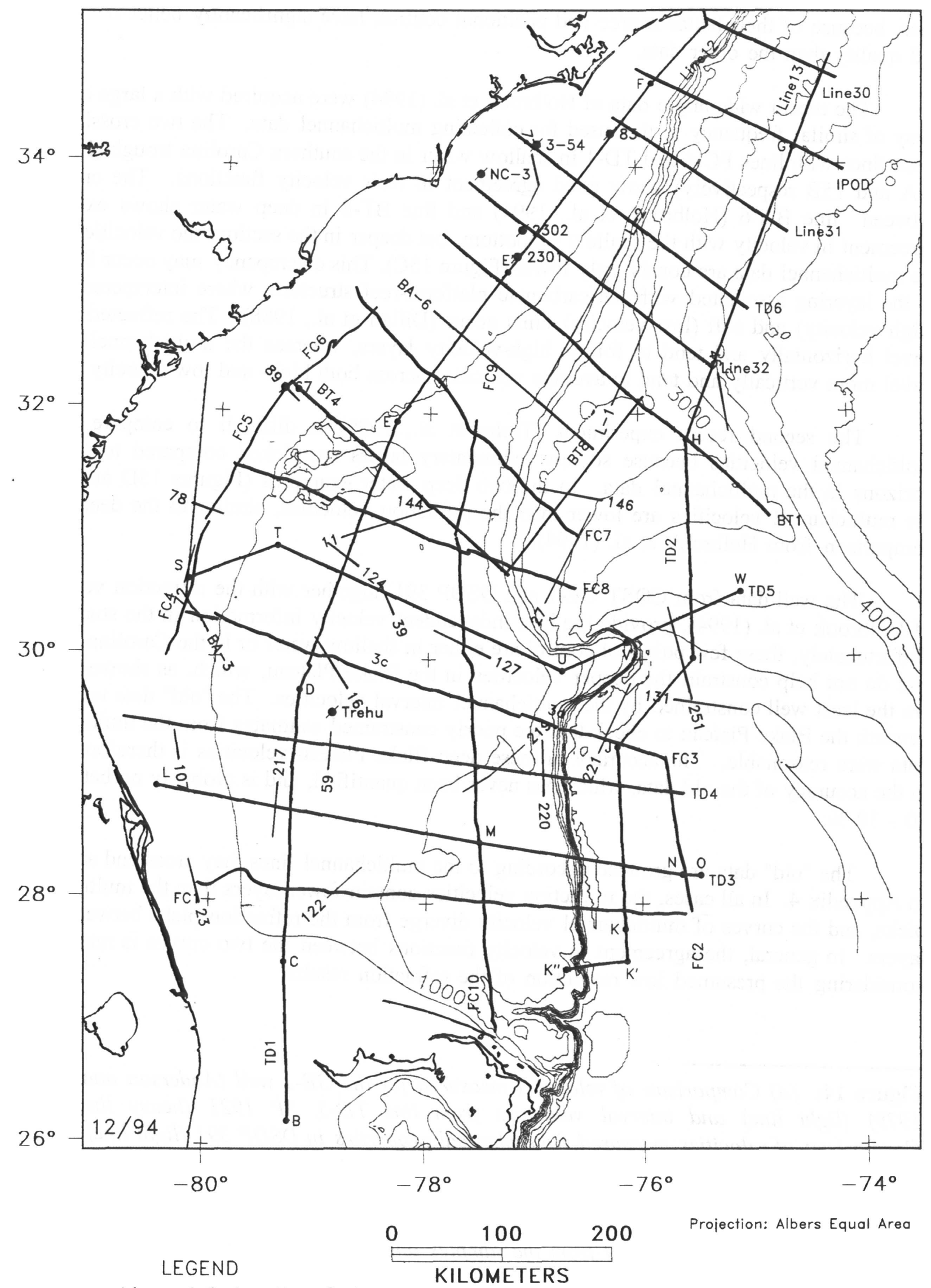

- Line of Refraction Data

- Point of Refraction Data 


\section{Velocity Smoothing}

An essential component in this project has been the smoothing of velocities. The original RMS velocities derived from velocity scans contain large short-wavelength oscillations (e.g., Figure 12) that are acceptable for purposes of stacking the data, but which are not geologically meaningful. These oscillations are primarily a function of the manual and noninteractive methodology used in 1970's processing. The purpose of velocity smoothing is to remove these short-wavelength variations in velocity while maintaining overall velocity trends. Smoothing also provided a mechanism for adjusting velocities to be consistent at line crossings.

Several assumptions have guided the smoothing process:

(1) The water velocity was set to a constant $1500 \mathrm{~m} / \mathrm{s}$. In the original scans, the water velocity varied between about 1480 and $1520 \mathrm{~m} / \mathrm{s}$. This change provides a smooth waterbottom reflection.

(2) Smoothing was performed in the interval velocity domain, rather than the RMS velocity domain, because small changes in RMS velocity yield large changes in interval velocity (Cordier, 1985) and because the geologically important velocity for constructing the data base is the interval velocity. This approach is based on the observation that smoothing in the interval velocity domain will automatically create a smoother RMS curve. This differs from the approach used by Klitgord and Schneider (1994), who smoothed in the RMS domain for the velocities north of Cape Hatteras.

(3) Interval velocities increase with depth. This relationship generally holds for most parts of the U.S. continental margin (e.g., Sheridan et al., 1988) and makes velocity analysis and computation simpler. The Blake Plateau is one region where this relationship is violated, because velocity inversions probably occur where higher velocity carbonate and lower velocity clastic units are interlayered (e.g., Trehu 1984, 1985; Dillon et al., 1988). However, the poor velocity control in the Blake Plateau makes resolving velocity inversions extremely unlikely, if not impossible. Further, rarely does one raw velocity estimate coincide with one unit boundary, and therefore the velocities are an average value taken from a resampled velocity curve. Our choice of an increase in the average velocity of each unit is based on assuming that the average (increasing) velocity curve is consistent with the high overall velocities inferred from the "old" refraction lines (Appendix 4).

(4) Sedimentary units do not have short wavelength $(<1 \mathrm{~km})$ variations in lithology and therefore in interval velocity. The most likely lateral gradations between carbonate and clastic sedimet occurs over distances of several kilometers.

(5) Abrupt lithologic (and velocity) changes can occur over the modern and paleo shelf/slope breaks (including the Blake Escarpment). These regions mark positions where erosional and depositional processes have been most pronounced and have caused terminations of units and reflections. These variations can be lateral and vertical, especially in the vicinity

Figure 15: A comparison of velocities from "recent" seismic refraction experiments (light lines) and from the multichannel profiles (heavy lines). (A) Line BA-3 (Holbrook et al., 1994) and line FC-4 on the Carolina platform. (B) Line BA-6 (Holbrook et al., 1994) and line TD-1 on the Carolina Platform. (C) Line BA-6 (Holbrook et al., 1994) and line BT-8 from the Blake Ridge. (D) Line 1 (Trehu et al., 1989) and line 32 in deep water. (E) Line 2 (Trehu et al., 1989) and line 32 in deep water. 


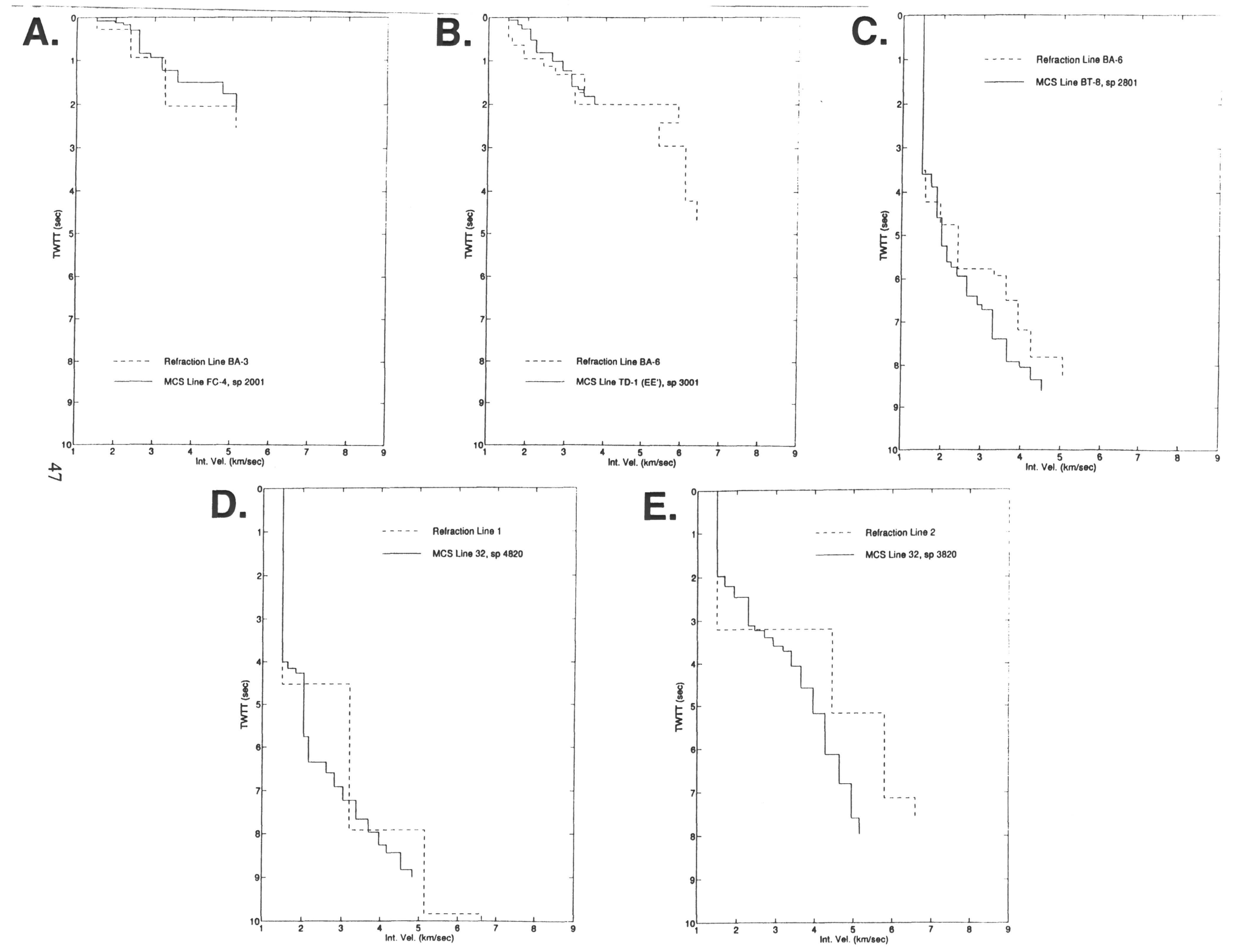




\section{DIGITIZING PROFILE DATA}

TRAVEL TIME

VELOCITY

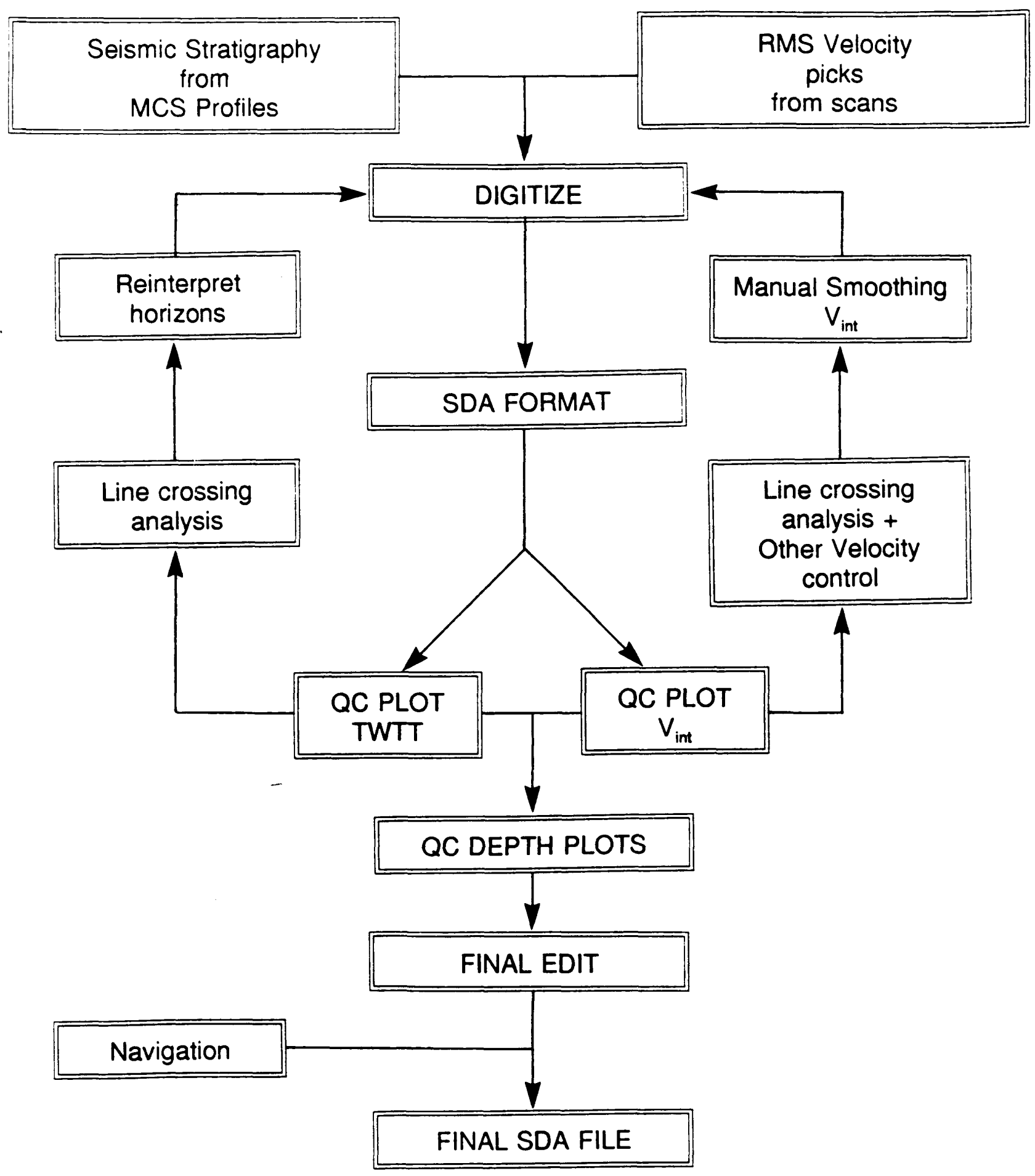


$1 \mathrm{inch} /$ second vertical). Minor adjustments in the stratigraphy were required at some of the line crossings, and these tended to be at junctions with the FC lines, which had been displayed at a scale different from the rest of the multichannel data.

An early step in digitizing the multichannel profile data was to digitize the bathymetry off NOS (1986) in regions where the mute patterns in the processing removed the bottom reflection. This was done manually by constructing cross sections of bathymetry from the chart along each affected profile. These estimated water depths were converted to travel time using a velocity of $1500 \mathrm{~m} / \mathrm{s}$, and manually inserted into the SDA files. In addition, this bathymetry was drawn onto the original mcs profile along with outcrop information (Paull et al., 1980; Popenoe, 1993) so that other horizons removed in the mute process could be drawn in and then digitized.

The stratigraphic discontinuities on the multichannel profiles tend to be reflections with wavelets lasting $20-60 \mathrm{~ms}$. We estimate that the uncertainty associated with digitizing the stratigraphic information averages about $30 \mathrm{~ms}$.

Stratigraphic horizon 30 (base Pliocene) was digitized separately from the other horizons and added to the data late in the compilation, when it because clear that omitting horizon 30 resulted in a discontinuity with the database north of Cape Hatteras (Klitgord et al., 1994). Horizon 30 is regionally extensive to the north (Klitgord et al., 1994), but had not been digitized south of Hatteras because it only occurred on the Carolina slope and rise and pinched out on the Blake Ridge. In order to keep the stratigraphic compilations north and south of Hatteras continuous, horizon 30 was digitized and merged into the rest of the database "after the fact".

The original full-scale copies of each multichannel profile used in this project, with the final stratigraphic interpretation drawn on, are archived at the USGS Data Library in Woods Hole, Massachusetts.

\section{Digital Velocity}

Raw data for the RMS velocities consisted primarily of velocity scans supplied to USGS by the seismic contractor as part of processing the data. In a few cases, raw velocities were hand digitized from velocity panels on the multichannel profiles because the original velocity scans were either unavailable or unuseable. Spot checks comparing the RMS velocities from panels on the profiles with the scans supplied by the contractor showed that the two were essentially identical and, hence, they have not been treated separately in this compilation.

On only one portion of one line was there no useable velocity information: line TD2HI (SP 3000 - 4981) for about $100 \mathrm{~km}$ on the south side of the Blake Outer Ridge. The velocities for sections $\mathrm{GH}$ and the rest of $\mathrm{HI}$ of line TD-2 were taken from the panel summaries. Inspection of the panels for much of line TD-2HI showed that the initial travel time estimates for the velocities had no consistent or reliable relationship with the travel time of the sea floor (varying by as much as several hundred milliseconds). We interpreted this situation to show that the velocity annotation file did not reliably match the multichannel data and the velocities were therefore not useable. All velocities in this interval have been interpolated 
through the region during the smoothing process. (Note that these original, unuseable RMS velocities on line TD-2HI are displayed as part of the initial data in Appendix 2; we interpret that the step increases shown in the plots of initial RMS and interval velocity at SP 3000 4981 are not real).

The accuracy of digitizing depends on the quality of the scan: the GSI, IPOD, and BT scans allow RMS velocities to be digitized with an accuracy of about $20-30 \mathrm{~m} / \mathrm{s}$, and travel times with an accuracy of about $20 \mathrm{~ms}$. The TD scans allow for an accuracy of about $80 \mathrm{~m} / \mathrm{s}$ in velocity and $50 \mathrm{~ms}$ in travel time. The FC scans allow about $100 \mathrm{~m} / \mathrm{s}$ for velocity and 25 $\mathrm{ms}$ for travel time. Subsequent smoothing in the interval velocity domain translated into adjustments of RMS velocity that often exceeded these values for each data type. Hence, the velocities, in general, could be digitized with more accuracy than the data inherently contained. The uncertainty introduced in the digitizing process is, therefore, insignificant in understanding the accuracy of the velocities.

The smoothing of velocities was done after final adjustments to the travel time estimates of the stratigraphic horizons. RMS velocities, resampled for each horizon, were converted to interval velocities using the Dix equation (Dix, 1955) and displayed in shot versus velocity space for each horizon. The velocity of the water layer was set to $1500 \mathrm{~m} / \mathrm{s}$. For horizons beneath the water layer, smoothing was done by hand on the shot-velocity plots, with adjustments made for: (1) removing short wavelength oscillations (shown in Figure 18); (2) generating increasing velocity values for deeper horizons; (3) bringing line crossing values into agreement; and (4) verifying that the final picks were broadly consistent with refraction data. The strategy used to project the refraction velocities onto these plots was: (a) convert refraction depths to travel time; (b) superimpose these travel times on the stratigraphic plots of each line to estimate which horizons correlated with which velocity intervals; and (c) compare velocities for horizons estimated from the refraction results with the velocities calculated from the multichannel data.

Smoothing velocities generally took many iterations, similar to adjustments of the stratigraphic travel time estimates, because changes often affected large regions, several horizons, and multiple lines. One advantage of the strategy of smoothing in the interval velocity domain was that modifications to shallower horizons did not change the deeper interval velocities, as would have been the case if smoothing were done in the RMS domain.

The velocities associated with horizon 30 were treated differently than the other horizons, because of its late addition to the digital compilation. For the lines where horizon 30 was added, interval velocities were estimated at the line crossings with TD-2, then interpolated along each line to be between the velocities for units 20 and 40 . Because units

Figure 17: (A) An example of SDA format without navigation. (B) An example of SDA format with navigation. Ref. - Reflector number; SP - Shot Point; Twtt - Two-way travel time; $V_{\text {rms }}$ $R M S$ velocity; $V_{\text {int }}$ - Interval velocity. None of the descriptors for the data (e.g., SP, Data, Twtt) are included in the SDA files; they are included for clarifying the format. Negative numbers in the data portions of the file, such as -3.0000 shown here, indicate missing horizons. 
20 and 40 were generally close in velocity (i.e., also close to the velocities for unit 30), separating out unit 30 has a negligible effect on the recalculated depths of the deeper horizons.

After final interval velocities were determined for each line, RMS velocity was recomputed, and depths were calculated for each horizon.

\section{Depth Conversions}

After all stratigraphic horizon estimates and velocity smoothing were finalized, all lines were plotted in depth to visually inspect the quality of the depth information. Additional edits were required on all of the profiles across the Blake Escarpment, and a few of the profiles across the Carolina slope, because of unusual and unrealistic geometries created where both travel times and velocities were changing rapidly. Edits eliminated the velocity data as unreliable, and the depth conversions show no data in these regions of steep morphology. Generally, these edits only affected about $10-20 \mathrm{~km}$ of data across the steepest bathymetry. This same procedure was used across the slope and beneath the paleoshelf edge for the study area north of Cape Hatteras (Klitgord and Schneider, 1994). A comparison of a depth profile for line TD-4 before and after velocity smoothing is shown in Figure 19.

\section{Final Format}

The final data, merged with navigation (Figure 17b), are archived in SDA format at the Data Library at USGS in Woods Hole, Massachusetts. The initial data are also archived in the Data Library in SDA format. These initial files preserve the original digitized information from both the stratigraphic horizon picks and the RMS velocity picks, but in an SDA format, rather than in the format generated at the digitizing table. This makes comparison with the final data simpler.

\section{DISCUSSION}

This data compilation contains profiles of travel time, depth, RMS velocity, and interval velocity for all of the seismic lines at identical scales (Appendices 1 to 3). Several of the more salient points that arise from inspecting these profiles (Appendices 1 to 3 ) are:

(1) Travel time plots show great distortion wherever water deepens rapidly, such as across the shelf-slope break and across the Blake Escarpment. The travel time plots, if viewed as cross sections, suggest that the deepest layers in the abyssal plain are considerably deeper than equivalent layers beneath the Blake Plateau (e.g., lines FC-1, FC-3, TD-3, TD-4, and TD5). In actuality, the depth converted profiles, which are cross sections, show that the deepest layers beneath the Blake Plateau are significantly deeper than equivalent layers beneath the abyssal plain. This fact has been emphasized in other analyses (e.g., Grow et al., 1979), but is easy to forget if depth sections are not routinely generated, which often is not done across continental margins because of poor velocity control.

Figure 18: Comparison of initial (upper) and final smoothed (lower) interval velocities for line 32 in the Carolina trough. 


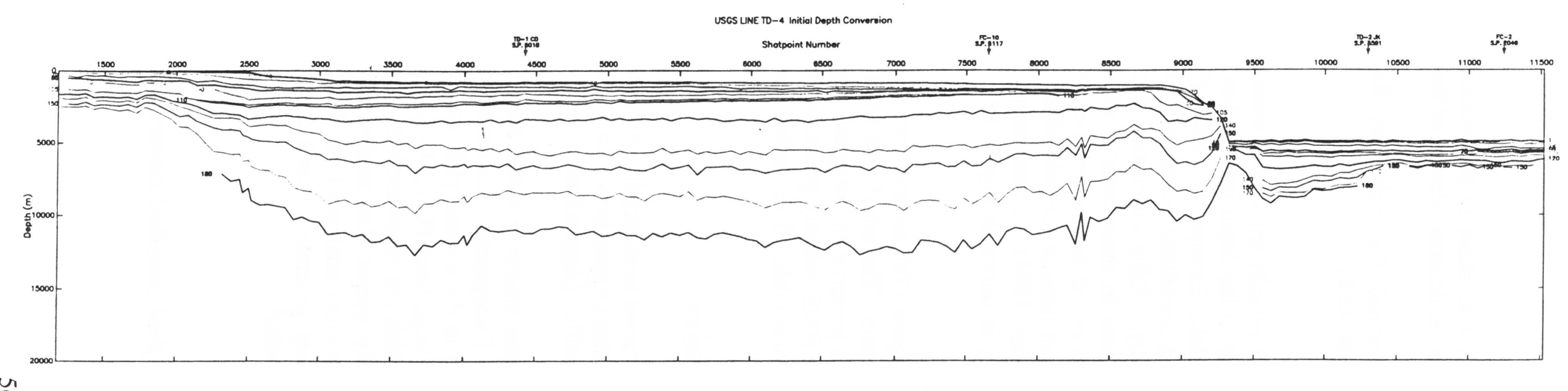

Й

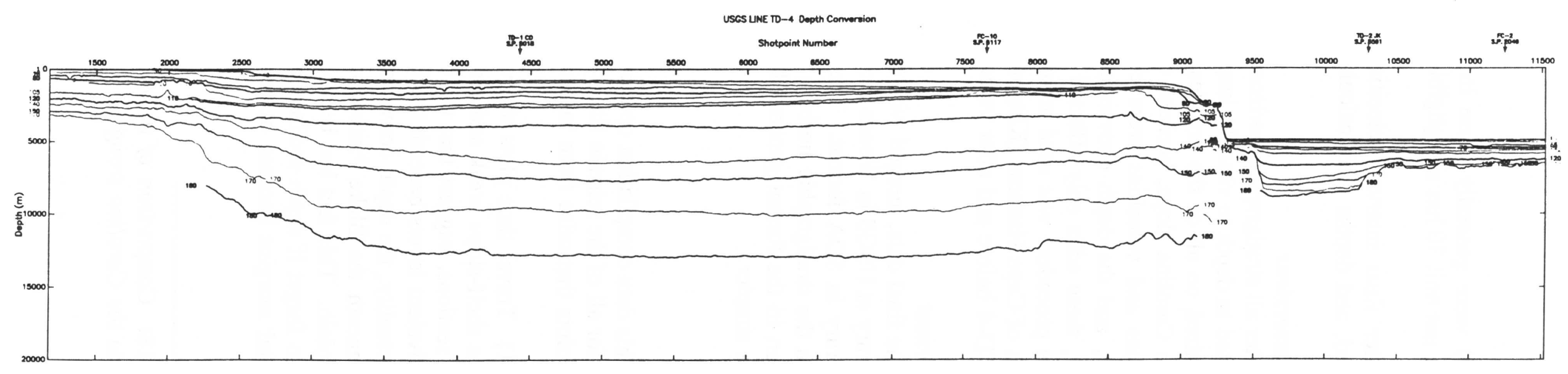


(2) Large scatter is a serious problem with almost all of the initial interval velocity plots, particularly with the deeper horizons (primarily Cretaceous and older, horizons $70-190$ ). This point reinforces the problem of poor velocity resolution, especially for the deeper velocities.

(3) The final RMS velocity plots contain some small, but identifiable, short-wavelength variations. These are a function of both the artificial increase in frequency of sampling (from several kilometers to $250 \mathrm{~m}$ ) and the recomputation of RMS velocities from smoothed interval velocities. These variations should not be considered geologically meaningful or otherwise representative of the data.

(4) Geological structure, in the form of faults or diapirs, has not been displayed digitally on the profiles. For example, the salt diapirs imaged on line 32 (Figure 3) are not shown in the digitized sections (Appendix 1). Nor are the faults explicitly drawn on the sections, such as TD-4 (compare Figure 4 with the digitized version in Appendix 1). Salt diapirs and fault offsets are shown indirectly as terminations of horizons.

The digital compilation of the stratigraphic and velocity data for this study involved two steps that were bottlenecks. These bottlenecks are easy to identify in hindsight, but should be emphasized in order to streamline future data compilations of similar scope. First, velocities should be taken directly from digital analysis during processing of the multichannel data. This would eliminate the manual and time consuming steps of initial digitizing and redigitizing during quality control. For velocities available from modern, interactive, multichannel processing platforms, this step would offer the advantage of smoothing of the RMS velocities during processing, as is routinely done in interactive velocity-analysis packages. This was not an option for this data set because digital velocities were not part of the product supplied by the contractor to USGS in the 1970's.

Second, automated velocity smoothing would have eliminated artifacts introduced during hand smoothing. The recent analysis by Klitgord and Schneider (1994) shows that smoothing can be successfully done in the RMS domain, with good results in the interval velocity domain. For the Carolina trough and Blake Plateau, automated smoothing would be still be difficult, if not impossible across the steep slopes where velocities and travel times change rapidly. These sharp transitions are often the most poorly preserved during computer smoothing. Automated smoothing also would not be optimal for velocities in the deeper Blake Plateau where an analysis that combined both the multichannel and old refraction velocities was sounder than one which relied on the poorly constrained multichannel velocities alone. A mixture of automated and hand smoothing might be necessary to accomodate smoothing between regions of smooth and steep topography and between shallow and deep picks.

Figure 19: Comparison of the depth section for line TD-4 before smoothing the interval velocities (upper) and after smoothing (lower). The jaggedness of the deeper horizons in the upper section is caused by the large scatter in the unsmoothed interval velocities. 


\section{SUMMARY}

This report presents one part of a program to develop a geophysical database for the East Coast of the United States, specifically to describe the digital seismic and velocity horizons interpreted from multichannel seismic-reflection profiles across the continental margin south of Cape Hatteras. A companion paper (Hutchinson et al., 1996) describes the spatial, gridded data base for each horizon. The data base for the continental margin north of Cape Hatteras has been described by Klitgord and Schneider (1994) and Klitgord et al. (1994).

(1) 18 multichannel seismic lines, consisting of 42 line segments totalling about 7,600 $\mathrm{km}$, were used to develop the digital stratigraphic and velocity information. The stratigraphic interpretations used in the database follow the stratigraphy of Poag (1991).

(2) A total of 17 seismic discontinuities were interpreted for both stratigraphic and velocity information. Each horizon was assigned an arbitrary, but successively larger number starting at the sea floor and ending at the deepest postrift unit. The stratigraphic numbering scheme is identical to that used by Klitgord et al. (1994) for the region north of Cape Hatteras.

(3) Even though the multichannel data were acquired using roughly similar equipment and source size, a large variation in data quality exists. Uncertainties can be assigned based on many criteria: e.g., the duration of the observed wavelet, frequency of the processed data, display scales, digitizing resolution. None of these uncertainties, however, is as large as the uncertainty in interpretation that arises from the lack of well-dated samples throughout the study region. Two end-member interpretations show that depths to Lower Cretaceous and Jurassic horizons differ by as much as $.9 \mathrm{~s}$, or up to $2-3 \mathrm{~km}$. Depths to the younger Cenozoic and Upper Cretaceous units are more consistent because of more abundant shallow boreholes and surface samples. The uncertainty in age does not affect the velocity or depth estimates associated with each horizon.

(4) Velocities for the study area are best constrained in the northern Carolina trough, and uncertainties are estimated at about $10-20 \%$. Data quality in the southern Carolina trough and Blake Plateau is compromised by poor, low-resolution velocity scans. Comparison of the poorly constrained multichannel velocities with recent and old refraction information suggests velocity uncertainties in the southern Carolina trough and Blake Plateau are probably no better than $20-30 \%$. Because of the velocity smoothing process, velocities for the landwardmost $20-30 \mathrm{~km}$ of each line are probably high by up to $20 \%$. 


\section{REFERENCES CITED}

Anderson, R.C., and Taylor, D.J., 1979, Geophysical studies, in P.A. Scholle, ed., Geological studies of the COST GE-1 well, United States South Atlantic Outer Continental Shelf area. U.S. Geological Survey Circular 800, p. 93-96.

Benson, W.E., Sheridan, R.E., et al., 1978, Initial Reports of the Deep Sea Drilling Project, v. 44: Washington (U.S. Government Printing Office), 1005 p.

Bryan, G.M., 1970, Hydrodynamic model of the Blake Outer Ridge: Journal of Geophysical Research, v. 75 , p. 4530 - 4537.

Bryan, G.M, Markl, R.G., and Sheridan, R.E., 1980, IPOD site surveys in the Blake Bahamas basin: Marine Geology, v. 35, p. $43-63$.

Bunce, E.T., Emery, K.O., Gerard, R.D., Knott, S.T., Lidz, L., Saito, T., and Schlee, J., 1965, Ocean Drilling on the Continental Margin: Science, v. 150, p. 709-716.

Charm, W.B., Nesteroff, W.D., and Valders, S., 1969, Detailed stratigraphic description of the JOIDES cores on the continental margin off Florida: U.S. Geological Survey Professional Paper 581-D, $13 \mathrm{p}$.

Cordier, J.-P., 1985, Velocities in Reflection Seismology; Dordrecht, Holland, D. Reidel Publishing Co., $201 \mathrm{p}$.

Dillon, W.P., Lee, M.W., and Coleman, D.F., 1994, Identifcation of marine hydrates in situ and their distribution off the Atlantic coast of the United States: Annals of the New York Academy of Sciences, v. 715, p. $364-380$.

Dillon, W.P., and McGinnis, L.D., 1983, Basement structure indicated by seismic-refraction measurements offshore from South Carolina and adjacent areas: U.S. Geological Survey Professional Paper 1313, p. O1 - O7.

Dillon, W.P., Paull, C.K., and Gilbert L.E., 1985, History of the Atlantic Continental Margin off Florida; The Blake Plateau basin, in Poag, C.W., ed., Geologic evolution of the United States Atlantic margin: New York, Van Nostrand Reinhold, p. 189-215.

Dillon, W.P., and Popenoe, P., 1988, The Blake Plateau Basin and Carolina Trough, in Sheridan, R.E., and Grow, J.A., eds., The Atlantic Continental Margin, U.S.: Geological Society of America, The Geology of North America, v. I-2, p. 291 - 328.

Dillon, W.P., Popenoe, P., Grow, J.A., Klitgord, K.D., Swift, B.A., Paull, C.K. and Cashman, K.V., 1983, Growth faulting and salt diapirism, their relationships and control in the Carolina Trough, eastern North America, in Watkins, J.S., and Drake, C.L., eds., Studies in continental margin geology: American Association of Petroleum Geologists Memoir 34, p. 21-46. 
Dillon, W.P., Sheridan, R.E., and Fail, J.P., 1976, Structure of the western Blake Bahama Basin as shown by 24 channel CDP profiling: Geology, v. 4, p. 459-462.

Dillon, W.P., Trehu, A.M., Valentine, P.C., and Ball, M.M., 1988, Eroded carbonate platform margin - the Blake Escarpment off Southeastern United States: in Bally, A.W., ed., Atlas of Seismic Stratigraphy: American Association of Petroleum Geologists Studies in Geology \#27, v. 2, p. 140-147.

Dillon, W.P., Valentine, P.C., and Paull, C.K., 1987, The Blake Escarpment -- a product of erosional processes in the deep ocean, in Cooper, R.A., and Shepard, A.N., eds., Science Applications of Current Diving Technology on the U.S. Continental Shelf: NOAA Symposium Series Undersea Research, v. 2, p. 177 - 190 (NOAA Undersea Research Program, Rockville, MD).

Dix, C.H., 1955, Seismic velocities from surface measurements: Geophysics, v. 20, p. 68-86.

Dowling, J.J., 1968, The East Coast onshore-offshore experiment, II. Seismic refraction measurements on the continental shelf between Cape Hatteras and Cape Fear: Bulletin of the Seismological Society of America, v. 58, p. $821-834$.

Ewing, J.L., and Ewing, M., 1959, Seismic refraction measurements in the Atlantic Ocean basins, in the Mediterranean Sea, on the Mid-Atlantic Ridge, and in the Norwegian Sea: Geological Society of America Bulletin, v. 70, p. 291-318.

Grim, M.S., Dillon, W.P., and Mattick, R.E., 1980, Seismic reflection, refraction, and gravity measurments from the continental shelf offshore from North and South Carolina: Southeastern Geology, v. 21, p. 239 - 249.

Grow, J.A., Mattick, R.E., and Schlee, J.S., 1979, Multichannel seismic depth sections and interval velocities over outer continental shelf and upper continental slope between Cape Hatteras and Cape Cod, in Watkins, J.S., Montadert, L., and Dickerson, P.W., eds., Geological and geophysical investigations of continental margins: American Association of Petroleum Geologists Memoir 29, p. 65-83.

Hathaway, J.C., Poag, C.W., Valentine, P.C., Miller, R.R., Schultz, D.M., Manheim, F.T., Kohout, F.A., Bothner, M.H., and Snagrey, D.A., 1979, U.S. Geological Survey core drilling on the Atlantic shelf: Science, v. 206, p. 515-527.

Heezen, B.C., and Sheridan, R.E., 1966, Lower Cretaceous rocks (Neocomian - Albian) dredged from Blake Escarpment: Science, v. 154, p. 1644 - 1647.

Hersey, J.B., Bunce, E.T., Wyrick, R.F., and Dietz, F.T., 1959, Geophysical investigation of the continental margin between Cape Henry, Virginia, and Jacksonville, Florida: Geological Society of America Bulletin, v. 70, p. 437-466. 
Holbrook, W.S., and Keleman, P.B., 1993, Large igneous province on the U.S. Atlantic margin and implications for magmatism during continental break up: Nature, v. 364, p. 433436.

Holbrook. W.S., Reiter, E.C., Purdy, G.H., Sawyer, D., Stoffa, P.L., Austin, J.A. Jr., Oh, J., and Makris, J., 1994, Deep structure of the U.S. Atlantic continental margin, offshore South Carolina, from coincident ocean bottom and multichannel seismic data: Journal of Geophysical Research, v. 99, p. 9155-9178.

Houtz, R.E., and Ewing, J.I., 1963, Detailed sedimentary velocities from seismic refraction profiles in the western North Atlantic: Journal of Geophysical Research, v. 68, p. 5233 5258 .

Hollister, C.D., Ewing, J.I., et al., 1972, Initial Reports of Deep Sea Drilling v. 11: Washington (U.S. Government Printing Office), 1077 p.

Hutchinson, D.R., Grow, J.A., Klitgord, K.D., and Swift, B.A., 1983, Deep structure and evolution of the Carolina Trough, in Watkins, J.S., and Drake, C.L., eds., Studies in Continental Margin Geology: American Association Petroleum Geologists Memoir 34, p. 129-152.

Hutchinson, D.R., Poag, C.W., Johnson, A.H., Popenoe, P. and Wright, C., 1996, Geophysical database of the East Coast of the United States: Southern Atlantic margin - stratigraphy and velocity in map grids: U.S. Geological Survey Open-File Report (in review).

Klitgord, K.D., and Behrendt, J.C., 1979, Basin structure of the U. S. Atlantic margin: American Association Petroleum Geologists Memoir 29, p. 85-112.

Klitgord, K.D., Hutchinson, D.R., and Schouten, H., 1988, U.S. Atlantic continental margin; Structural and tectonic framework, in Sheridan, R.S., and Grow, J.A., eds., The Atlantic Continental Margin, U.S., The Geology of North America, v. I-2, Geological Society of America, v. I-2, ch. 3, p. 19-55.

Klitgord, K.D., Poag, C.W., Schneider, C.M., and North, L., 1994, Geophysical database of the East Coast of the United States northern Atlantic continental margin: cross sections and gridded database (Georges Bank basin, Long Island platform, and Baltimore Canyon trough): U.S. Geological Survey Open-File Report 94-637, 187 p.

Klitgord, K.D., and Schneider, C.M., 1994, Geophysical Database of the East Coast of the United States Northern Atlantic Margin: Velocity Analyses, U.S. Geological Survey, Open File Report \#94-192, 74 p.

Kvenvolden, K.A., 1993, Gas hydrates - geological perspective and global change: Reviews of Geophysics, v. 31, p. 173 - 187. 
Lee, M.W., Hutchinson, D.R., Agena, W.F., Dillon, W.P., Miller, J.J., and Swift, B.A., 1994, Seismic Character of Gas Hydrates on the Southeastern U.S. Continental Margin: Marine Geophysical Researches 16: p. 163-184.

Leg 44 Shipboard Scientific Party, 1978, Site 391: Blake Bahama Basin, in Benson, W.E., Sheridan, R.E., and others, Initial reports of the Deep Sea Drilling Project, Leg 44: Washington (U.S. Government Printing Office), p. 153-336.

Magneville, P., 1970, "Flexichoc," a new implosion source for offshore seismic processing: Institut Francais Petrole Ref. 19347.

Markl, R.G., and Bryan, G.M., 1983, Stratigraphic evolution of the Blake Outer Ridge: American Association of Petroleum Geologists Bulletin, v. 67, p. 666-683, 1488-1490.

Markl, R.G., Bryan, G.M., and Ewing, J.L., 1970, Structure of the Blake-Bahama outer ridge: Journal of Geophysical Research, v. 75, p. 4539-4555.

Mountain, G.S., and Tucholke, B.E., 1985, Mesozoic and Cenozoic geology of the Atlantic continental slope and rise, in Poag, C.W., ed., Geologic evolution of the United States Atlantic margin: New York, Van Nostrand Reinhold, p. 293-341.

NOS (National Ocean Service), 1986, Bathymetric Map of the Atlantic Ocean, southeastern United States: Washington (U.S. Department of Commerce, National Oceanic and Atmospheric Administration), 1:1,000,000.

Palmer, A.W., 1983, The Decade of North American Geology 1983 - Geologic Timescale: Geology, v. 11, p. 503-504.

Paull, C.K., Popenoe, P., Dillon, W.P., and McCarthy, S.M., 1980, Geologic subcrop map of the Florida-Hatteras shelf and slope and inner Blake Plateau. U.S. Geological Survey Miscellaneous Field Studies Map MF-1171, 1;500,000.

Payton, C.E., ed., 1977, Seismic stratigraphy - Applications to hydrocarbon exploration: American Association of Petroleum Geologists Memoir 26, 516 p.

Pinet, P.R., Popenoe, P., and Nelligan, D.F., 1981, Reconstruction of Cenozoic flow patterns over the Blake Plateau: Geology, v. 9, no. 6, p. 266-270.

Poag, C.W., 1978, Stratigraphy of the Atlantic continental shelf and slope of the United States: Annual Review of Earth and Planetary Sciences, v. 6, p. $251-280$.

Poag, C.W., 1985, Depositional history and stratigraphic reference section for central Baltimore Canyon Trough, in Poag, C.W., ed., Geologic Evolution of the United States Atlantic Margin: p. 217-263. 
Poag, C.W., 1991, Rise and demise of the Bahama-Grand Banks gigaplatform, northern margin of the Jurassic proto-Atlantic seaway, Marine Geology, 102, p. 63-130.

Poag, C.W., and Schlee, J.S., 1984, Depositional sequences and stratigraphy gaps on submerged United States Atlantic margin, in Schlee, J.S., ed., Interregional Unconformities and Hydrocarbon Accumulation, The American Association of Petroleum Geologists Memoir 36, p. 165-182.

Poag, C.W., and Valentine, P., 1988, Mesozoic and Cenozoic stratigraphy of the United States Atlantic continental shelf and slope, in Sheridan, R.S. and Grow, J.A., eds., The Atlantic Continental Margin, U.S., The Geology of North America, Vol. I-2, Geological Society of America, p. 67-85.

Poag, C.W., and Ward, L.W., 1993, Allostratigraphy of the U.S. Middle Atlantic Continental Margin--characteristics, distribution and depositional history of principal unconformitybounded Upper Cretaceous and Cenozoic sedimentary units: U.S. Geological Survey Professional Paper 1542, 81 p.

Popenoe, P., 1993, Bottom Character of the northeastern Blake Plateau. U.S. Geological Survey Open File Report 93-724, 36 p.

Poppe, L.J., ed., 1981, Data File - Atlantic Margin Coring Project (AMCOR) of the U.S. Geological Survey: U.S. Geological Survey Open-File Report 81-239, 96 p.

Schlager, W., Bourgeois, F., Mackenzie, G., and Smit, J., 1988, Boreholes at Great Isaac and site 626 and the history of the Florida Straits, in Austin, J.A., Jr., and Schlager, W., et al., Proceedings of the Ocean Drilling Program, Scientific Results, v. 101, p. 425-437.

Sheridan, R.E., Berman, R.M., and Corman, D.B., 1971, Faulted limestone block dredged from Blake Escarpment: Bulletin Geological Society of America, v. 82, p. 199 - 206.

Sheridan, R.E., Crosby, J.T., Bryan, G.M., and Stoffa, P.L., 1981, Stratigraphy and structure of the southern Blake Plateau, northern Florida Straits and northern Bahama Platform from multichannel seismic-reflection data: American Association of Petroleum Geologists Bulletin, v. 65, p. 2571 - 2593.

Sheridan, R.E., Drake, C.L., Nafe, J.E., and Hennion, J., 1966, Seismic refraction study of continental margin east of Florida: American Association of Petroleum Geologists Bulletin, v. 50, p. 1972 - 1991.

Sheridan, R.E., and Enos, P., 1979, Stratigraphic evolution of the Blake Plateau after a decade of scientific drilling, in Talwani, M., Hay, W., and Ryan, W.B.F., eds., Deep drilling results in the Atlantic Ocean: Continental margins and paleoenvironment: Maurice Ewing Series, v. 3, American Geophysical Union Geophysical Monograph, p. 109-122. 
Sheridan, R.E., Gradstein, F.M., et al., 1983, Initial Reports of Deep Sea Drilling Program v. 76: Washington (U.S. Government Printing Office), 947 p.

Sheridan, R.A., Grow, J.A., and Klitgord, K.D., 1988, Geophysical data, in Sheridan R.S., and Grow, J.A., eds., The Atlantic Continental Margin, U.S., The Geology of North America, v. I-2, Geological Society of America, p. 177-196.

Tator, B.A., and Hatfield, L.E., 1975a, Bahamas present complex geology (Part 1): Oil and Gas Journal, v. 73(43), p. 172 - 176.

Tator, B.A., and Hatfield, L.E., 1975b, Bahamas present complex geology (Part 2): Oil and Gas Journal, v. 73(44), p. $120-122$.

Trehu, A.M., 1984, Effects of bottom currents and uppermost sediment thickness on oceanbottom seismometer data (abs.): EOS, Transactions, American Geophysical Union, v. 65 , p. 1,014 .

Trehu, A.M., 1985, A note on the effect of bottom currents on an ocean bottom seismometer: Bulletin Seismological Society of America, v. 75, p. 1,195 - 1,204.

Trehu, A.M., Ballard, A., Dorman, L.M., Gettrust, J.F., Klitgord, K.D., and Schreiner, A., 1989, Structure of the lower crust beneath the Carolina trough, U.S. Atlantic Margin: Journal of Geophysical Research, v. 94, p. 10,585 - 10,600.

Wise, R.A., and Oliver, H.L., 1988, Reprocessing of marine multichannel seismic reflection profile line 12, Cape Hatteras, North Carolina, to Shell Mohawk Well, Canada: U.S. Geological Survey Open-File Report 88-51, 17 p.

Woollard, G.P., Bonini, W.E., and Meyer, R.P., 1957, A seismic refraction study of the subsruface geology of the Atlantic Coastal Plain and continental shelf between Virginia and Florida: University of Wisconsin Technical Report, Contract No. N7ONR-28512, $128 \mathrm{p}$.

Wright, E.L., and Hos̄om, J.P., 1986, Seismic-reflector database software, Steiger, D., ed., Proceedings: IEZEE, 1986 Working Symposium on Oceanographic Data Systems, La Jolla, California, p. 184-190. 


\section{NOTE}

APPENDICES $1-4$ are a separate document on 11 in. $\mathrm{x} 17$ in. paper

- Page 67 follows - 
66 


\section{APPENDIX 1}

Multichannel Seismic Profiles:

Travel Time Interpretations and Depth Conversions 


\section{EXPLANATORY NOTES}

This appendix gives line drawing interpretations of the seismic stratigraphy in both twoway travel time and depth. These interpretations represent the final, smoothed data. The horizontal scales for all travel time plots and depth plots are $25 \mathrm{~km} /$ inch. The vertical scales are $2 \mathrm{~s} / \mathrm{in}$ for travel time plots and $5 \mathrm{~km} / \mathrm{in}$ for depth plots. Vertical exaggeration is about $5 \mathrm{x}$.

The lines are organized according to their position. All strike lines, progressing from shallow water to deep water, are shown first; then all dip lines, progressing from north to south are shown. Line locations are shown in Figure 1-1 (this page), Figure 1 of the main text and Plate 1 that accompanies this report. The following table gives the actual order of the lines:

\begin{tabular}{||c||l|l||}
\hline Page No. & Number of Sheets & \multicolumn{1}{|c|}{ USGS Line Number } \\
\hline \hline 69 & 1 & FC-4 FC-5 FC-6 \\
\hline $70,71,72$ & 3 & TD-1 Line 12 \\
\hline 73 & 1 & FC-10 \\
\hline 74 & 1 & FC-9 \\
\hline 75 & 1 & BT-8 \\
\hline 76,77 & 2 & TD-2 \\
\hline 78 & 1 & Line 13 \\
\hline 79 & 1 & FC-2 \\
\hline 80 & 1 & Line 30 \\
\hline 81 & 1 & Line IPOD \\
\hline 82 & 1 & Line 31 \\
\hline 83 & 1 & Line TD-6 \\
\hline 84 & 1 & Line 32 \\
\hline 85 & 1 & Line BT-1 \\
\hline 86 & 1 & Line FC-7 \\
\hline 87 & 1 & Line BT-4 \\
\hline 88 & 1 & Line FC-8 \\
\hline 89,90 & 2 & Line TD-5 \\
\hline 91 & 1 & Line FC-3 \\
\hline 92 & 1 & Line TD-4 \\
\hline 93,94 & 2 & Line TD-3 \\
\hline 95 & 1 & Line FC-1 \\
\hline & & \\
\hline
\end{tabular}

Figure 1-1: Location of Multichannel Seismic Profiles. Plate 1 shows shot point locations.

\section{Multichannel Profile Locations}

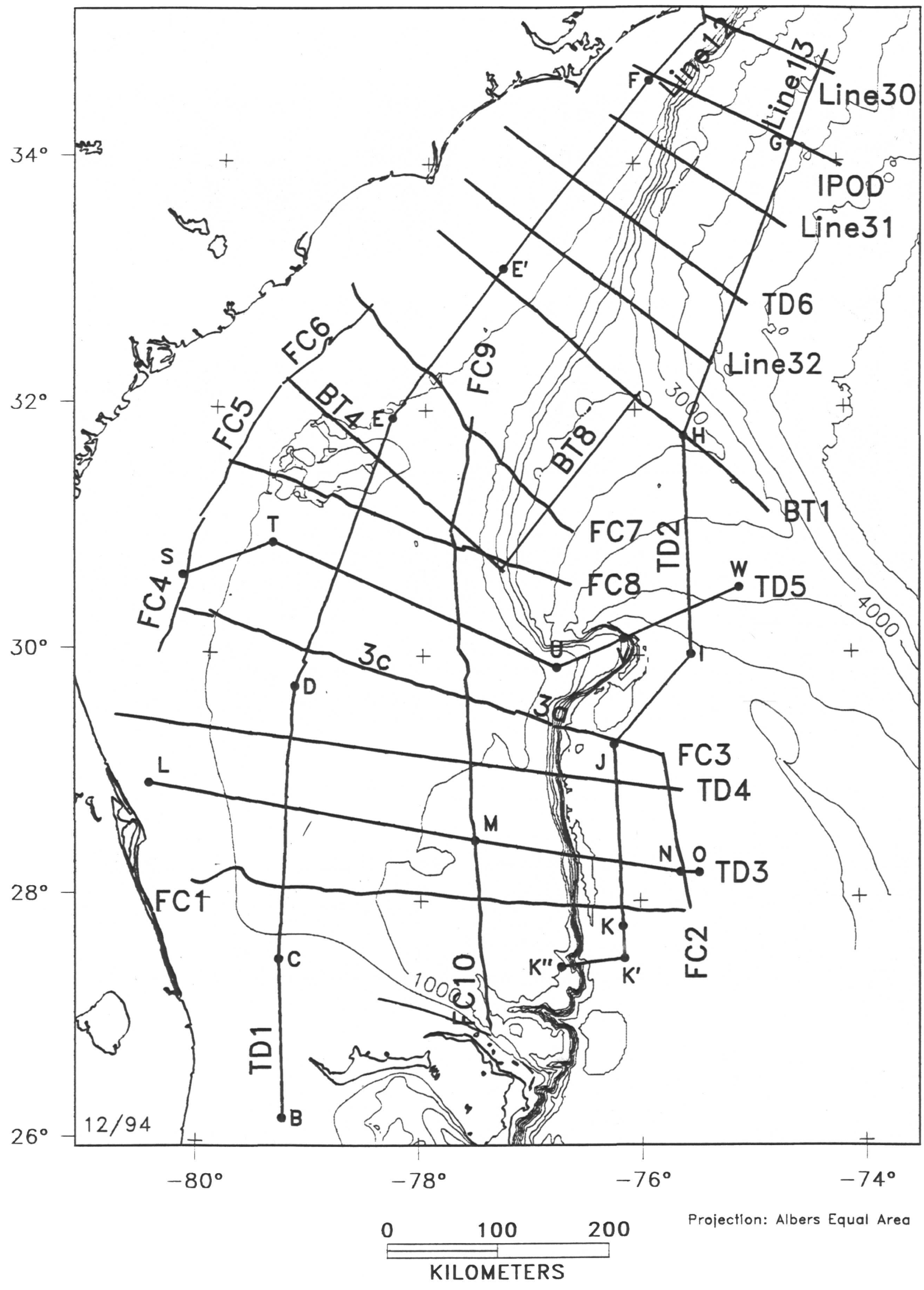



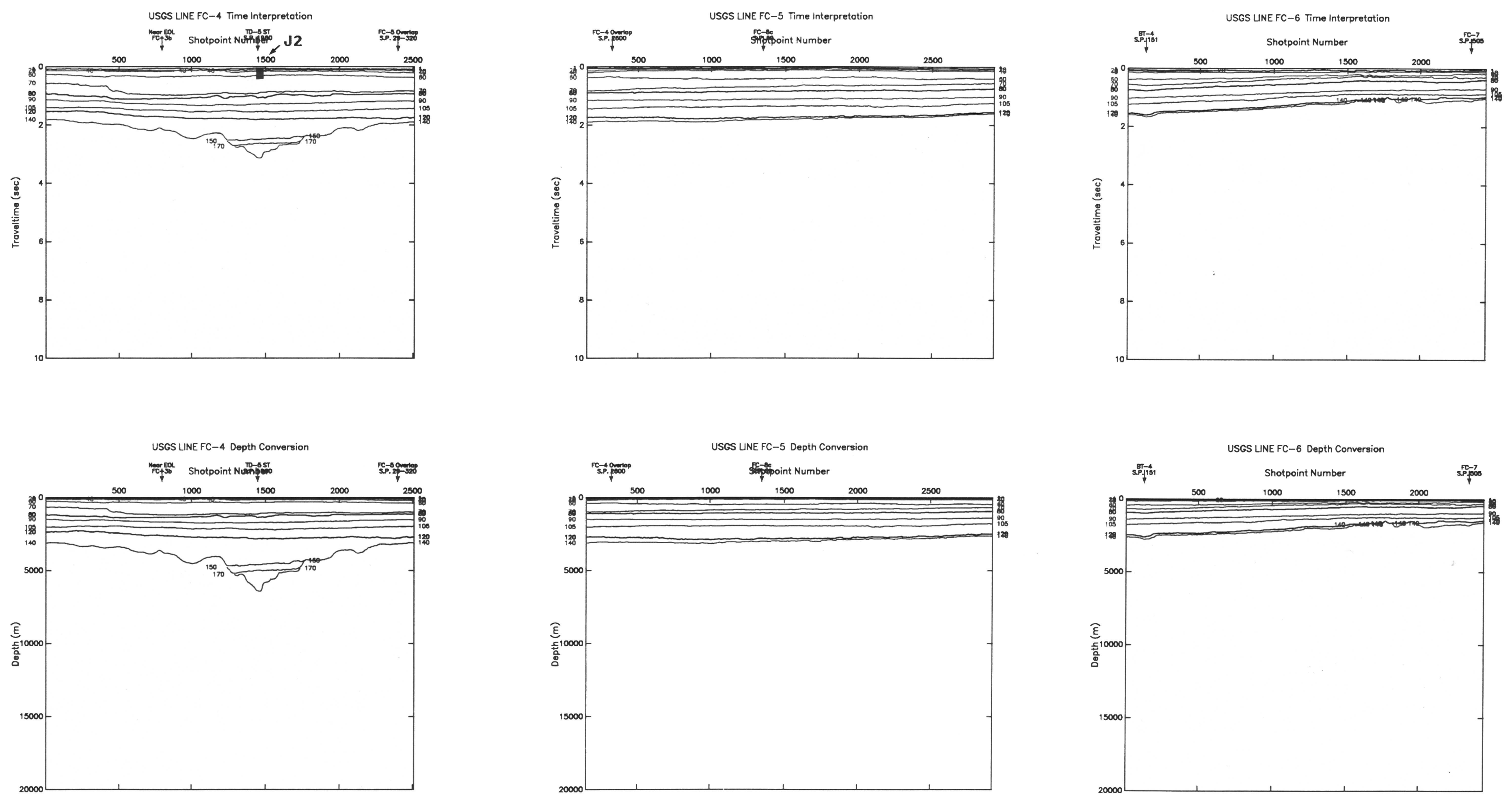

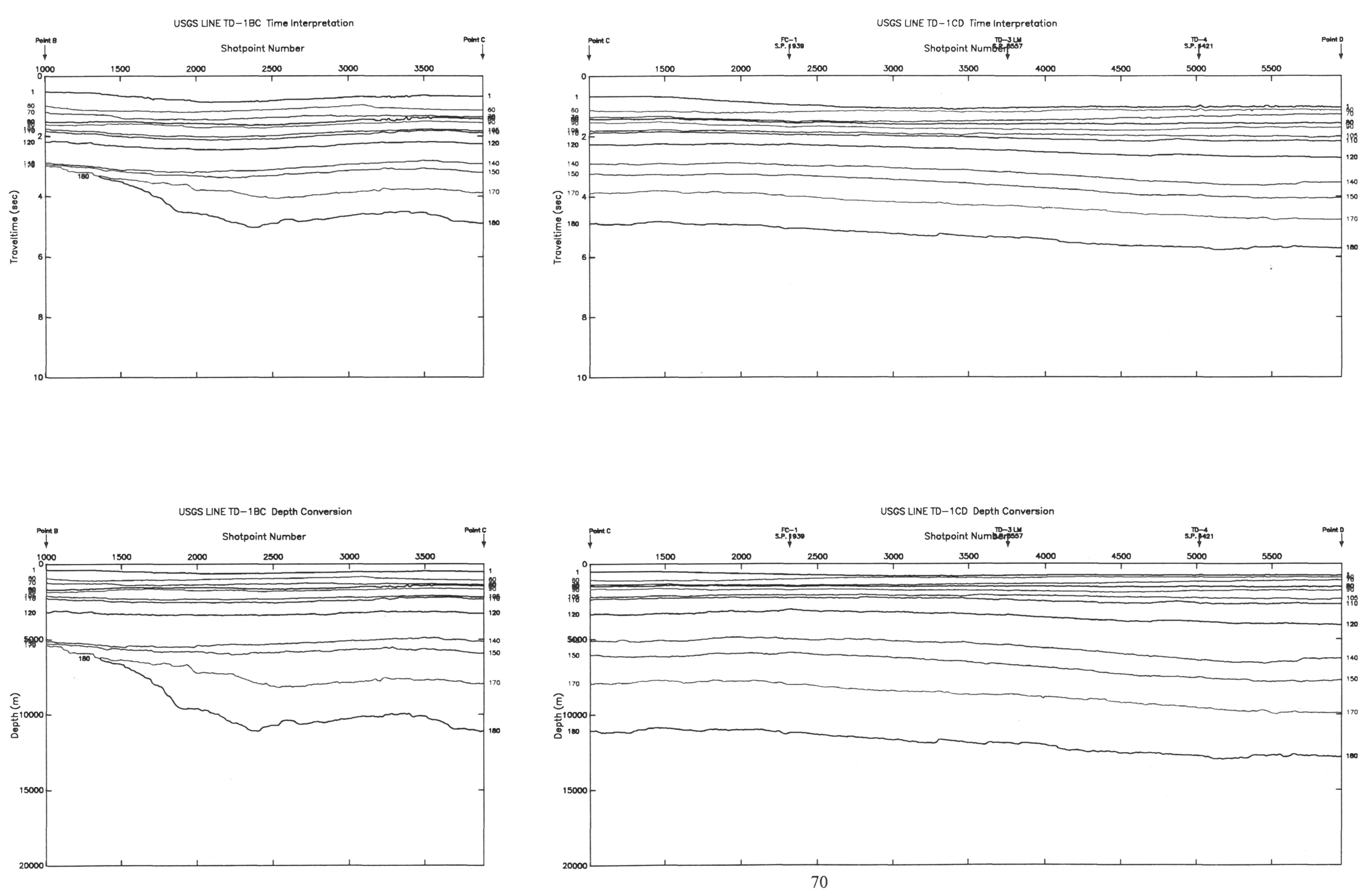


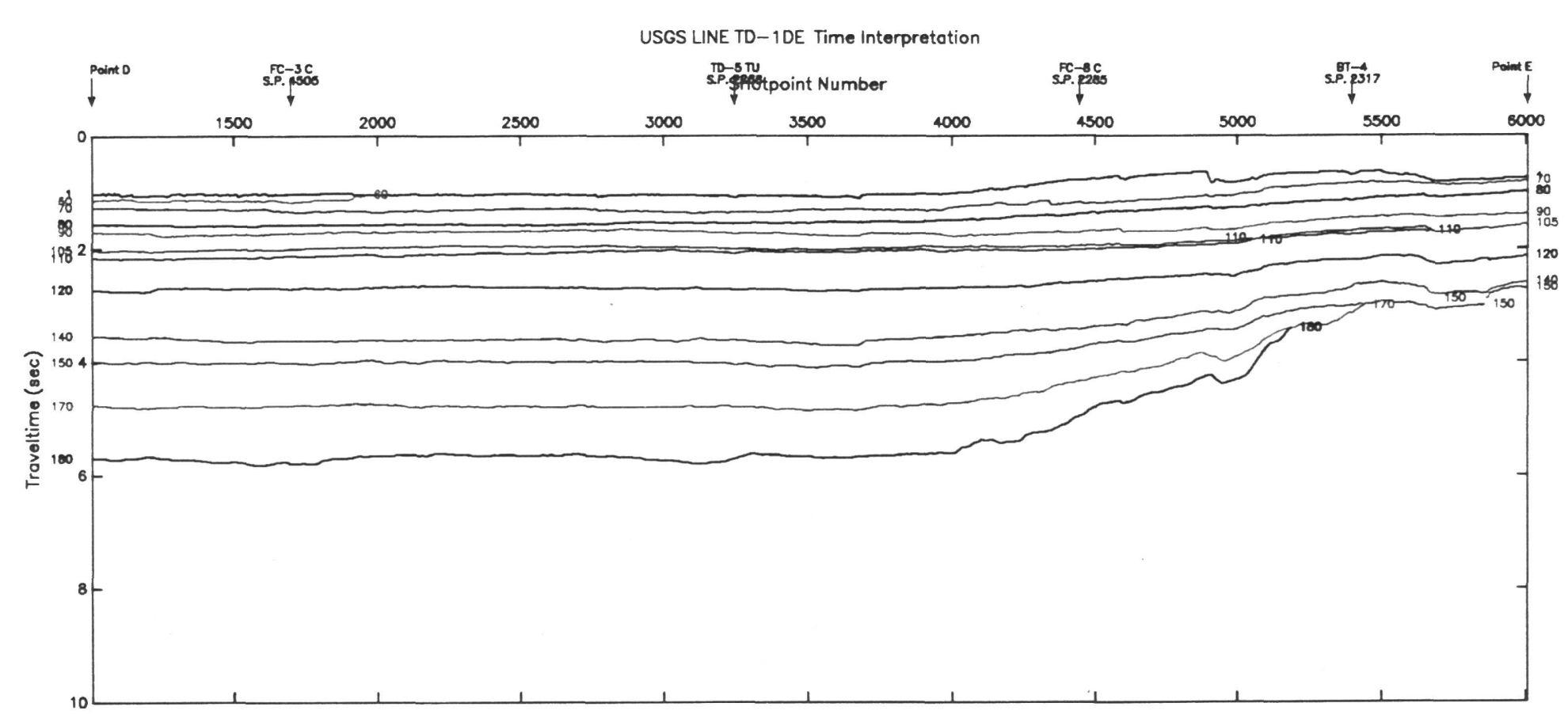

USGS LINE TD-1EE'(1) Time Interpretation
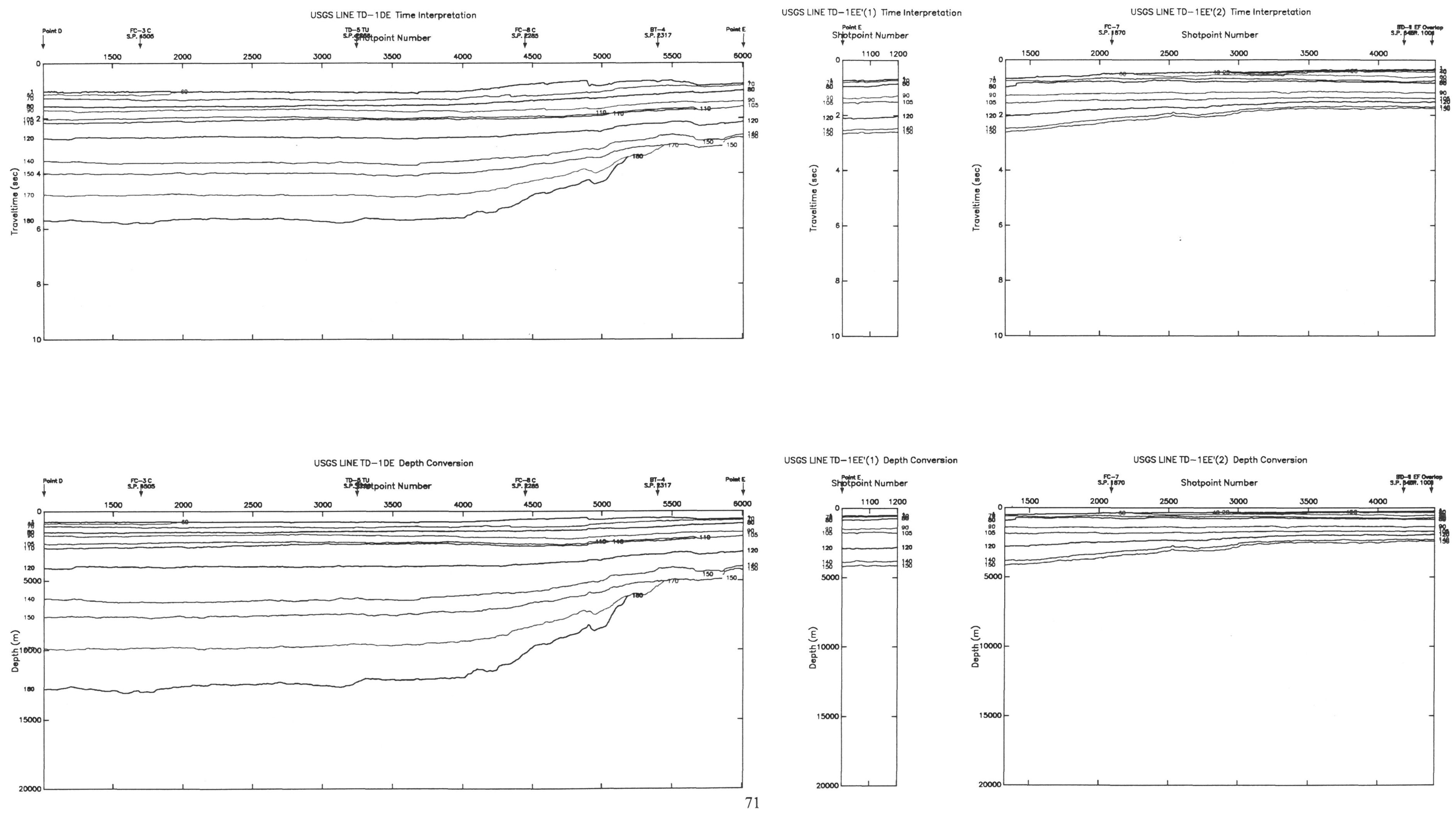

USGS UNE TD-1EE'(1) Depth Conversion
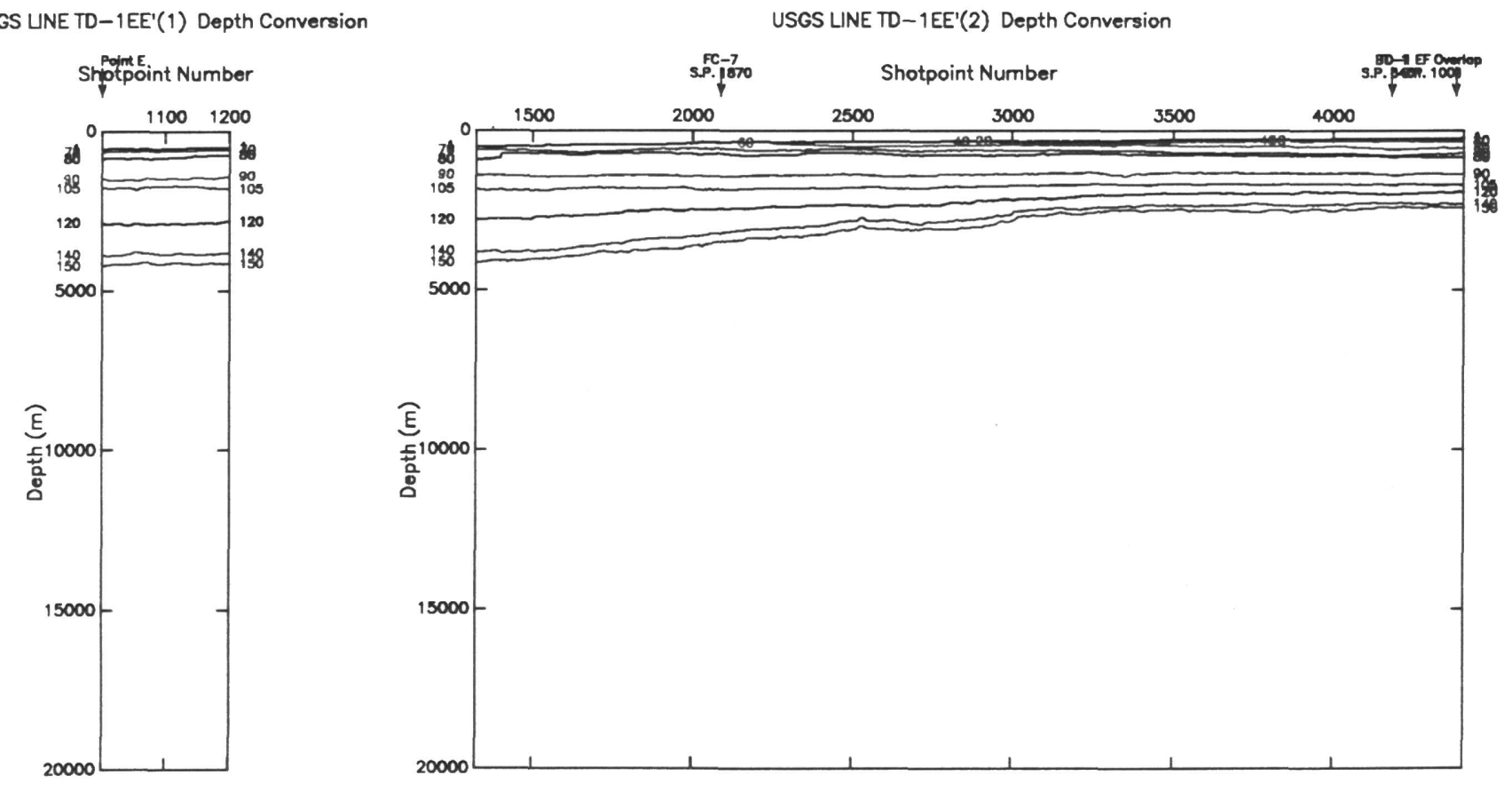

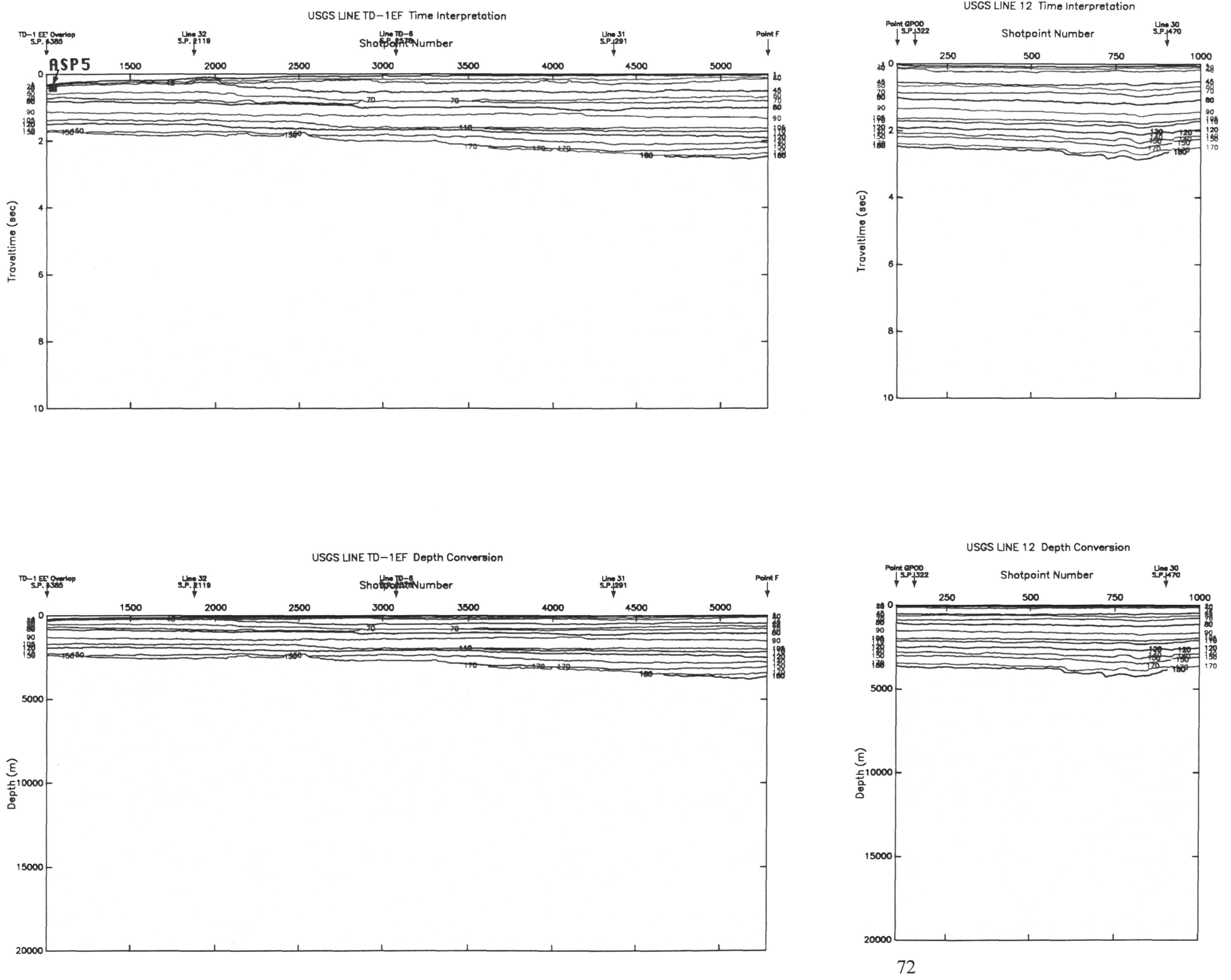

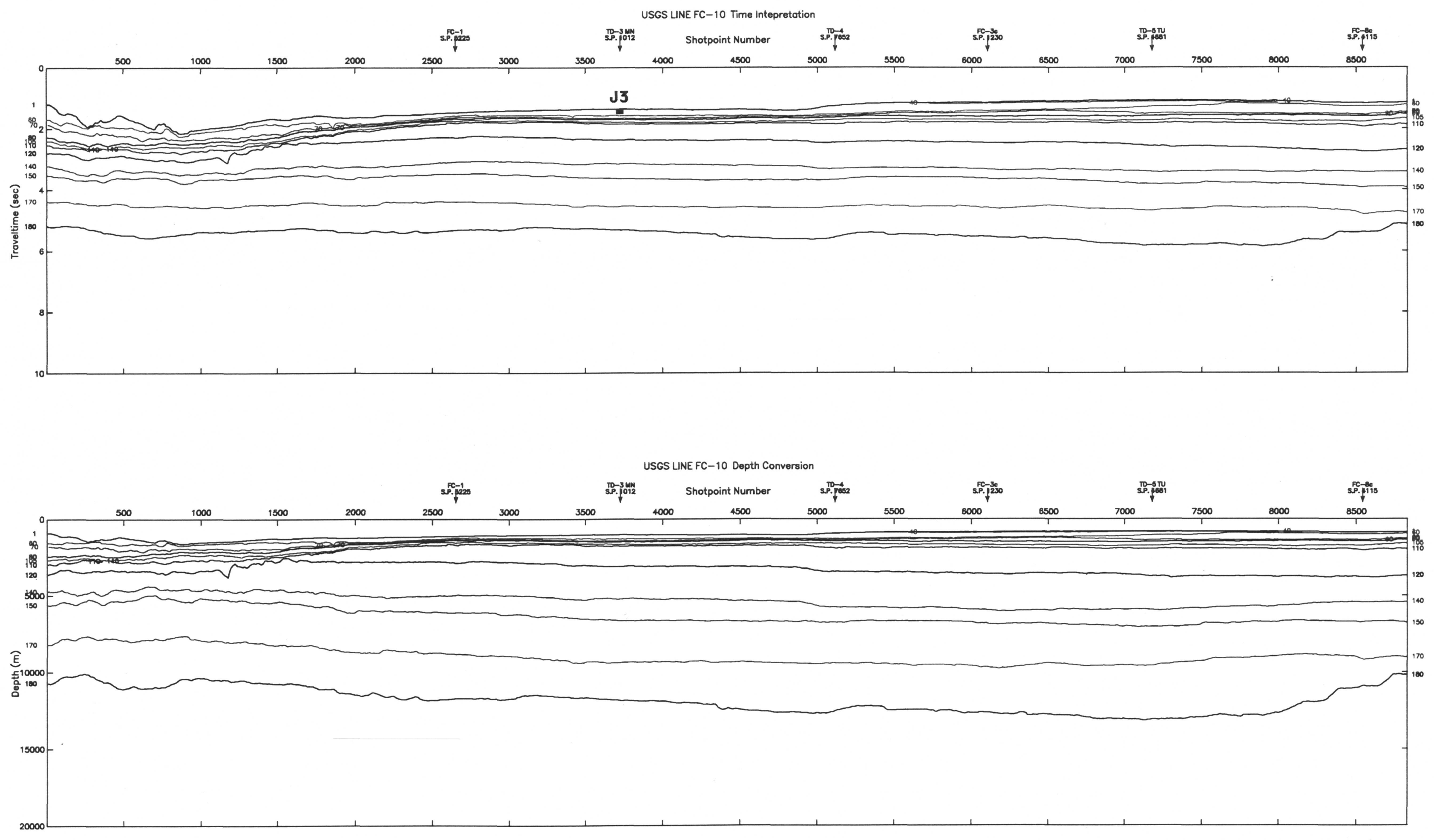

73 

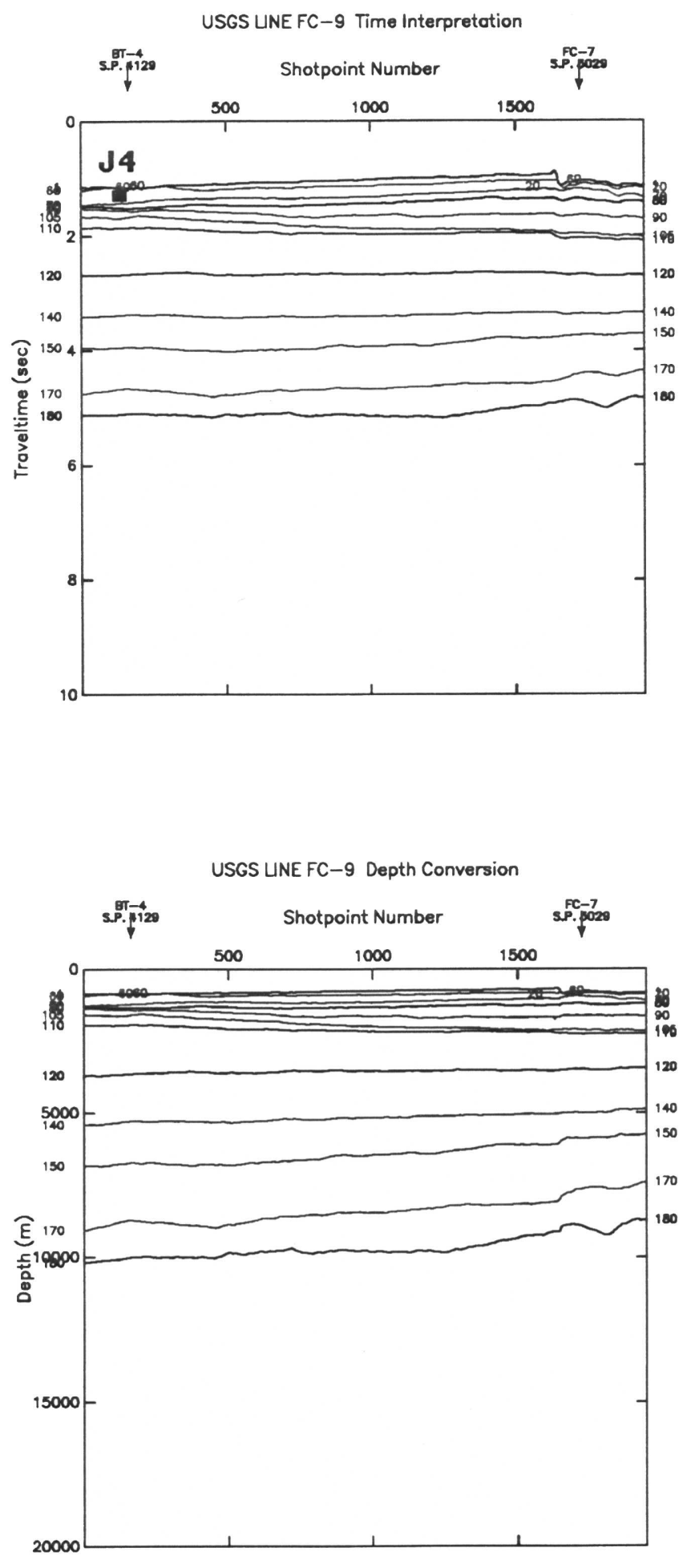

74 

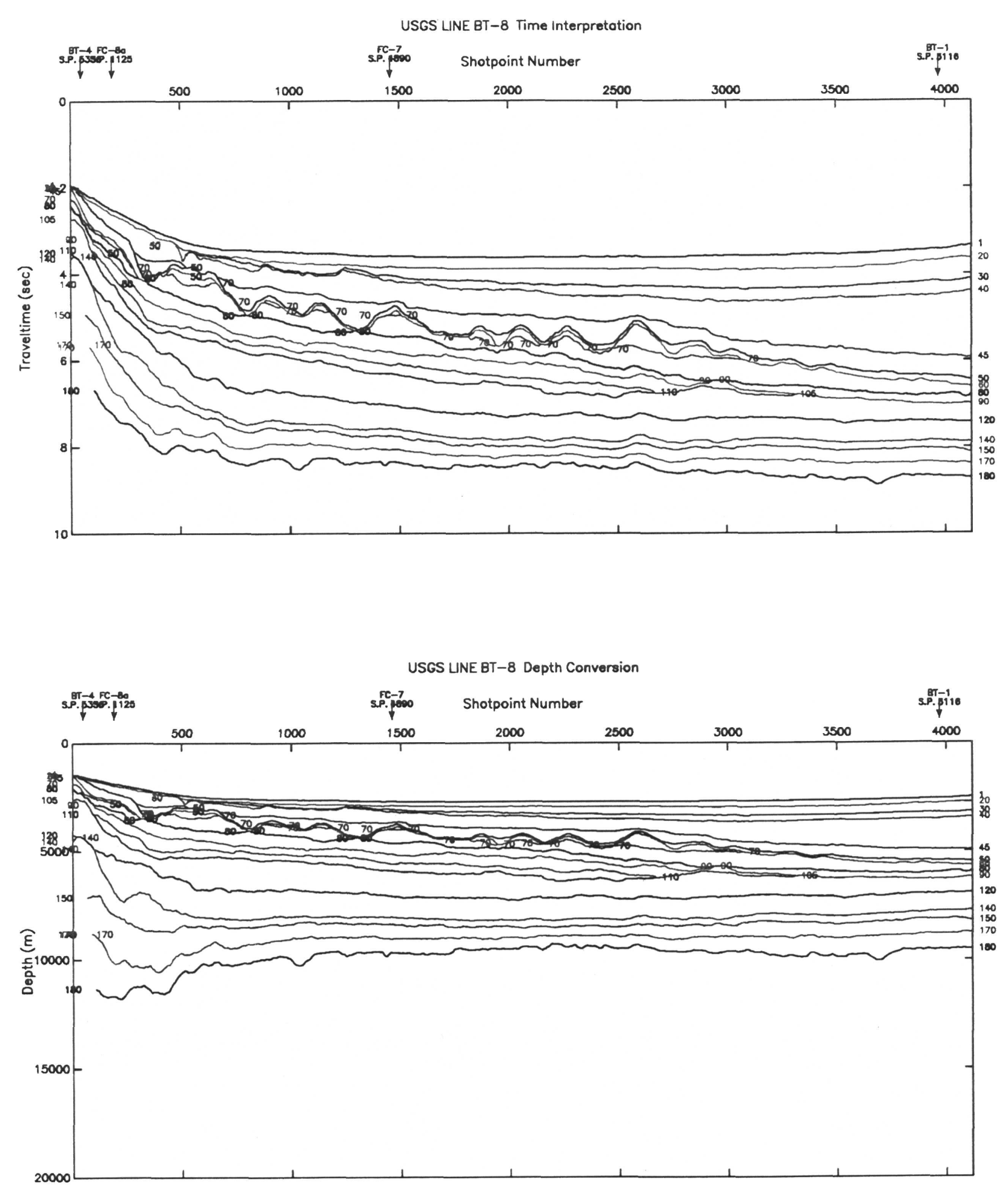

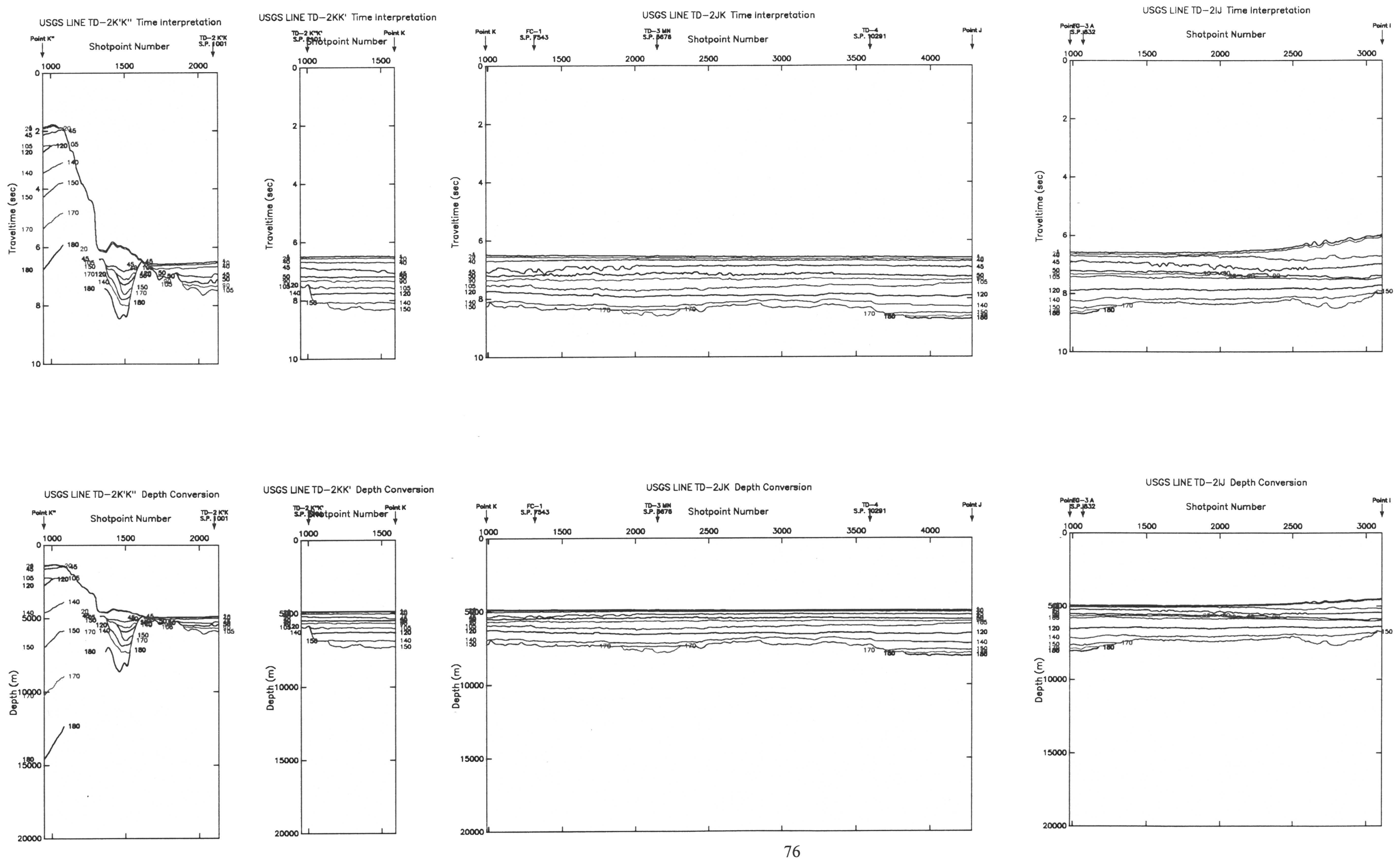

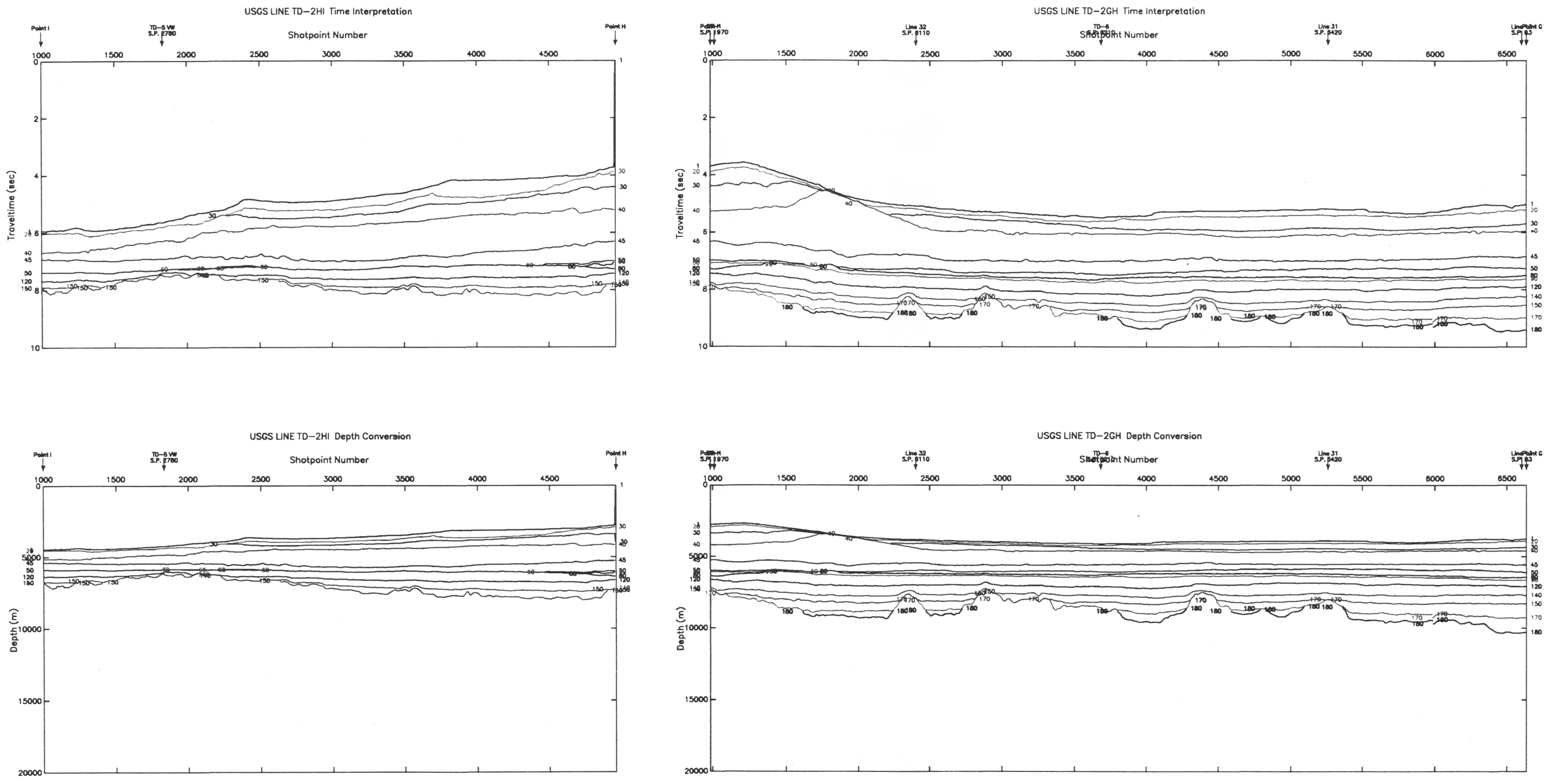

77 

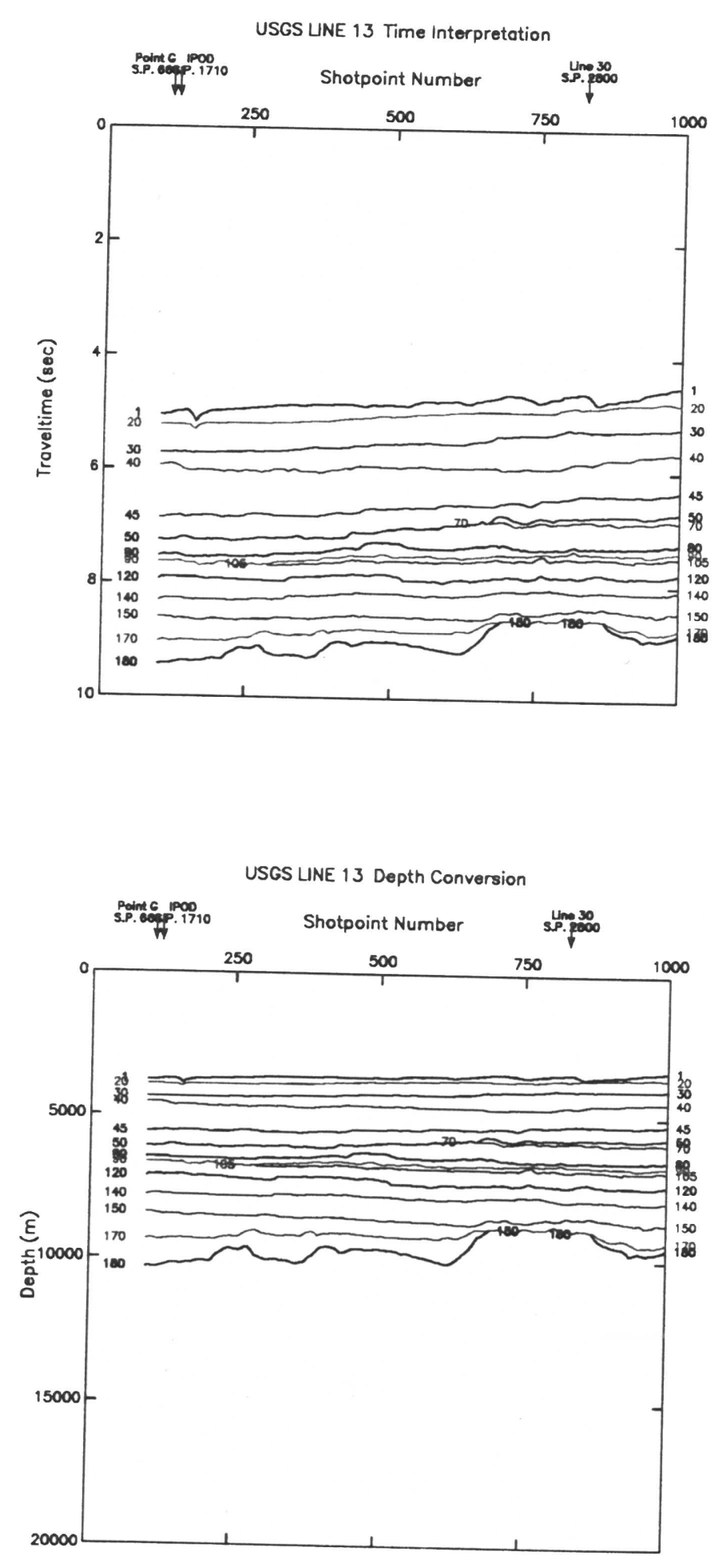

78 

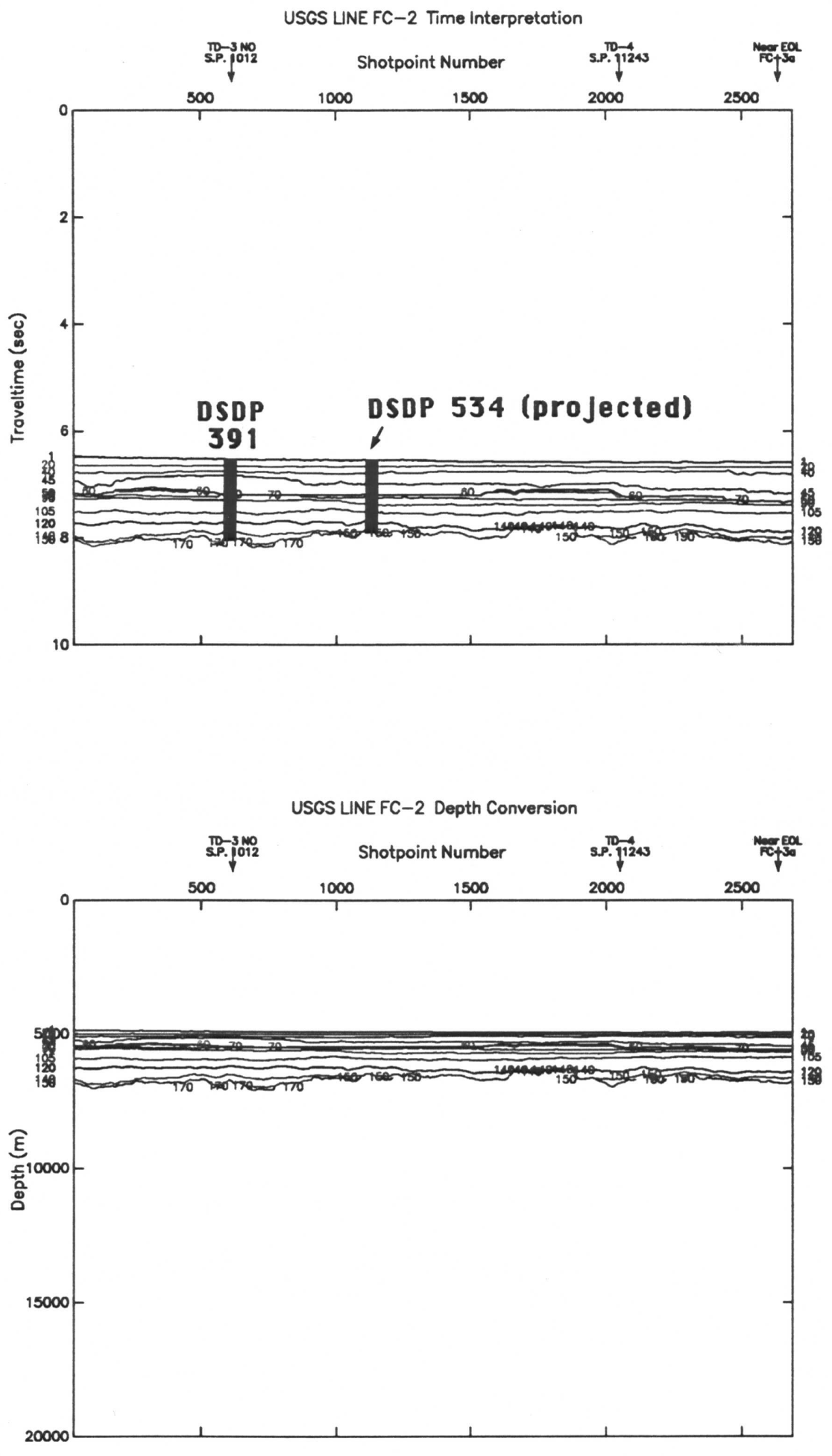

79 

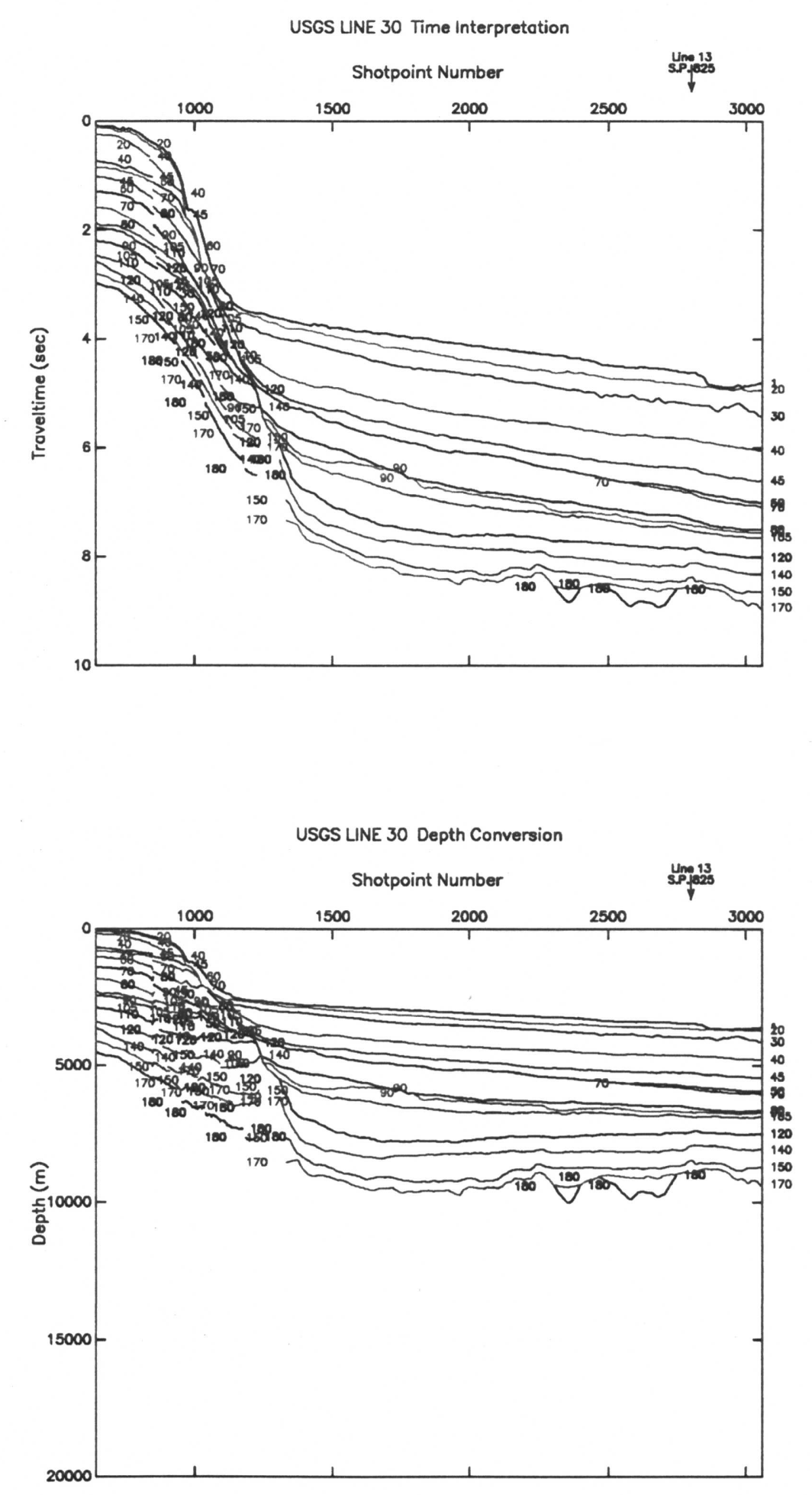

80 

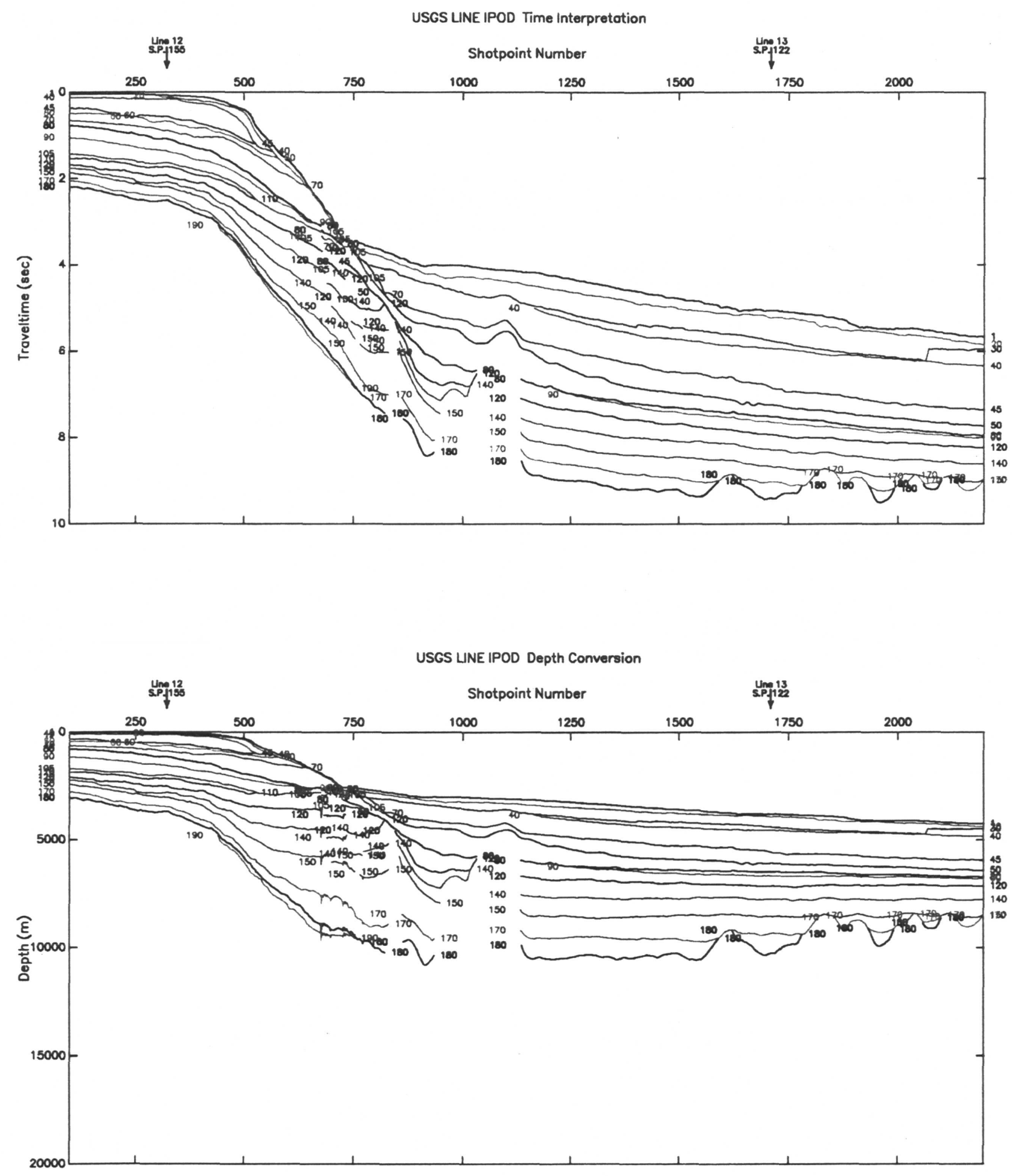

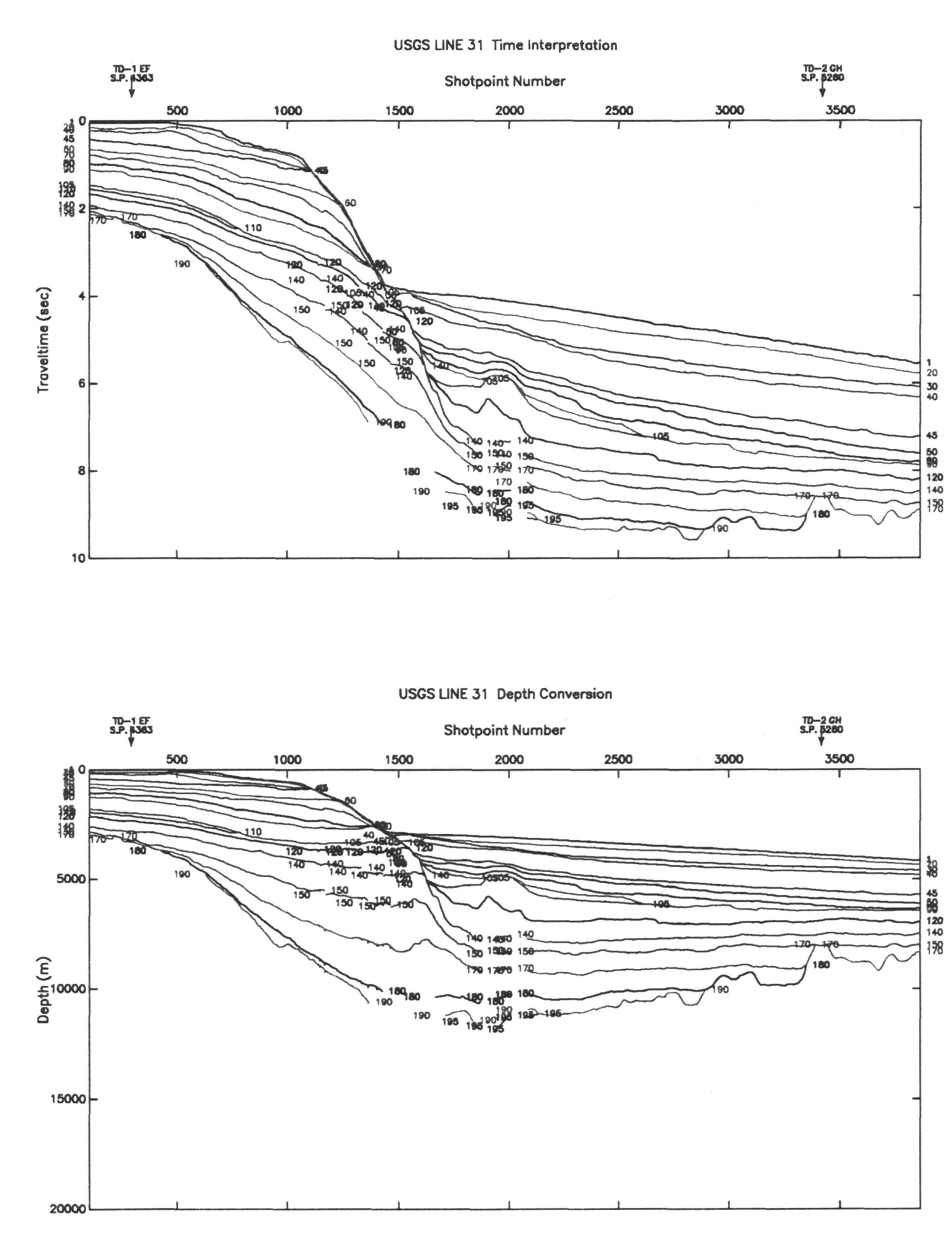

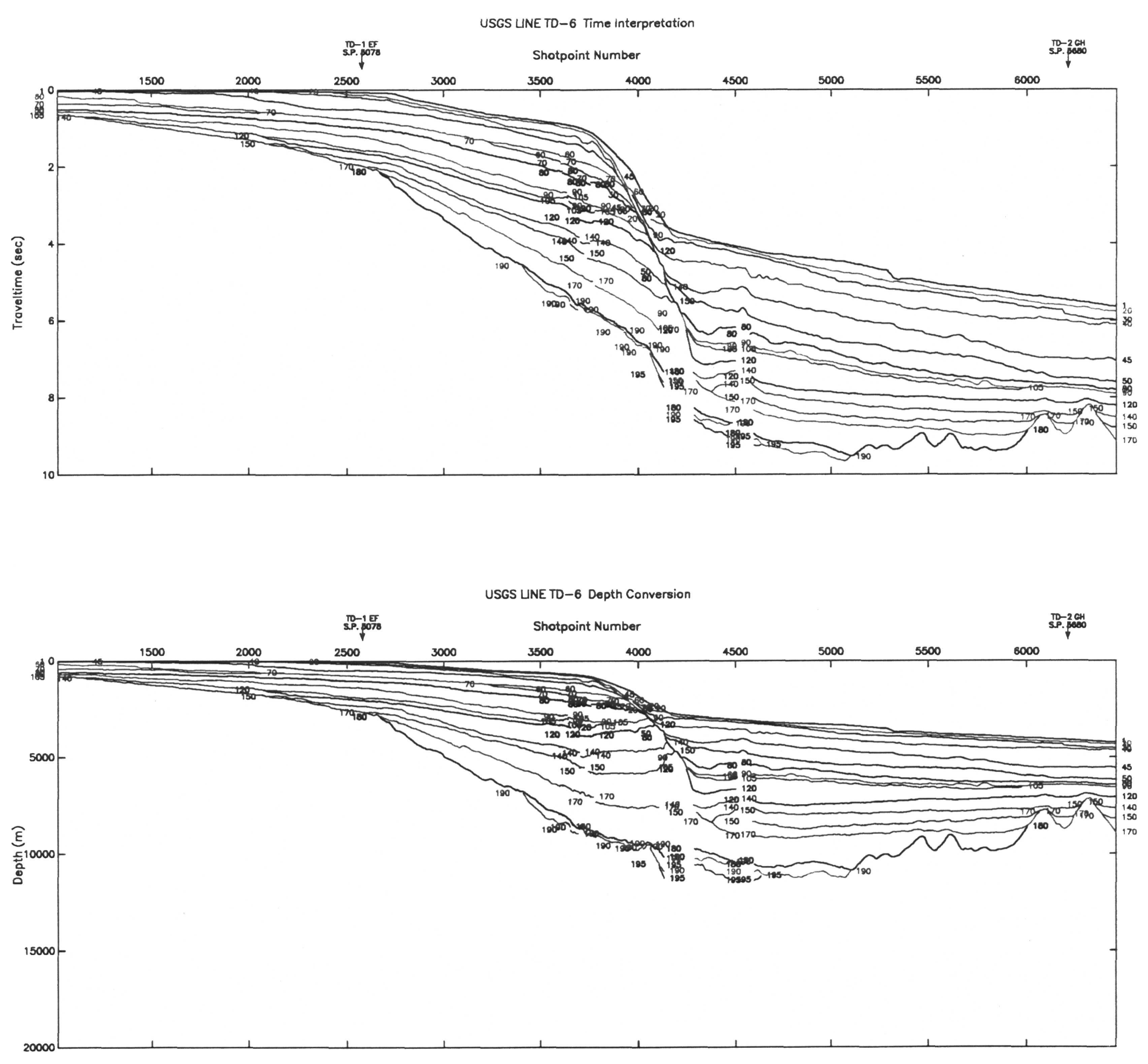

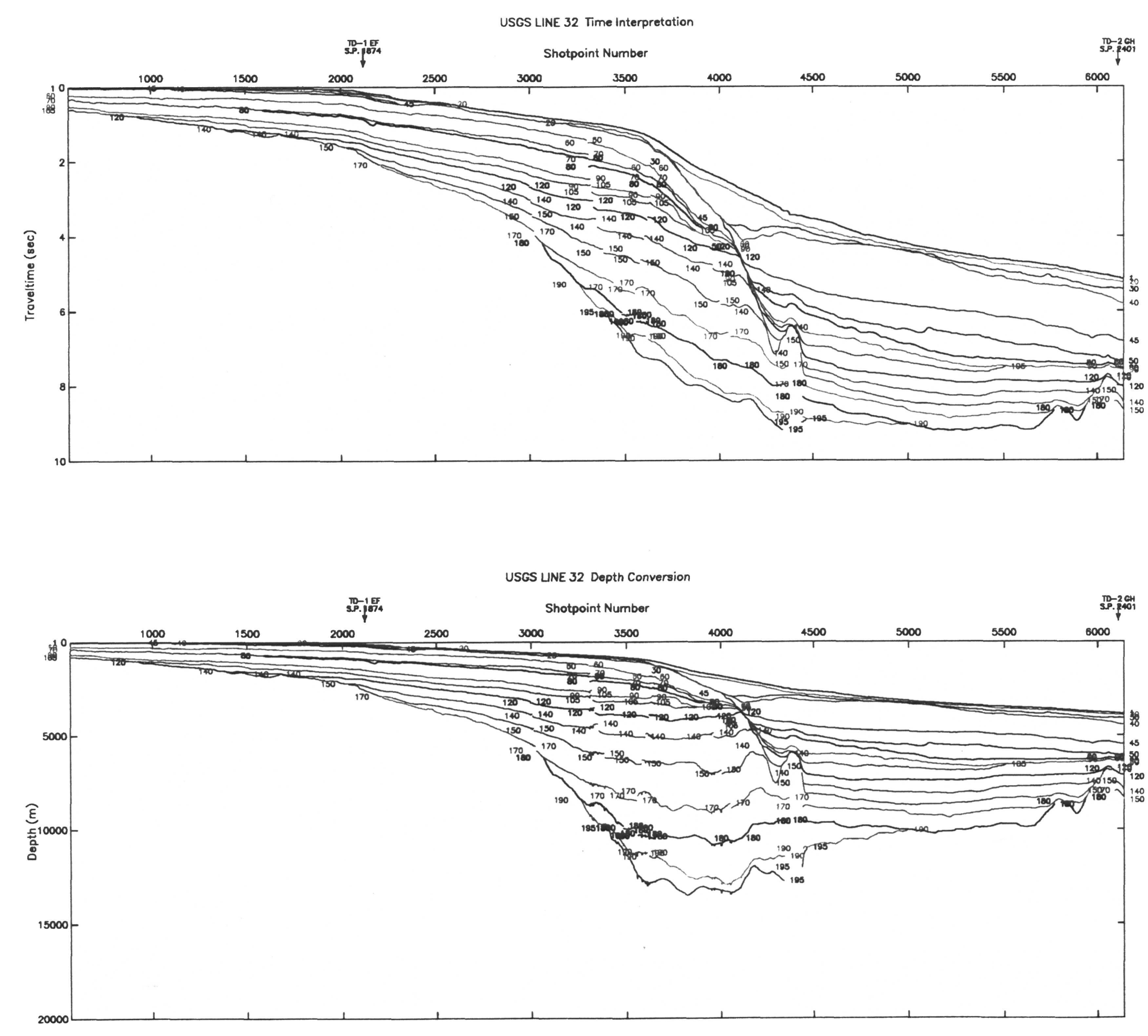

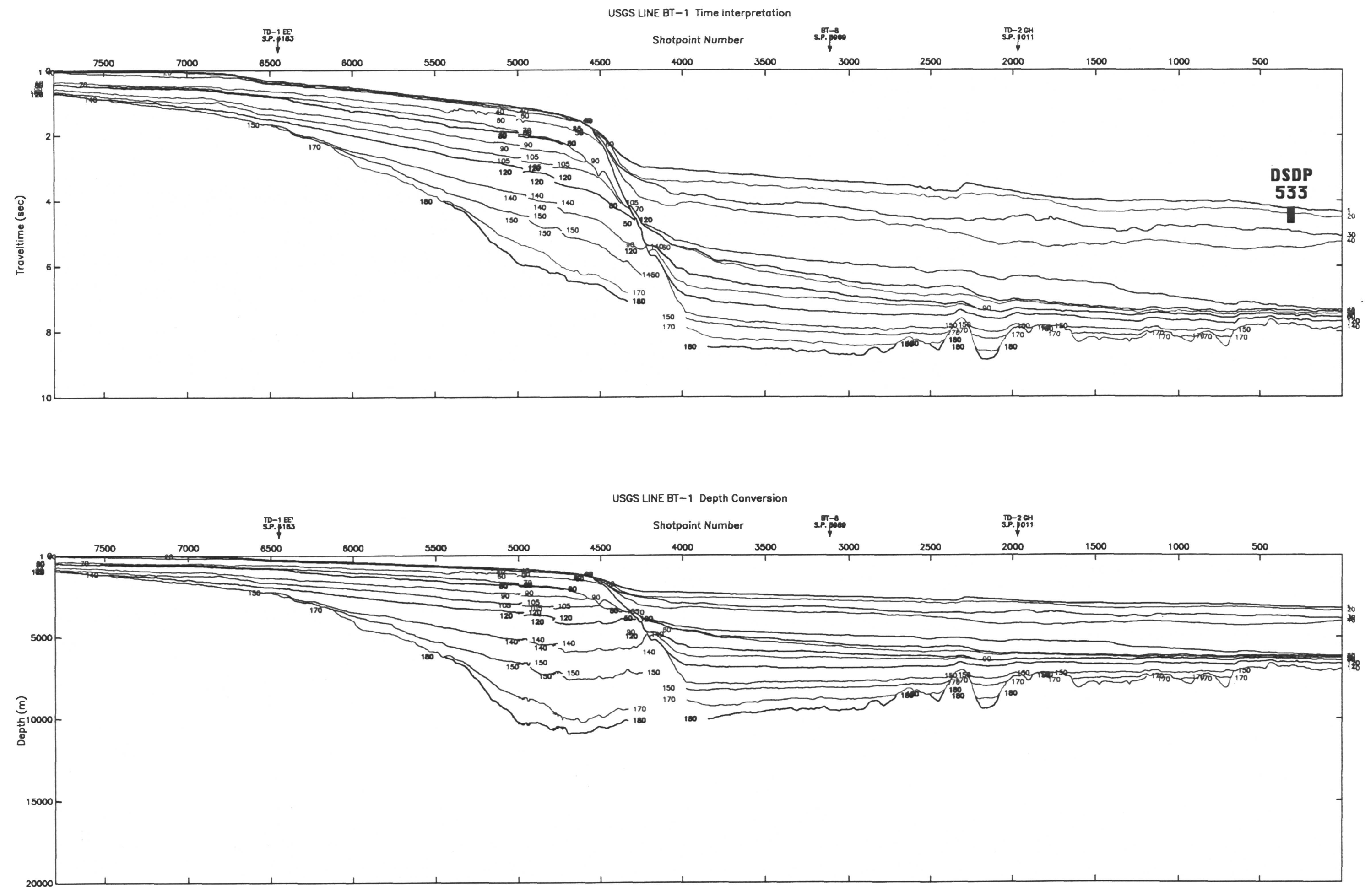

85 

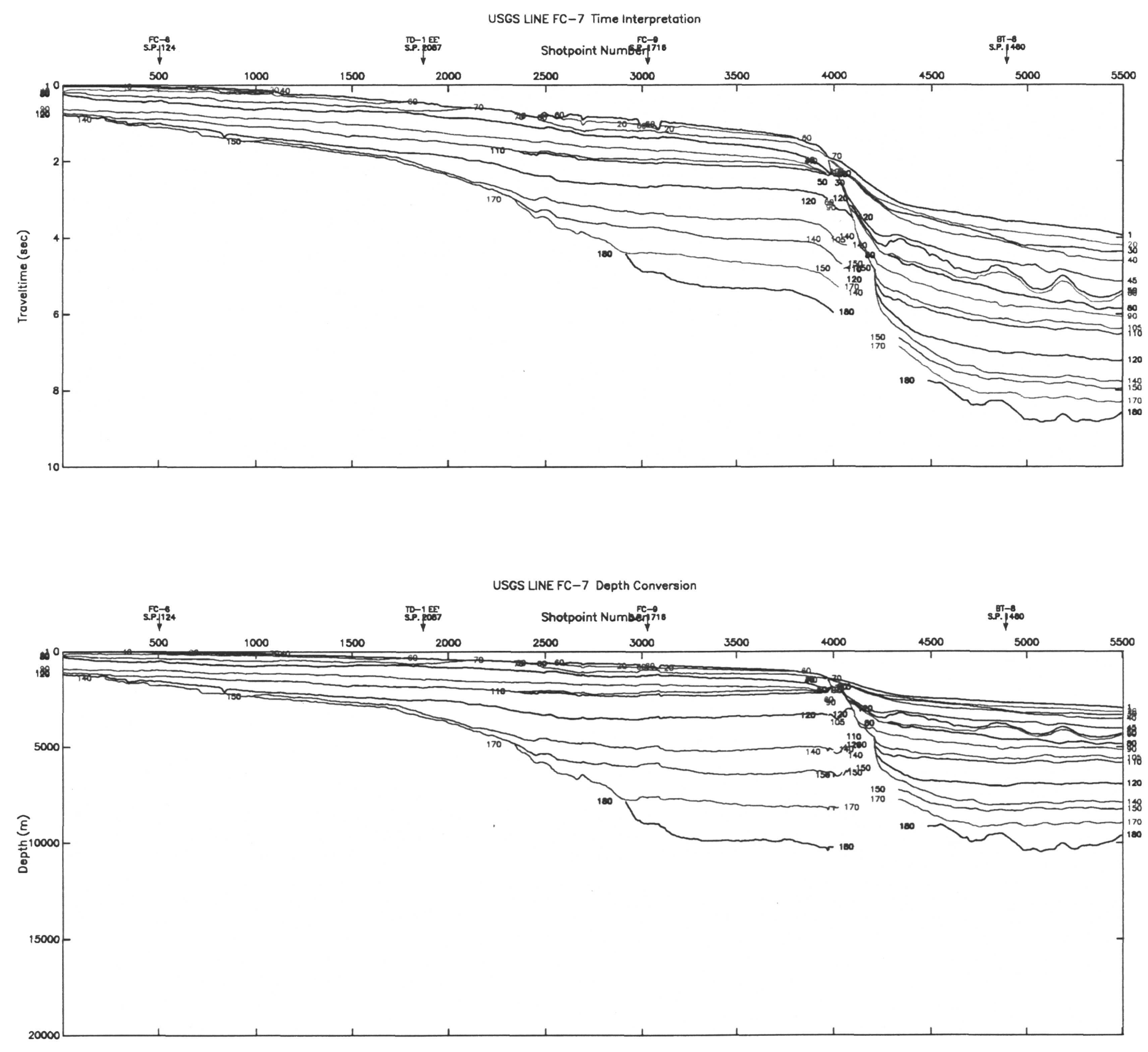

86 

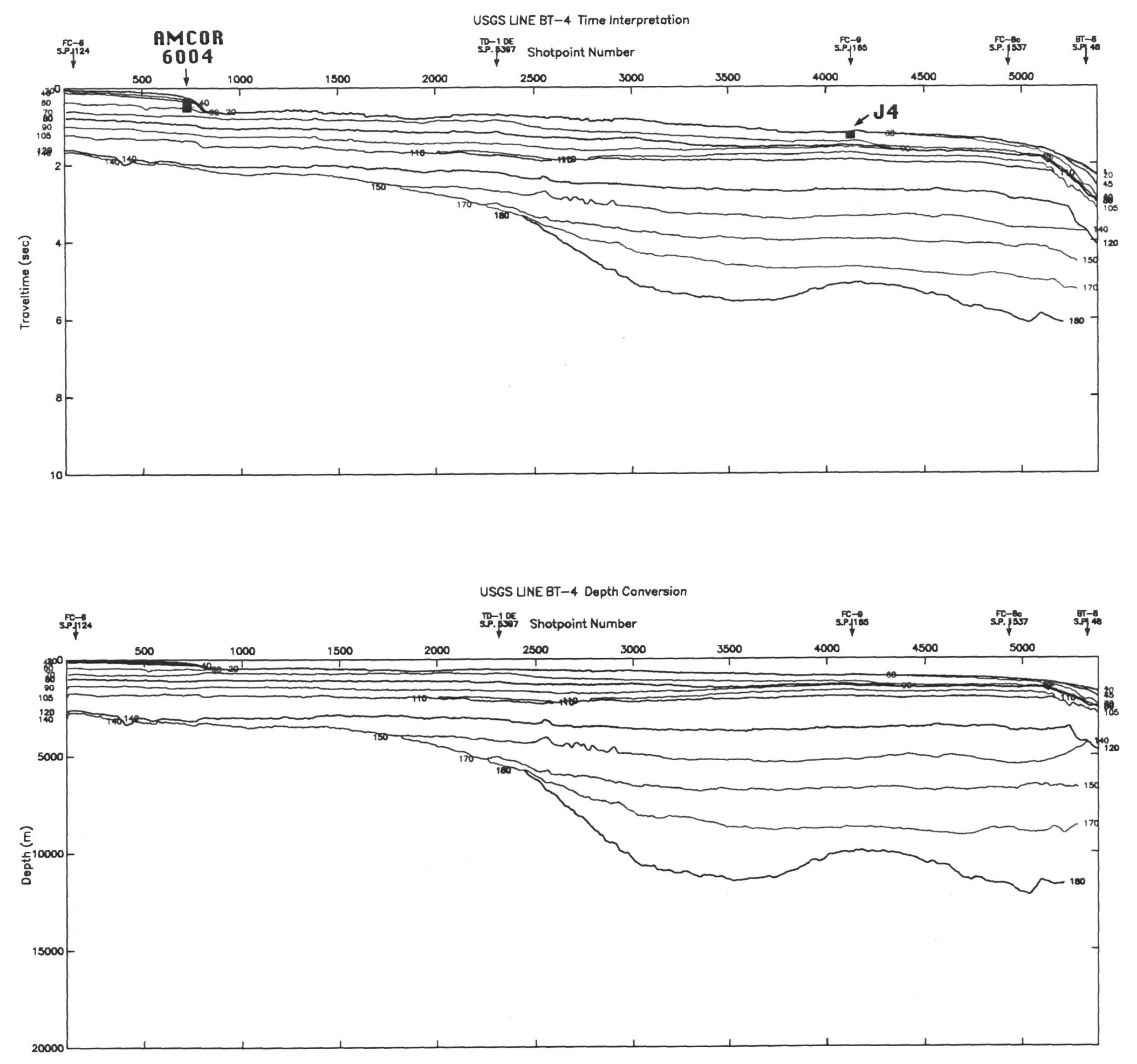

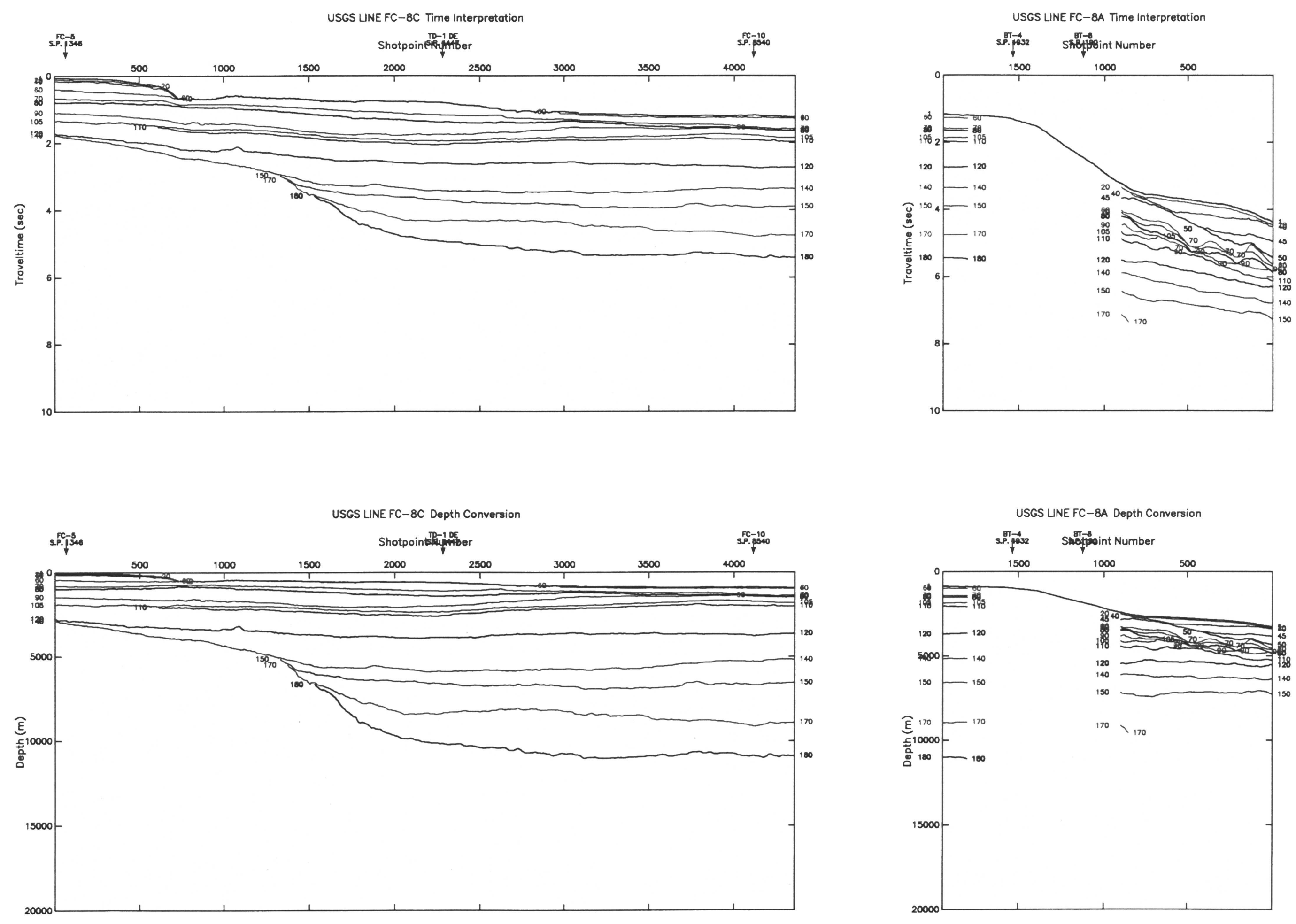

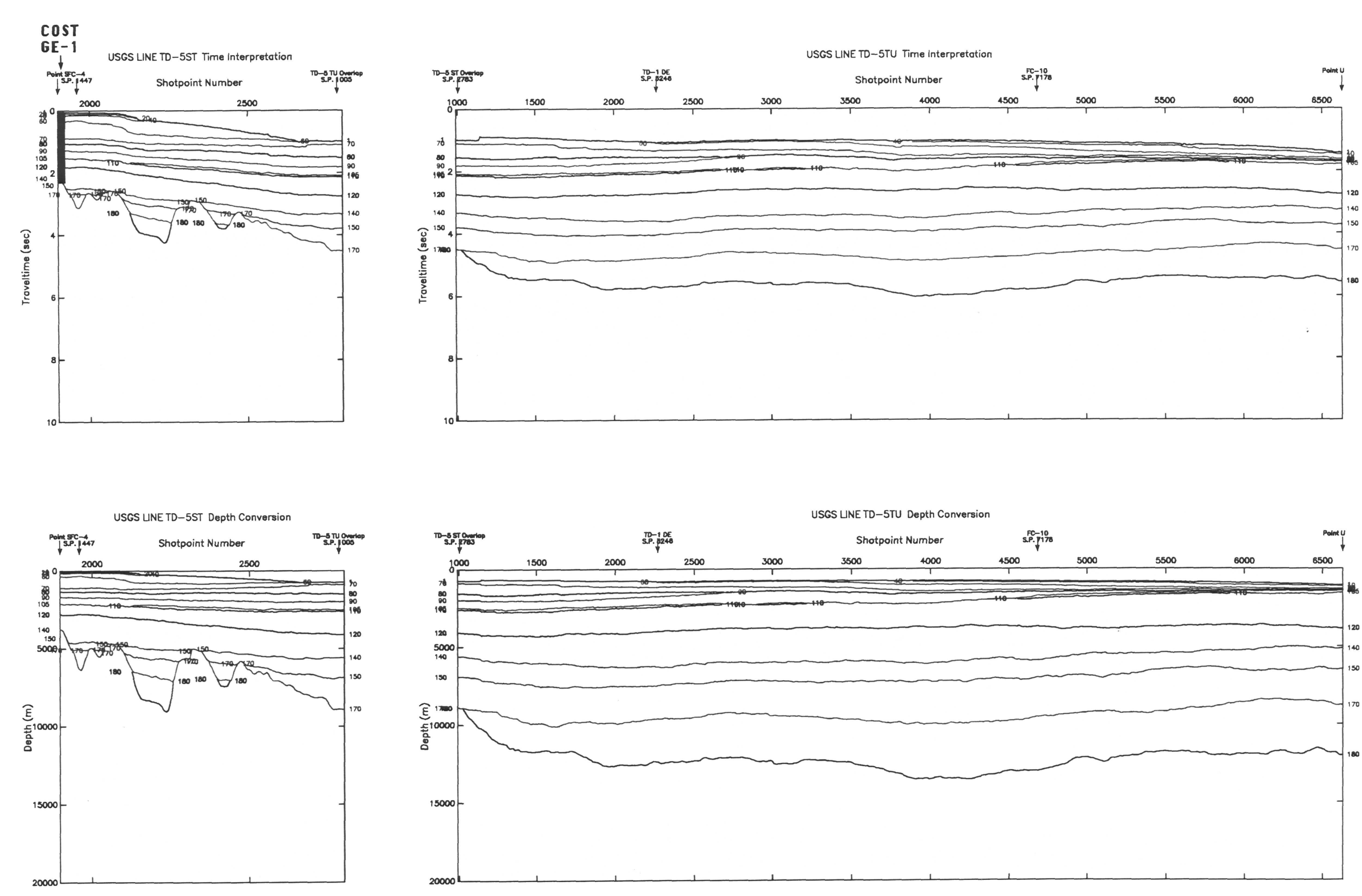

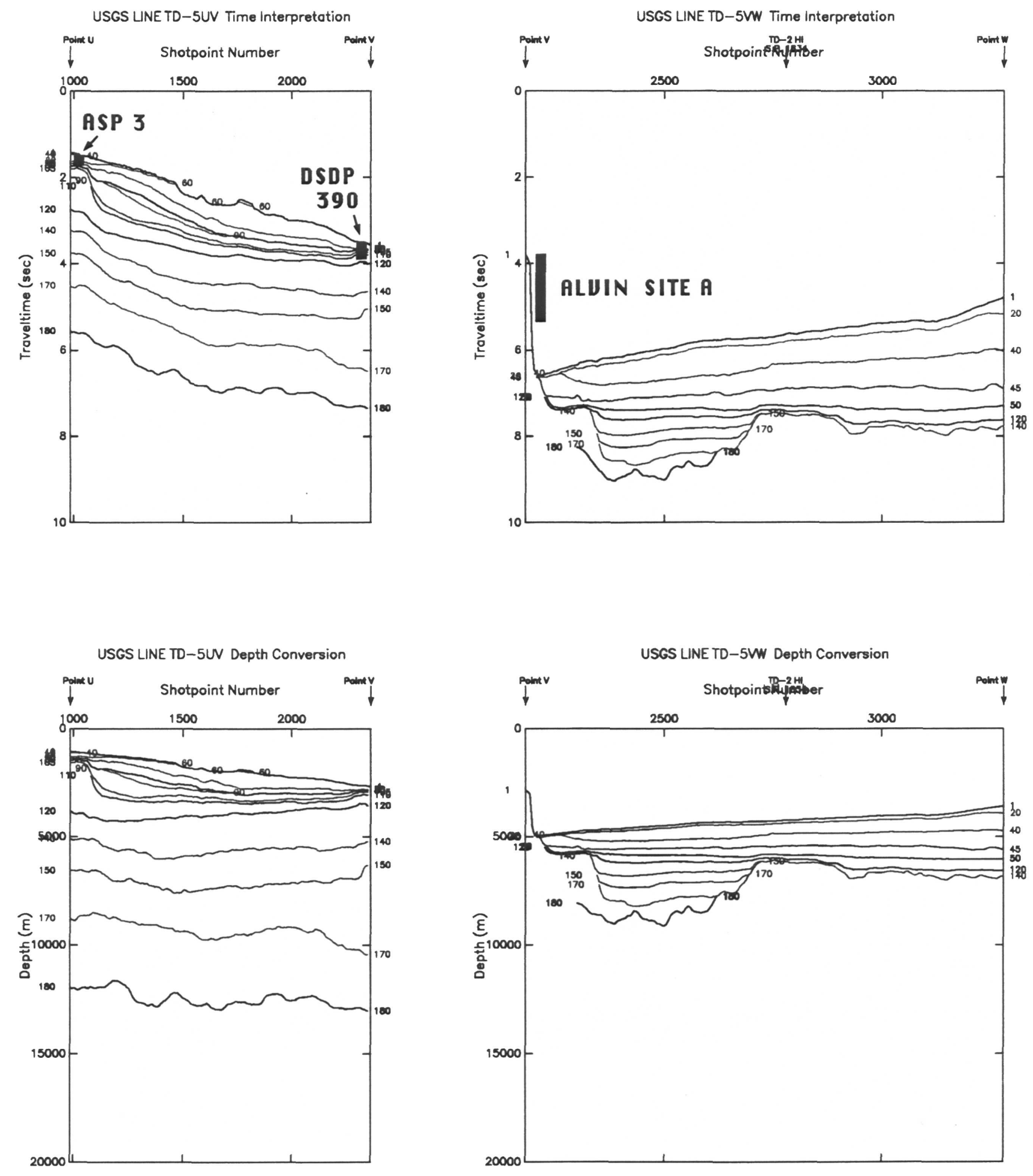

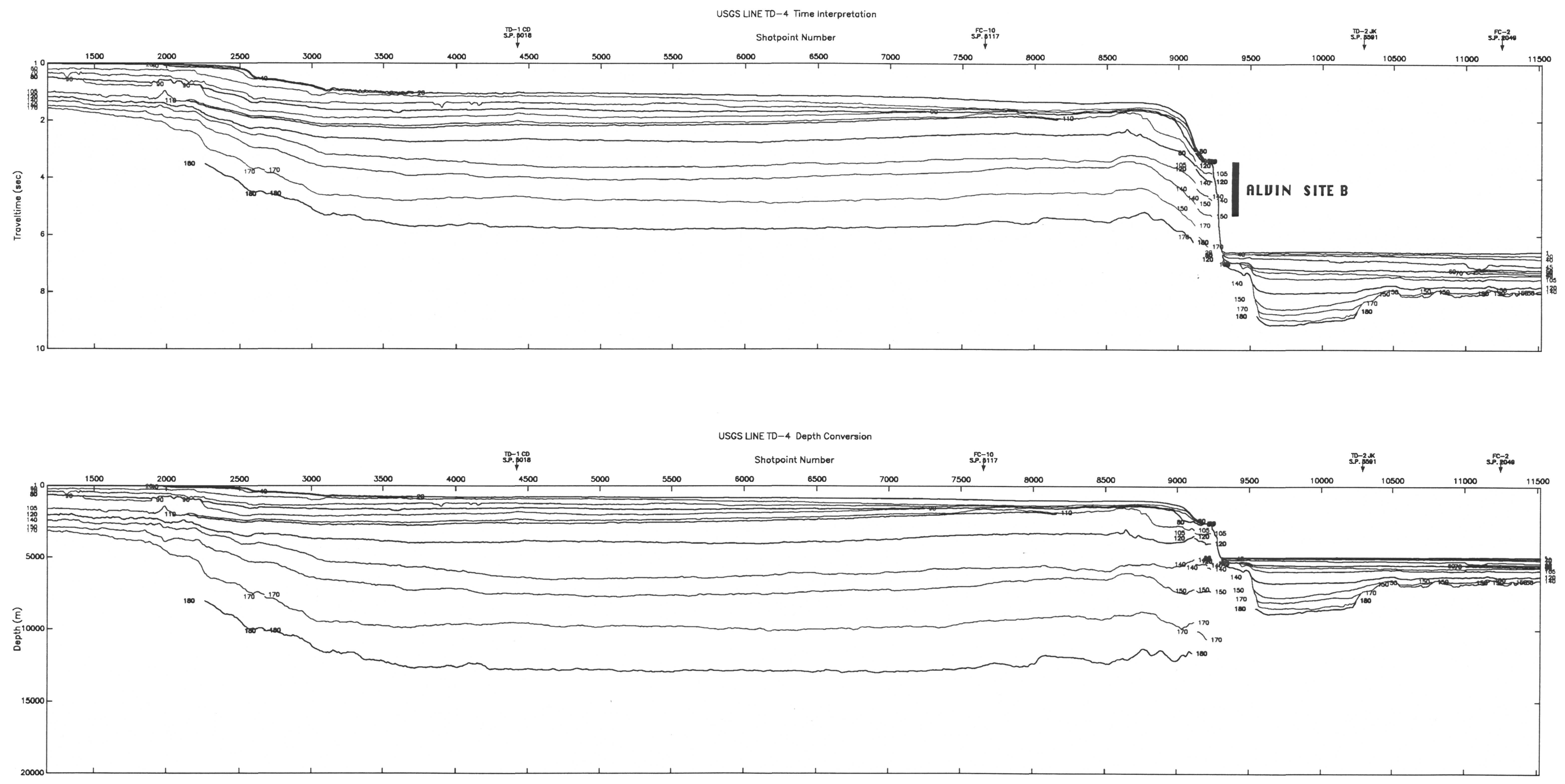

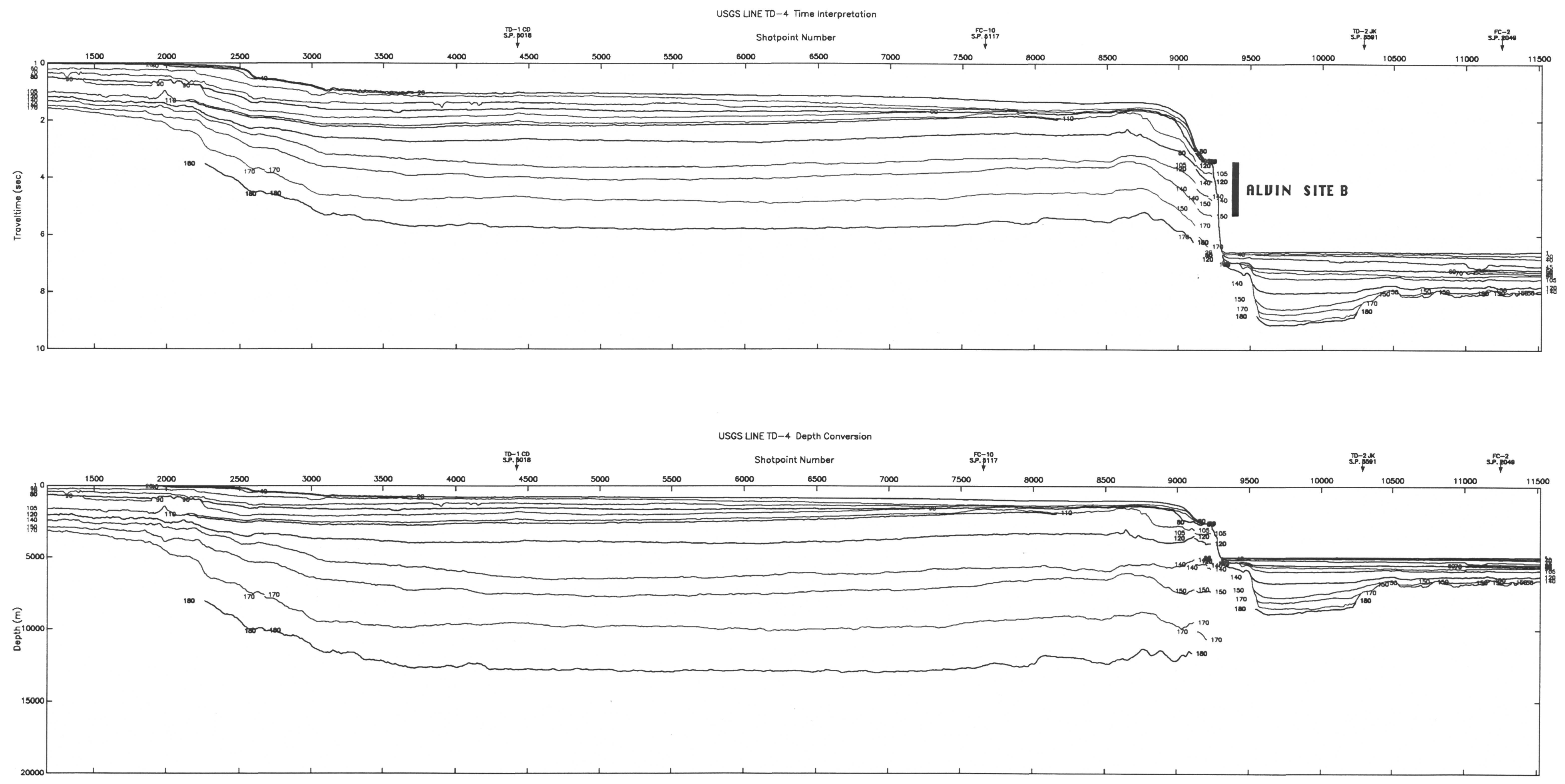

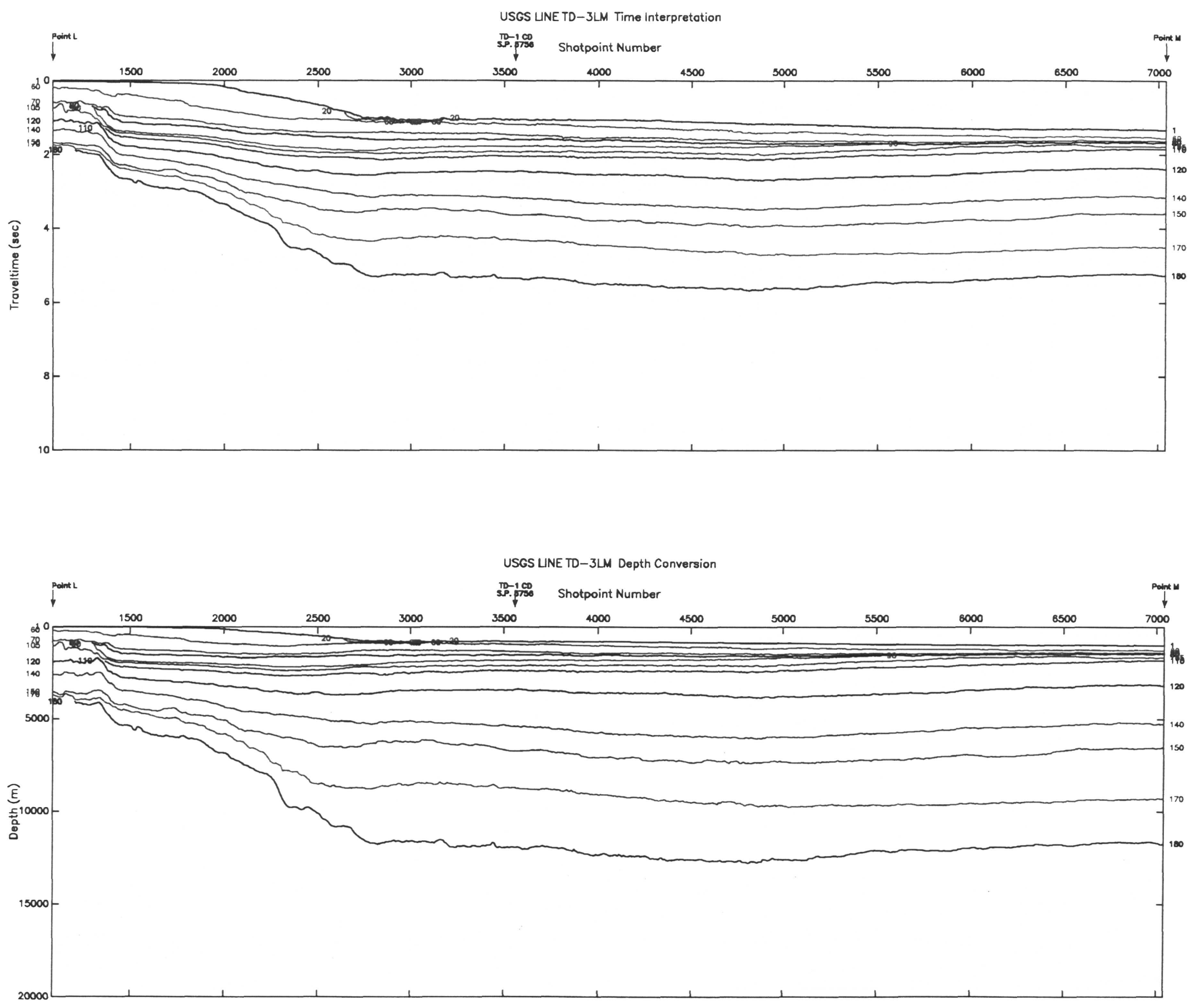


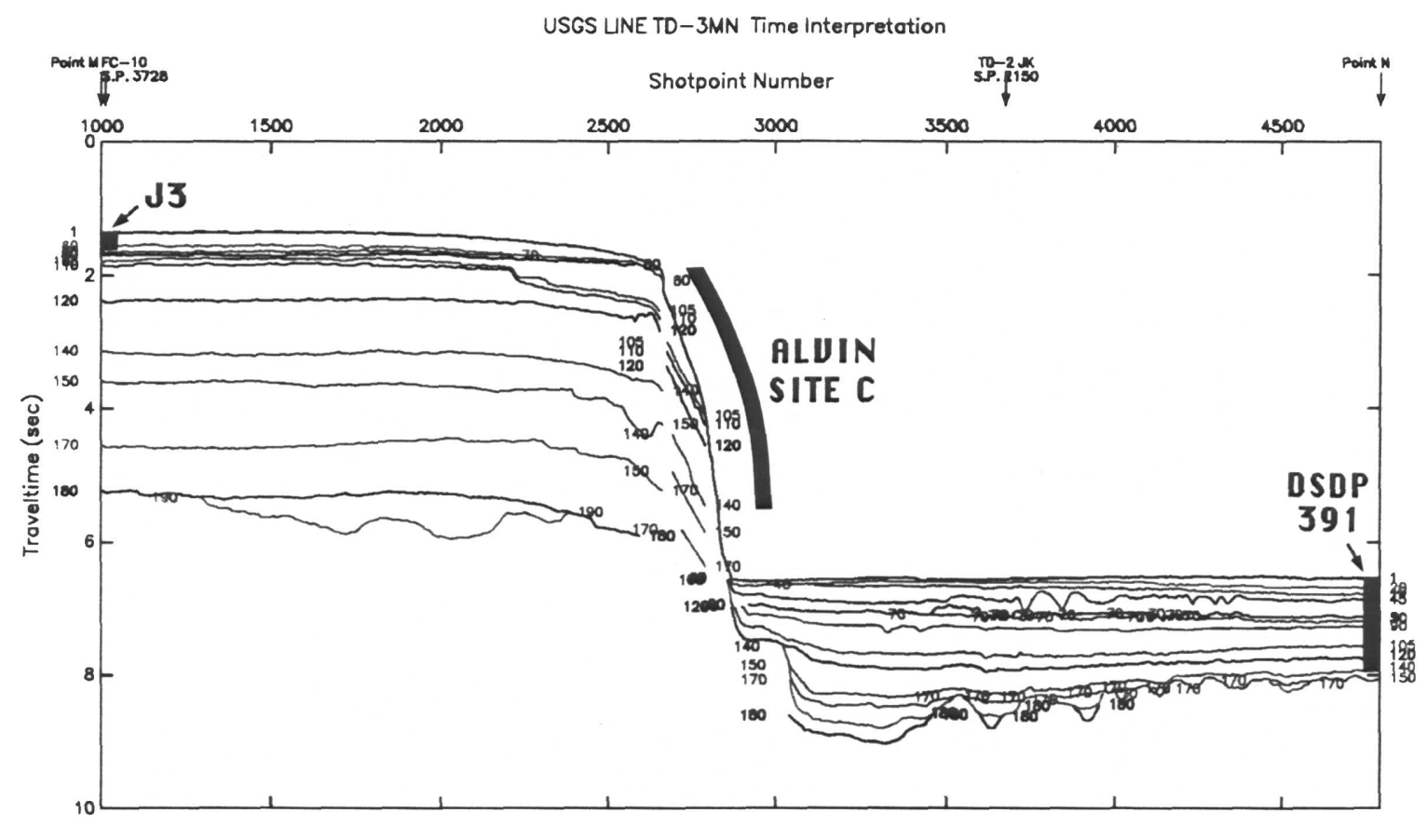

USGS UNE TD-3NO Time Interpretation
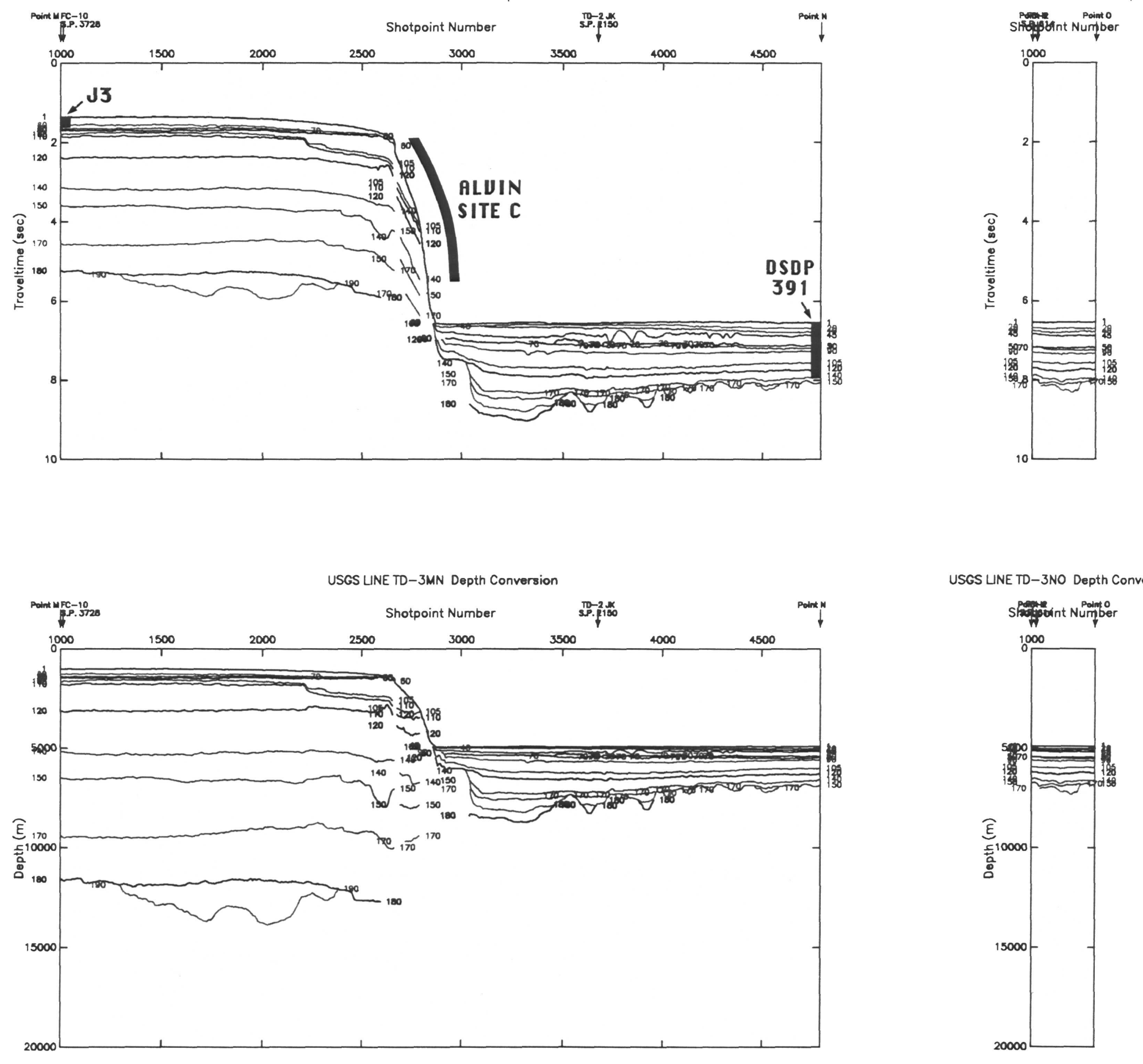

USGS LNE TD-3NO Depth Conversion

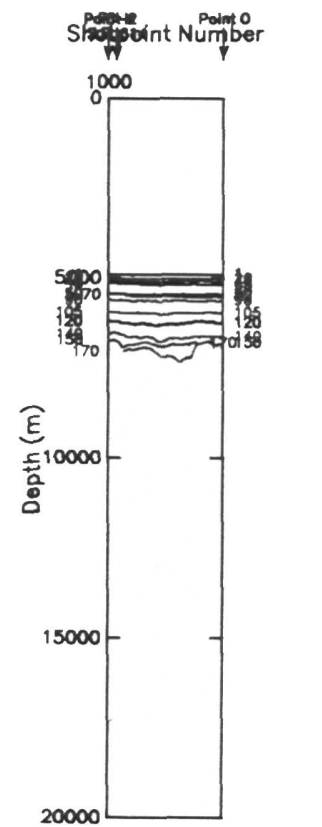



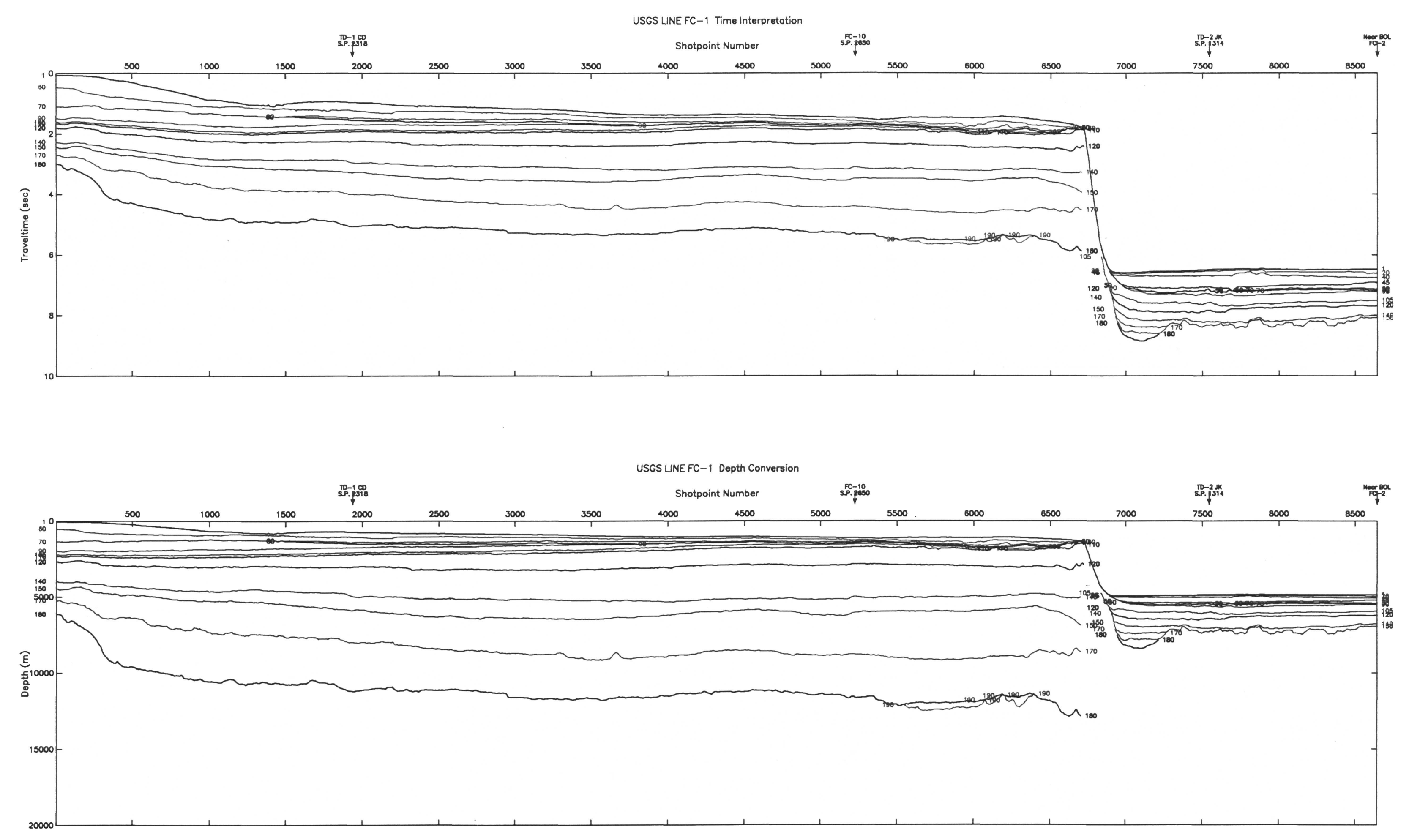


\section{APPENDIX 2}

Multichannel Seismic Profiles:

Initial and Final RMS Velocity Plots 


\section{EXPLANATORY NOTES}

This appendix gives initial (unsmoothed) and final (smoothed) RMS velocity estimates for each stratigraphic horizon. The horizontal and vertical scales for all plots are $25 \mathrm{~km} / \mathrm{inch}$ and $1000 \mathrm{~m} / \mathrm{s}$ per inch, respectively. The upper plots show the control points, i.e., where velocity scans exist (every $3-10 \mathrm{~km}$ ). The lower plots have velocity values interpolated every 5 shots $(250 \mathrm{~m})$. The small scale jitter in the final RMS plots is not geologically meaningful.

The lines are organized according to their position. All strike lines, progressing from shallow water to deep water, are shown first; then all dip lines, progressing from north to south are shown. Line locations are shown in Figure 1-1 (Appendix 1), Figure 1 of the main text and Plate 1 that accompanies this report. The following table gives the order of the lines:

\begin{tabular}{||c||l|l||}
\hline Page No. & Number of Sheets & USGS Line Number \\
\hline \hline 98 & 1 & FC-4 FC-5 FC-6 \\
\hline $99,100,101$ & 3 & TD-1 Line 12 \\
\hline 102 & 1 & FC-10 \\
\hline 103 & 1 & FC-9 \\
\hline 104 & 1 & BT-8 \\
\hline 105,106 & 2 & TD-2 \\
\hline 107 & 1 & Line 13 \\
\hline 108 & 1 & FC-2 \\
\hline 110 & 1 & Line 30 \\
\hline 111 & 1 & Line IPOD \\
\hline 112 & 1 & Line 31 \\
\hline 113 & 1 & Line TD-6 \\
\hline 114 & 1 & Line 32 \\
\hline 115 & 1 & Line BT-1 \\
\hline 116 & 1 & Line FC-7 \\
\hline 117 & 1 & Line BT-4 \\
\hline 118,119 & 2 & Line FC-8 \\
\hline 120,121 & 2 & Line TD-5 \\
\hline 122 & Line FC-3 \\
\hline 123,124 & 2 & Line TD-4 \\
\hline 125 & 1 & Line TD-3 \\
\hline & & Line FC-1 \\
\hline
\end{tabular}



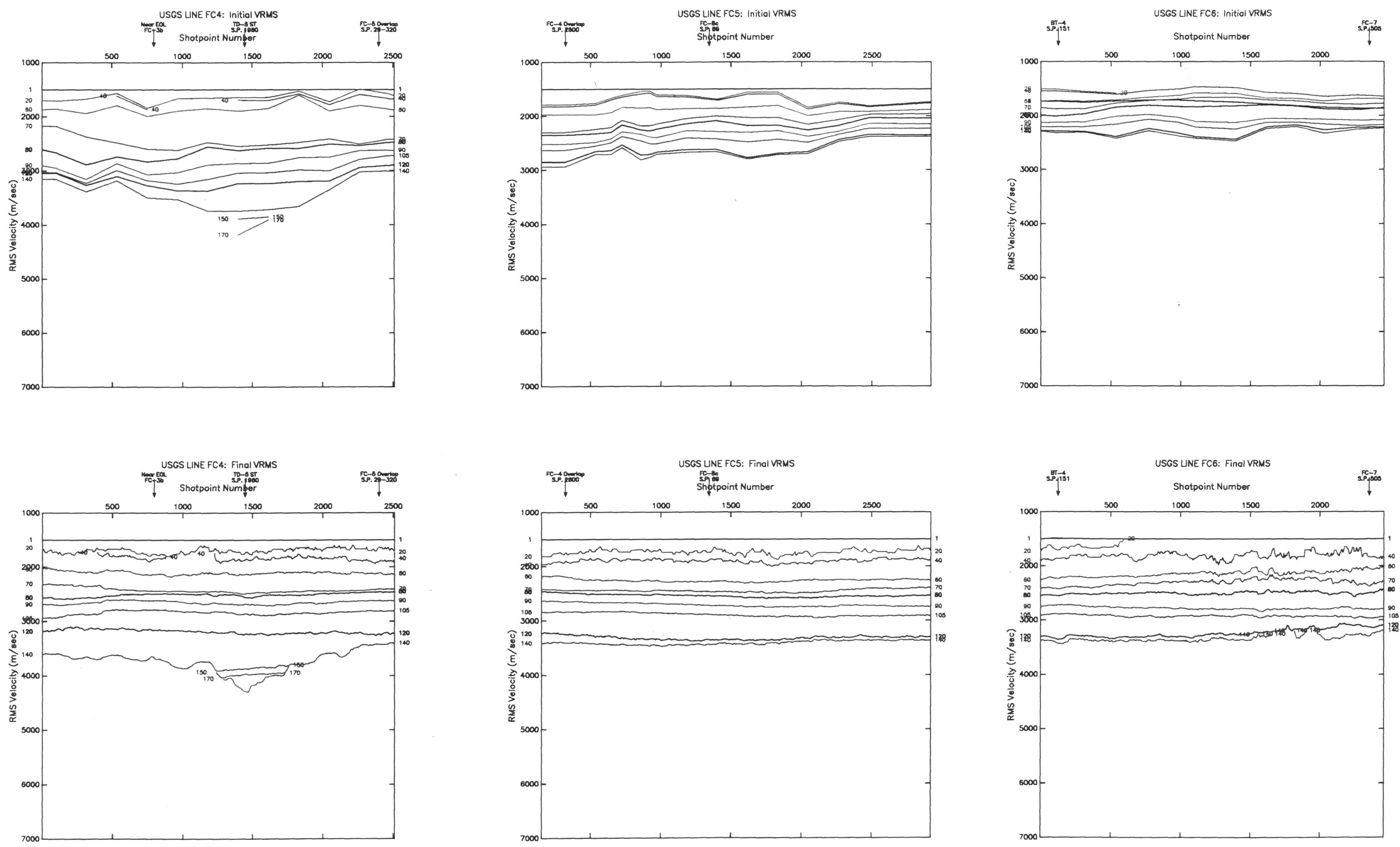


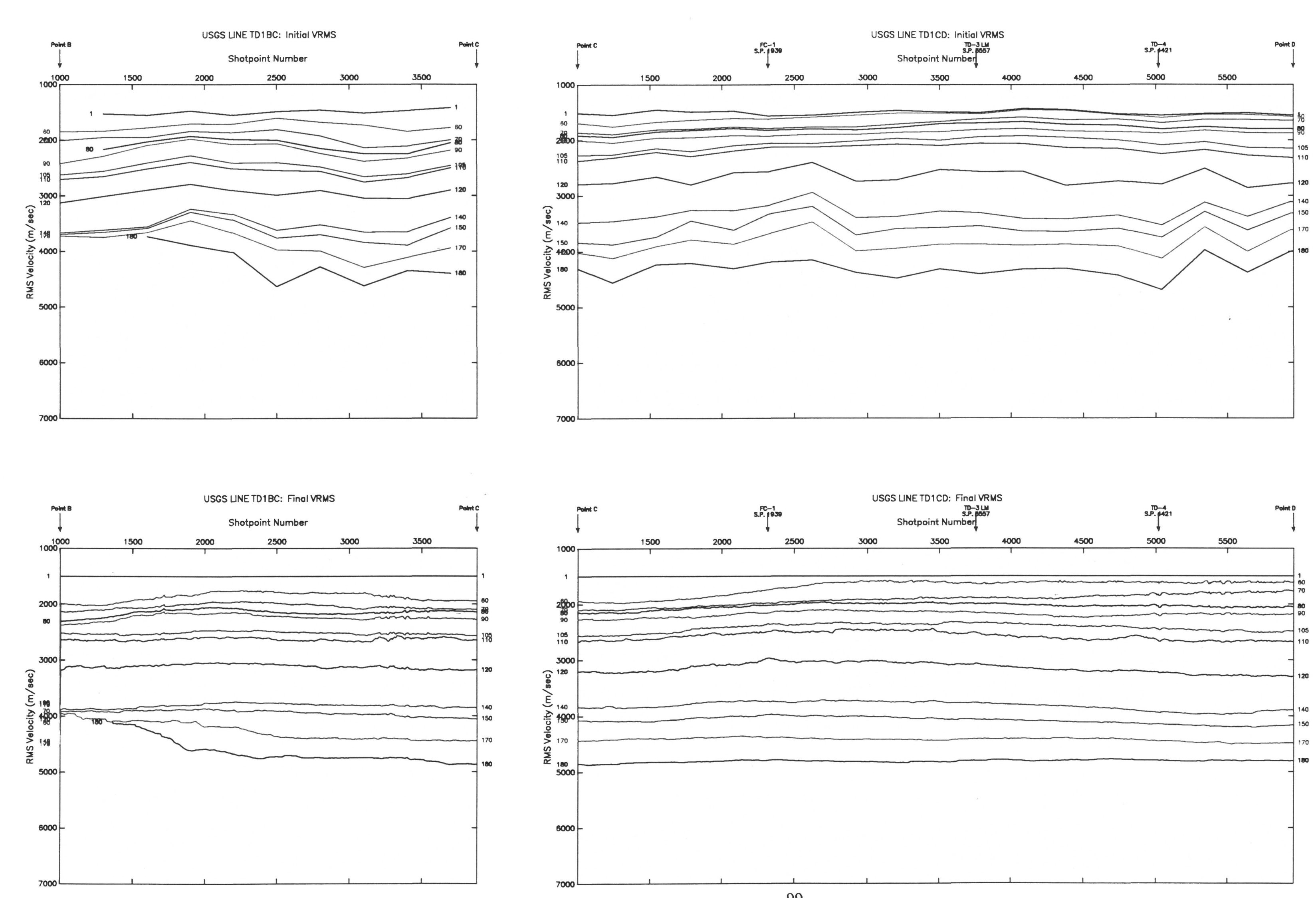



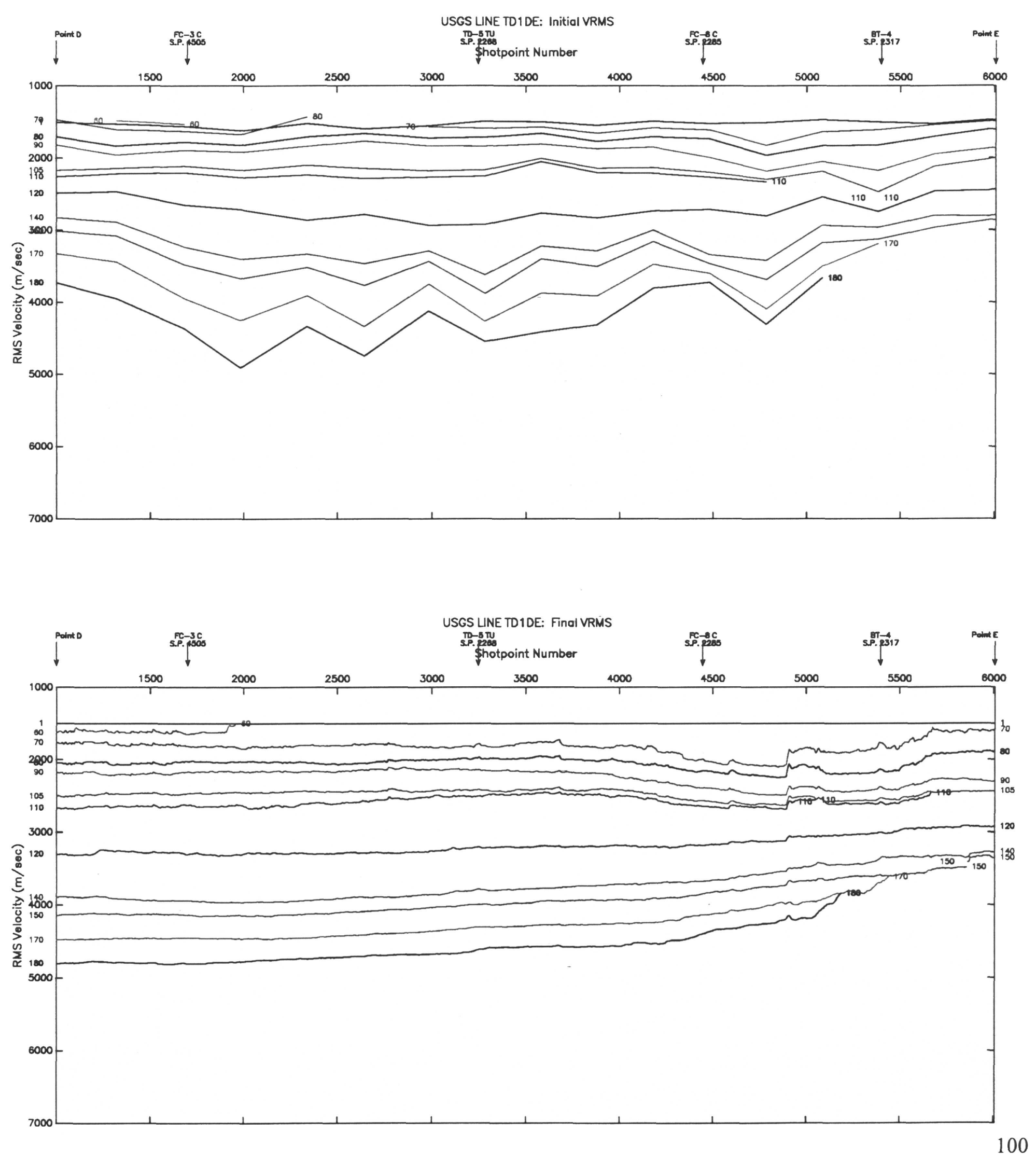
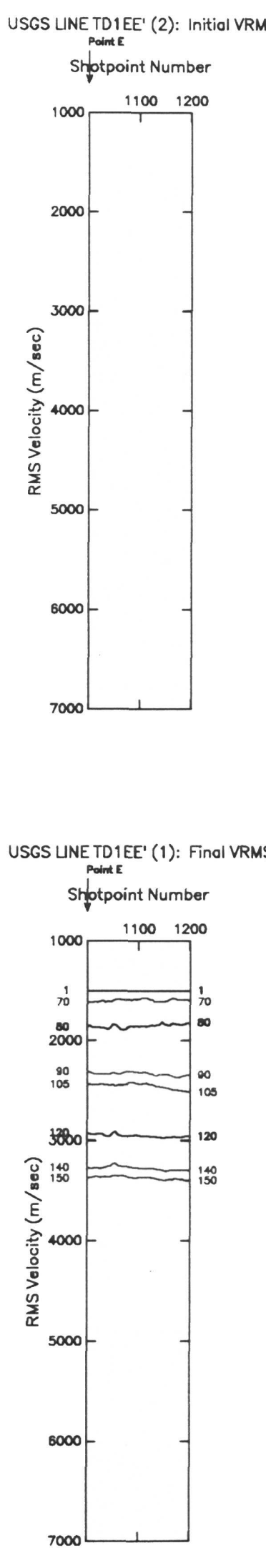
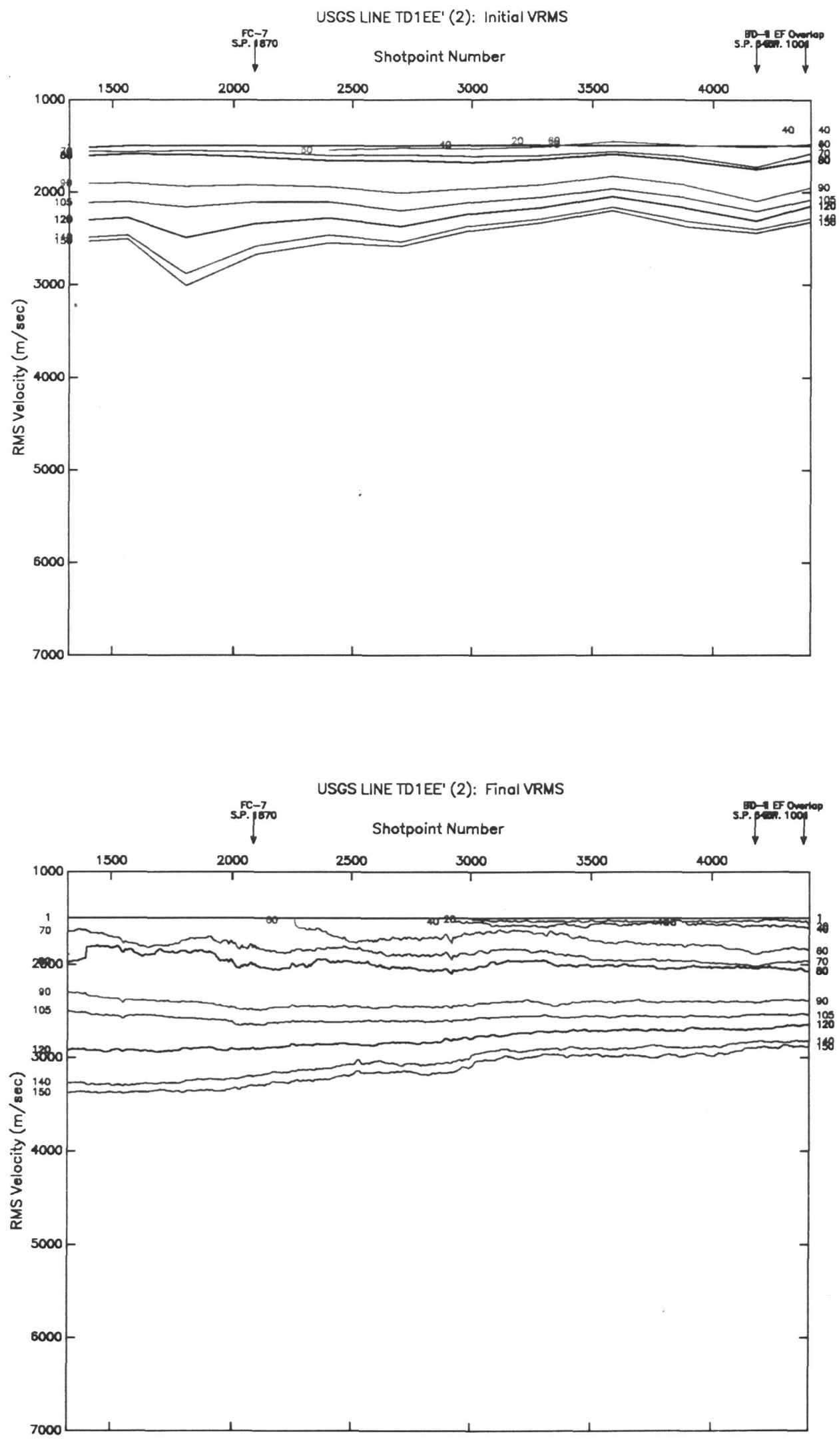

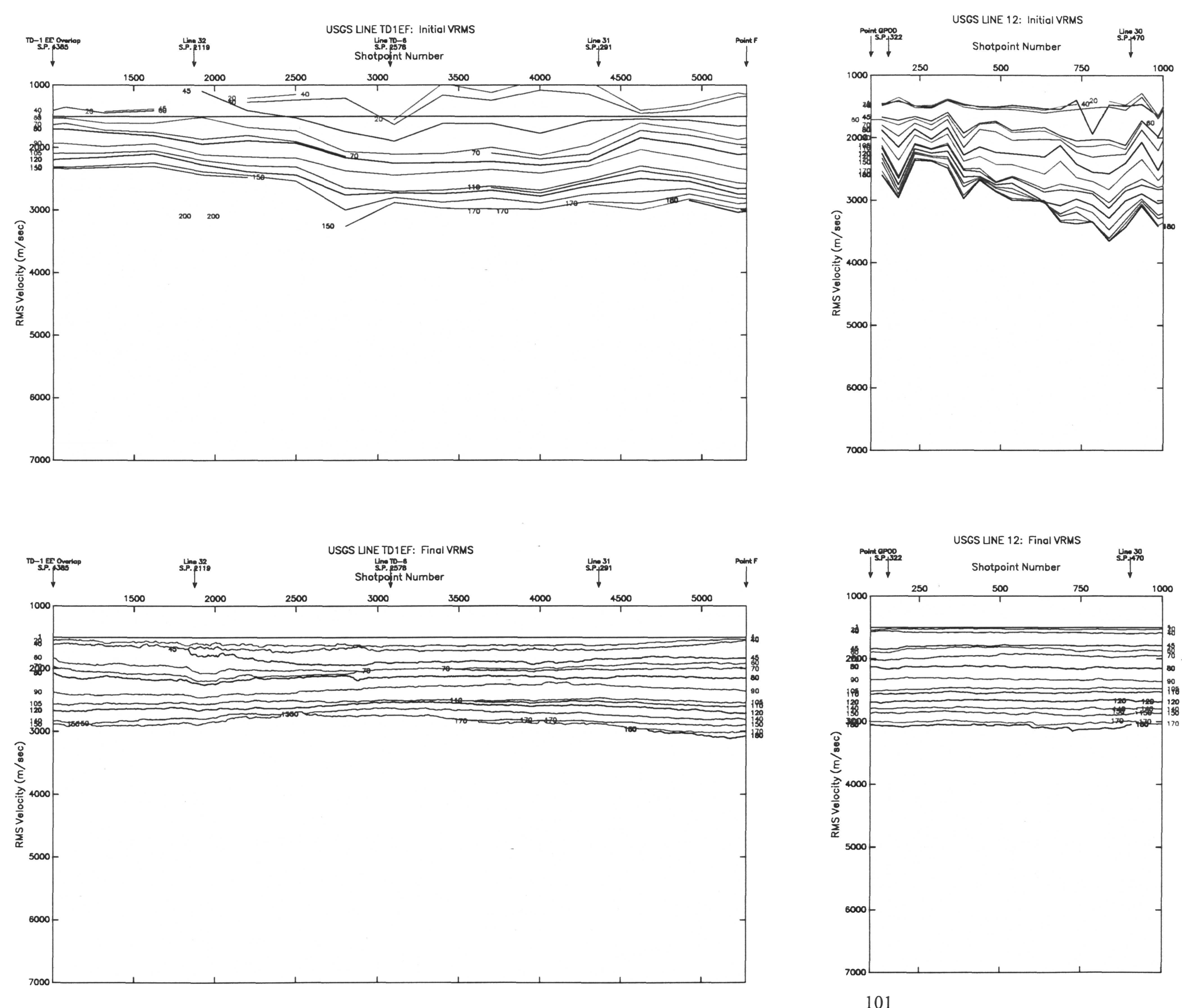

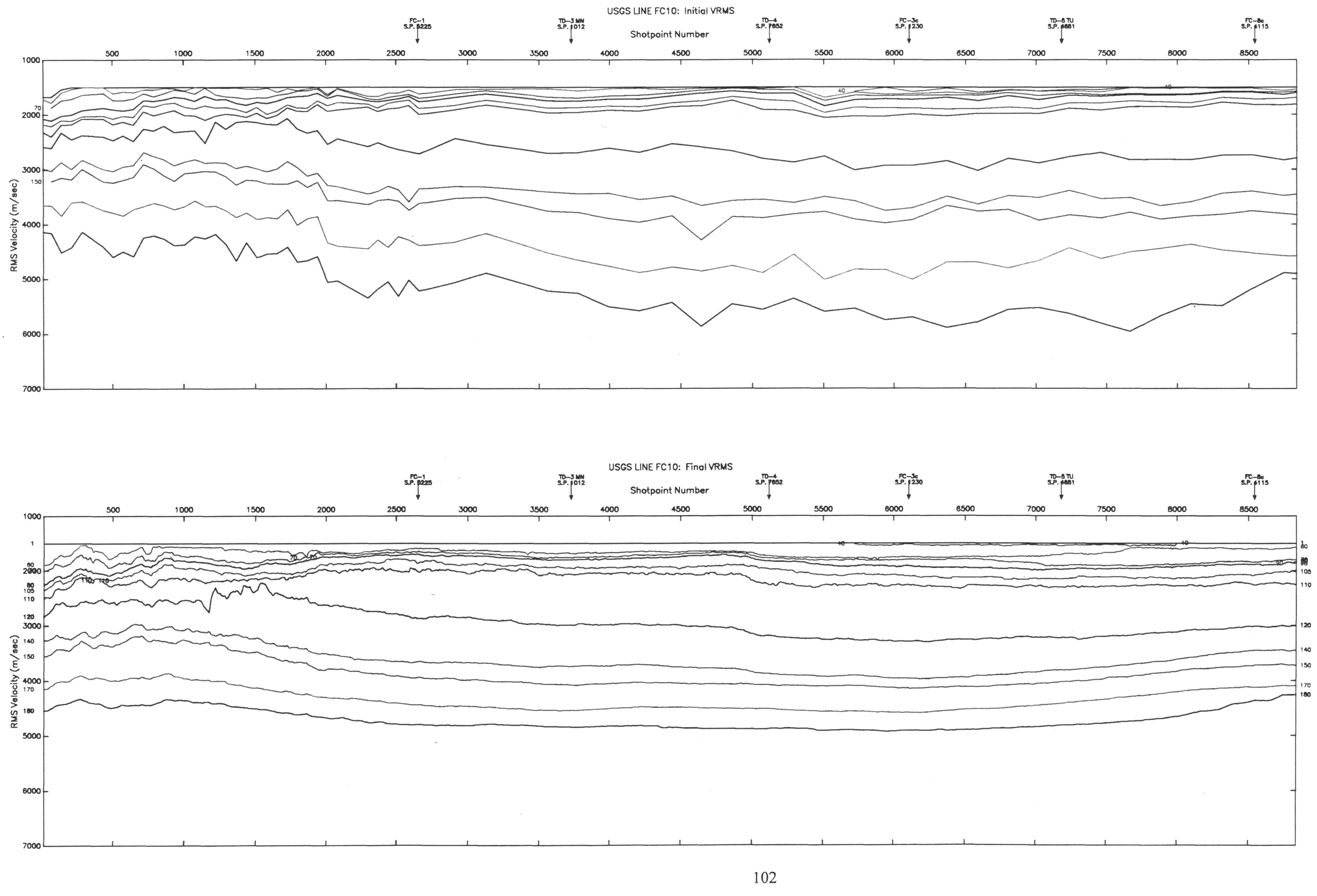
<smiles>C1#CC2CCCCC2C1</smiles>

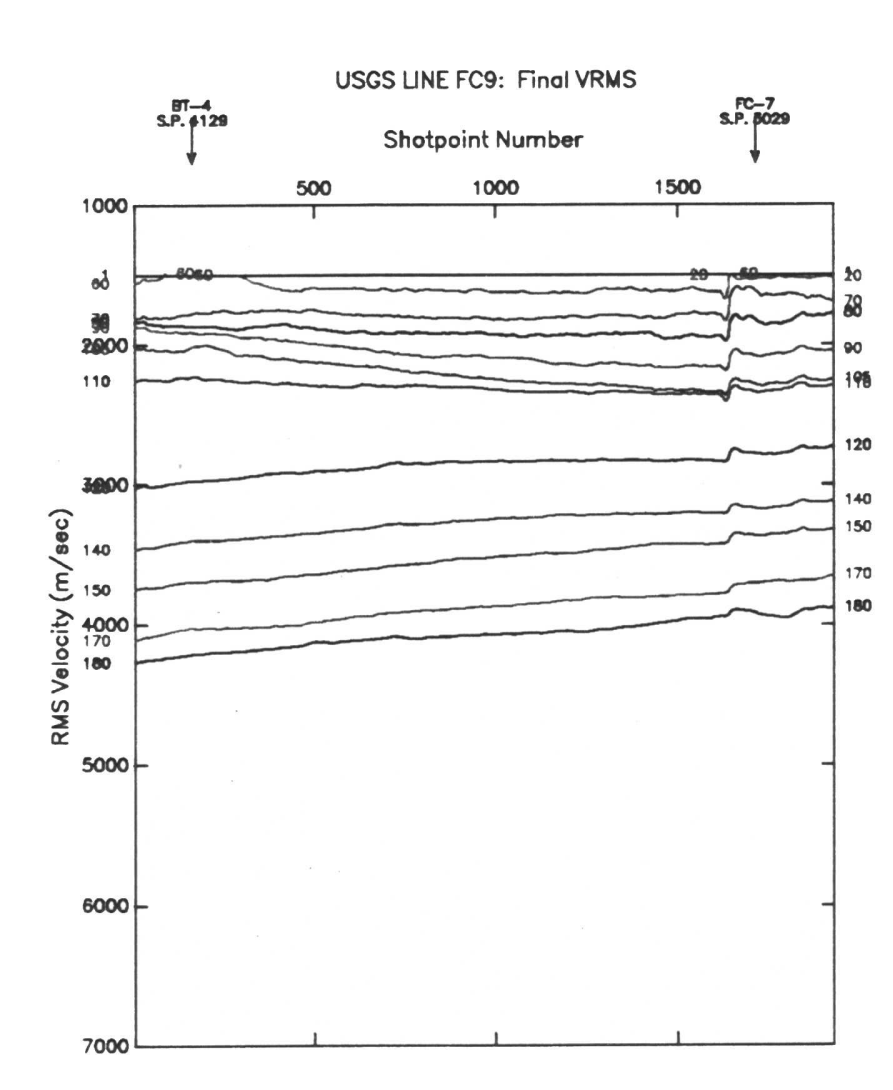




$$
E
$$



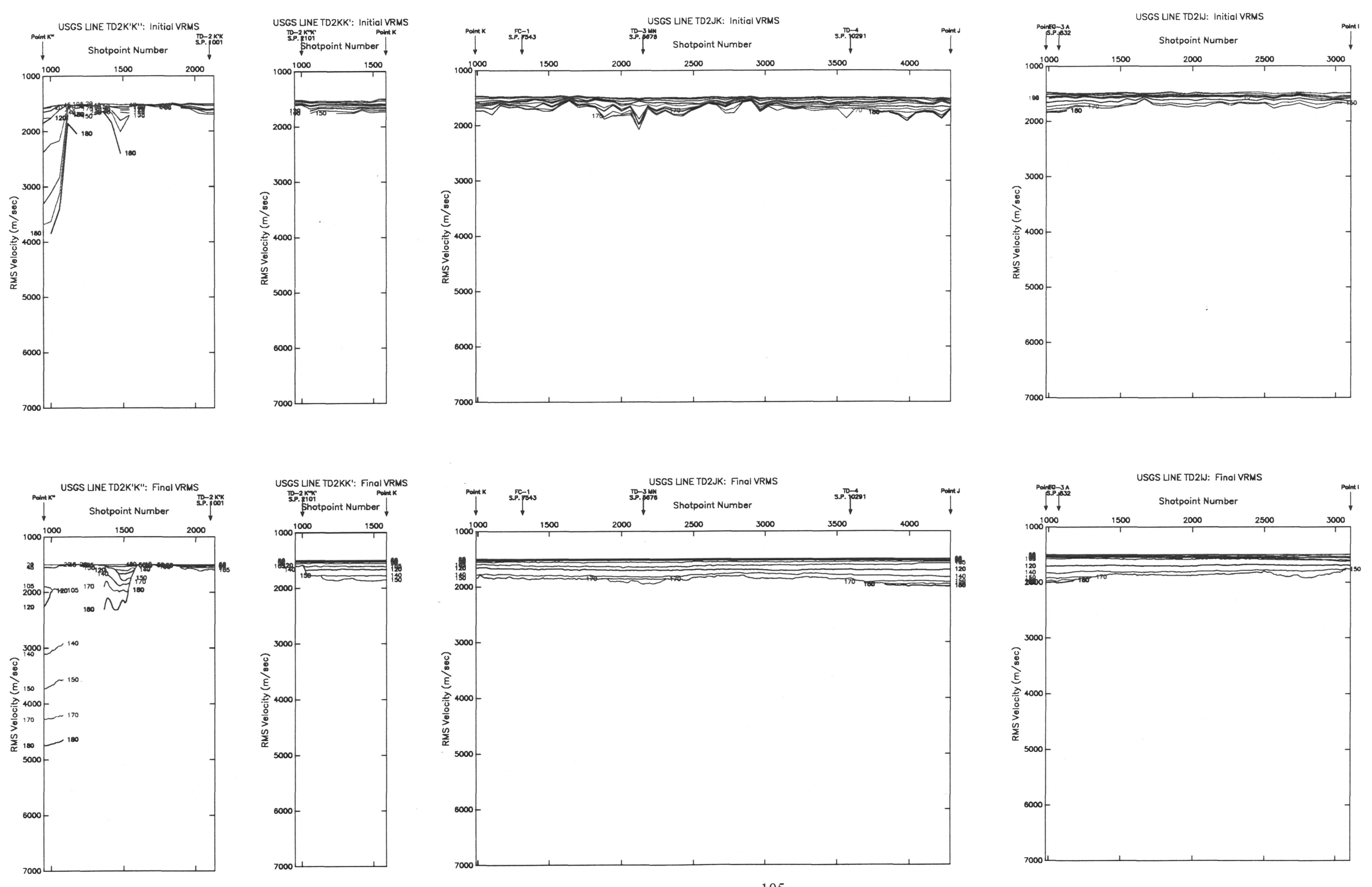

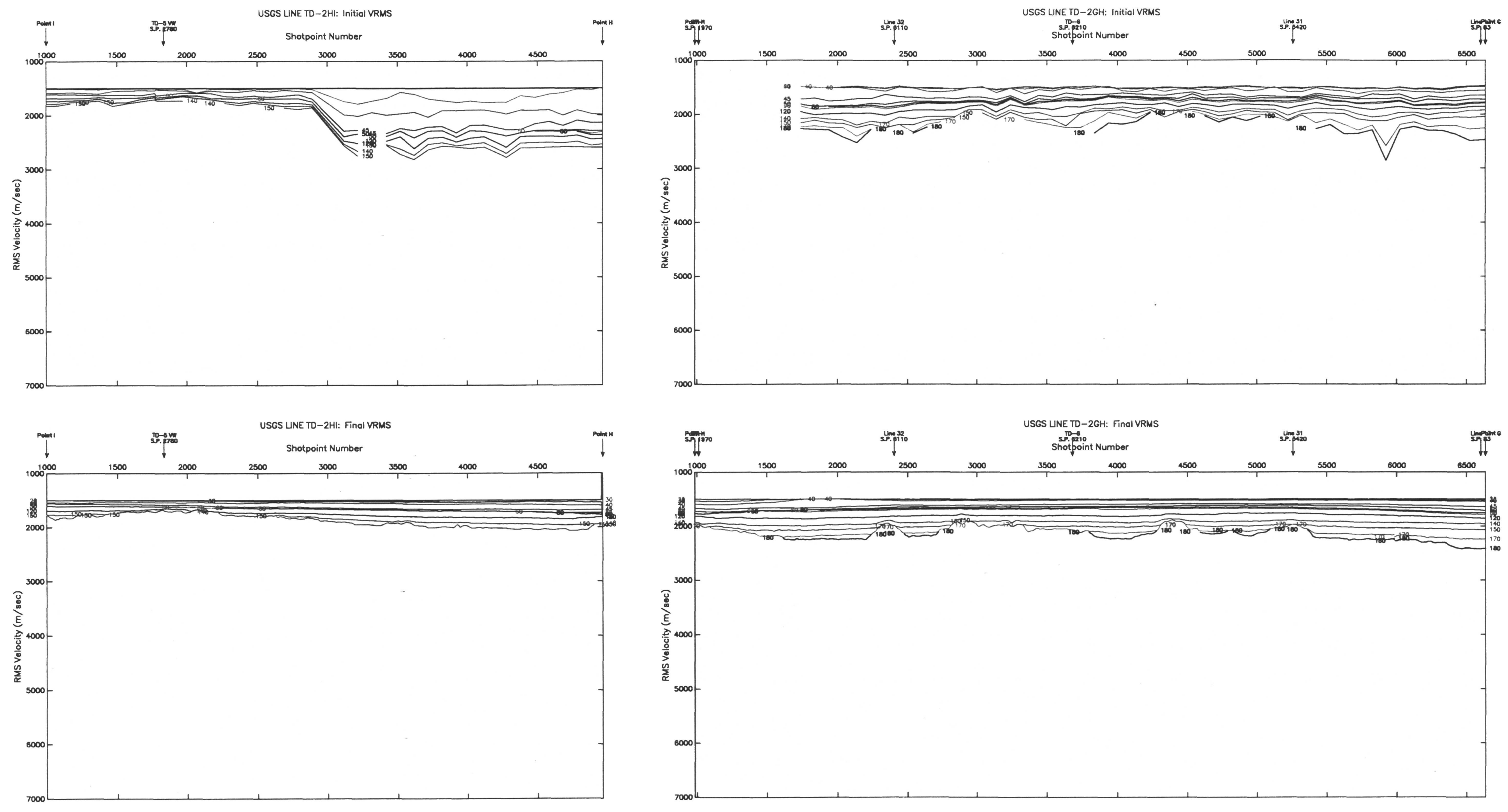

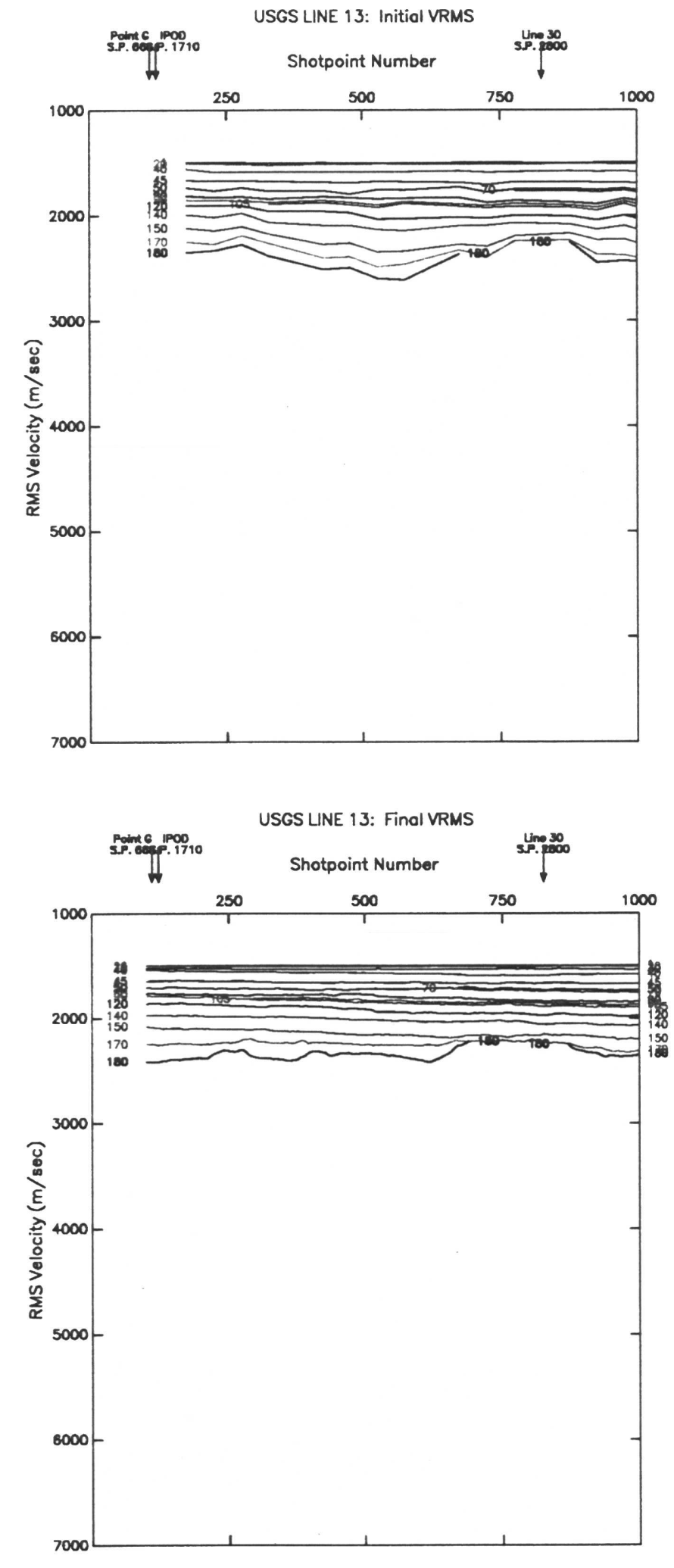

107 


$$
F
$$



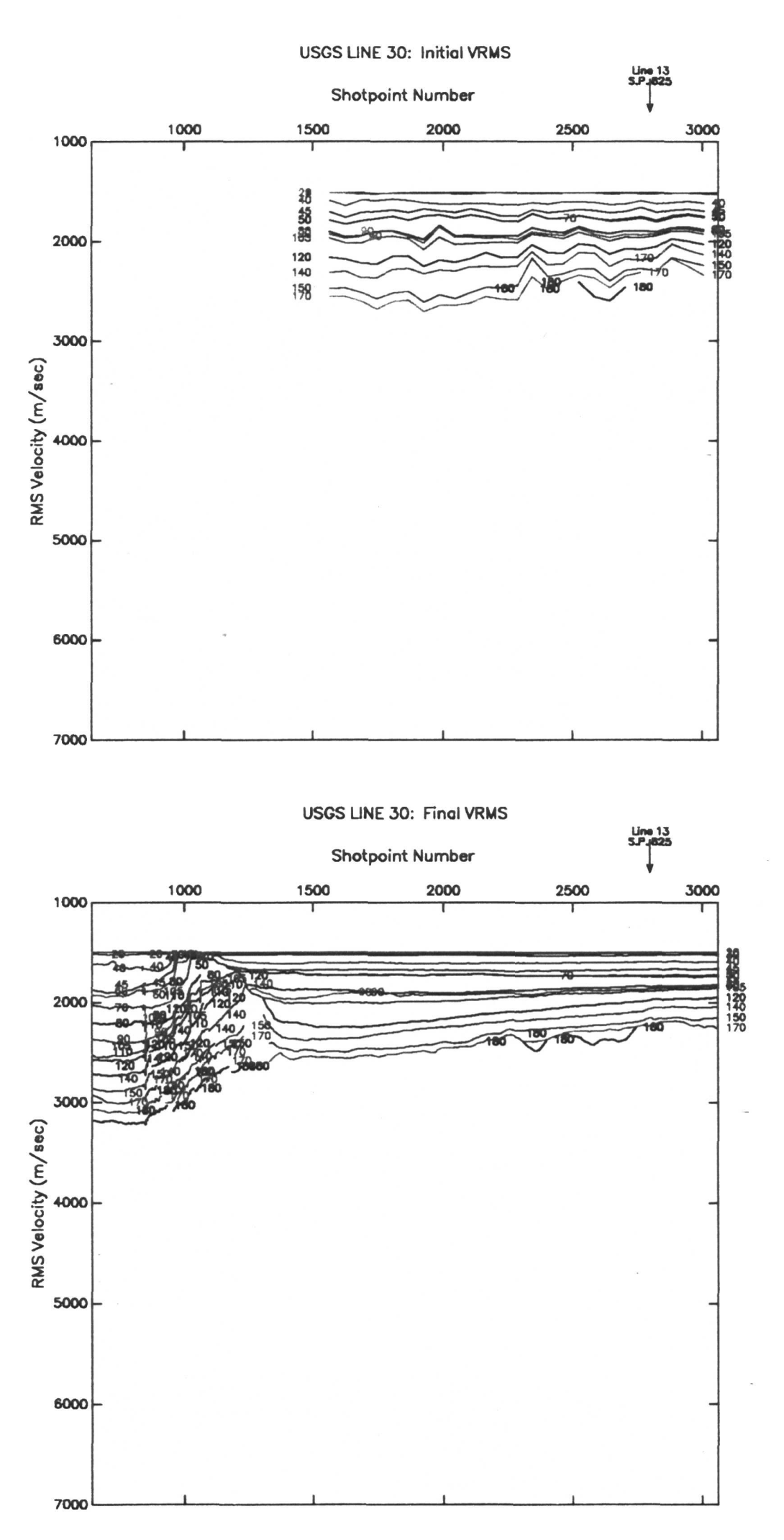

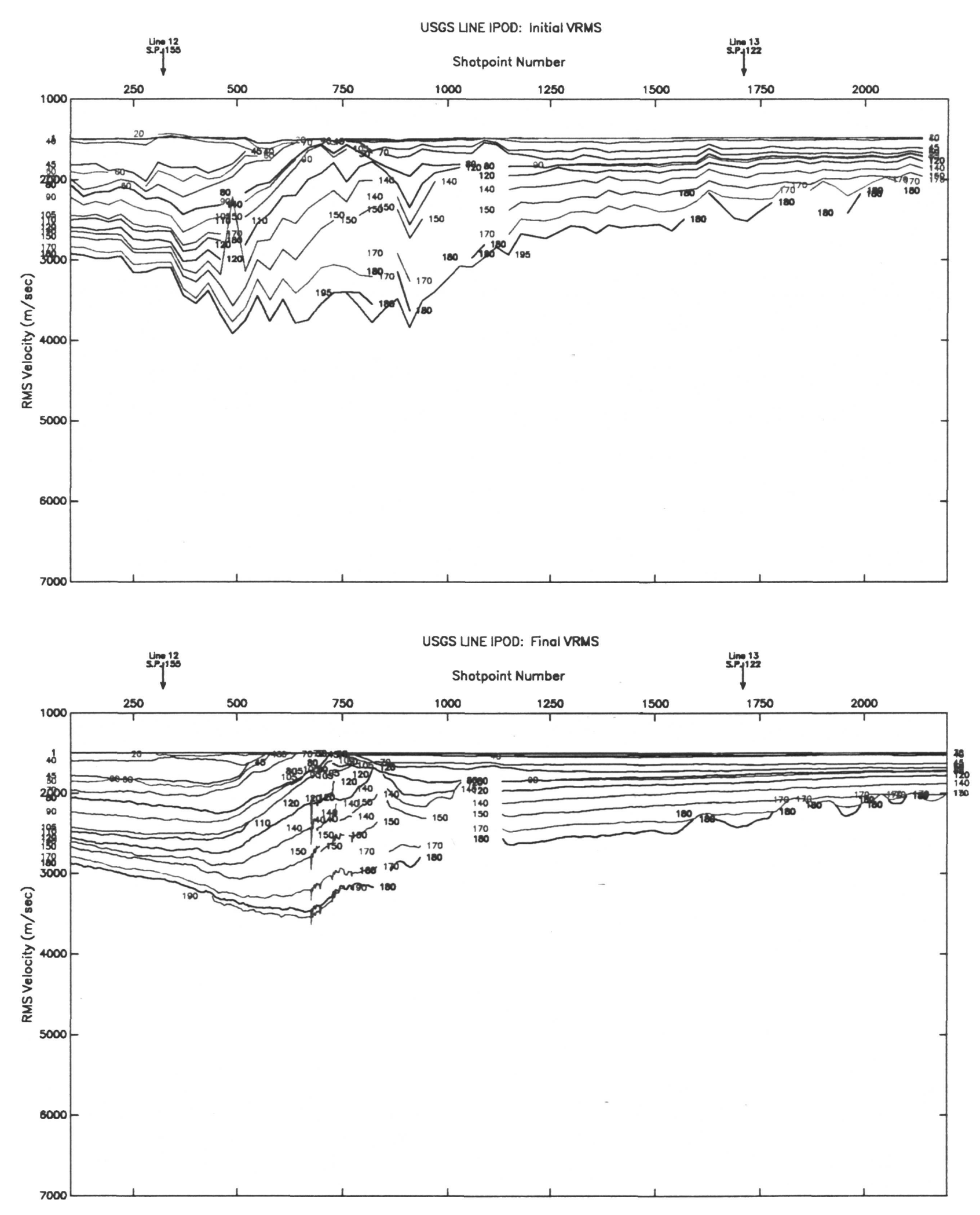


$$
F
$$



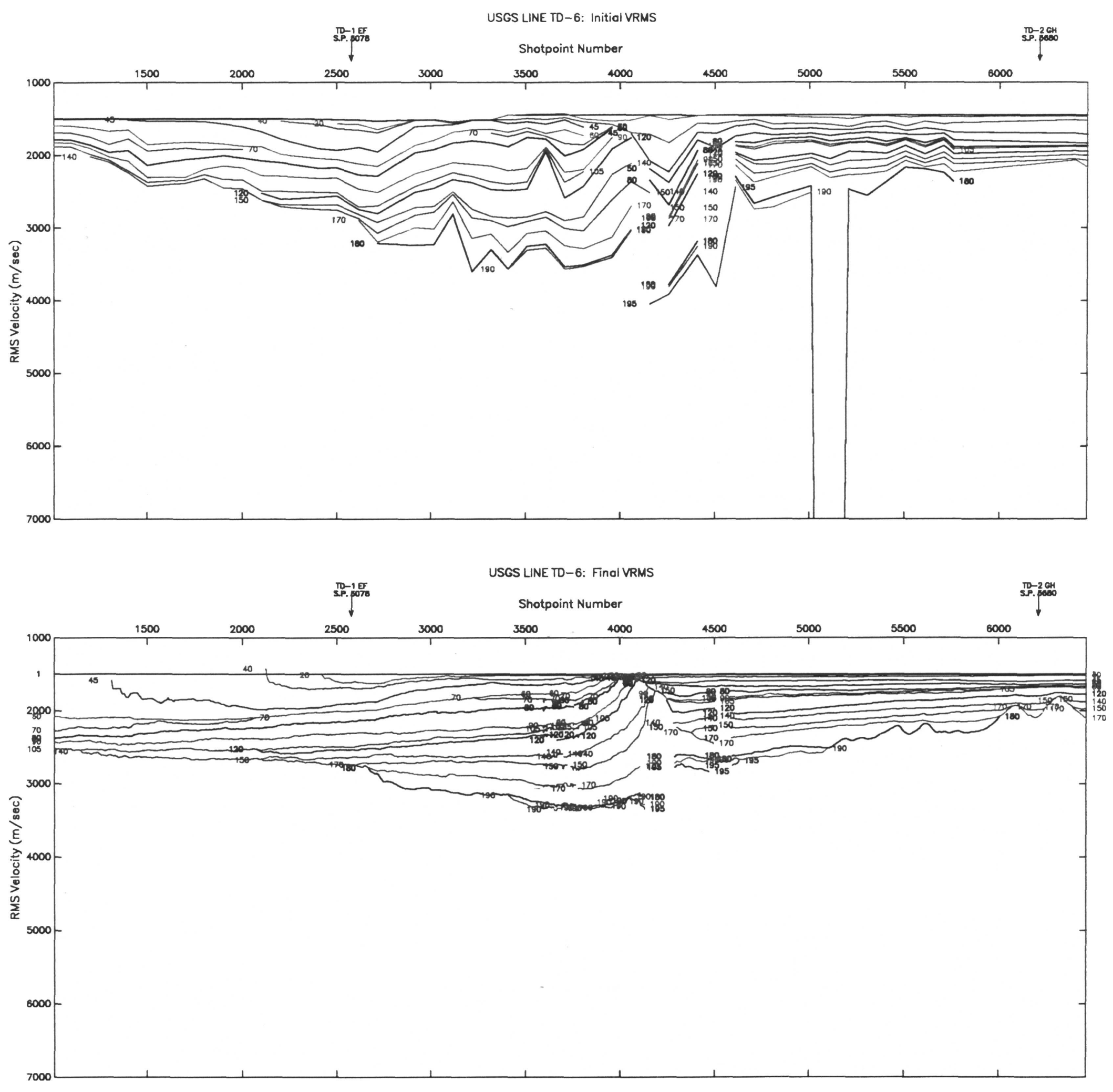

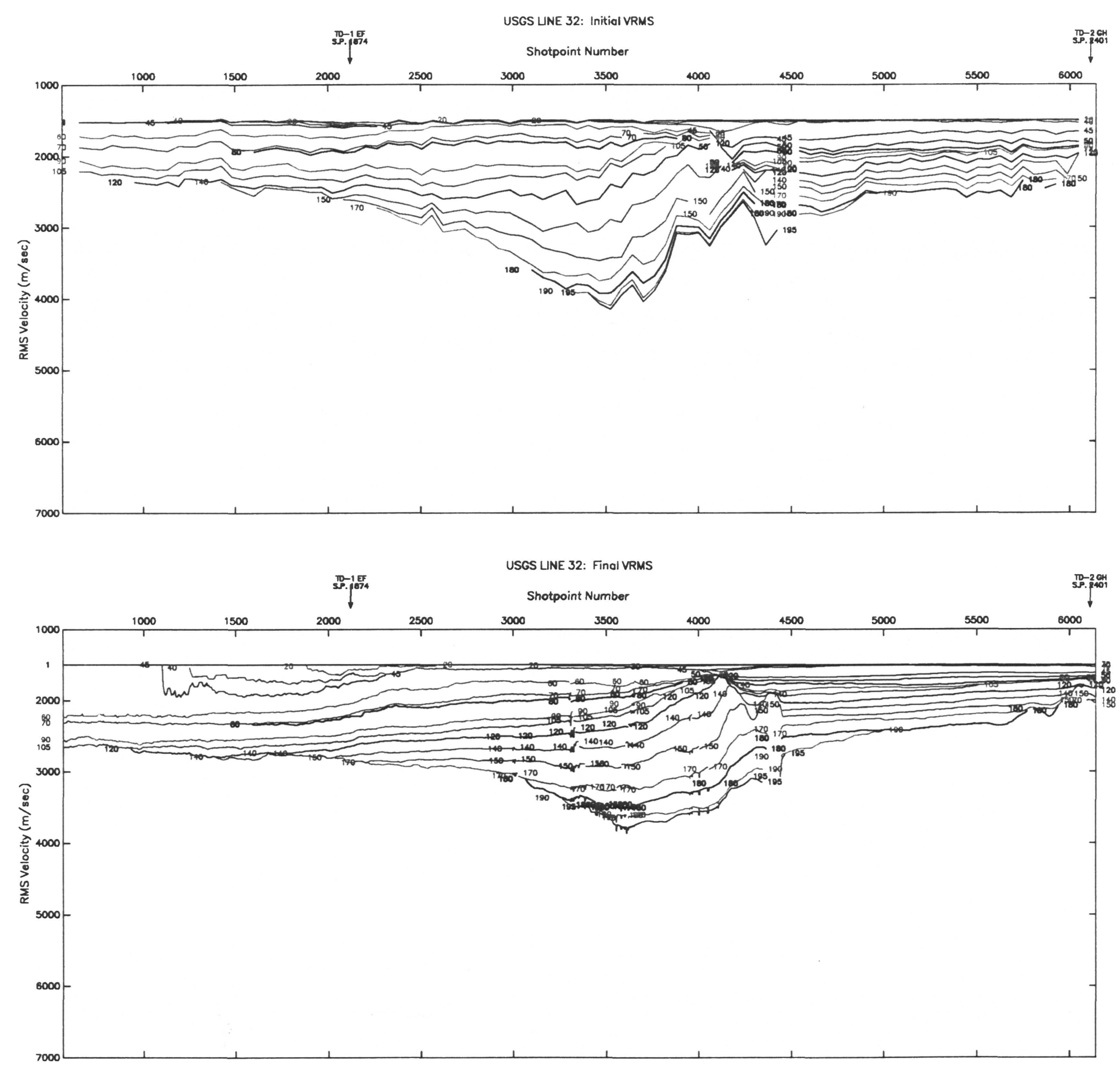

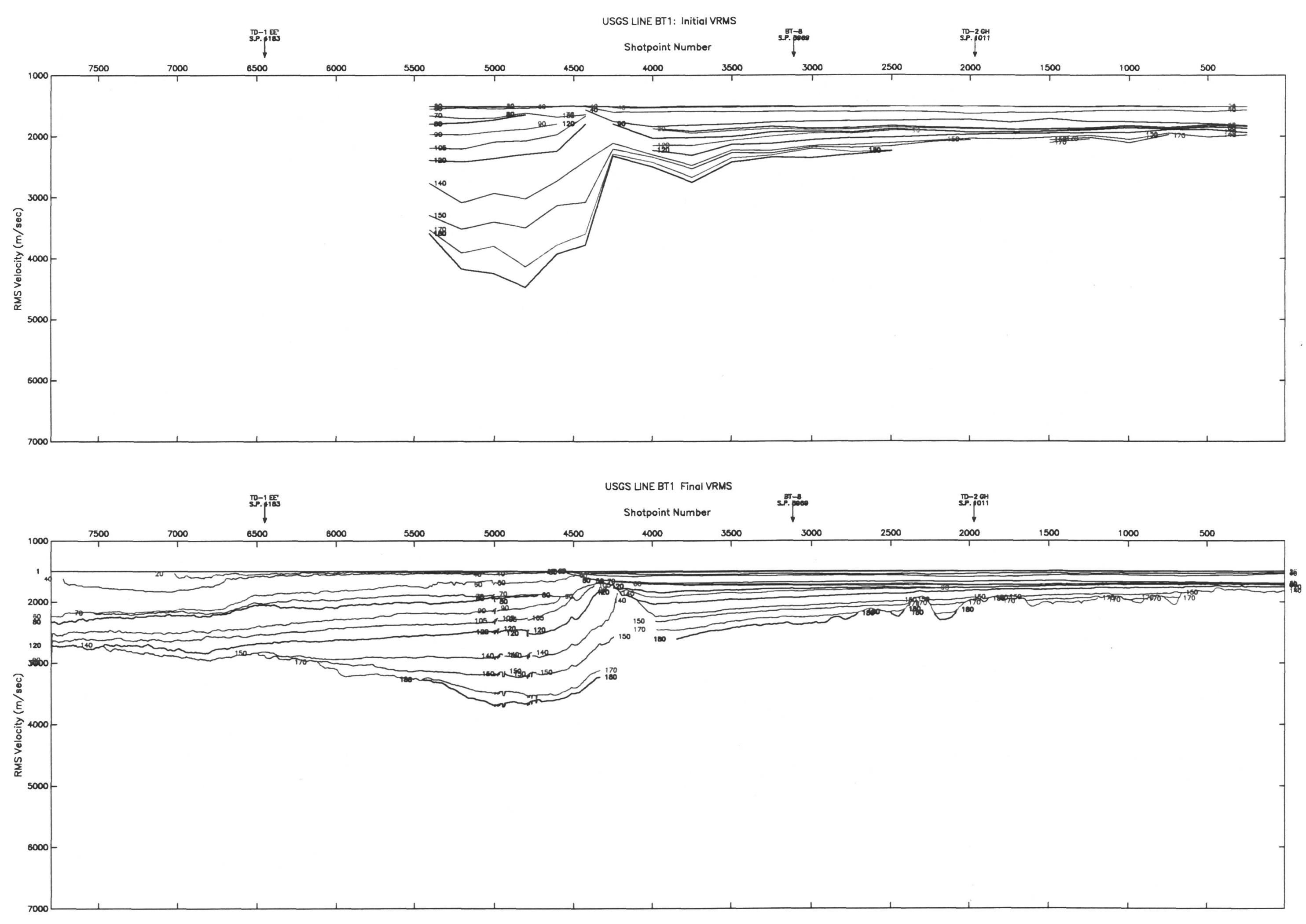

114 

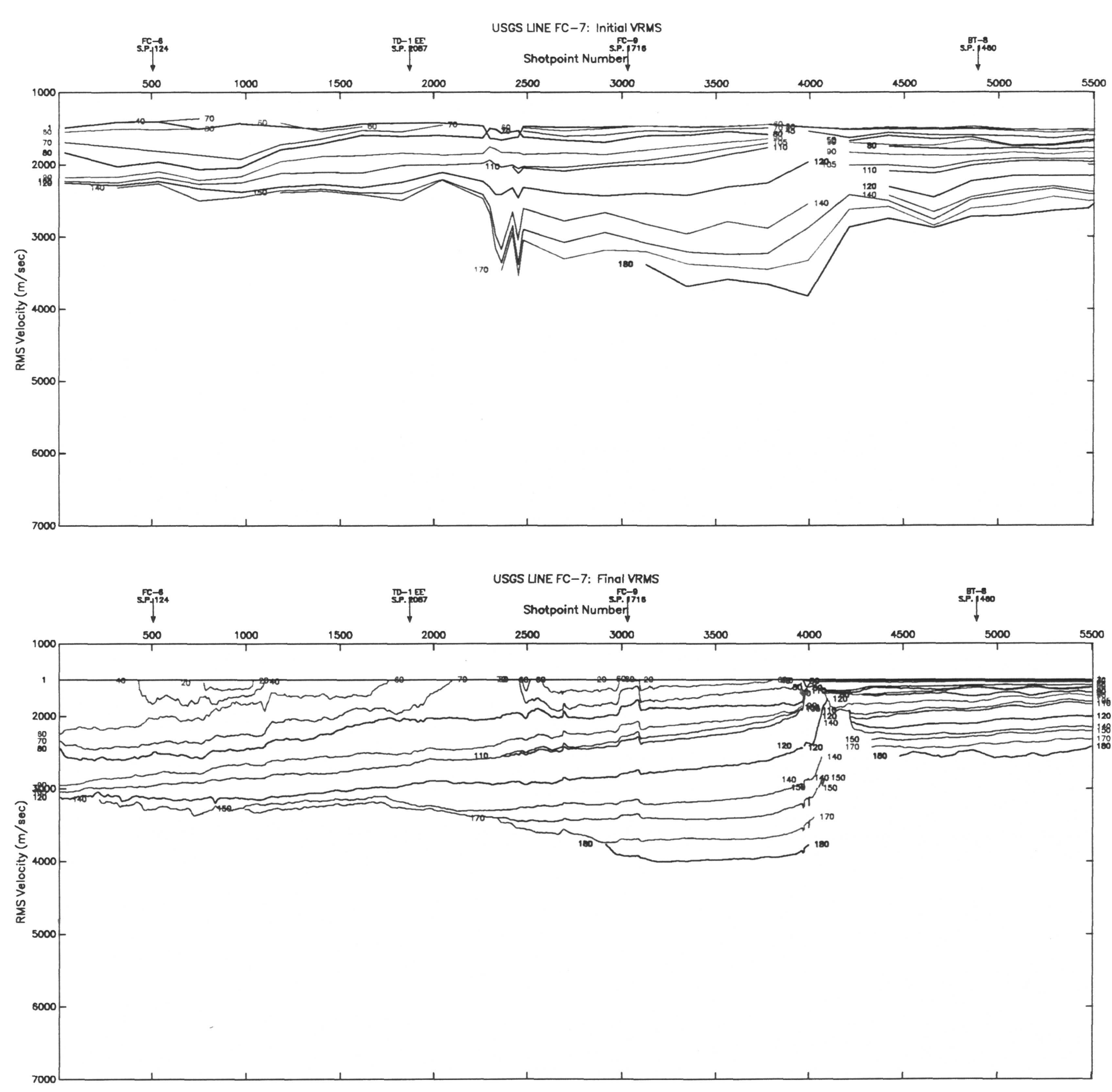

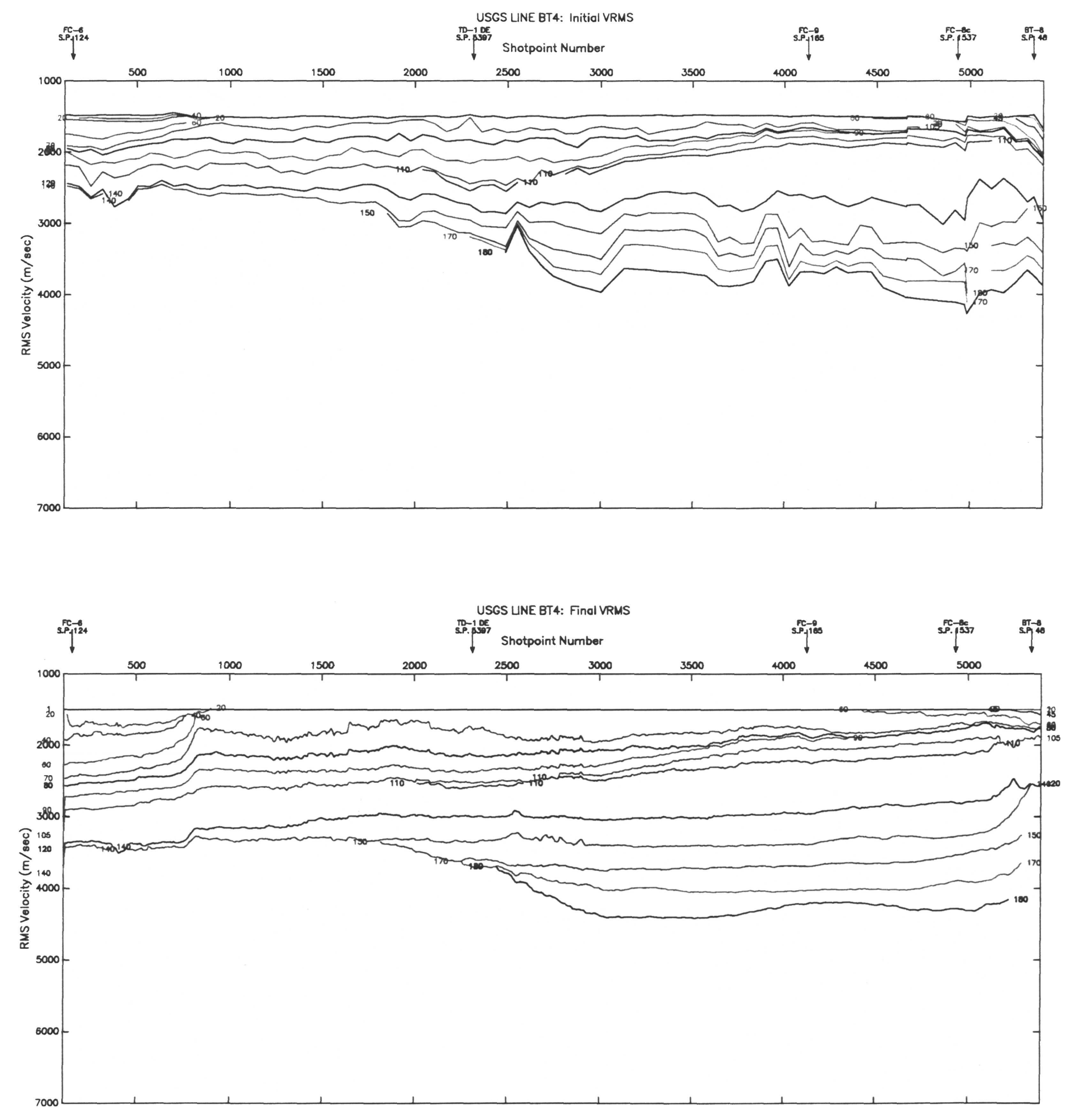

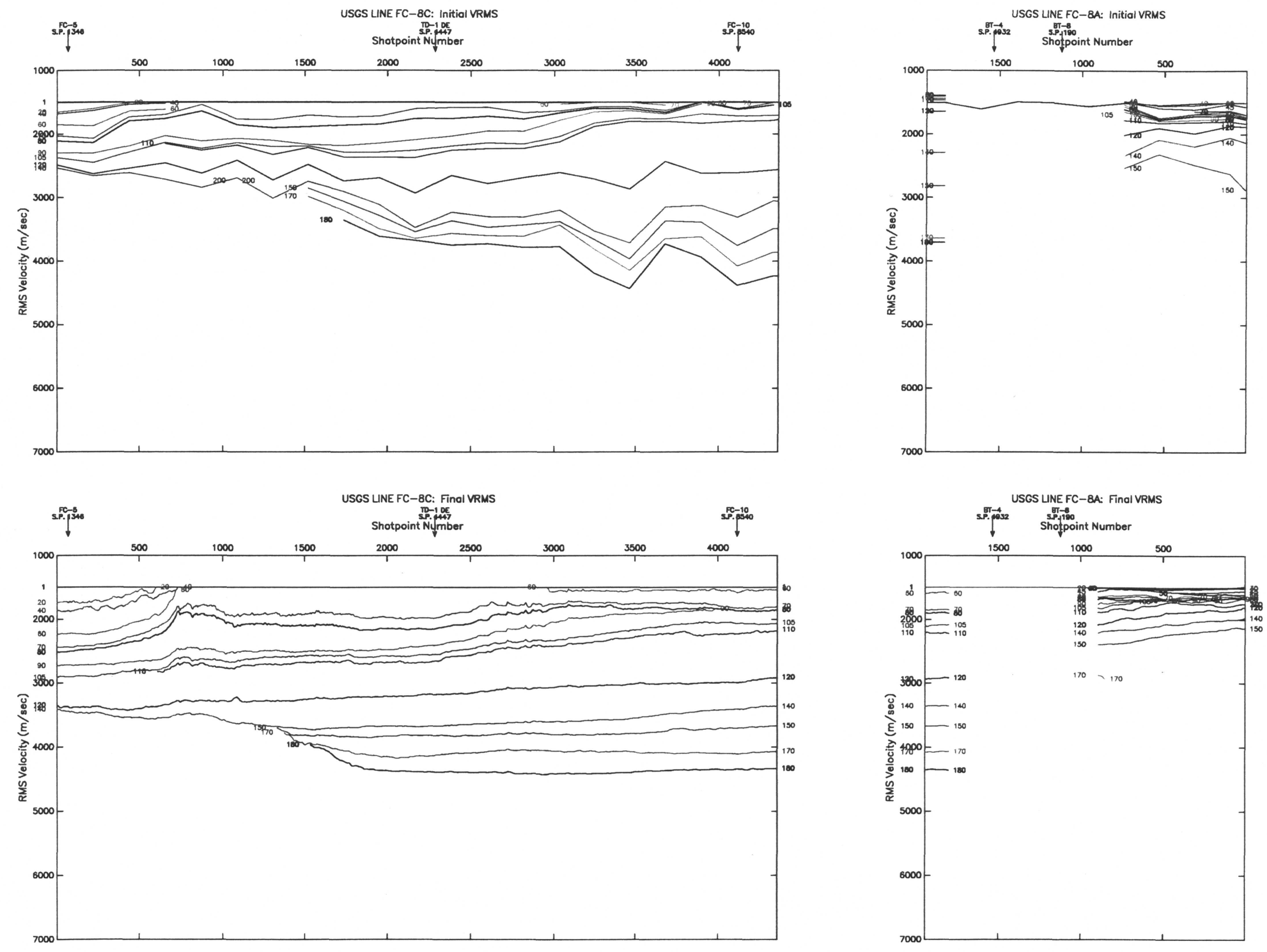

117 

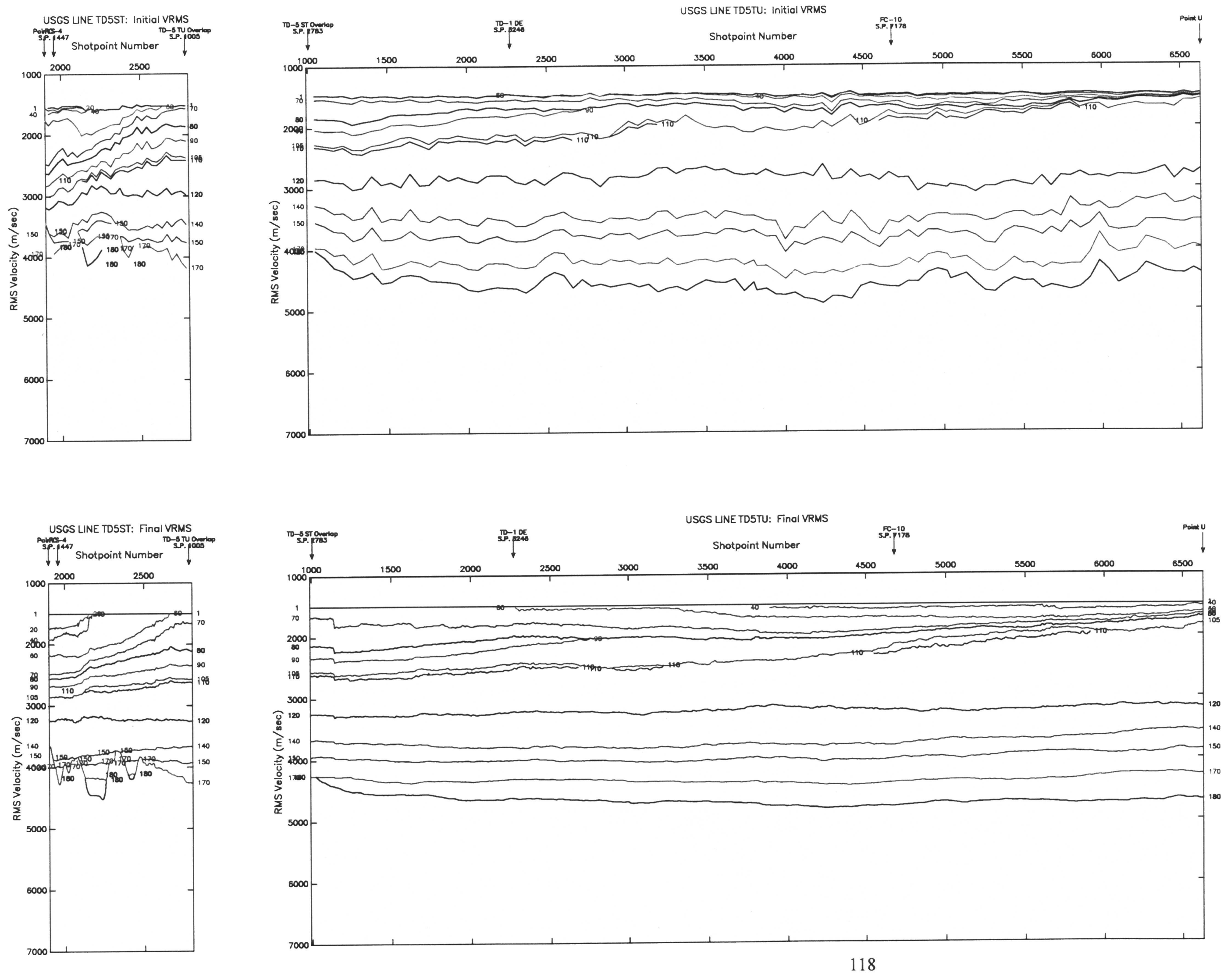

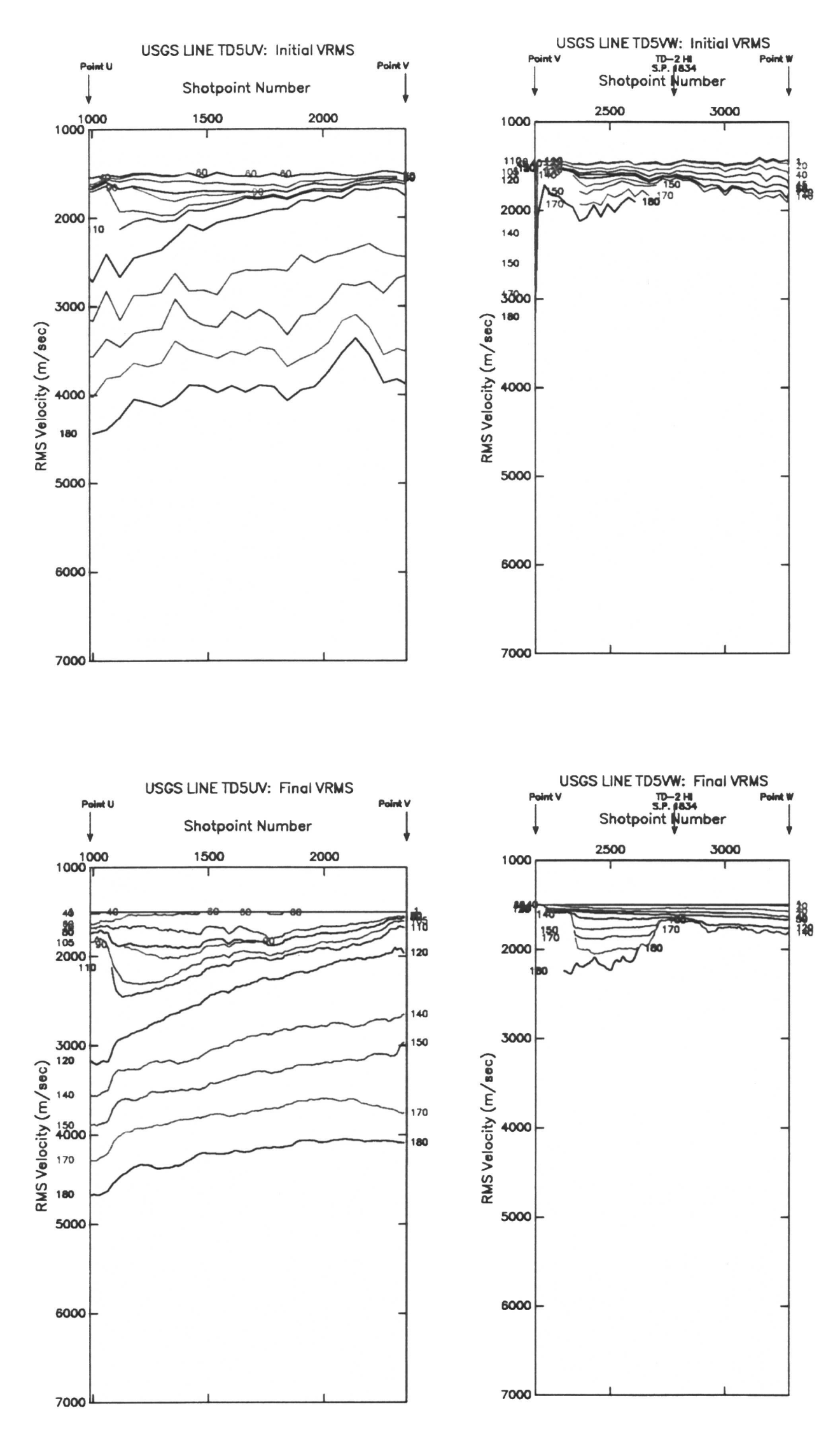

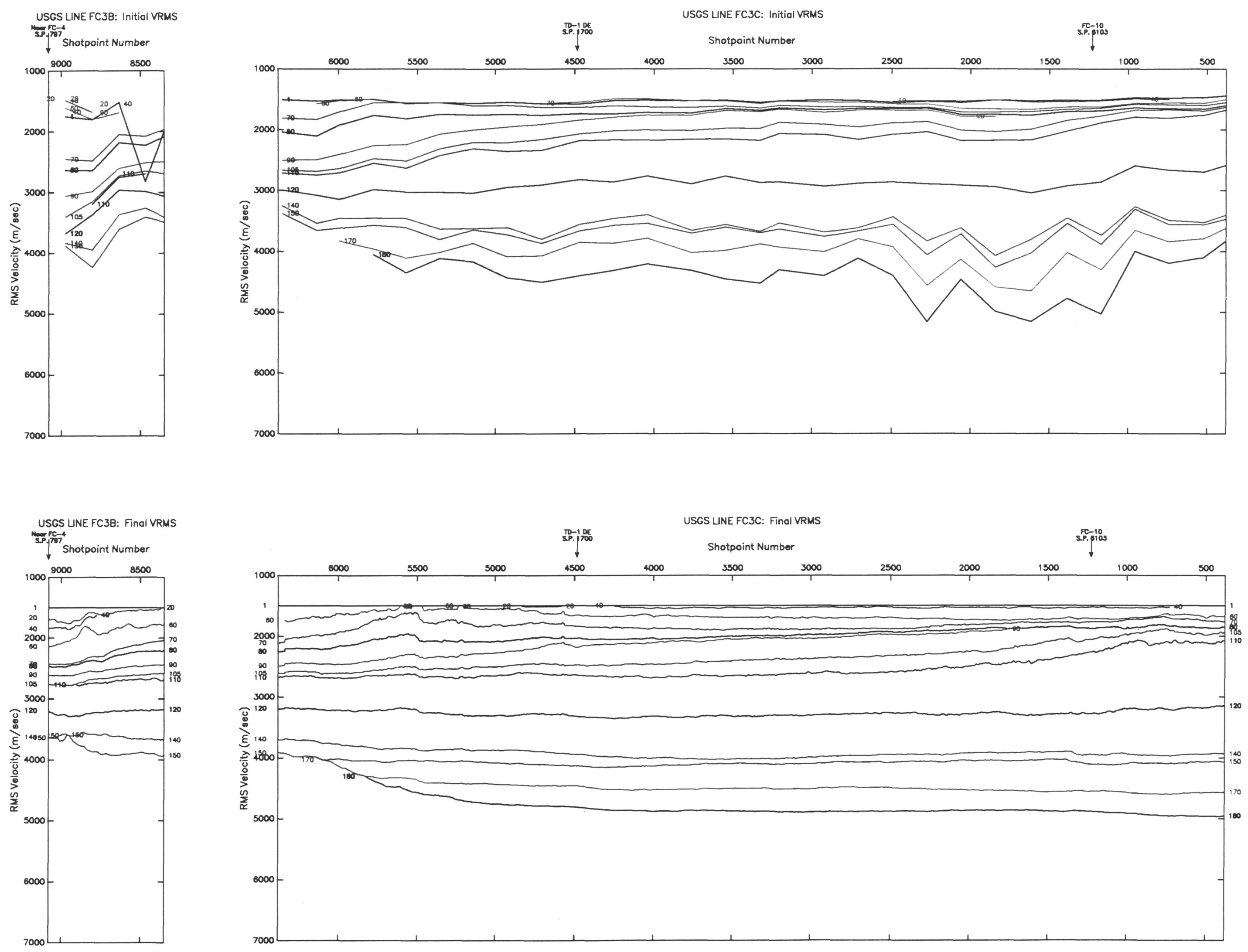
USGS LINE FC3A2: Initiol VRMS Shotpoint Number

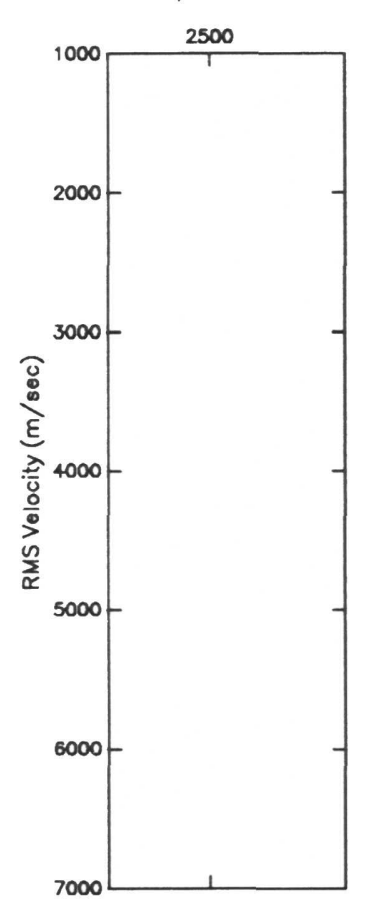

USGS LNE FC 3A2: Final VRMS Shotpoint Number

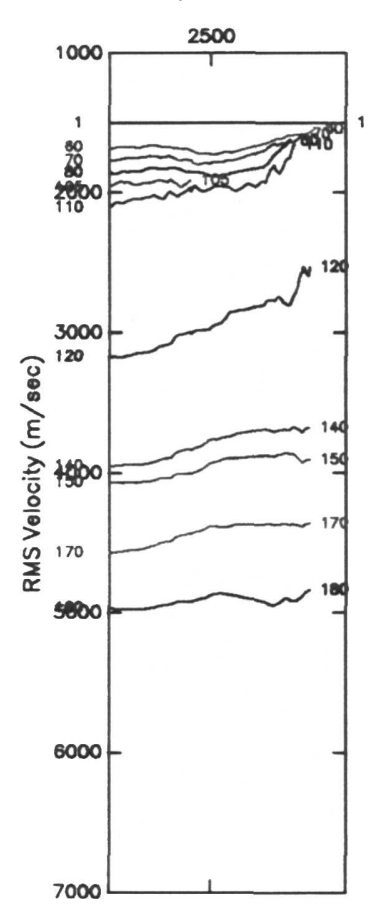

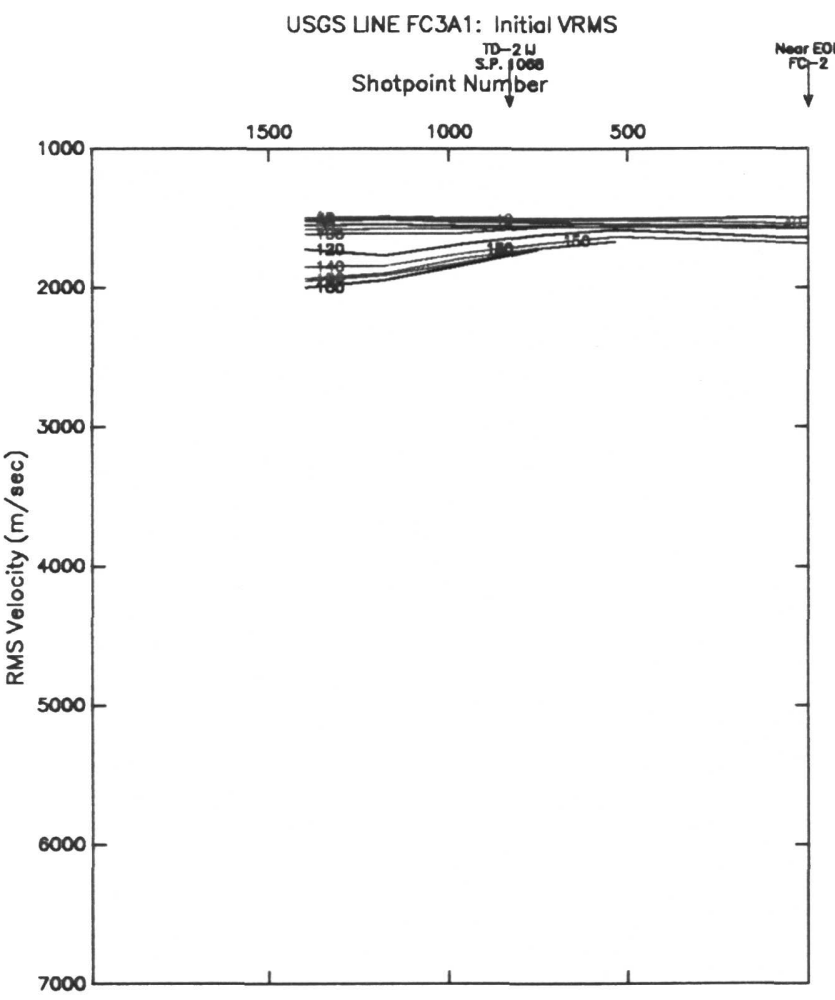

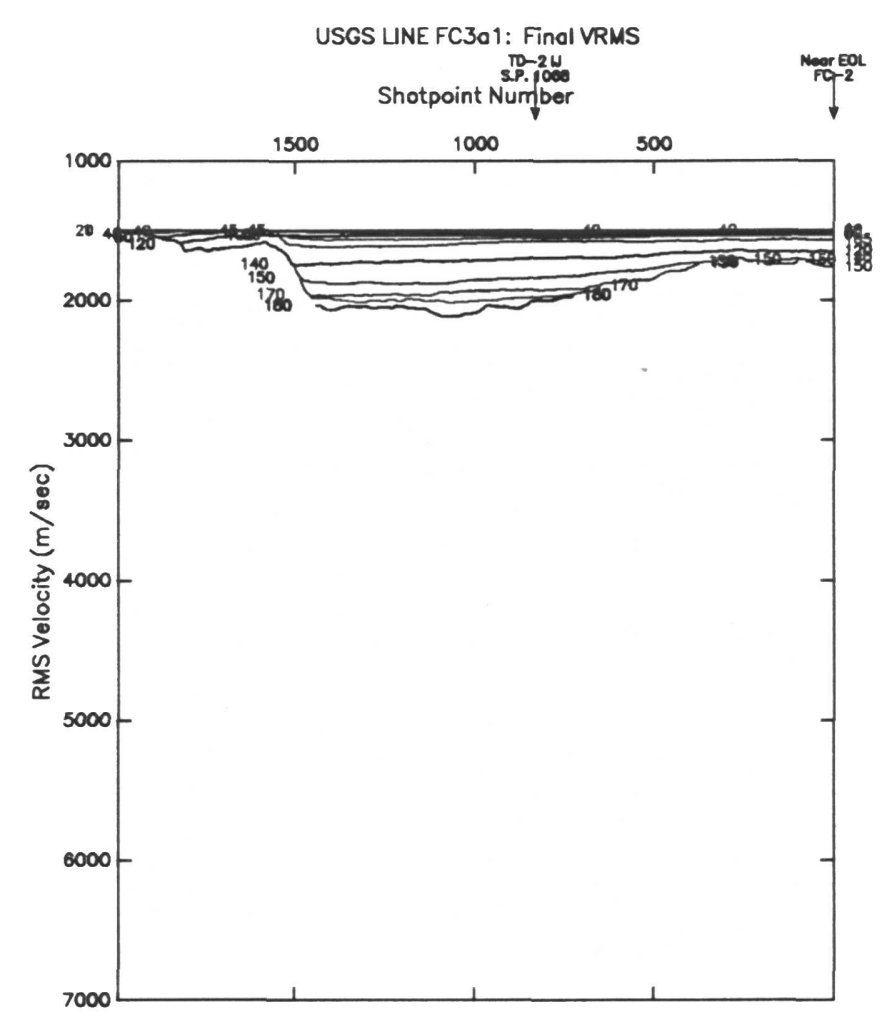

121 

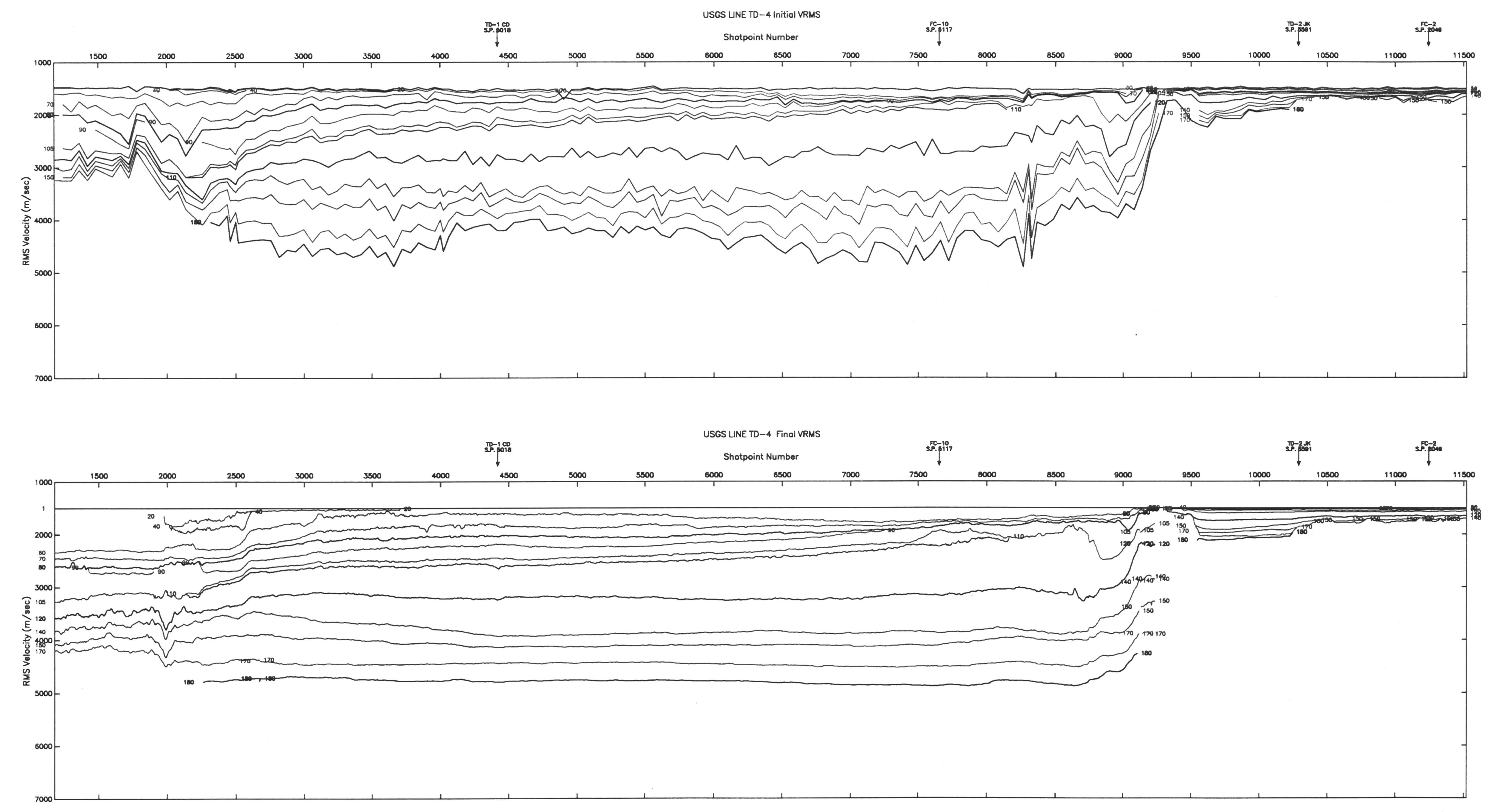

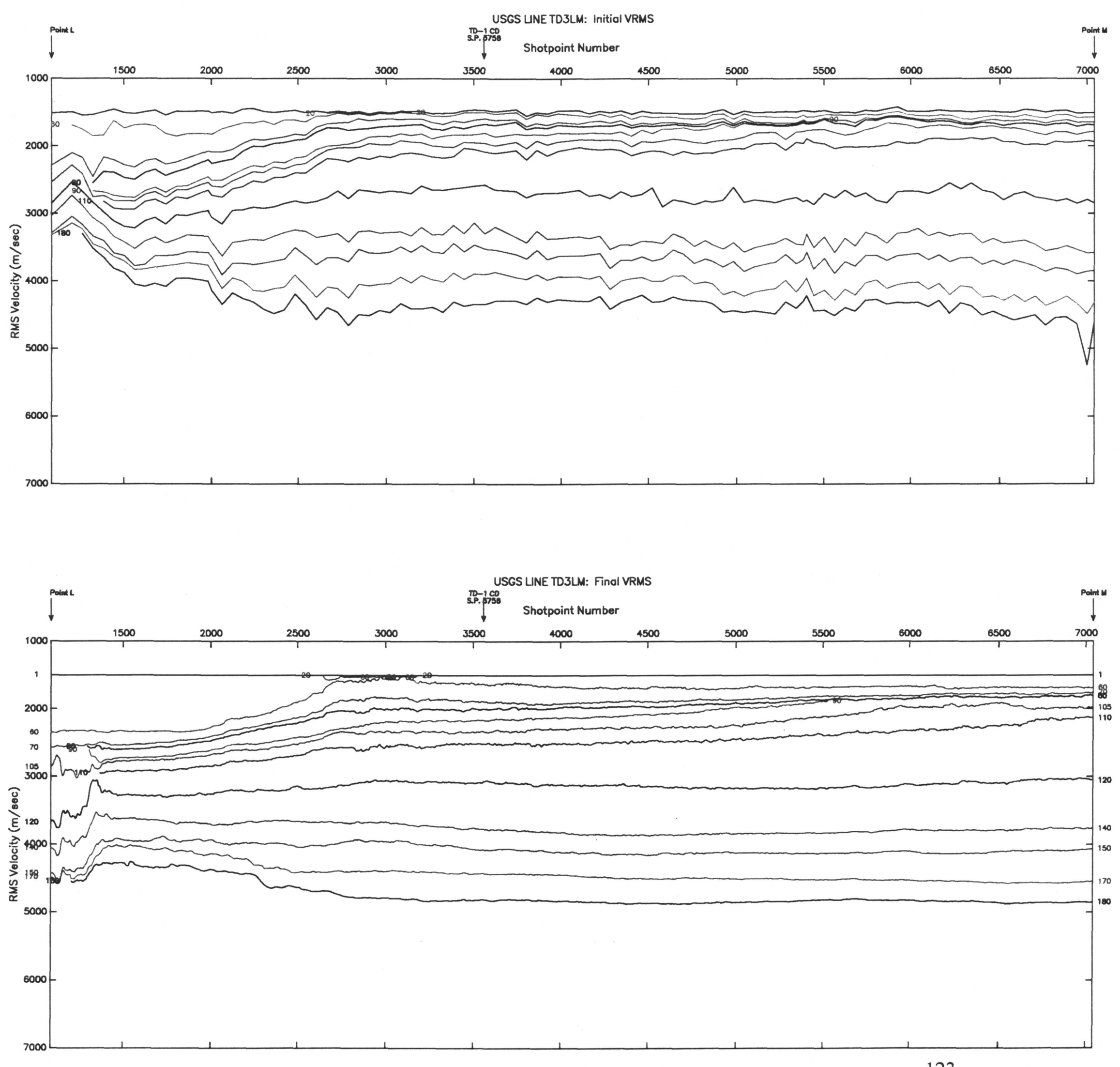


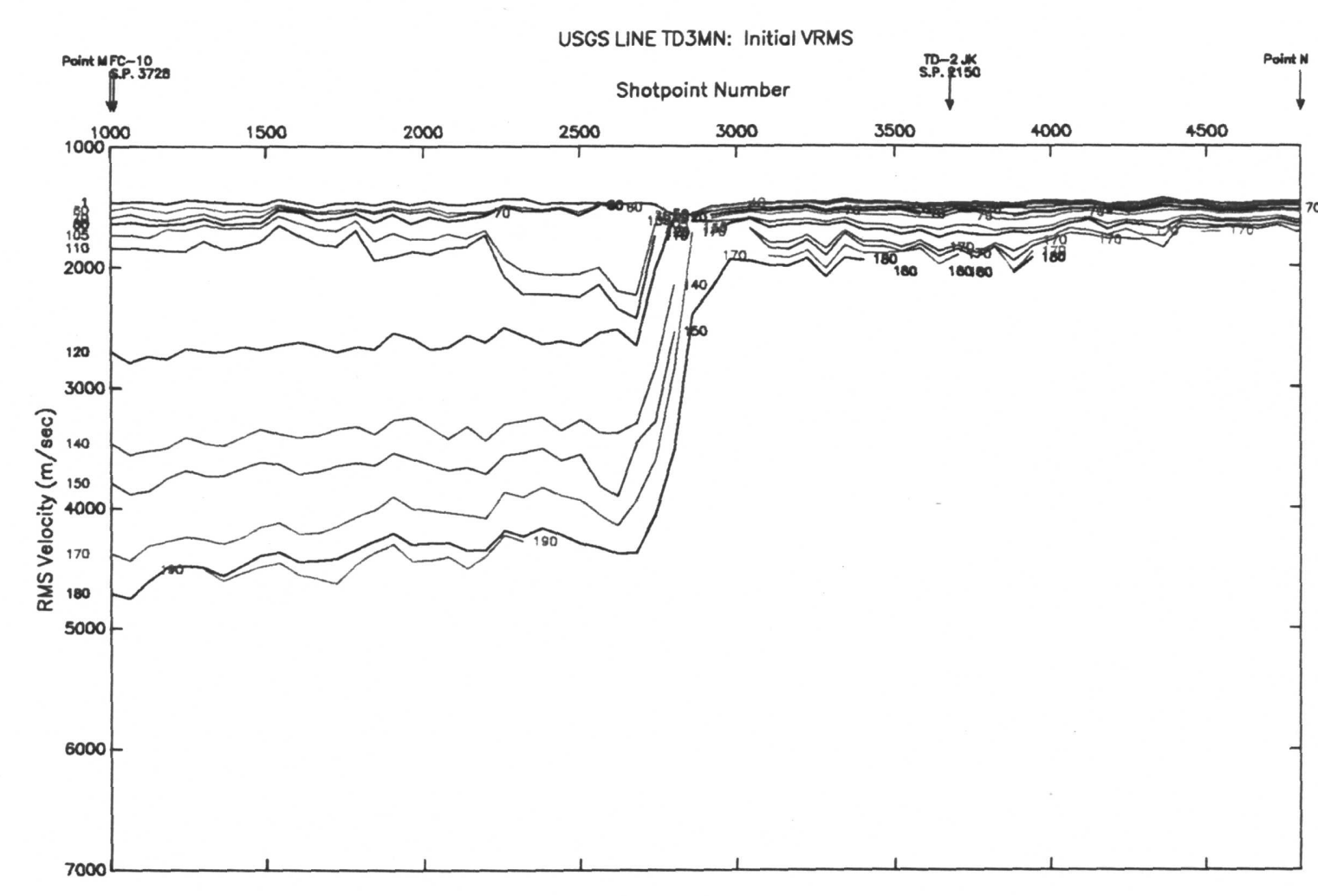

USGS LNE TOSNO: Initiol VRMS

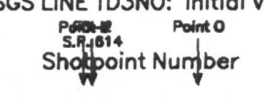
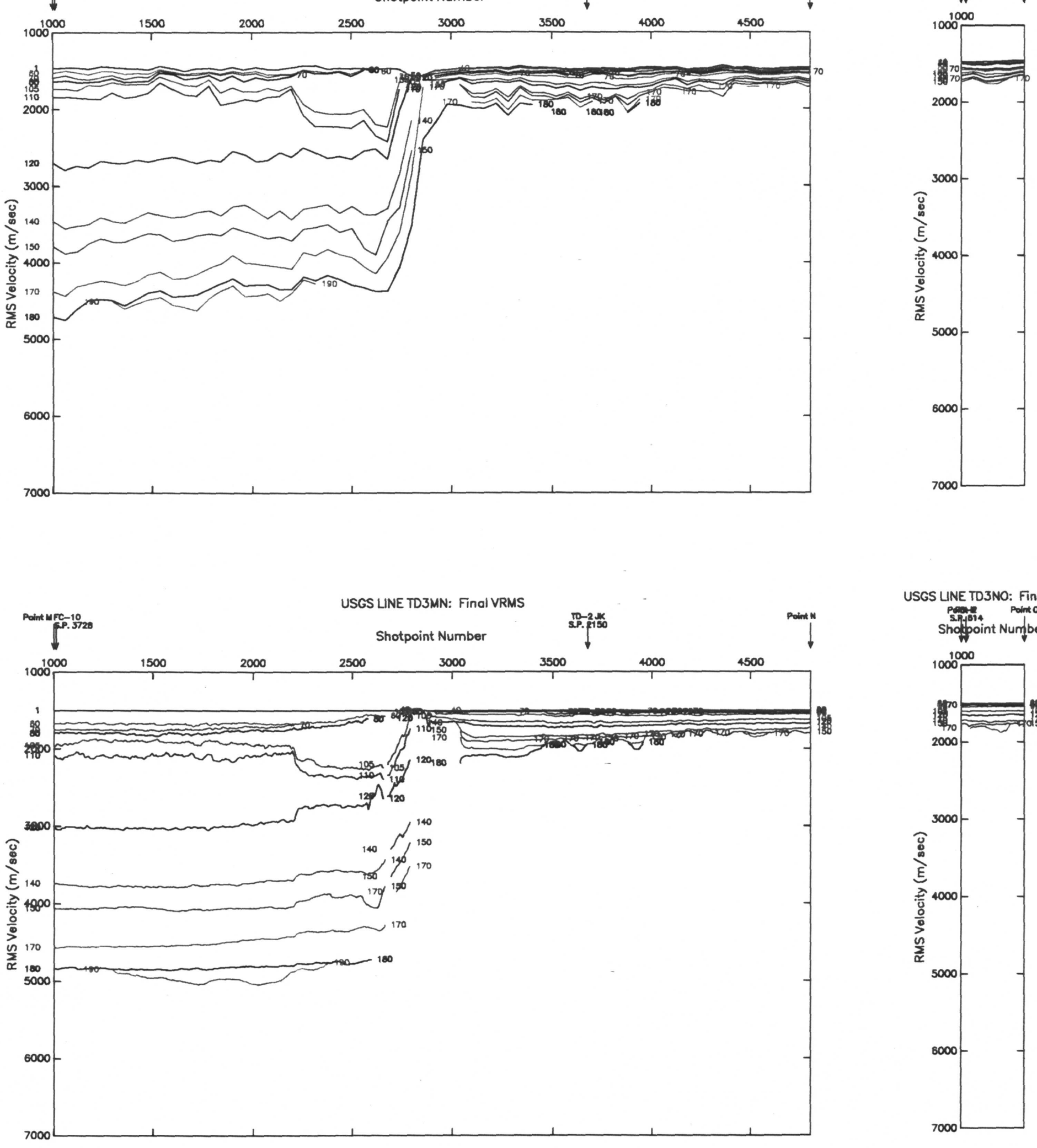

USGS LNE TOJNO: Final VRMS

Shofjoint Nunguer

100000

貿

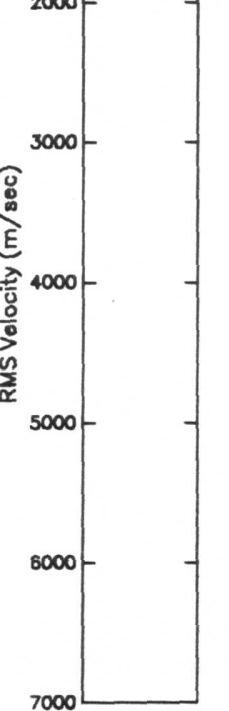




\section{APPENDIX 3}

Multichannel Seismic Profiles:

Initial and Final Interval Velocity Plots 


\section{APPENDIX 3}

Multichannel Seismic Profiles:

Initial and Final Interval Velocity Plots 


\section{EXPLANATORY NOTES}

This appendix gives initial (unsmoothed) and final (smoothed) interval velocity estimates for each horizon interpreted in the seismic stratigraphy. The horizontal and vertical scales for all plots are identical ( $25 \mathrm{~km} / \mathrm{inch}$ and $1000 \mathrm{~m} / \mathrm{s}$ per inch, respectively). The upper (unsmoothed) plots show the control points, i.e, where velocity scans exist (every

The lines are organized according to their position. All strike lines, progressing from shallow water to deep water, are shown first; then all dip lines, progressing from north to south are shown. Line locations are shown in Figure 1-1 (Appendix 1). Figure 1 of the main text and Plate 1 that accompanies this report. The following table gives the order of the lines:

\begin{tabular}{|c|c|c|}
\hline Page No. & Number of Sheets & USGS Line Number \\
\hline 128 & 1 & FC-4 FC-5 FC-6 \\
\hline $129,130,131$ & 3 & TD-1 Line 12 \\
\hline 132 & 1 & FC-10 \\
\hline 133 & 1 & FC-9 \\
\hline 134 & 1 & BT-8 \\
\hline 135,136 & 2 & TD-2 \\
\hline 137 & 1 & Line 13 \\
\hline 138 & 1 & $\mathrm{FC}-2$ \\
\hline 139 & 1 & Line 30 \\
\hline 140 & 1 & Line IPOD \\
\hline 141 & 1 & Line 31 \\
\hline 142 & 1 & Line TD-6 \\
\hline 143 & 1 & Line 32 \\
\hline 144 & 1 & Line BT-1 \\
\hline 145 & 1 & Line FC-7 \\
\hline 146 & 1 & Line BT-4 \\
\hline 147 & 1 & Line FC-8 \\
\hline 148,149 & 2 & Line TD-5 \\
\hline 150,151 & 2 & Line $\mathrm{FC}-3$ \\
\hline 152 & 1 & Line TD-4 \\
\hline 153,154 & 2 & Line TD-3 \\
\hline 155 & 1 & Line $\mathrm{FC}-1$ \\
\hline
\end{tabular}



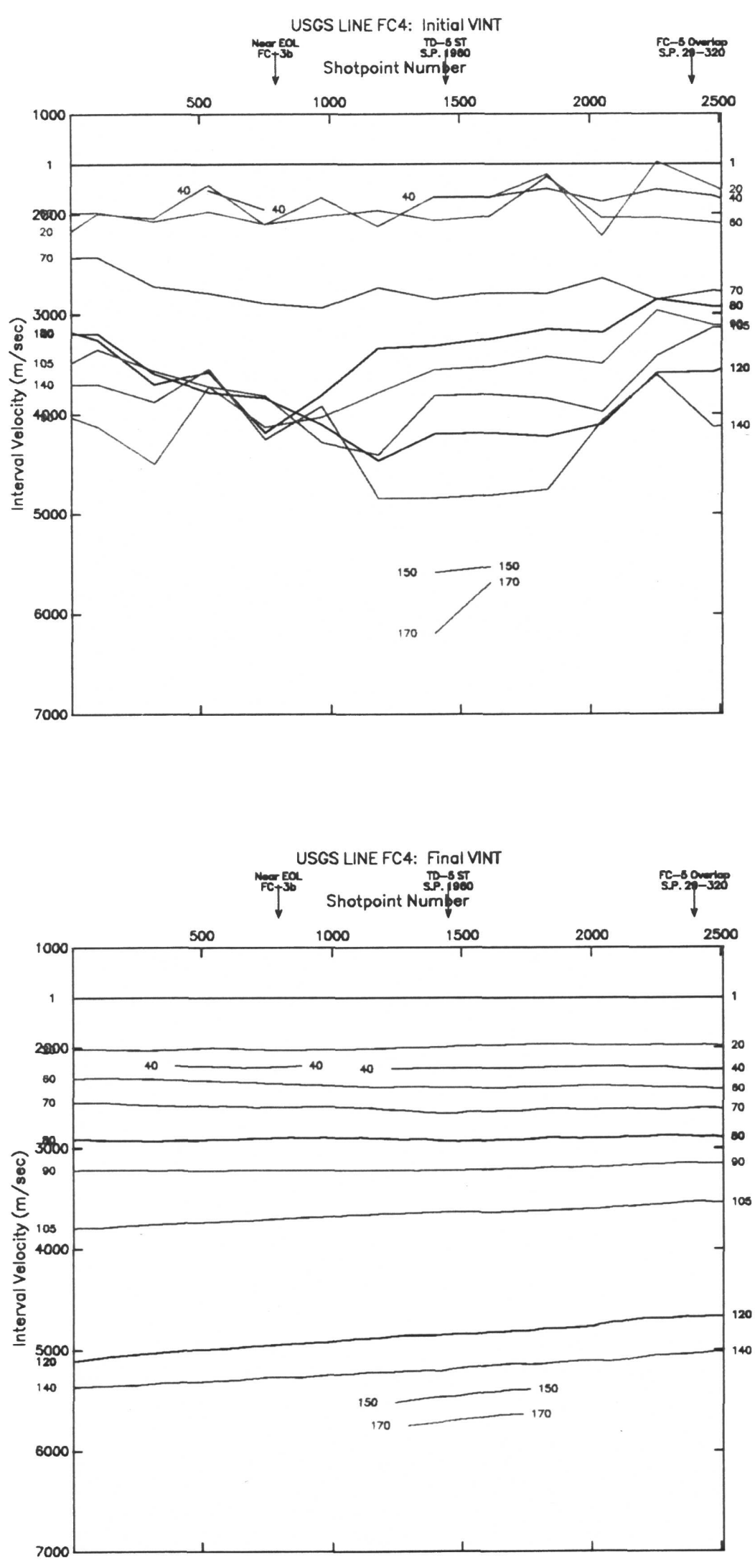
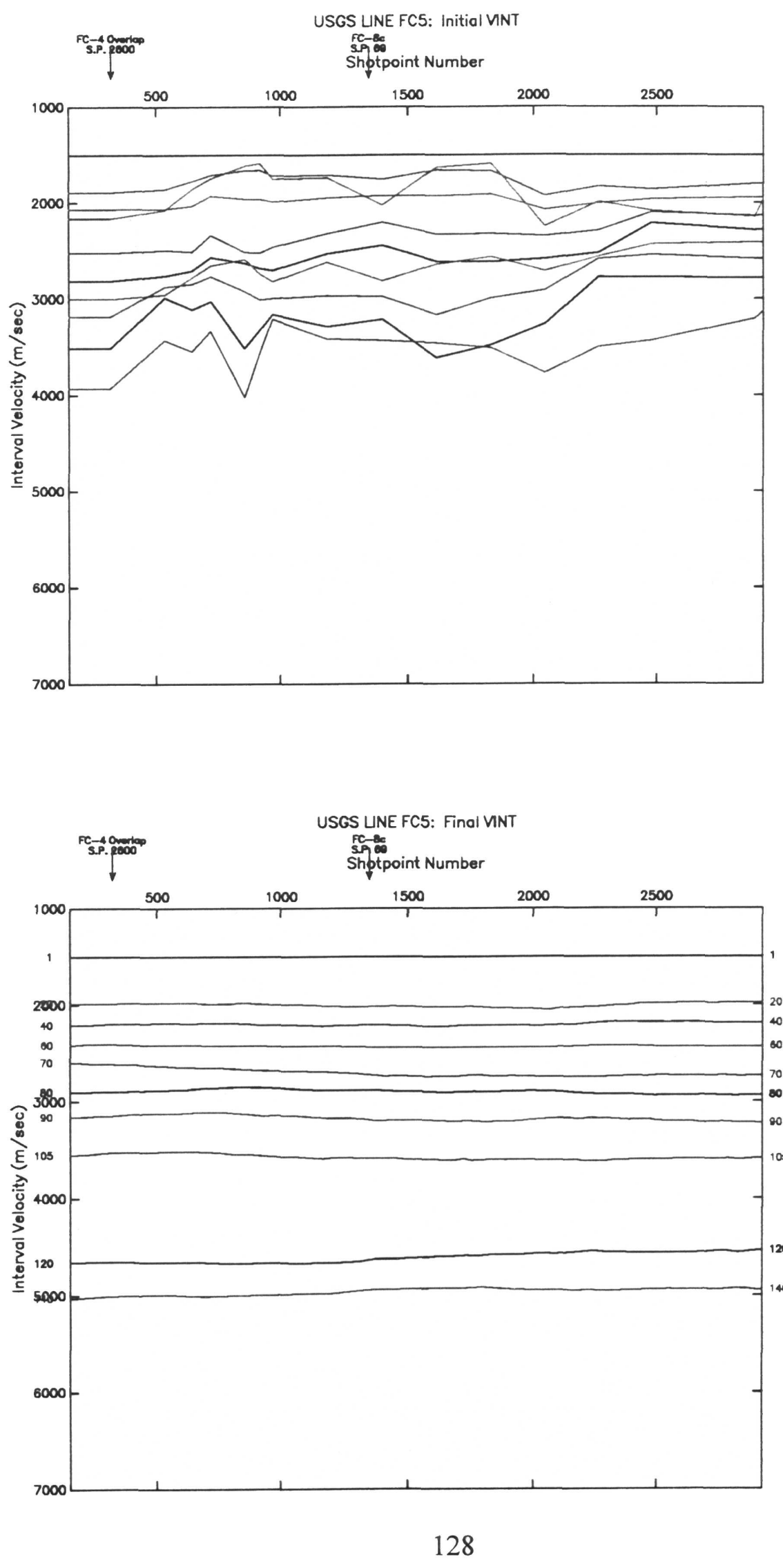
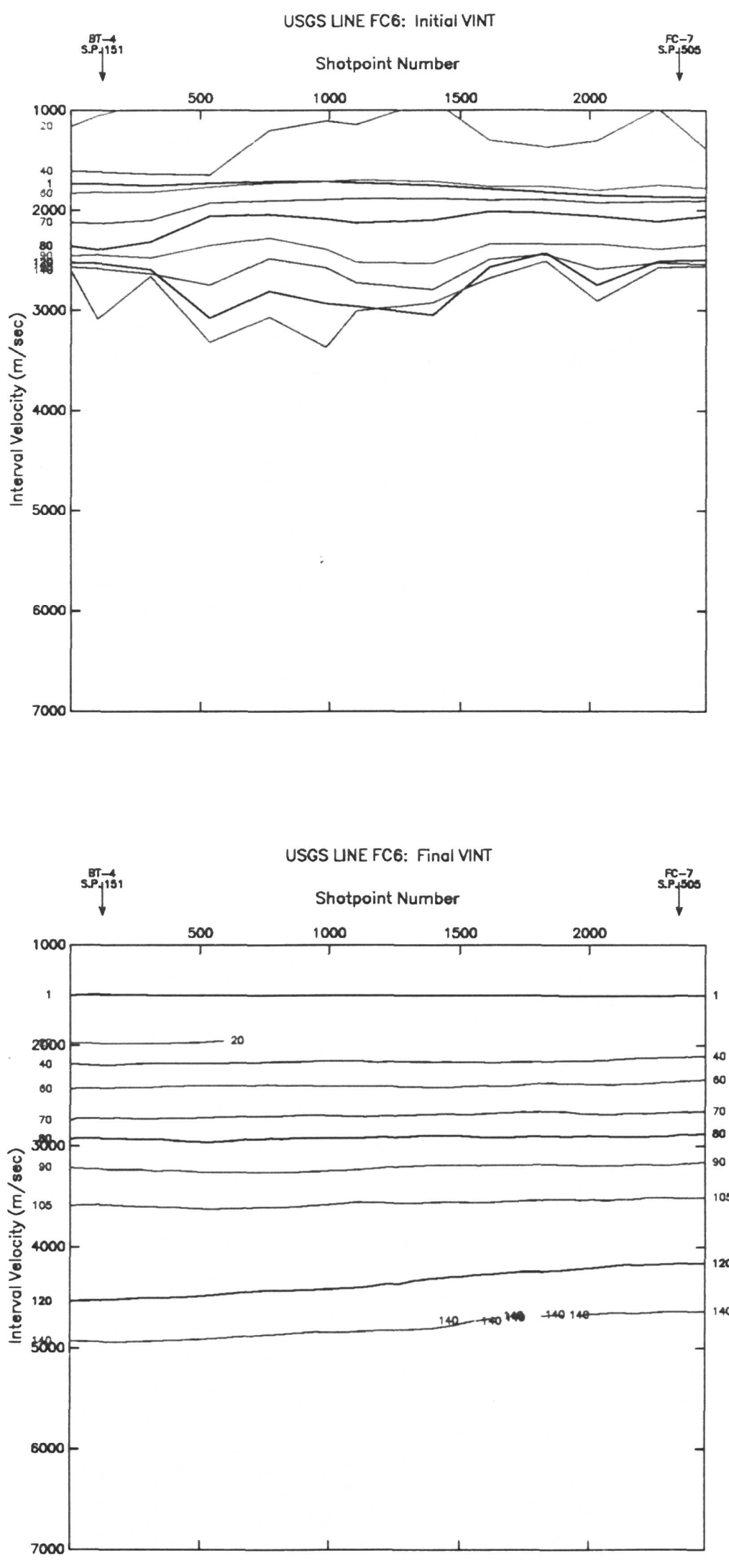

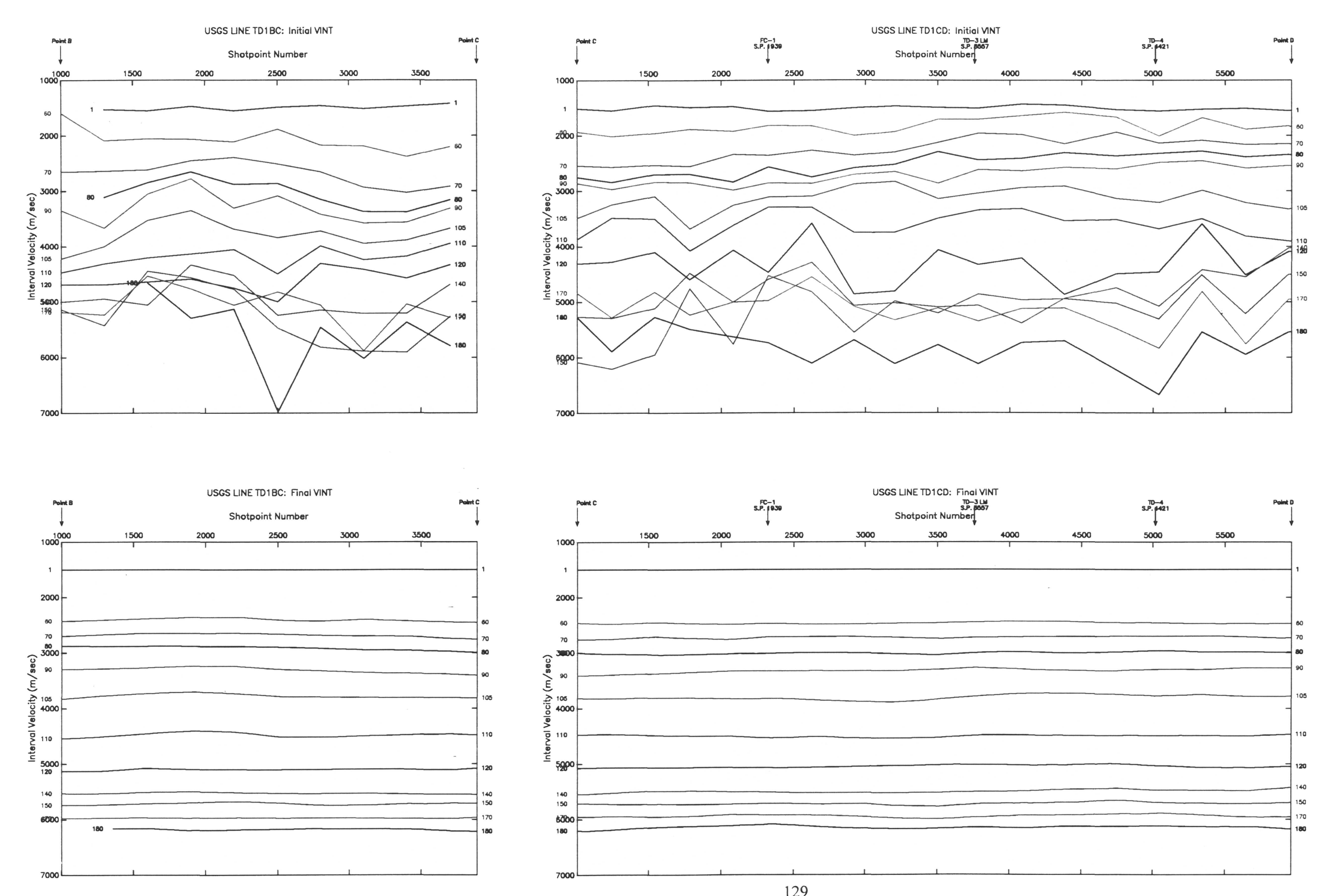

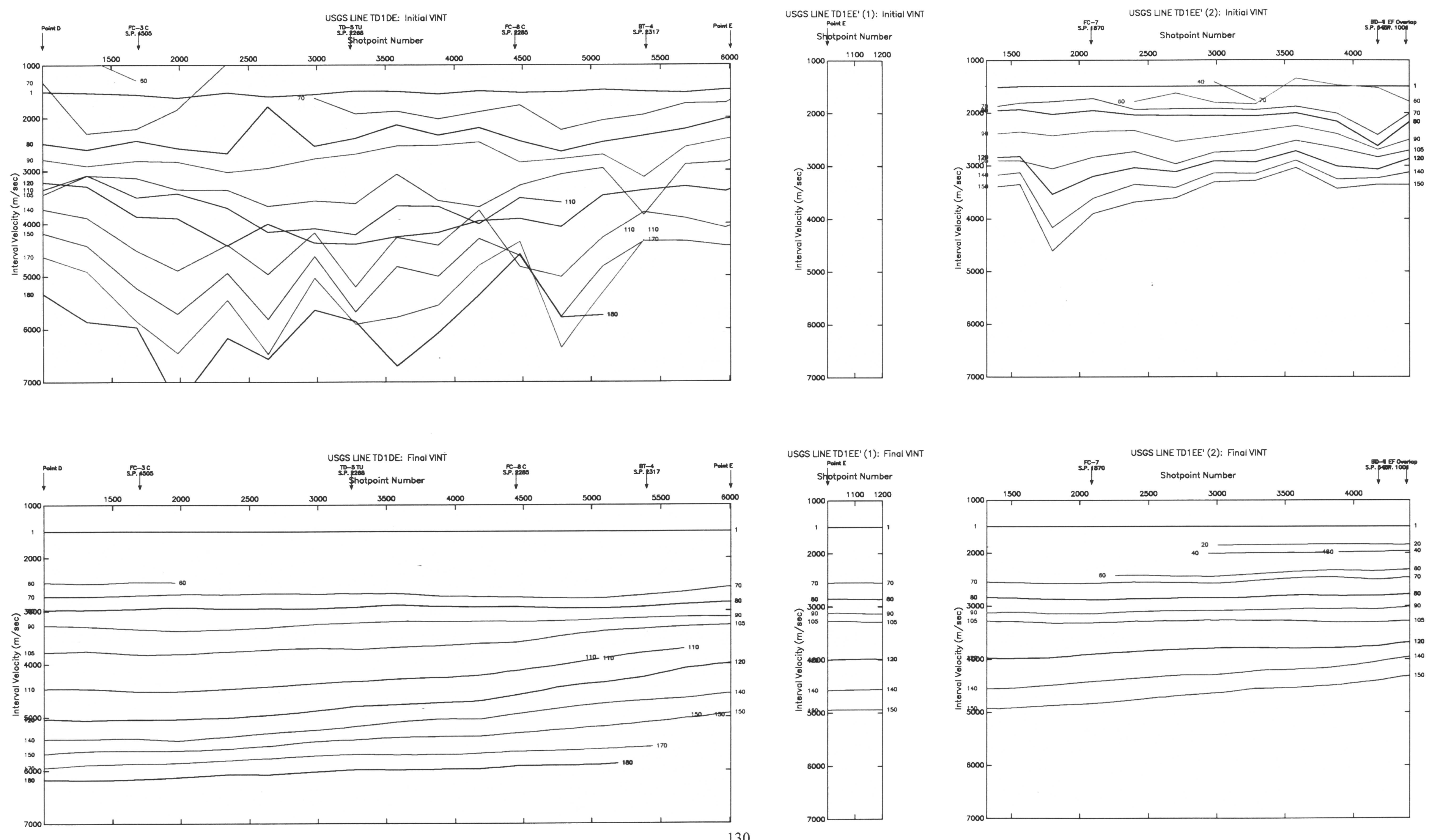

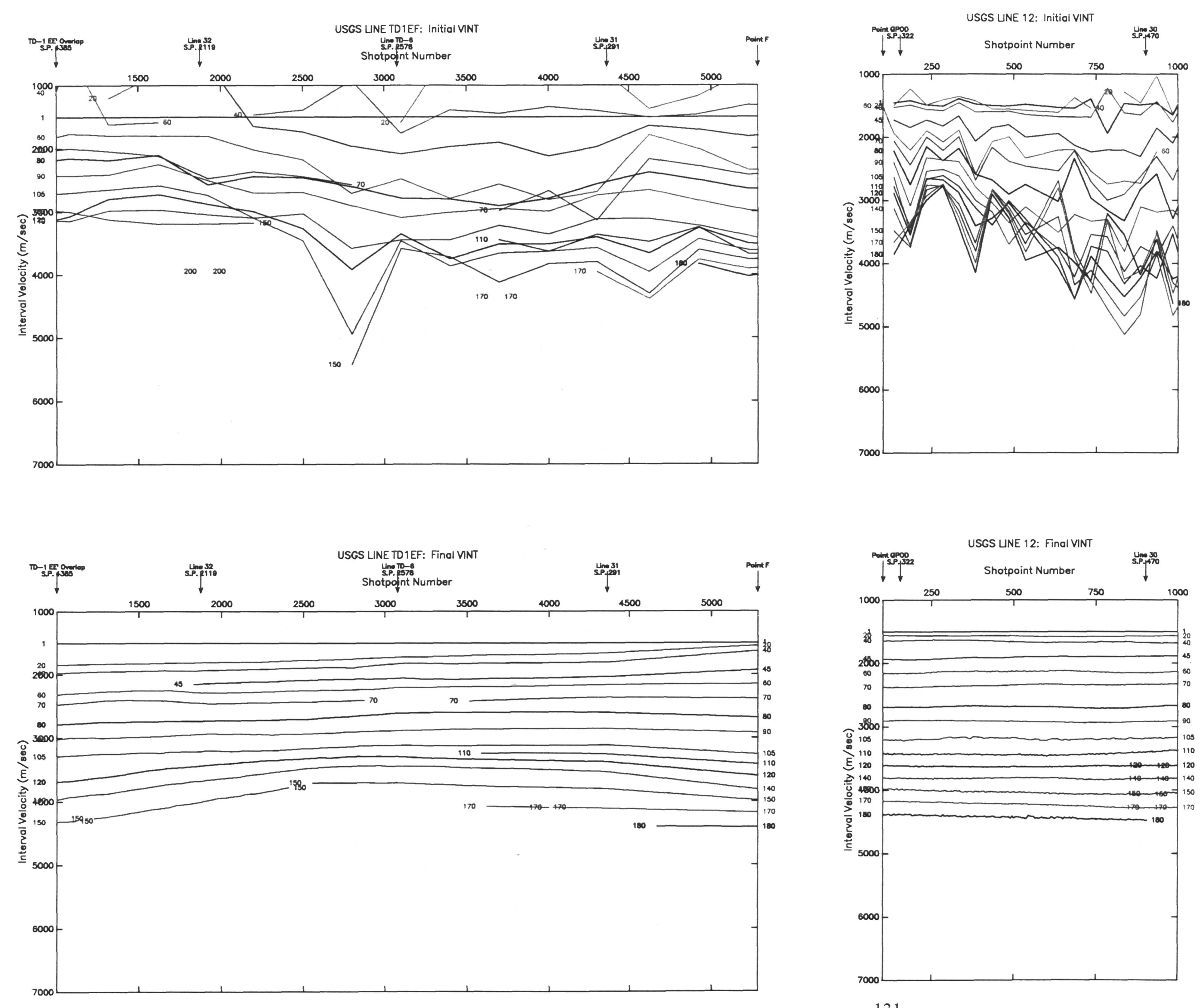

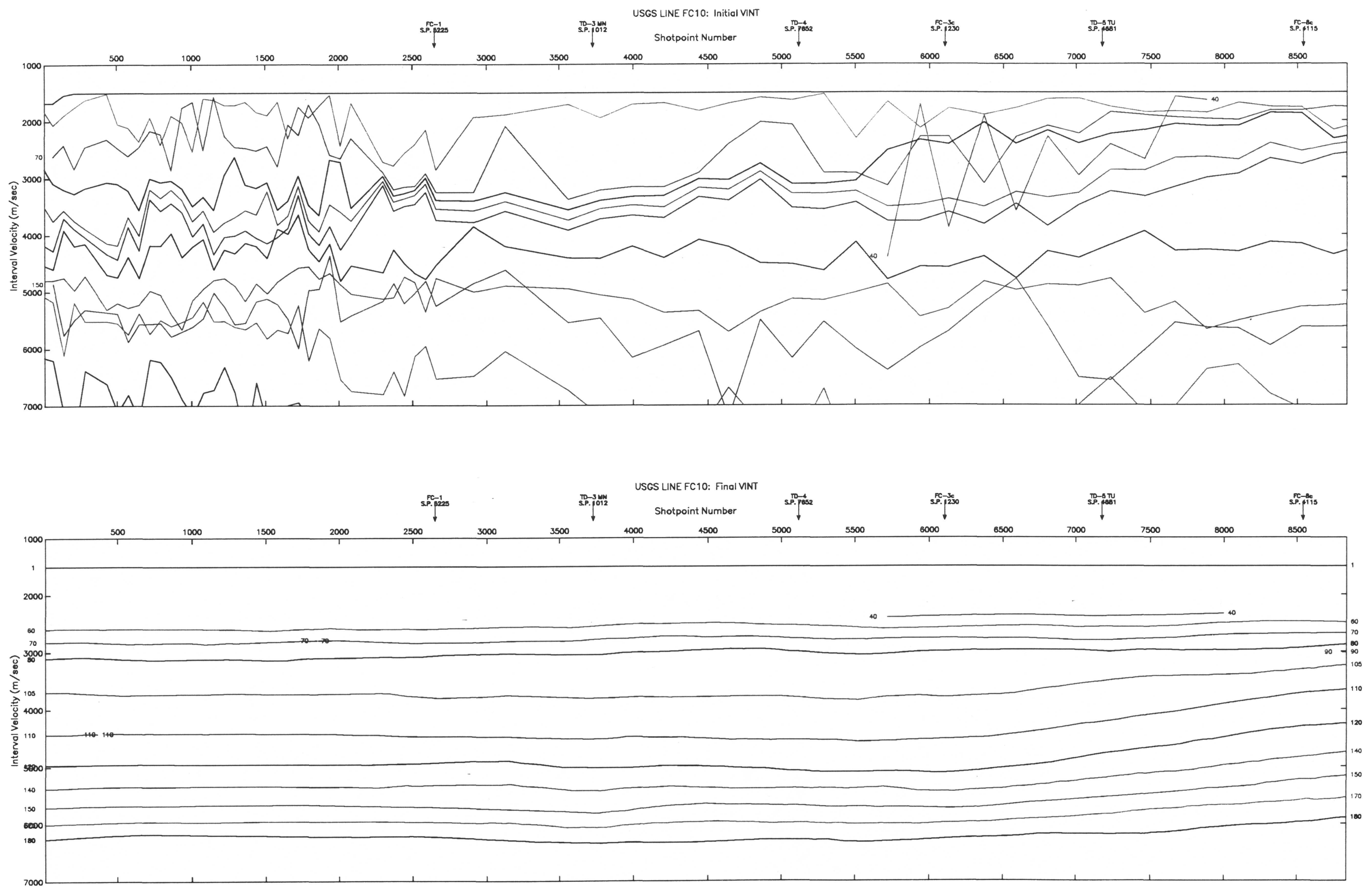

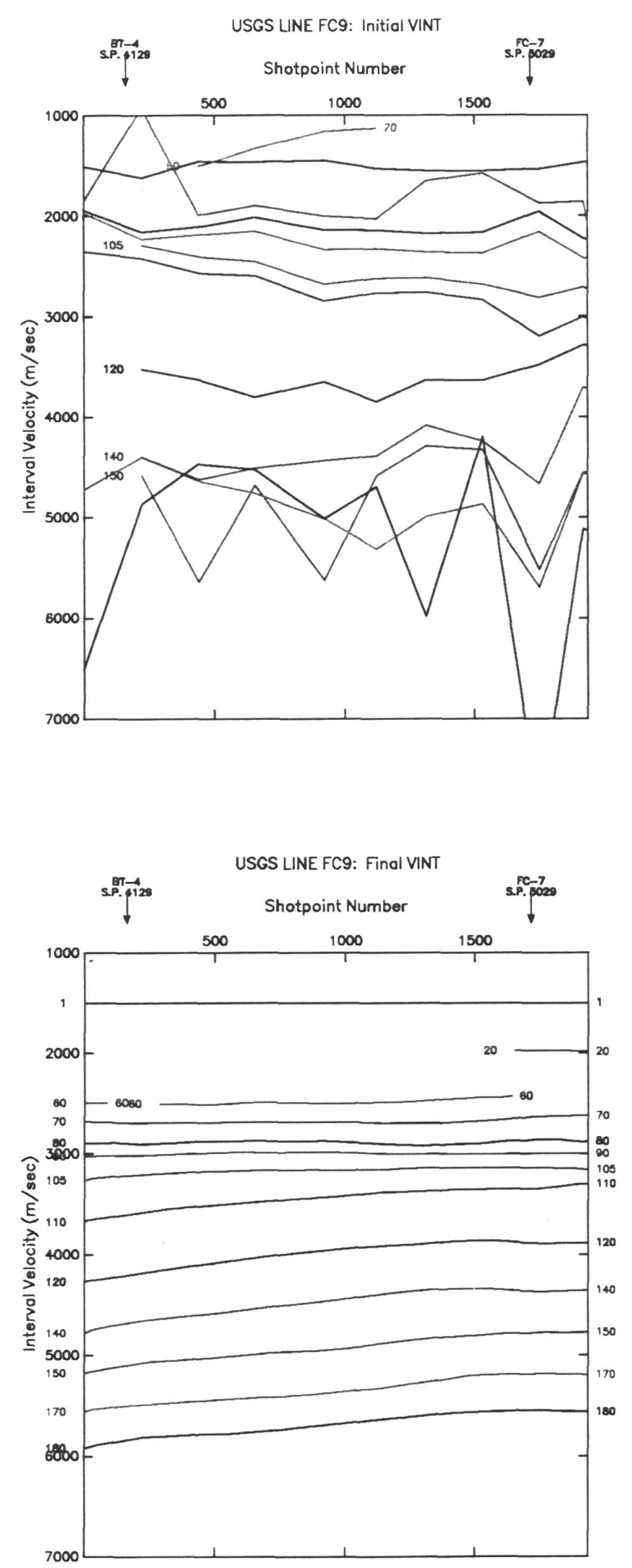

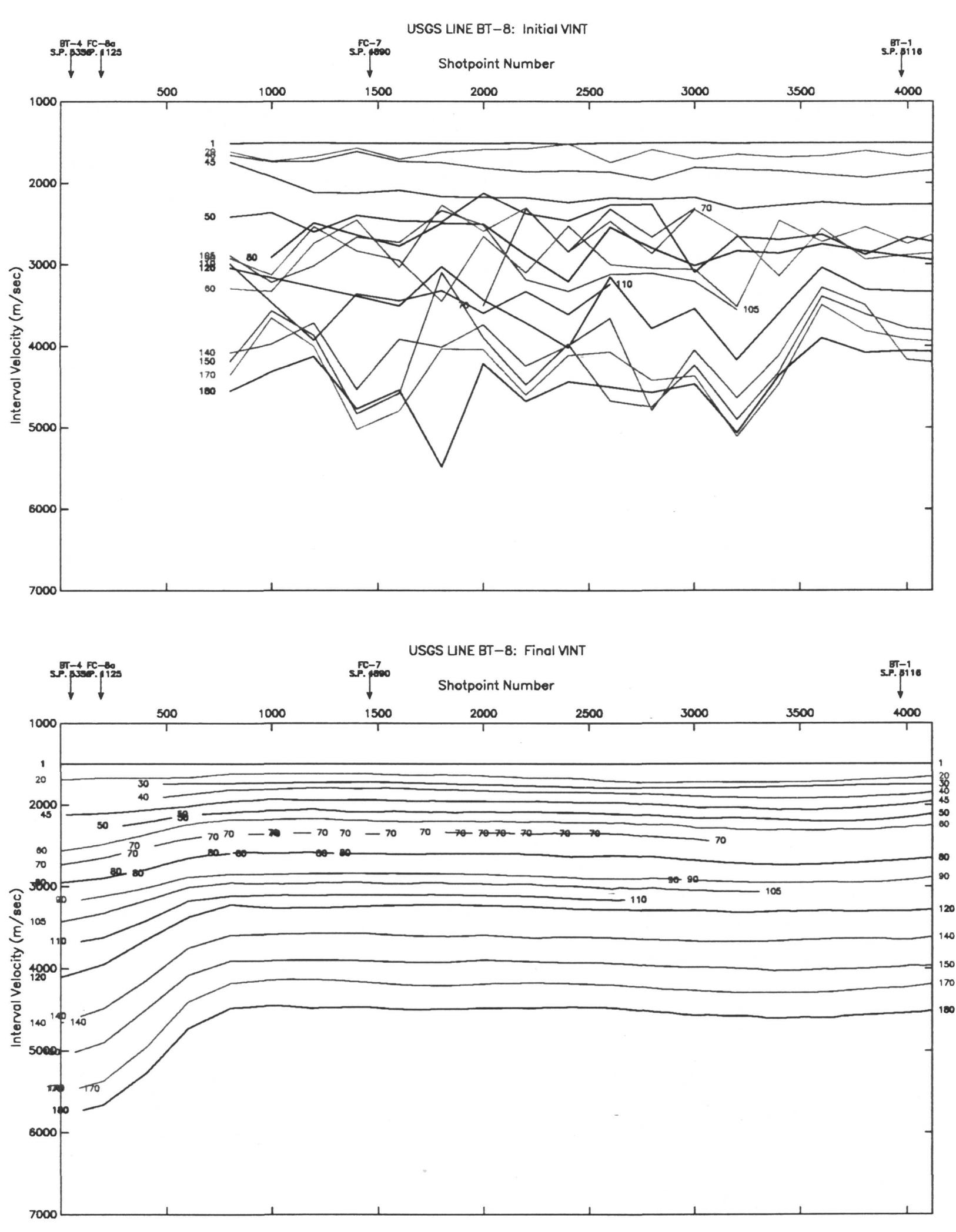

134 

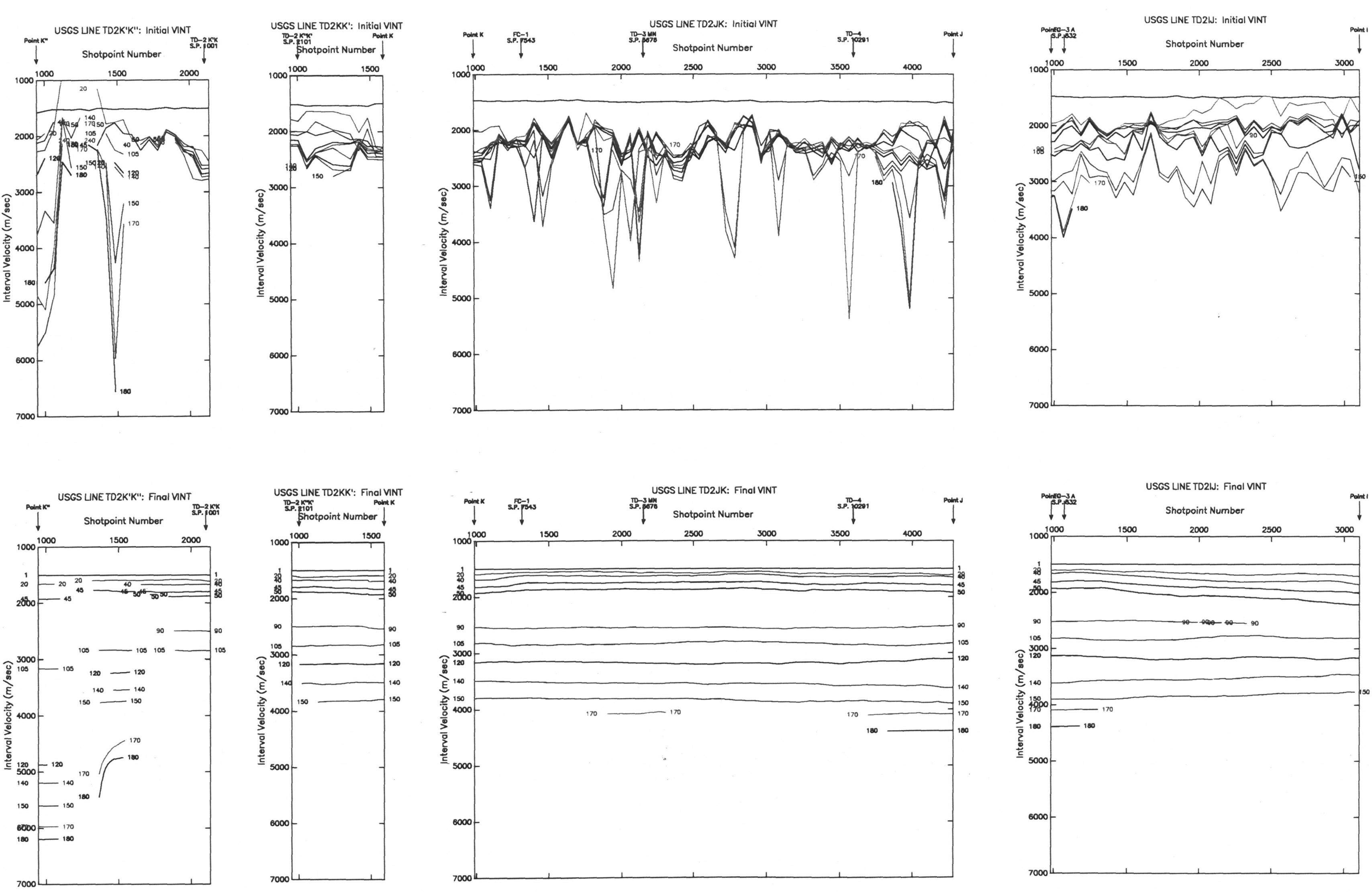

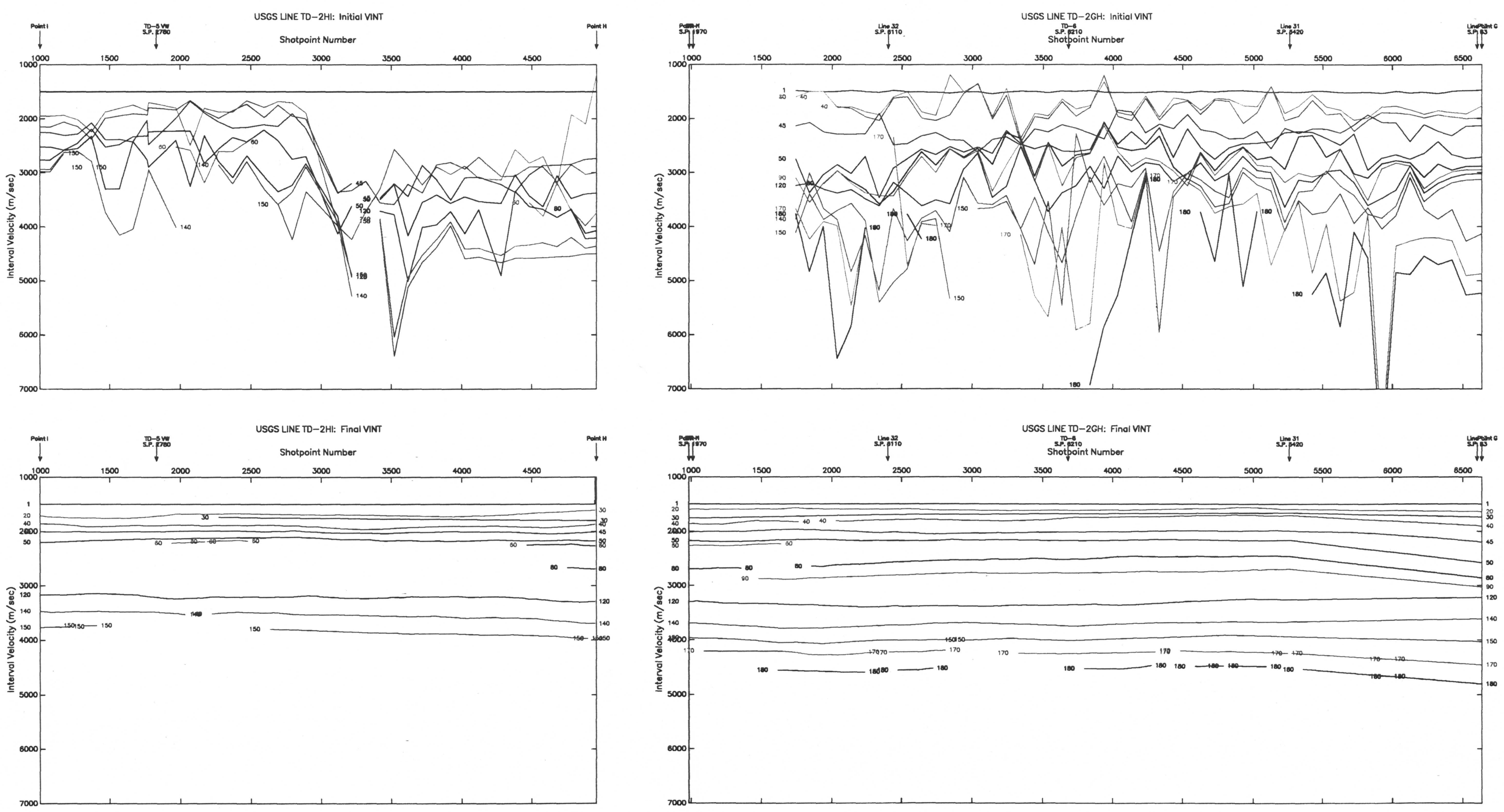

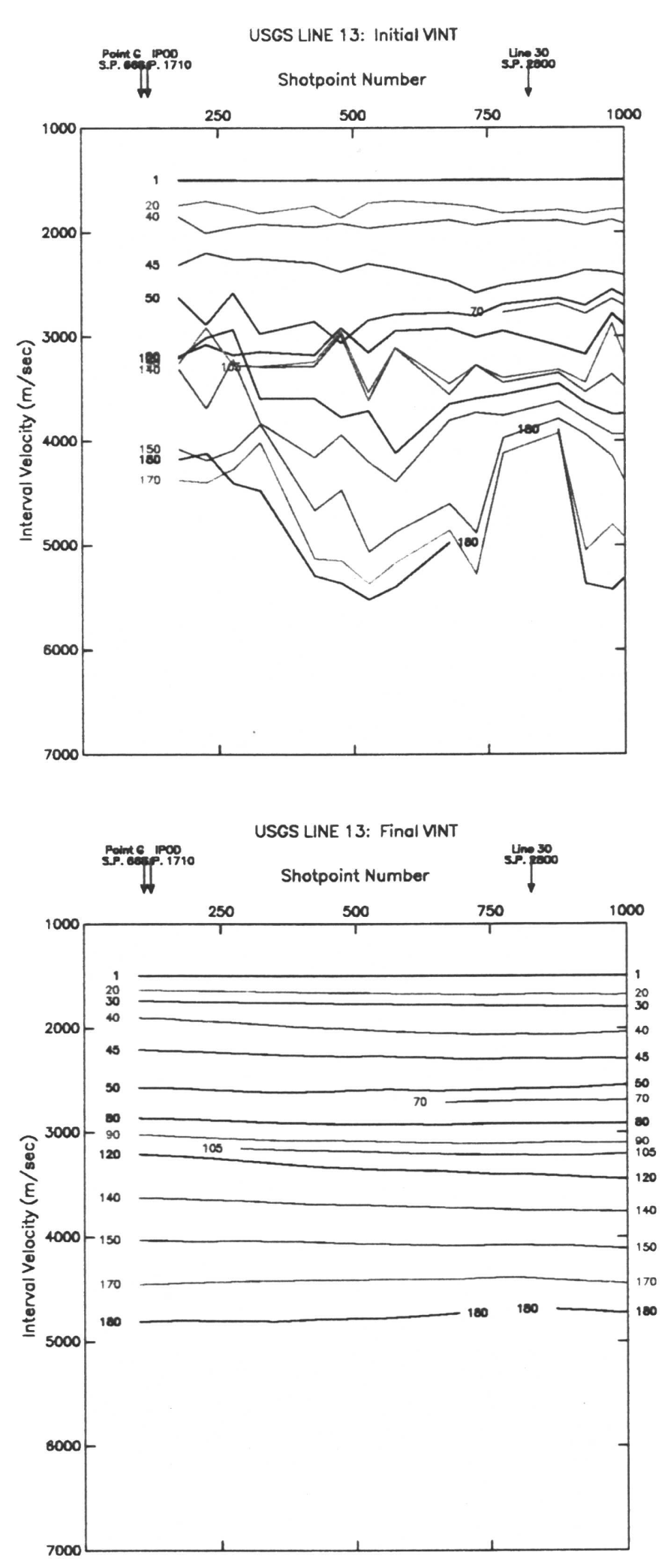

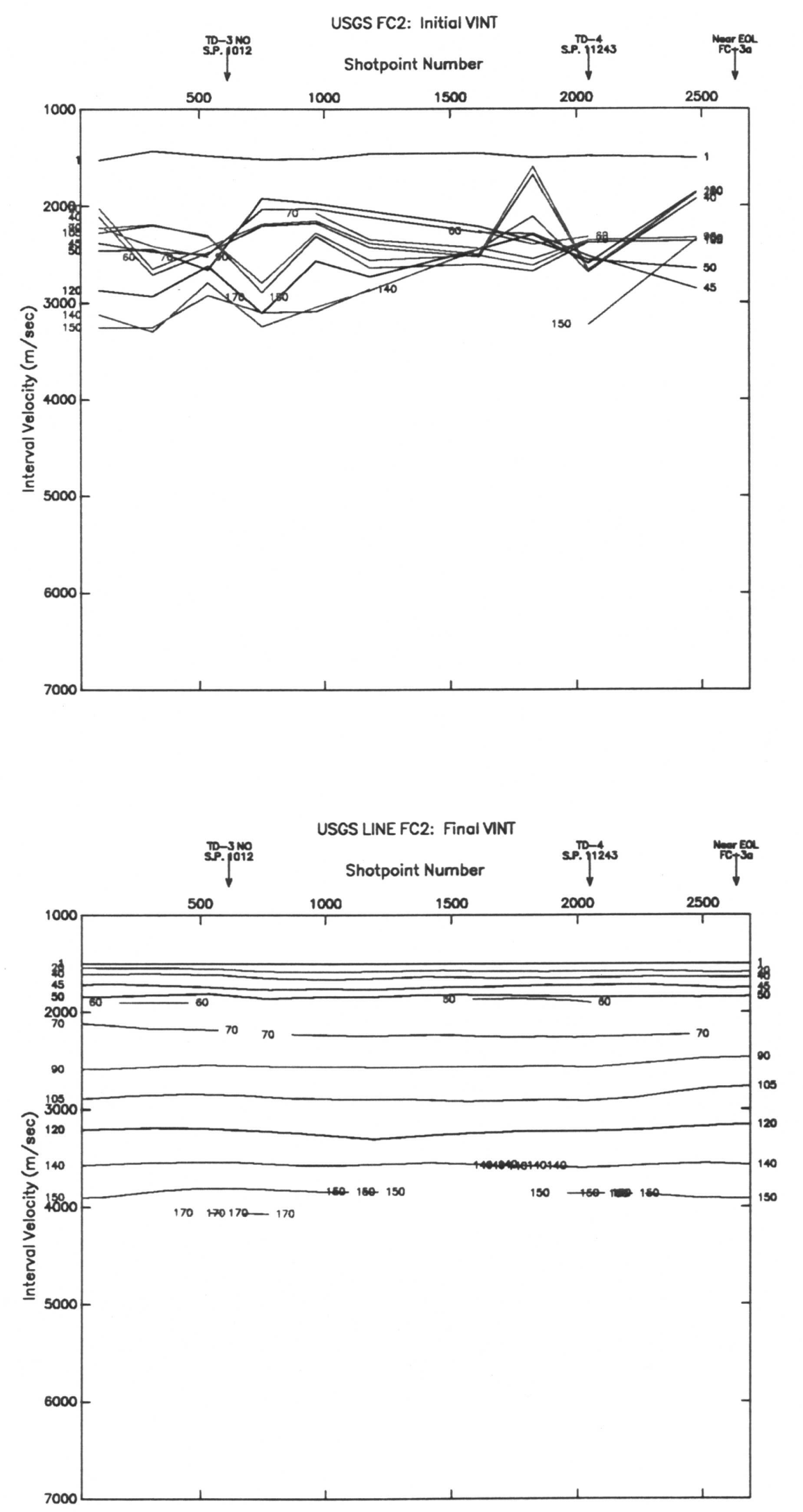

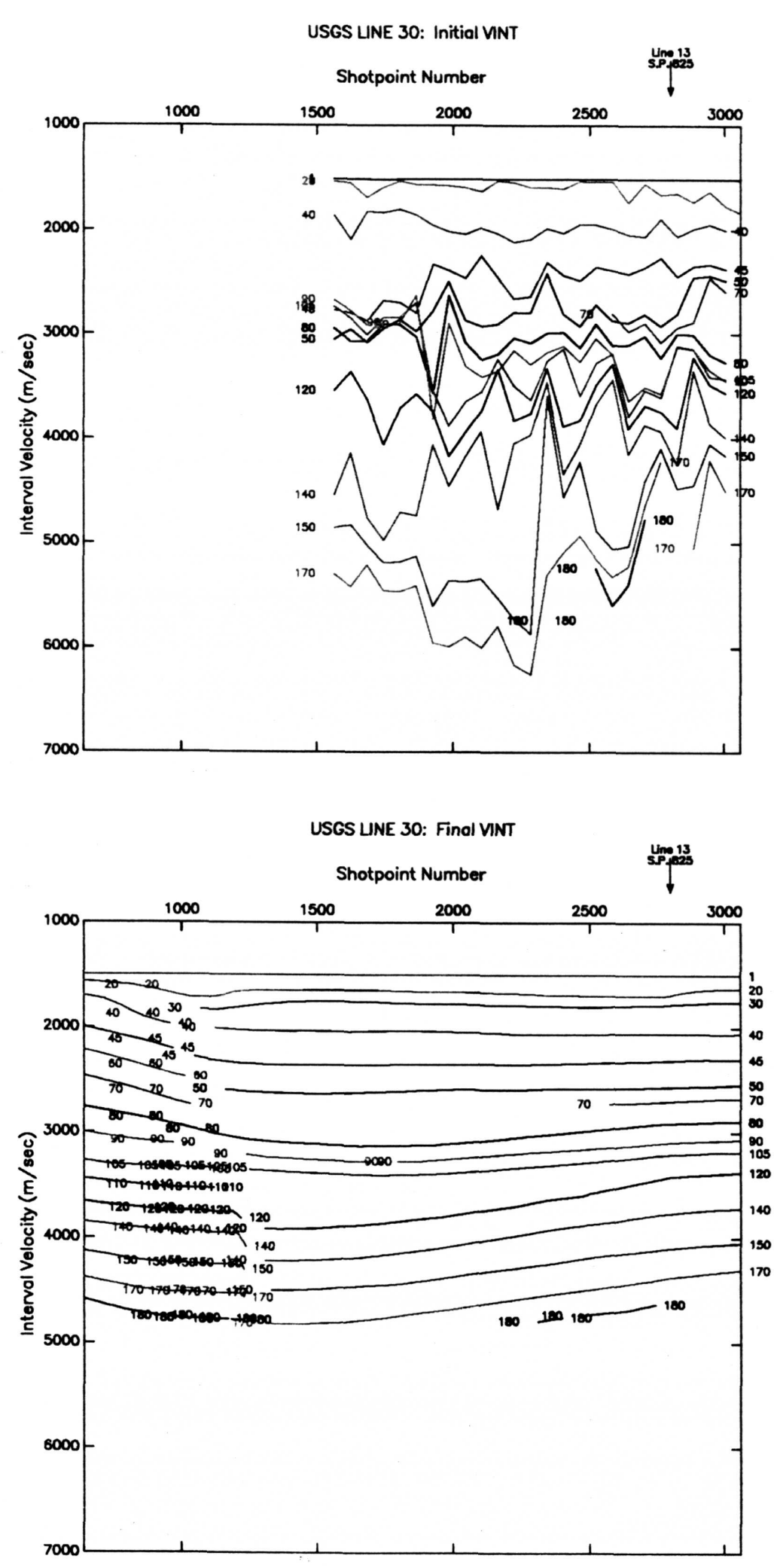

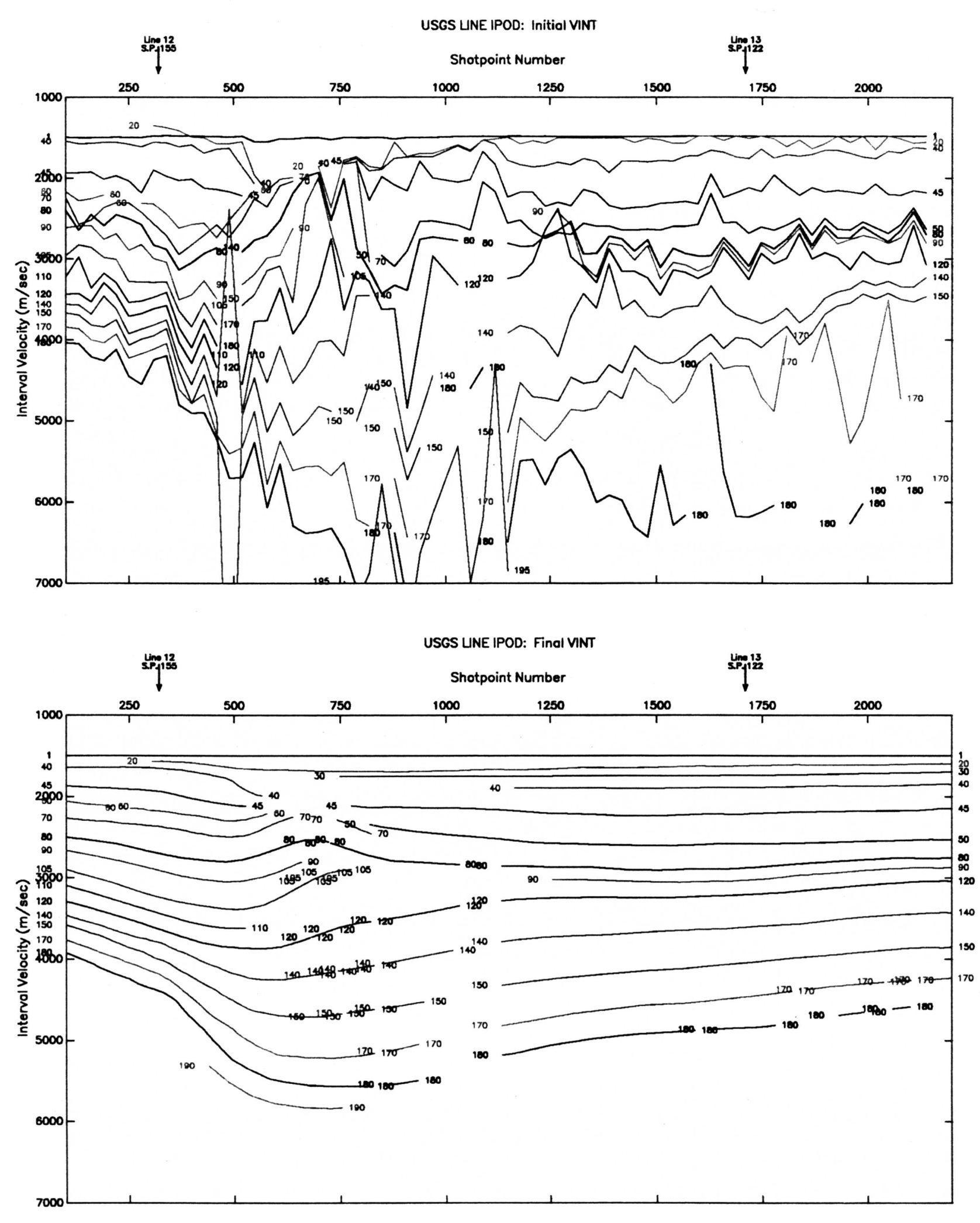


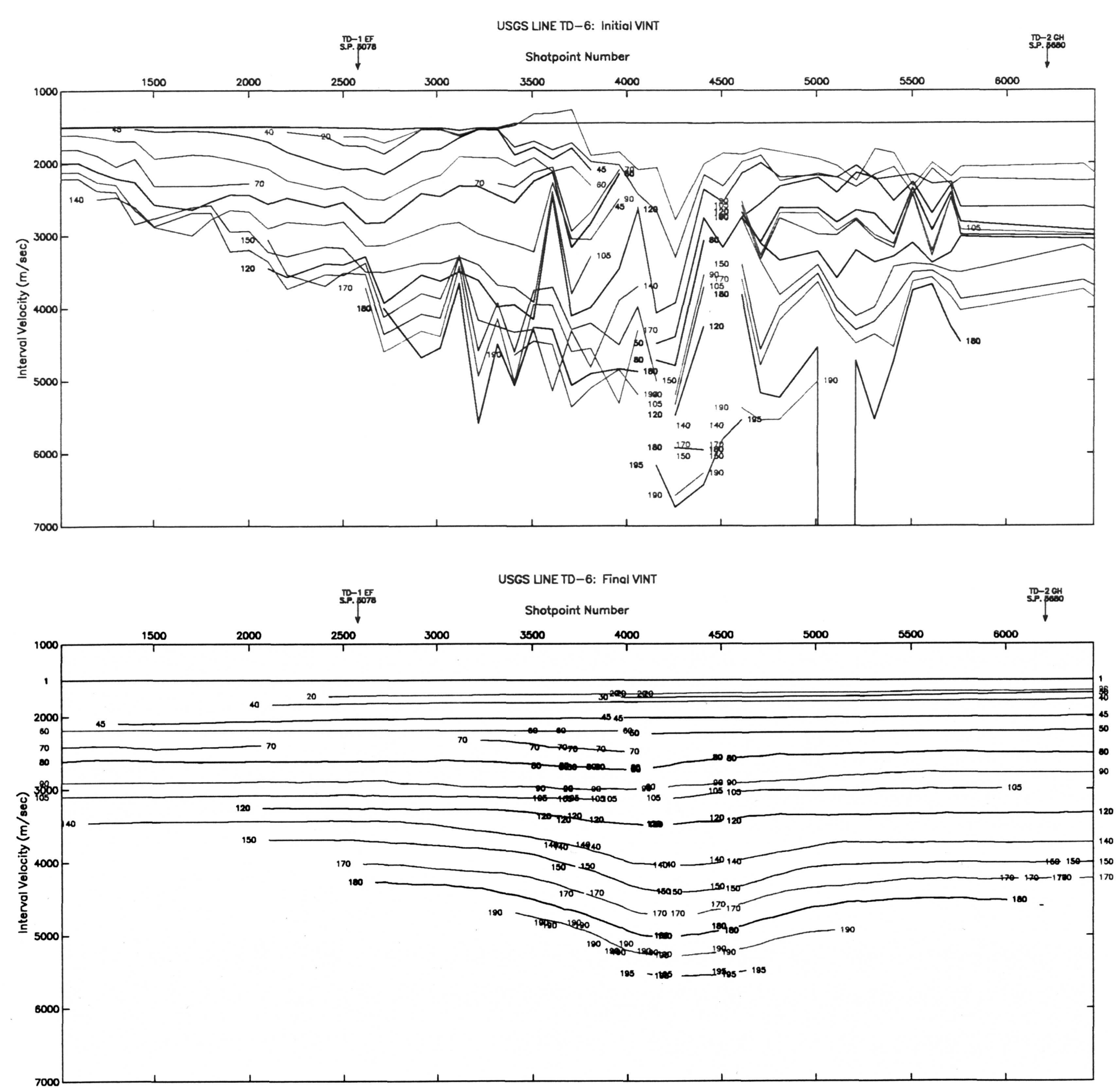

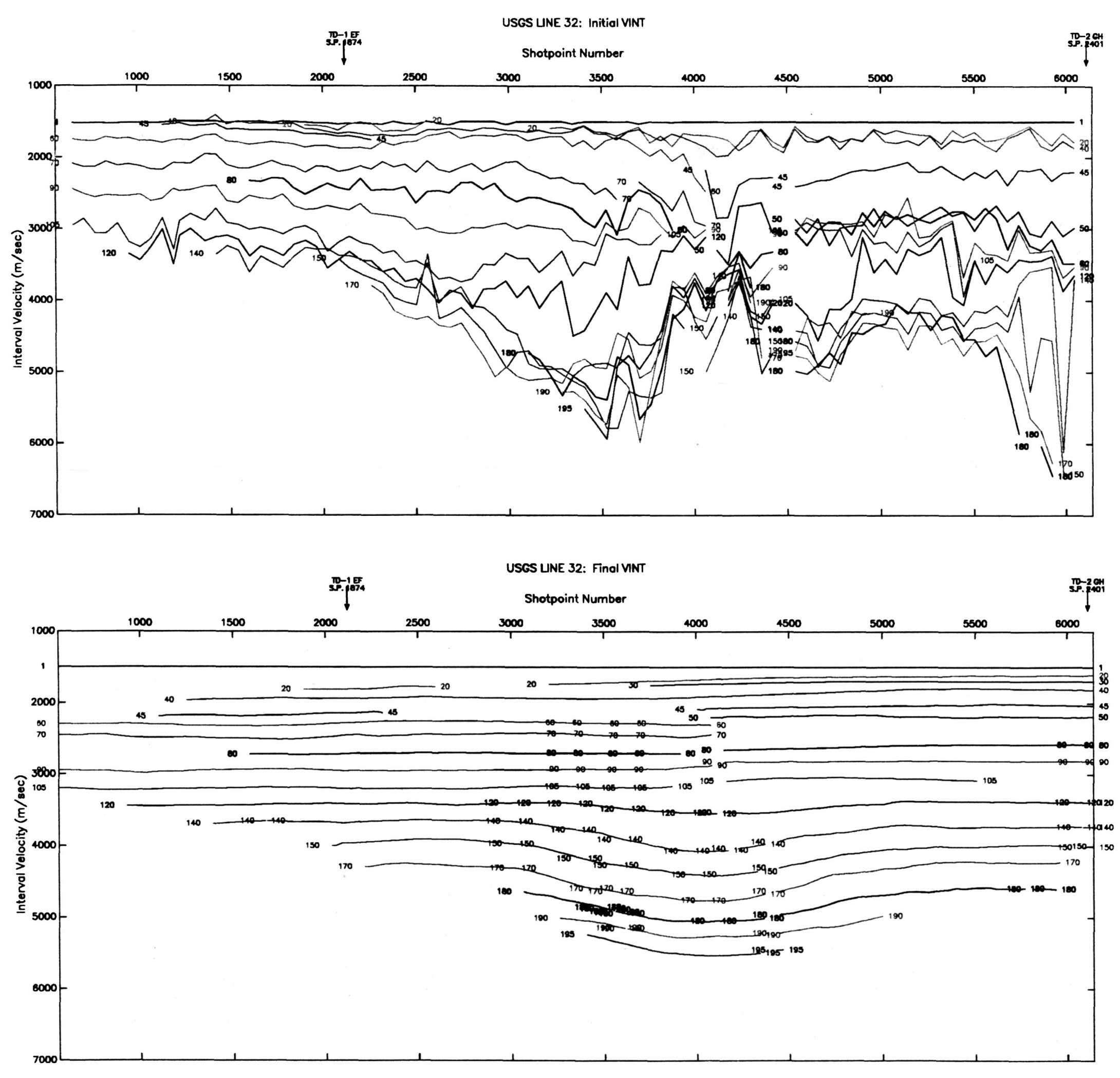

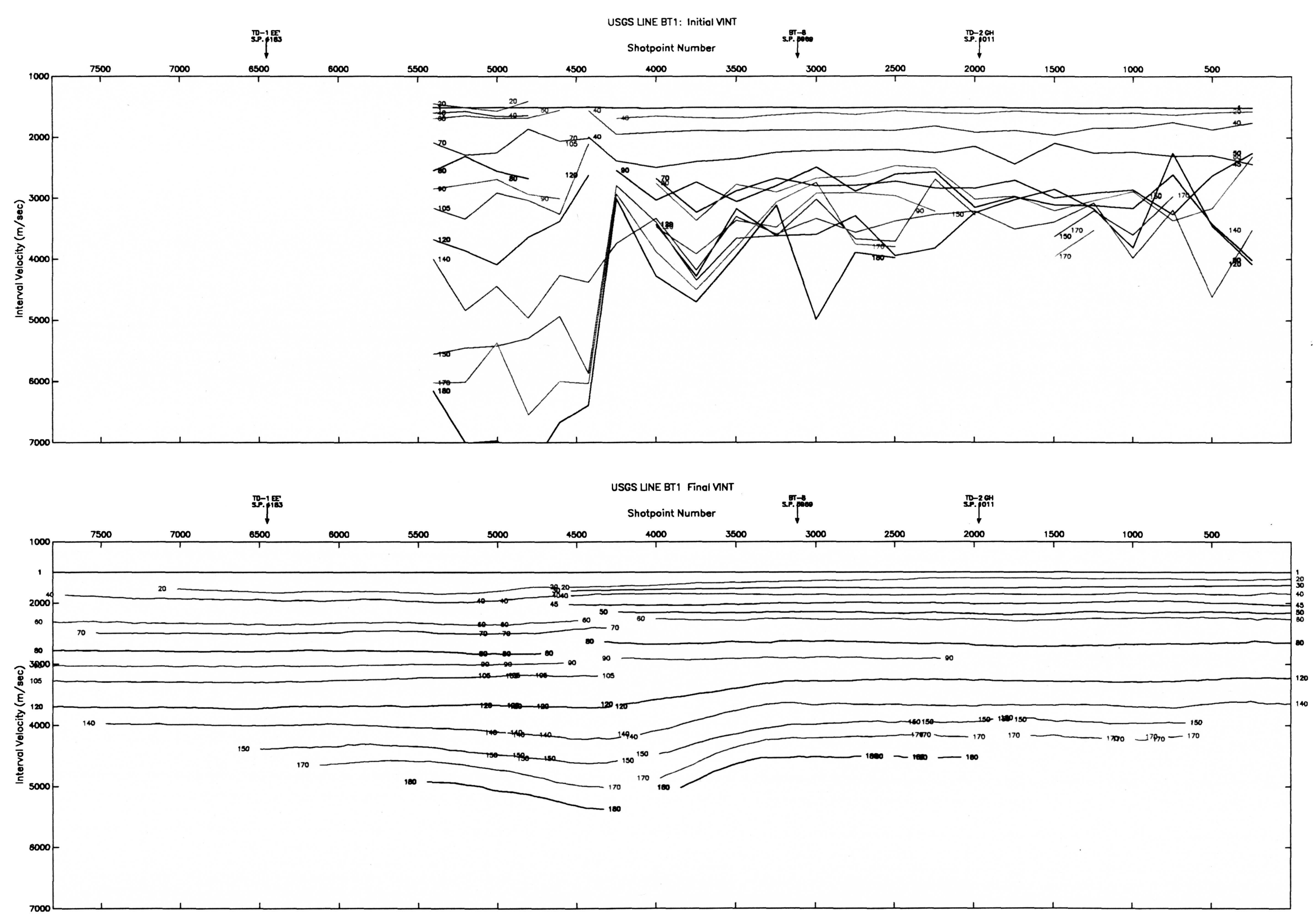

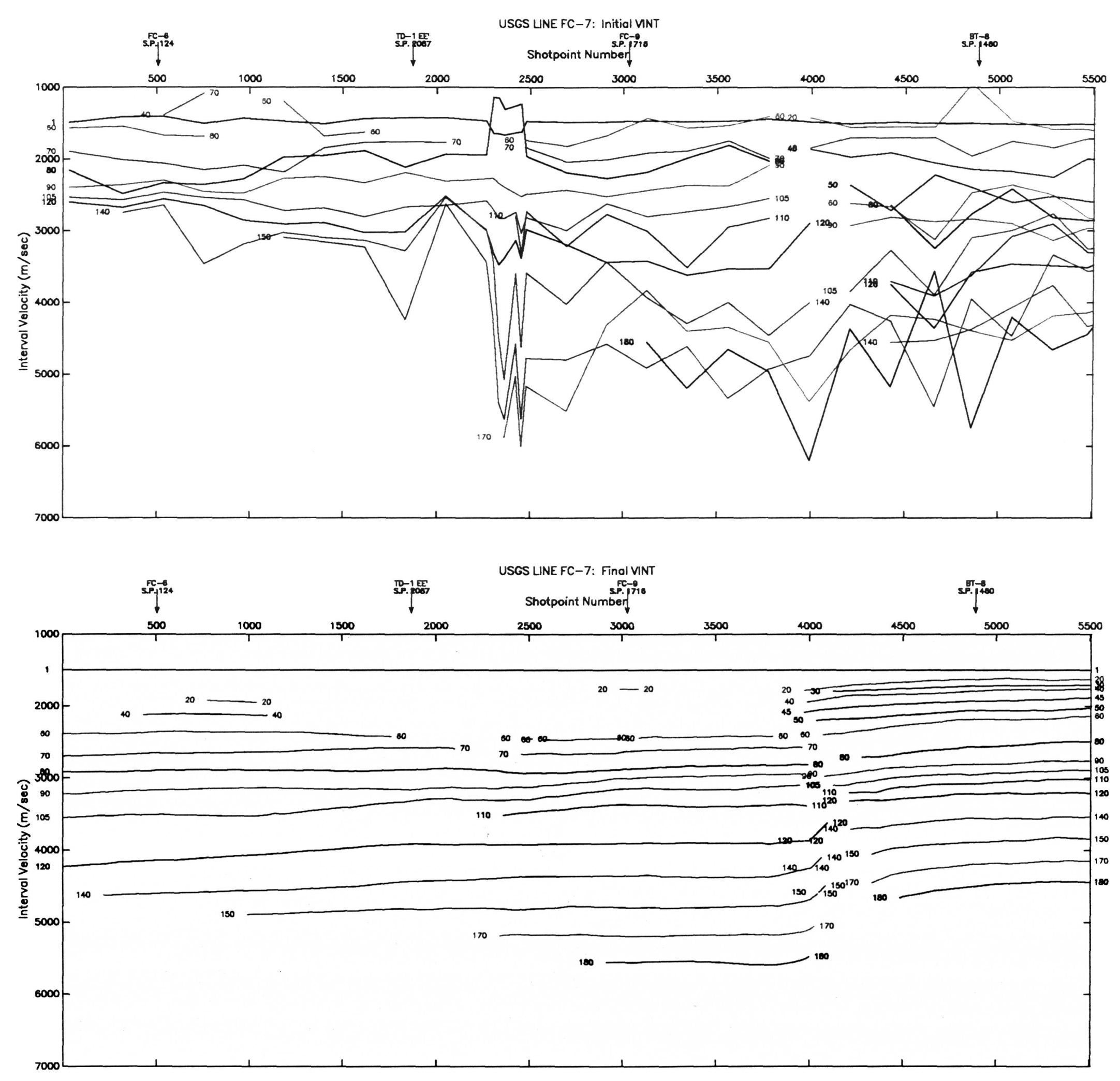

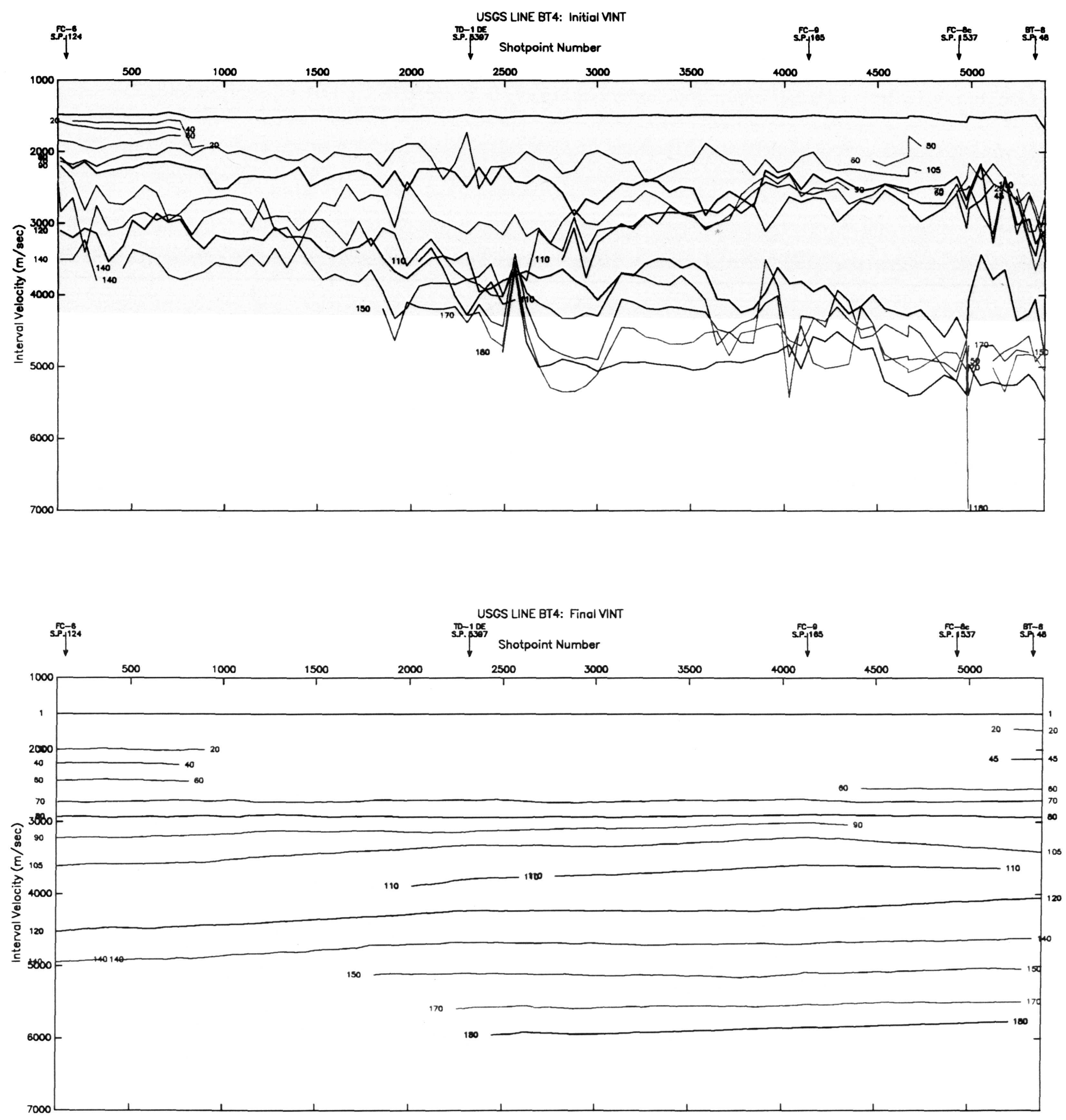

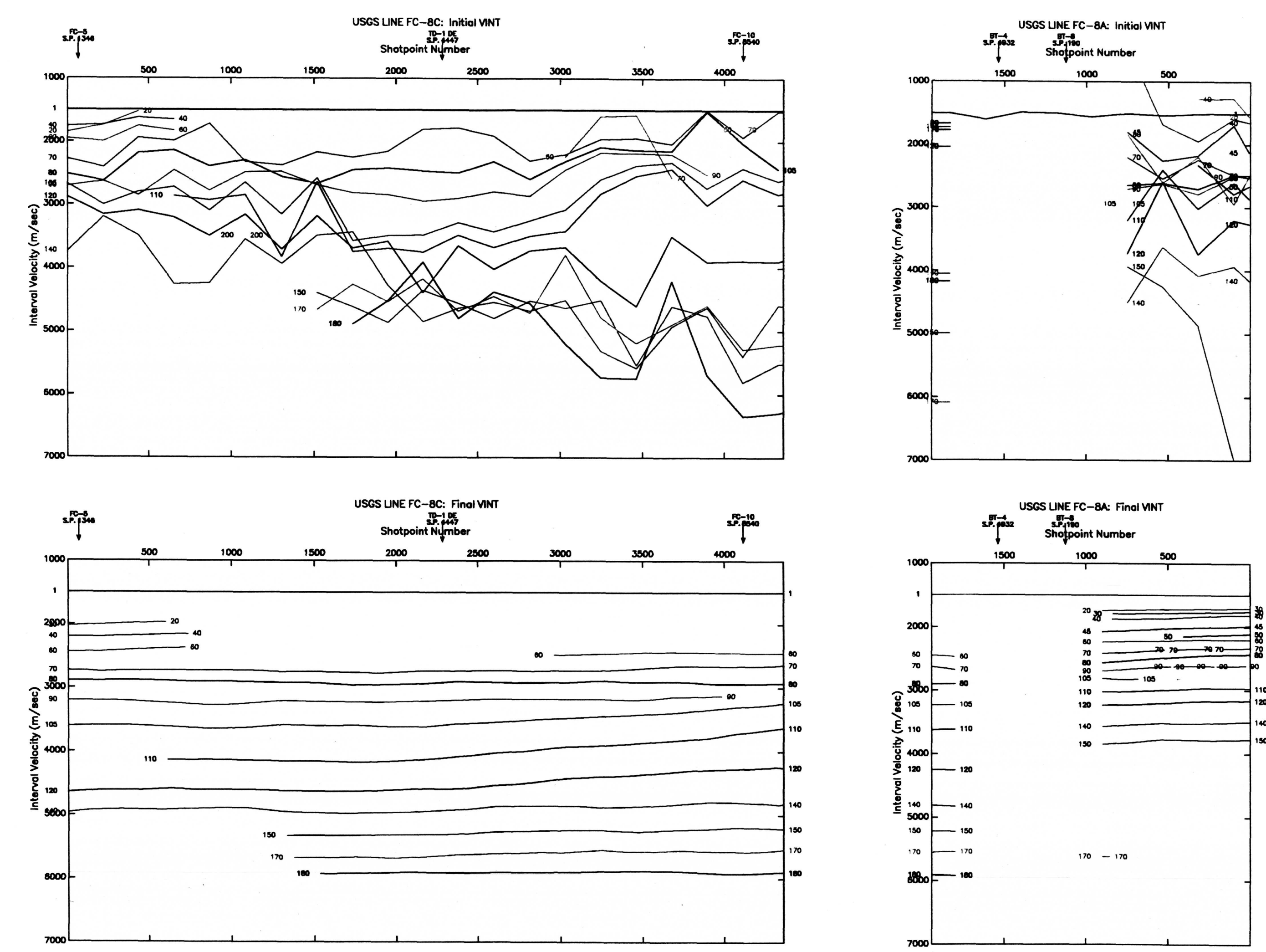

147 

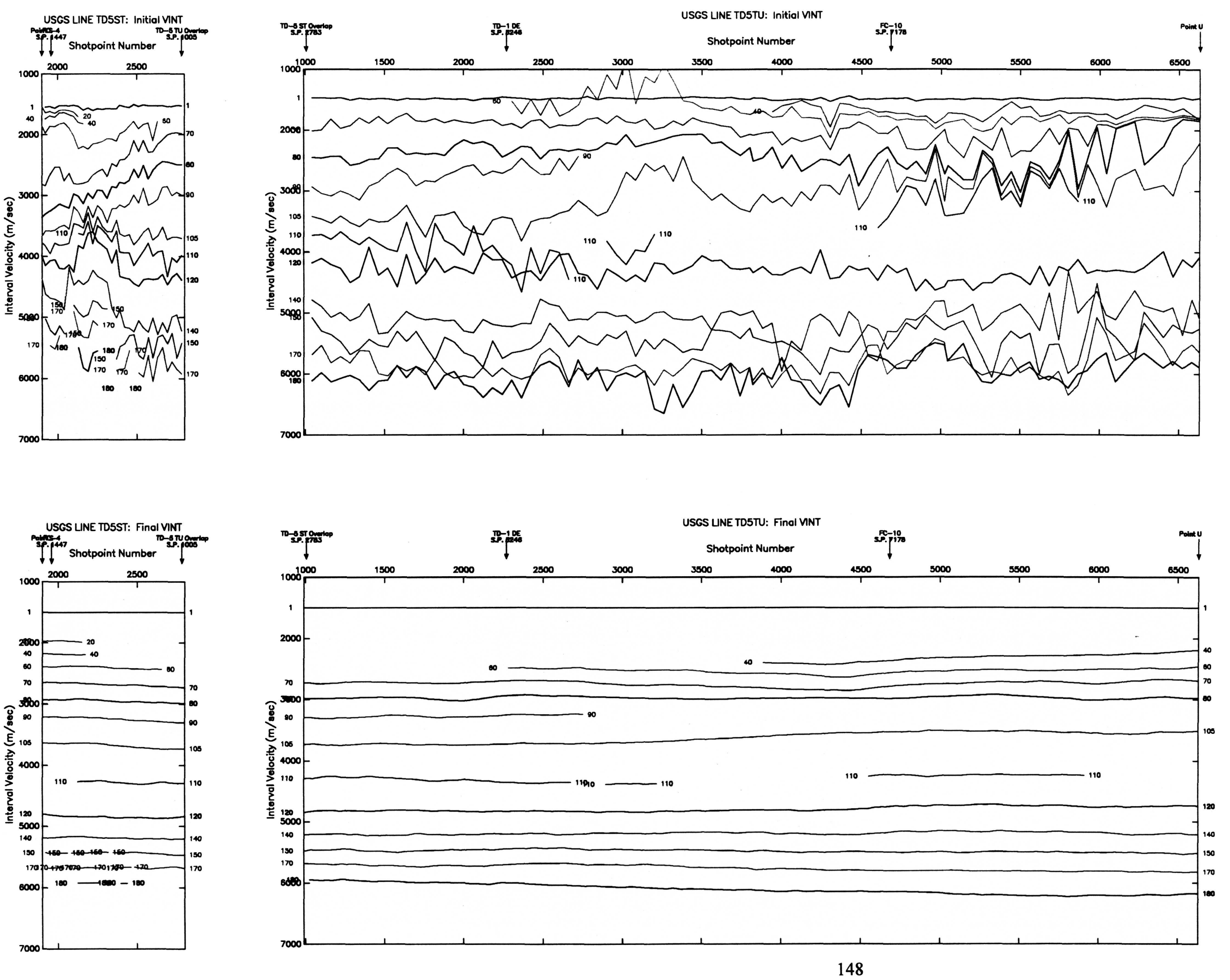

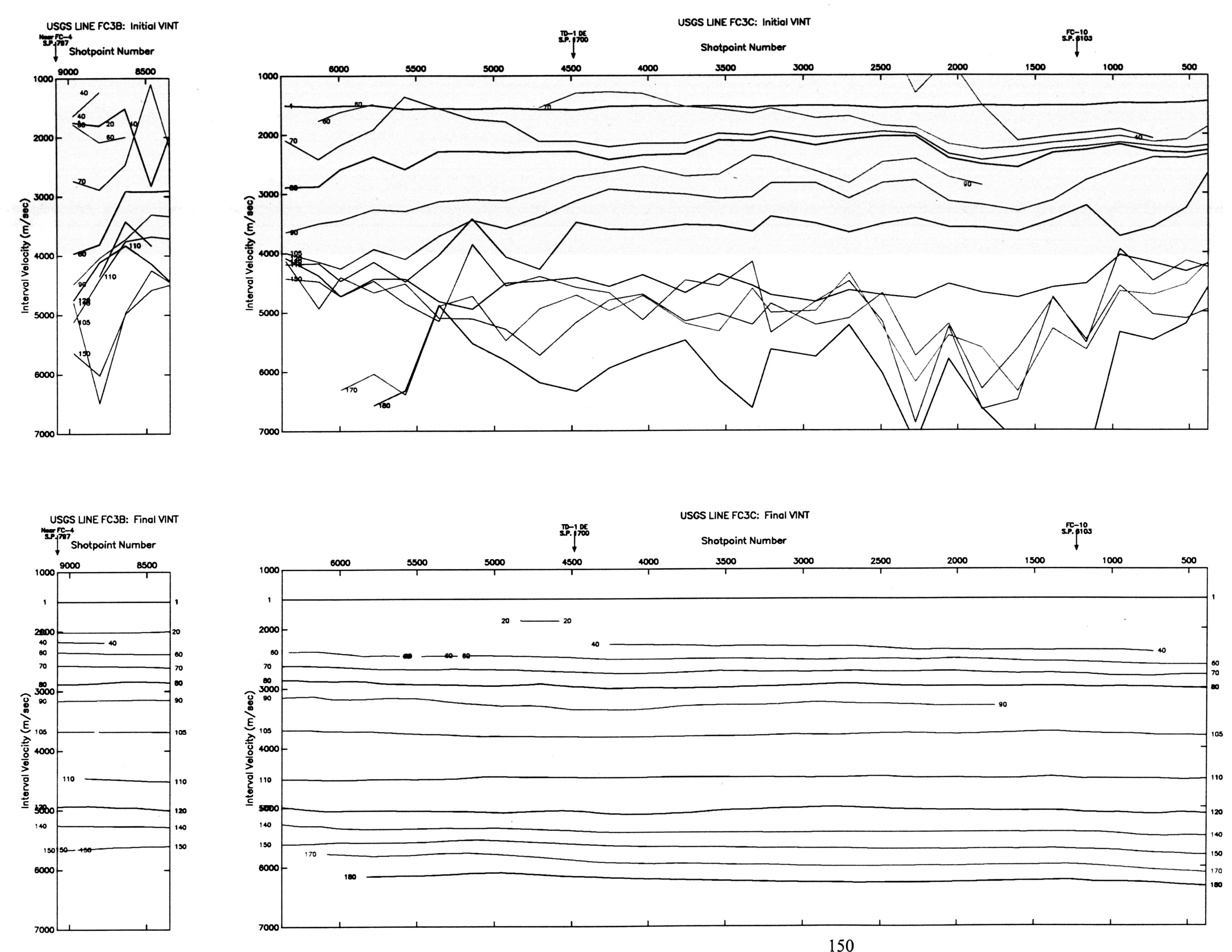

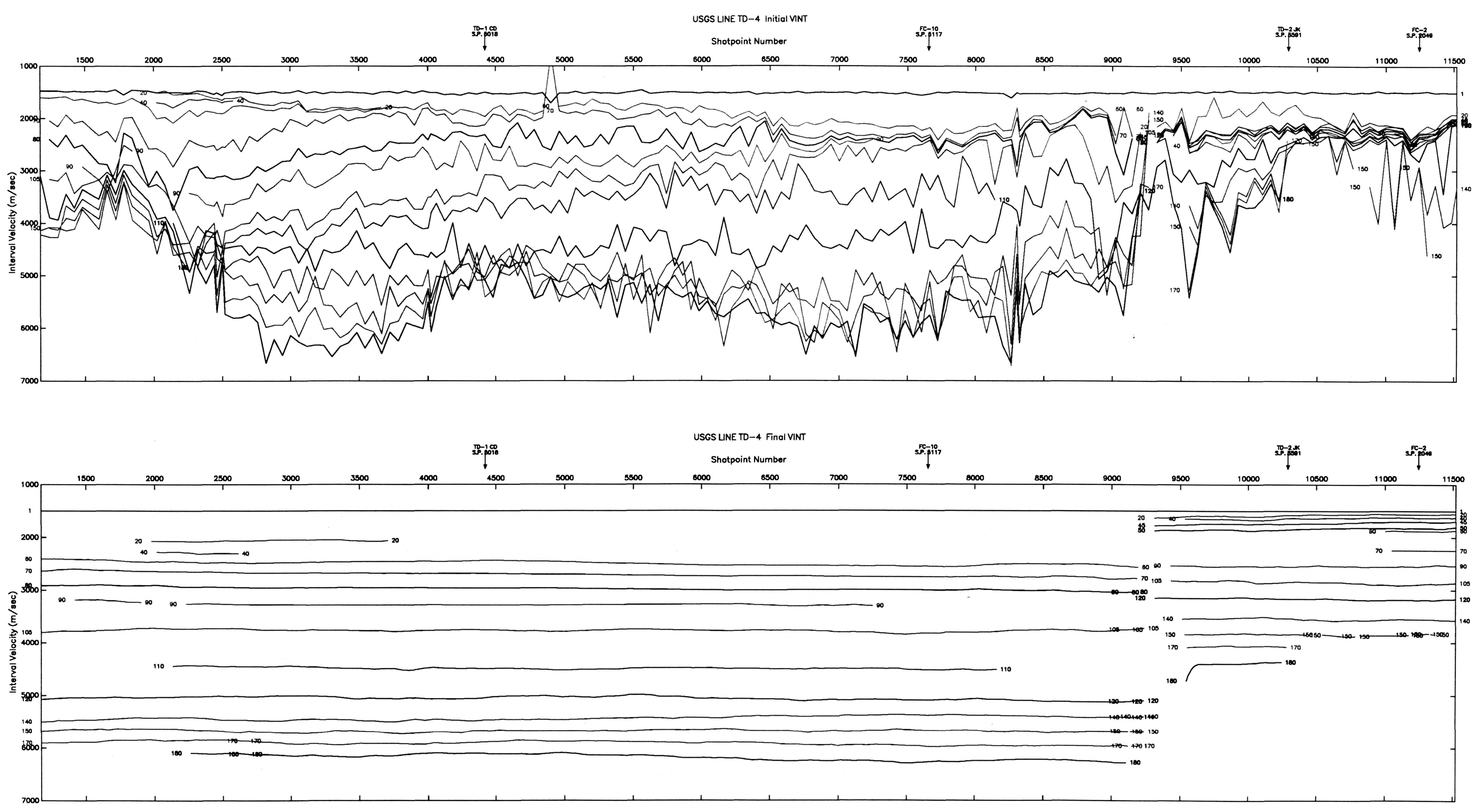

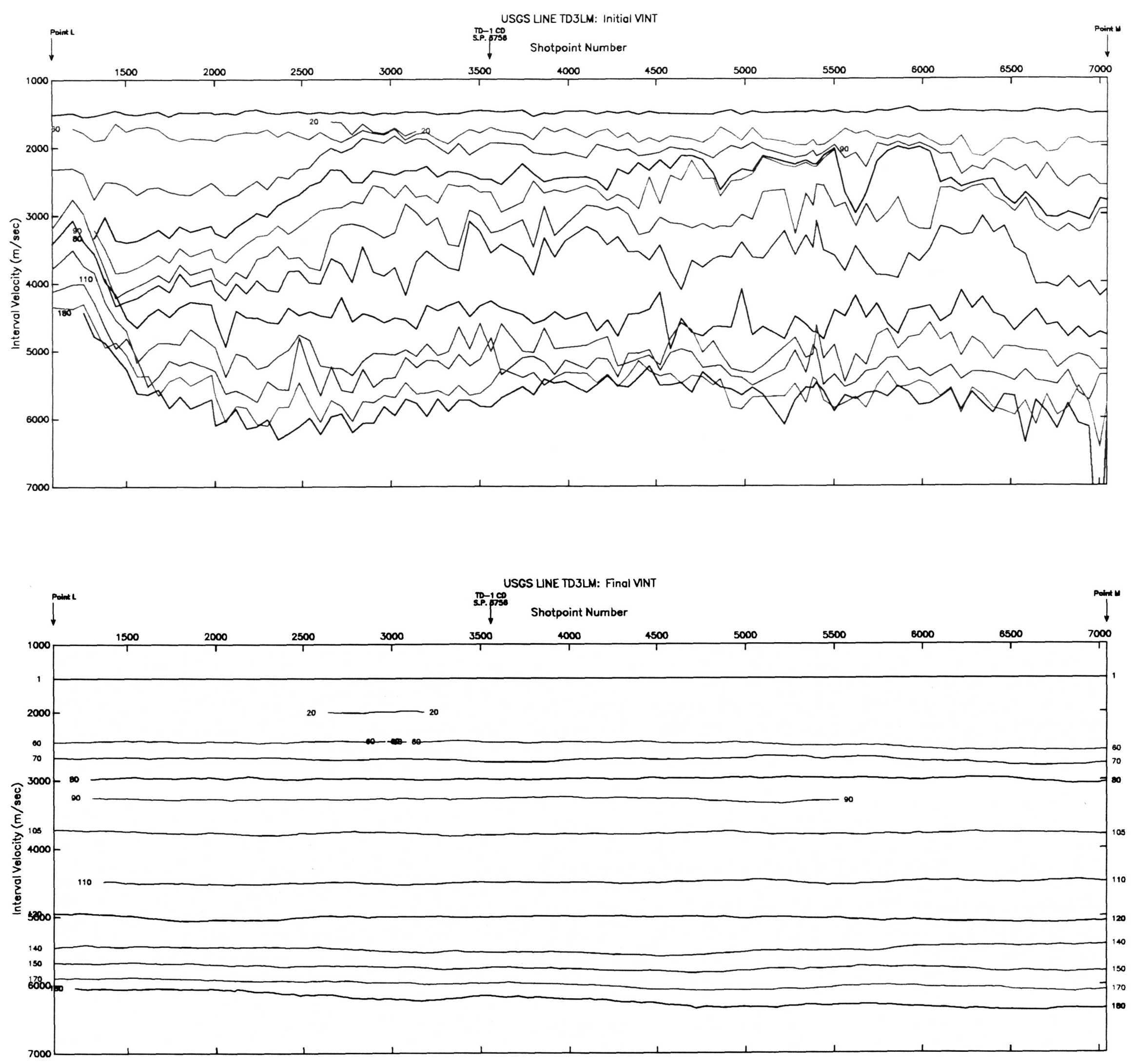

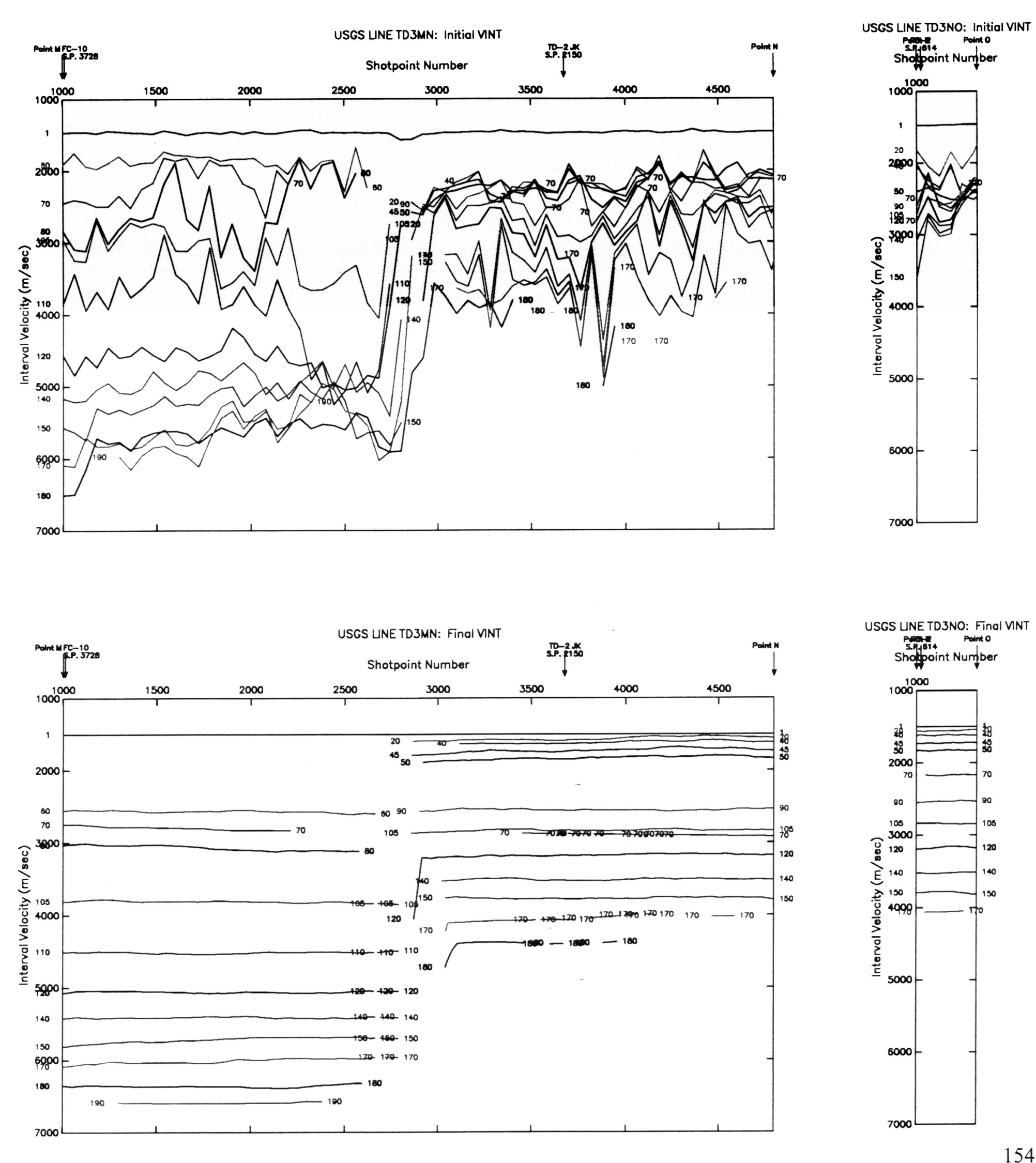

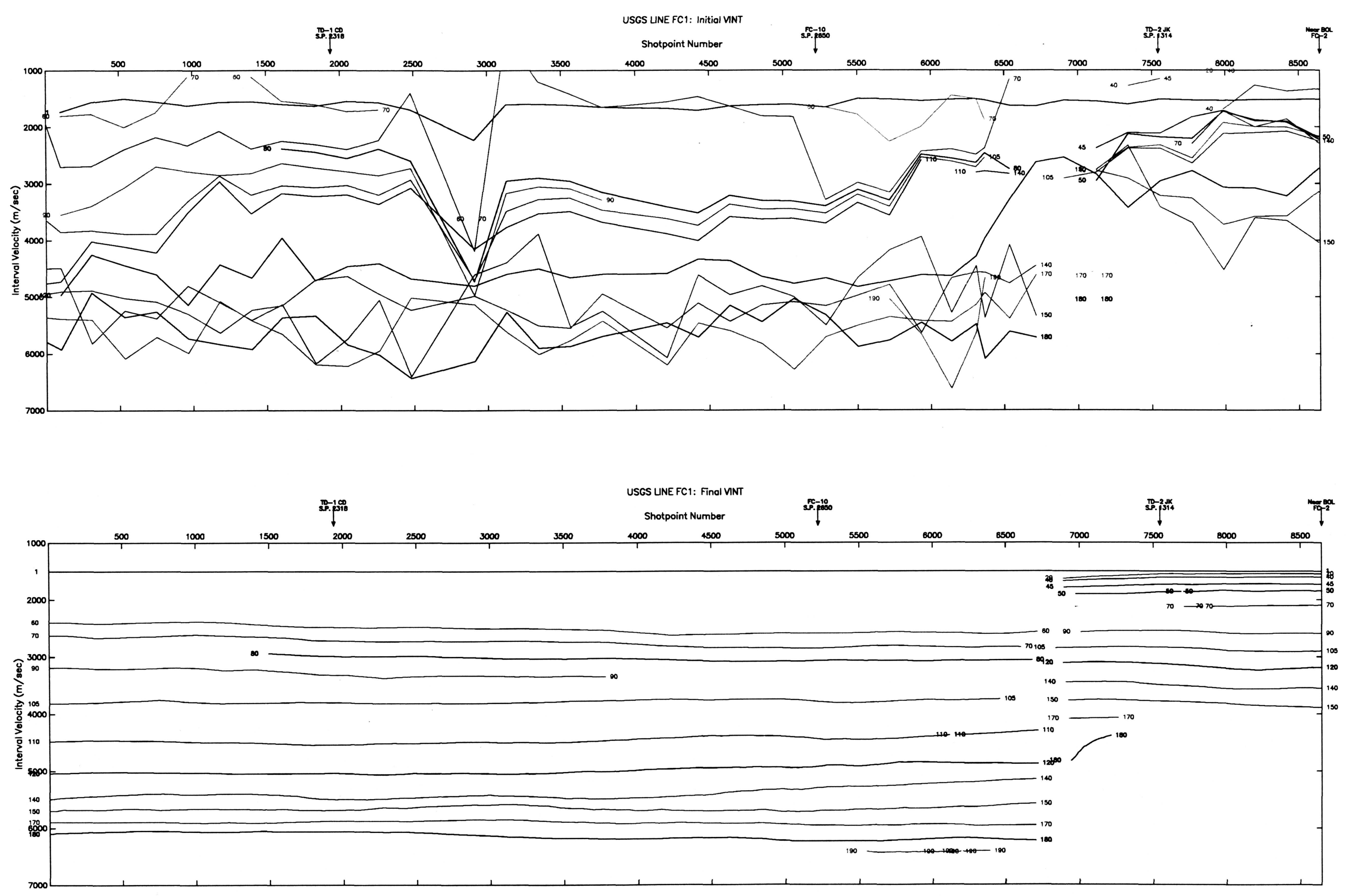


\section{APPENDIX 4}

Independent Refraction Profiles:

Comparison with Multichannel Interval Velocities 


\section{EXPLANATORY NOTES}

This appendix gives provides travel-time/velocity plots from independent refraction experiments compared to interval velocities at intersecting or nearby multichannel profiles. Beneath the xy plots are travel time sections showing the location and approximate depth of penetration to the multichannel lines they cross. All strike lines, progressing from shallow water perce The refraction lines are labelled according to the following scheme:

\begin{tabular}{|c|c|c|c|c|}
\hline $\begin{array}{l}\text { Page } \\
\text { No. } \\
\end{array}$ & $\begin{array}{l}\text { Refraction } \\
\text { Line } \\
\end{array}$ & $\begin{array}{l}\text { Crossing } \\
\text { MCS line }\end{array}$ & Reference & Comment \\
\hline 159 & 72 & FC-4 & Sheridan et al. (1988) & $11-55$ of Hersey et al. (1959) \\
\hline 159 & BA-3 & FC-4 & Holbrook et al. (1994) & \\
\hline 159 & 78 & FC-5 & Sheridan et al. (1988) & 12-55 of Hersey et al. (1959) \\
\hline 159 & 67 & FC-5 & Sheridan et al. (1988) & 10-54 of Hersey et al. (1959) \\
\hline 160 & 16 & TD-1 & Sheridan et al. (1988) & 3-56 of Hersey et al. (1959) \\
\hline 160 & 124 & TD-1 & Sheridan et al. (1988) & 29-55 of Hersey et al. (1959) \\
\hline 160 & 11 & TD-1 & Sheridan et al. (1988) & 2-56 of Hersey et al. (1959) \\
\hline 160 & BA-6 & TD-1 & Holbrook et al. (1994) & \\
\hline 161 & 2301 & TD-1 & Dowling (1968) & \\
\hline 161 & 83 & TD-1 & Sheridan et al. (1988) & 13-54 of Hersey et al. (1959) \\
\hline 162 & 219 & FC-10 & Sheridan et al. (1988) & 99 of Sheridan et al. (1966) \\
\hline 162 & 127 & FC-10 & Sheridan et al. (1988) & 30-55 of Hersey et al. (1959) \\
\hline 163 & 144 & FC-9 & Sheridan et al. (1988) & 36-55 of Hersey et al. (1959) \\
\hline 164 & 146 & BT-8 & Sheridan et al. (1988) & 37-55 of Hersey et al. (1959) \\
\hline 164 & BA-6 & BT-8 & Holbrook et al. (1994) & \\
\hline 165 & 131 & TD-2 & Sheridan et al. (1988) & 31-55 of Hersey et al. (1959) \\
\hline 165 & 251 & TD-2 & Sheridan et al. (1988) & G15 of Ewing and Ewing (1959) \\
\hline 166 & $3-54$ & TD-6 & Hersey et al. (1959) & \\
\hline 166 & 77 & TD-6 & Sheridan et al. (1988) & 12-54 of Hersey et al. (1959) \\
\hline 167 & $\mathrm{NC}-3$ & Line 32 & Grim et al. (1980) & from Woollard et al. (1957) \\
\hline 167 & 77 & Line 32 & Sheridan et al. (1988) & 12-54 of Hersey et al. (1959) \\
\hline 167 & 2302 & Line 32 & Dowling (1968) & \\
\hline 167 & $\mathrm{~L} 2$ & Line 32 & Trehu et al. (1989) & \\
\hline 167 & $\mathrm{~L} 1$ & Line 32 & Trehu et al. (1989) & \\
\hline
\end{tabular}

\begin{tabular}{||c|c|c|l|l||}
\hline 167 & 46 & Line 32 & Sheridan et al. (1988) & 7-8 of Houtz and Ewing (1963) \\
\hline 168 & 27 & FC-7 & Sheridan et al. (1988) & 4-55 of Hersey et al. (1959) \\
\hline 169 & 89 & BT-4 & Sheridan et al. (1988) & 14-55 of Hersey et al. (1959) \\
\hline 169 & 11 & BT-4 & Sheridan et al. (1959) & 2-56 of Hersey et al. (1959) \\
\hline 170 & 11 & FC-8 & Sheridan et al. (1959) & 2-56 of Hersey et al. (1959) \\
\hline 170 & 27 & FC-8 & Sheridan et al. (1988) & $4-55$ of Hersey et al. (1959) \\
\hline 171 & 72 & TD-5 & Sheridan et al. (1988) & 11-55 of Hersey et al. (1959) \\
\hline 171 & 39 & TD-5 & Sheridan et al. (1988) & 6-55 of Hersey et al. (1959) \\
\hline 171 & 127 & TD-5 & Sheridan et al. (1988) & 30-55 of Hersey et al. (1959) \\
\hline 172 & 251 & TD-5 & Sheridan et al. (1988) & G15 of Ewing and Ewing (1959) \\
\hline 173 & 221 & FC-3 & Sheridan et al. (1988) & 102 of Sheridan et al. (1966) \\
\hline 174 & 107 & TD-4 & Sheridan et al. (1988) & 19 of Sheridan et al. (1966) \\
\hline 174 & 59 & TD-4 & Sheridan et al. (1988) & 9 of Sheridan et al. (1966) \\
\hline 174 & 219 & TD-4 & Sheridan et al. (1988) & 99 of Sheridan et al. (1966) \\
\hline 174 & 220 & TD-4 & Sheridan et al. (1988) & 100 of Sheridan et al. (1966) \\
\hline 175 & 217 & TD-3 & Sheridan et al. (1988) & 97 of Sheridan et al. (1966) \\
\hline 175 & Trehu & TD-3 & Trehu (1984, 1985) & \\
\hline 176 & 23 & FC-1 & Sheridan et al. (1988) & 4 of Sheridan et al. (1966) \\
\hline 176 & 122 & FC-1 & Sheridan et al. (1988) & 24 of Sheridan et al. (1966) \\
\hline
\end{tabular}




\section{Locations of Refraction Data Sets}

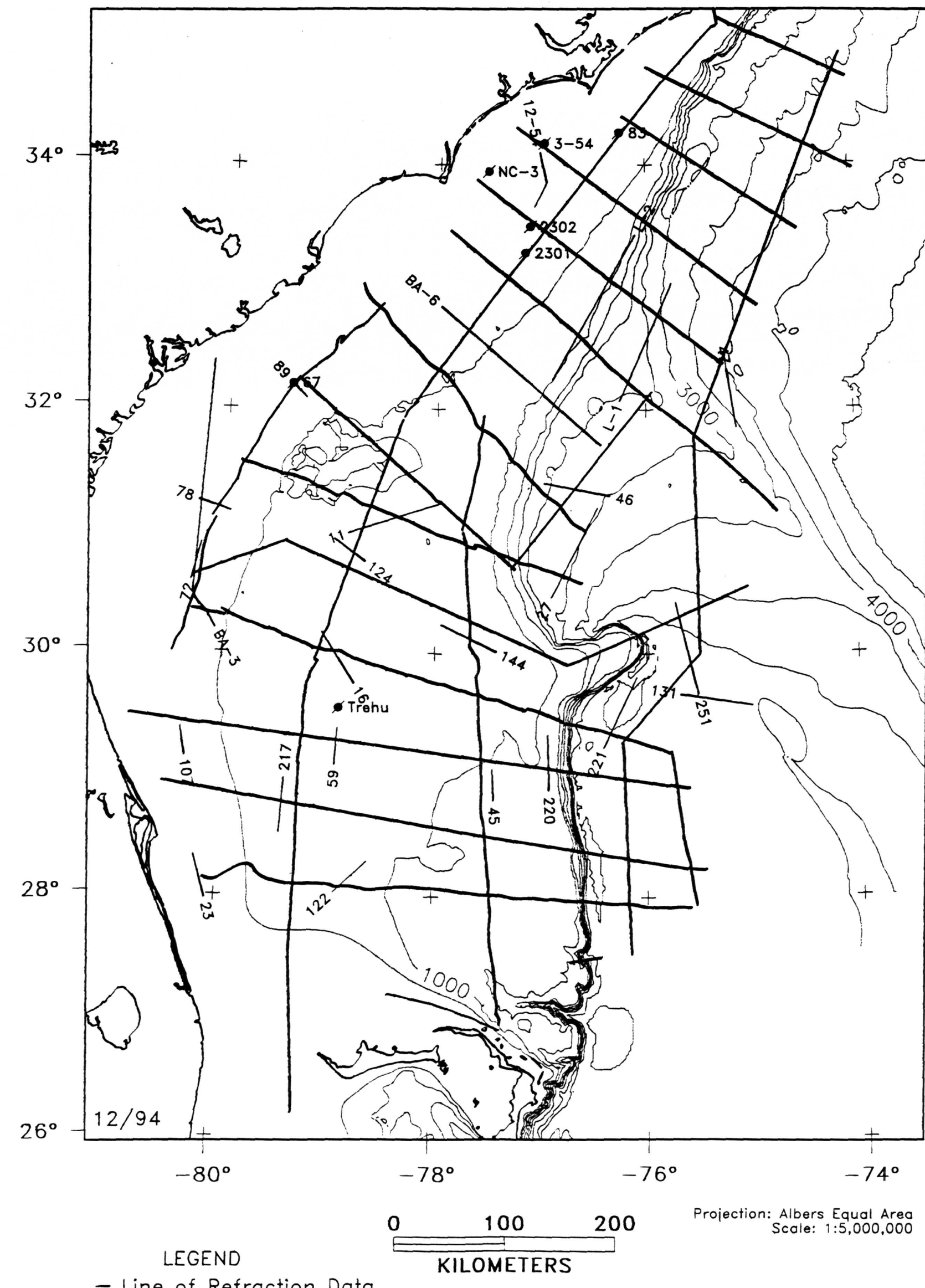




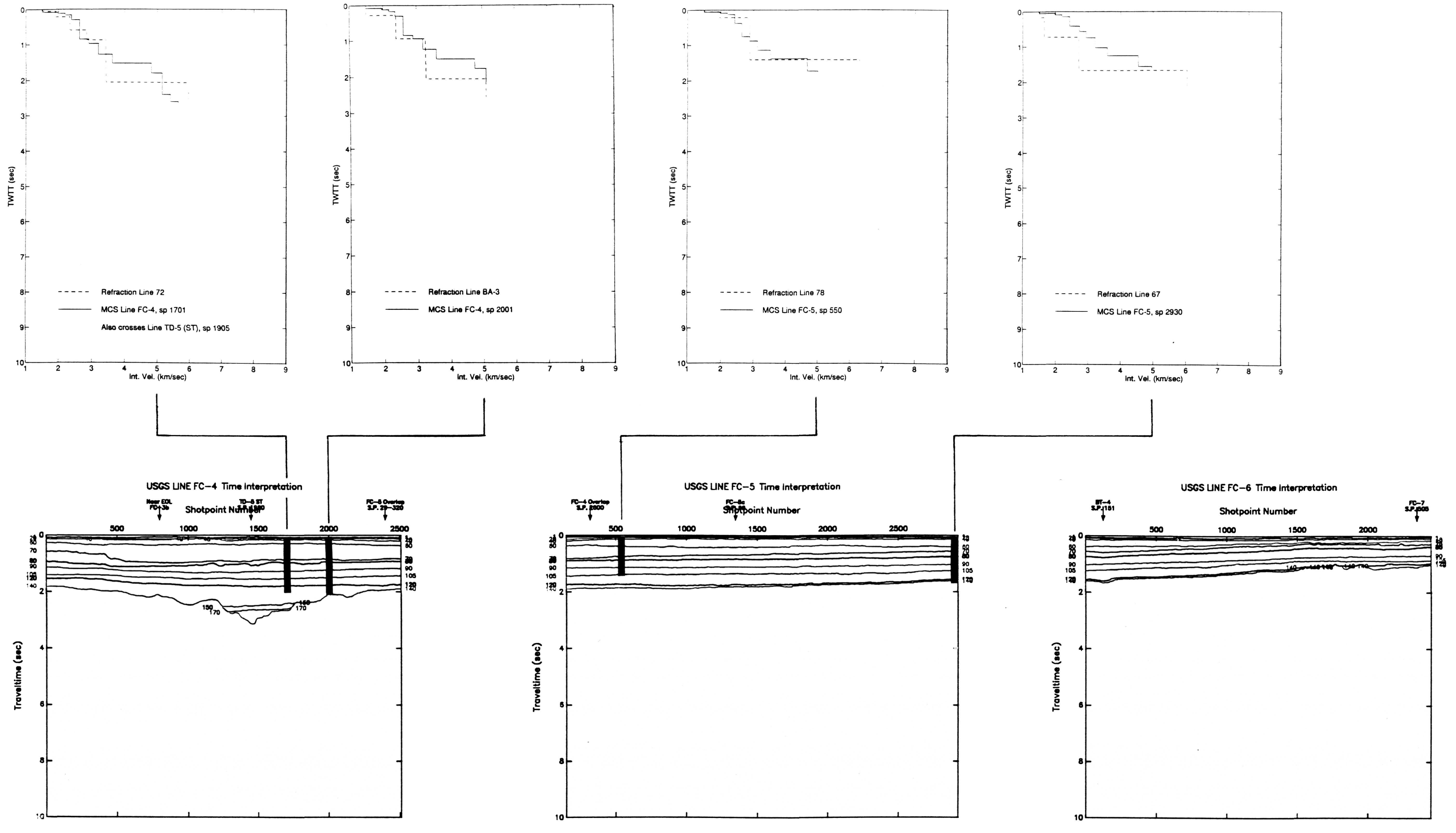




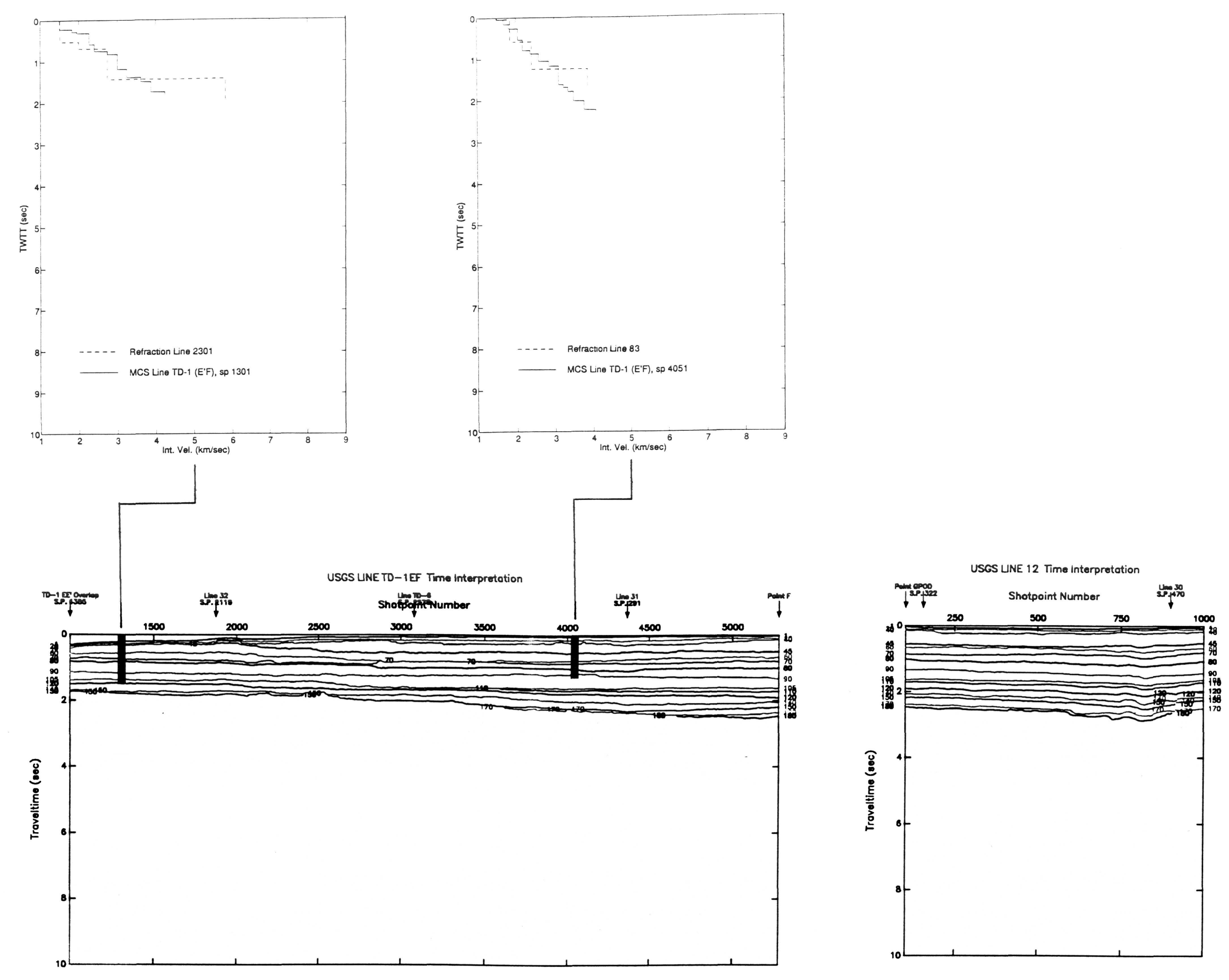


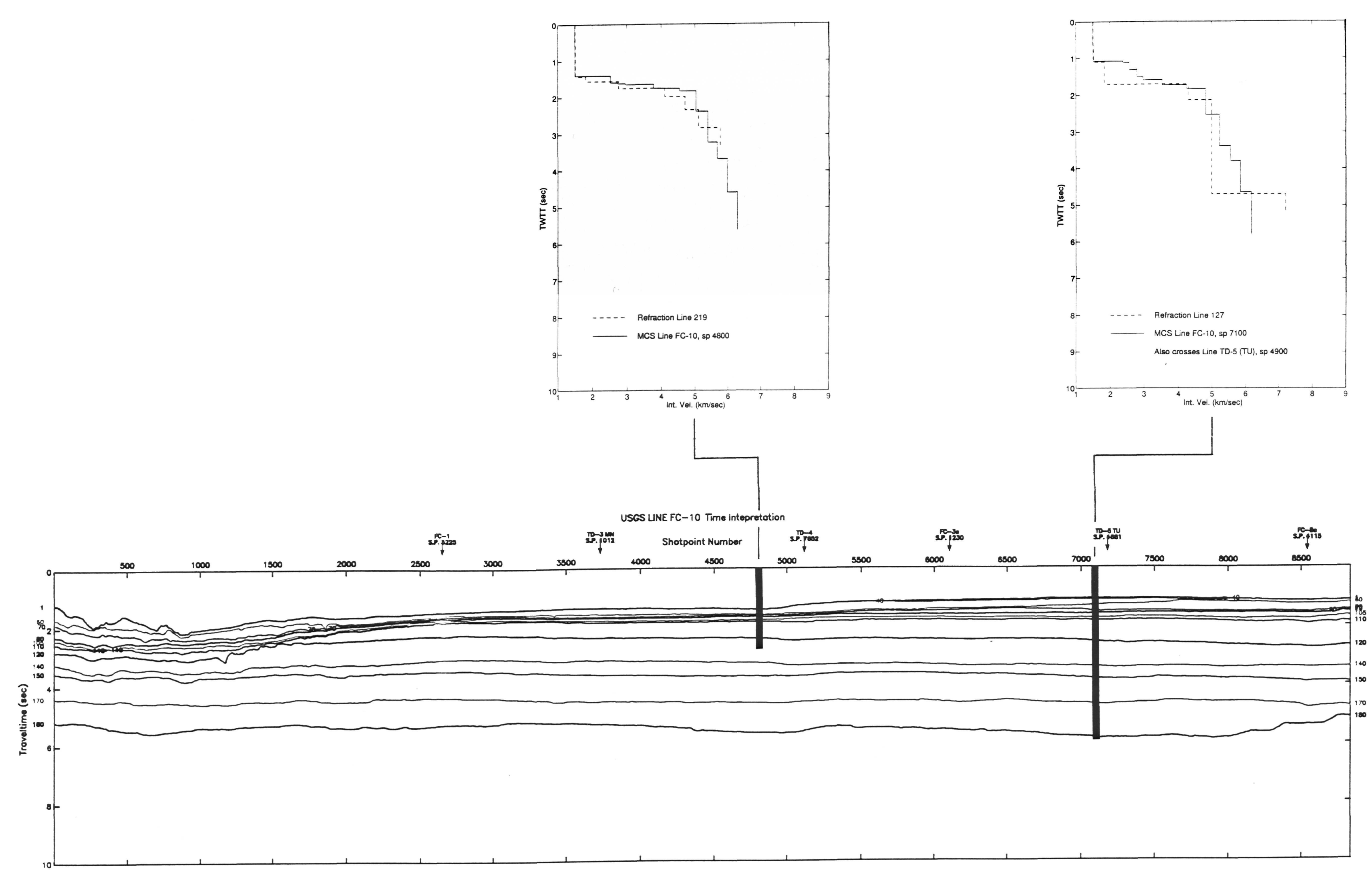




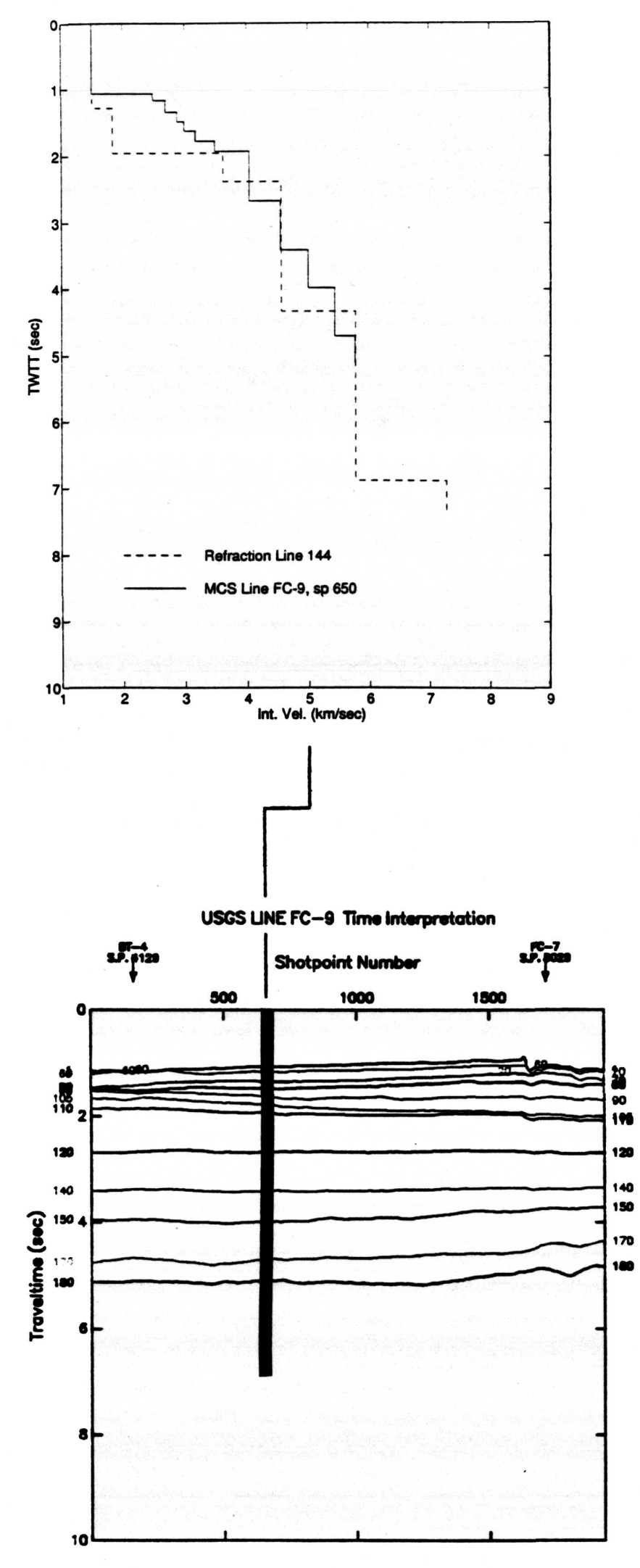

163 


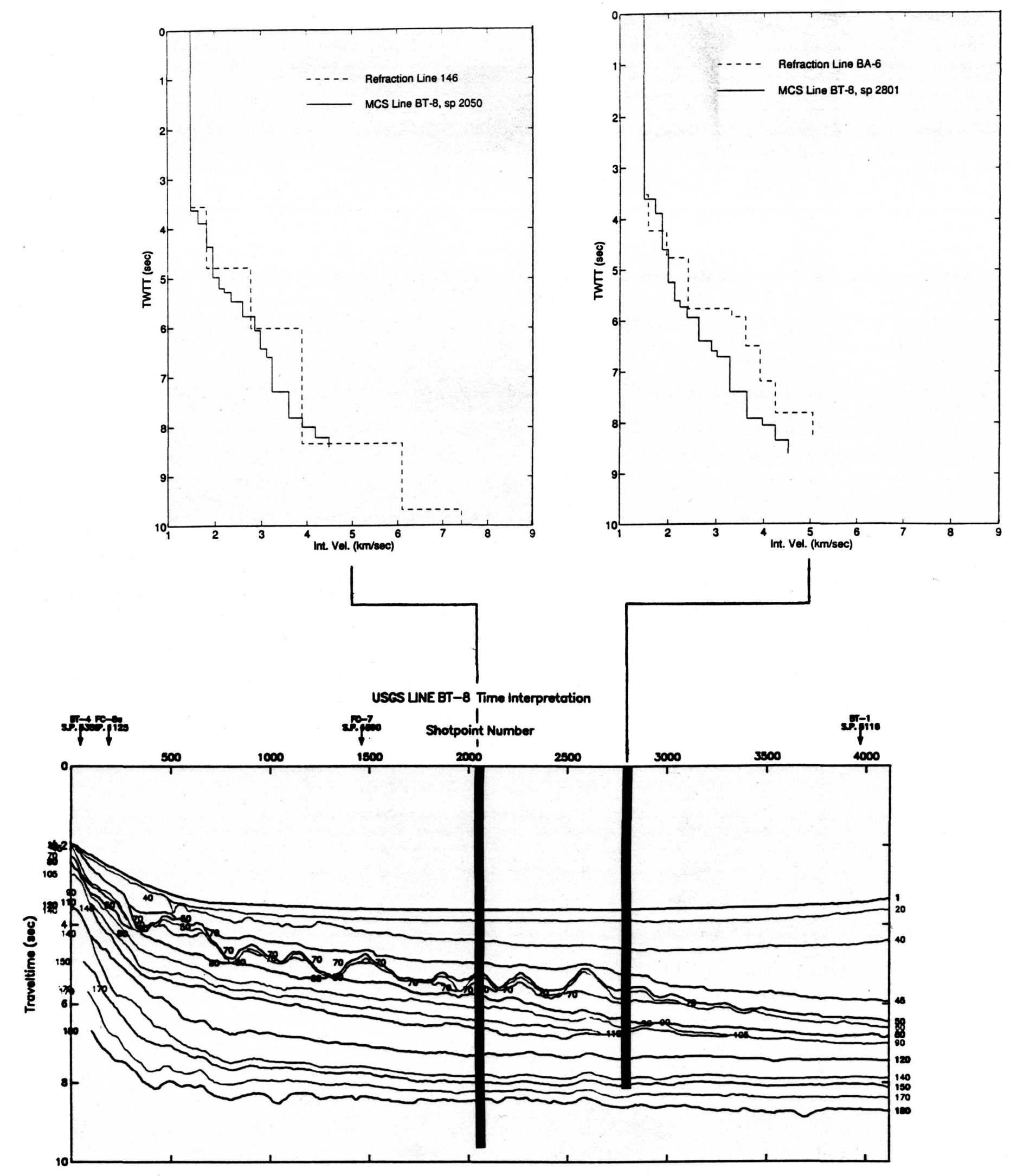



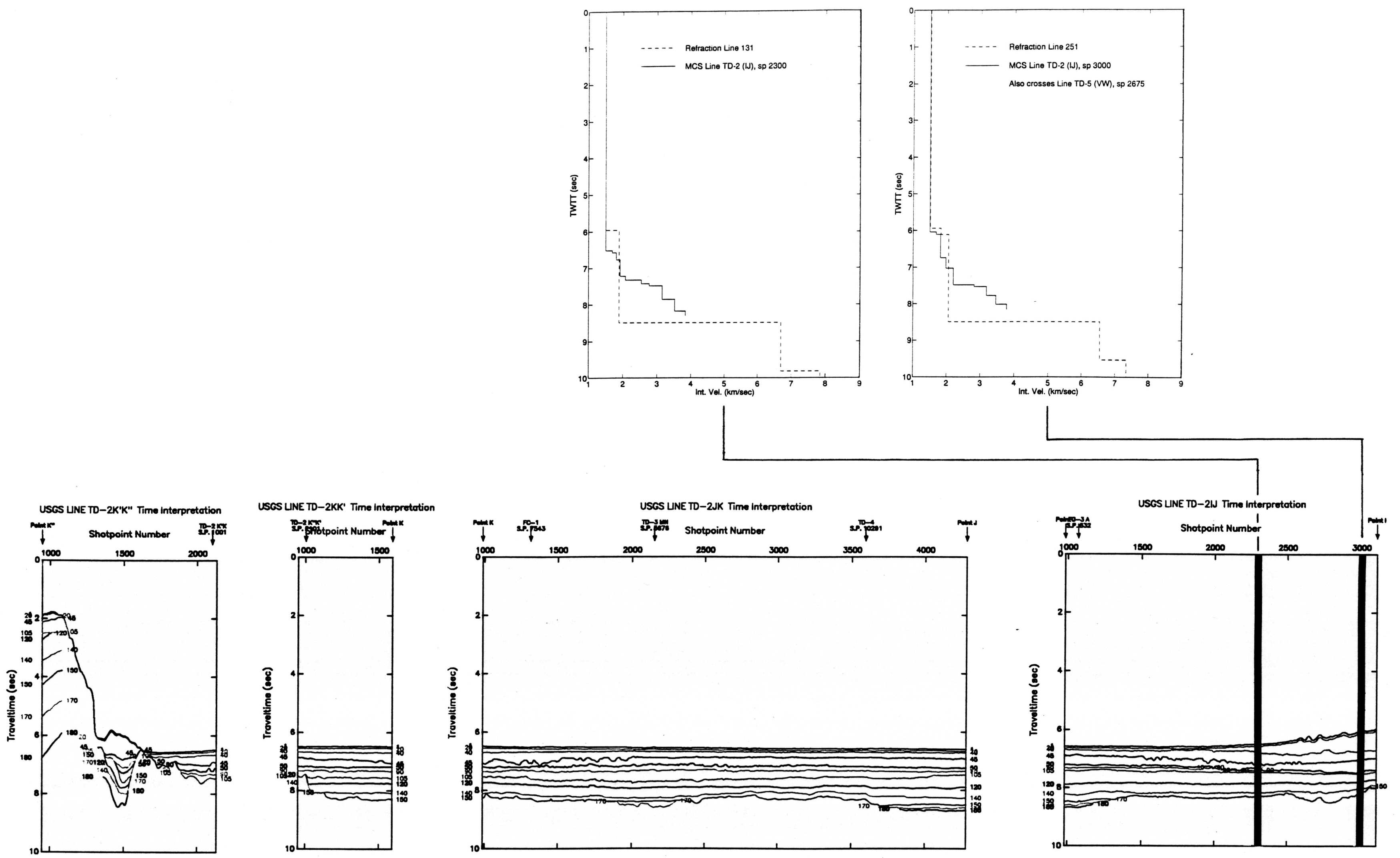


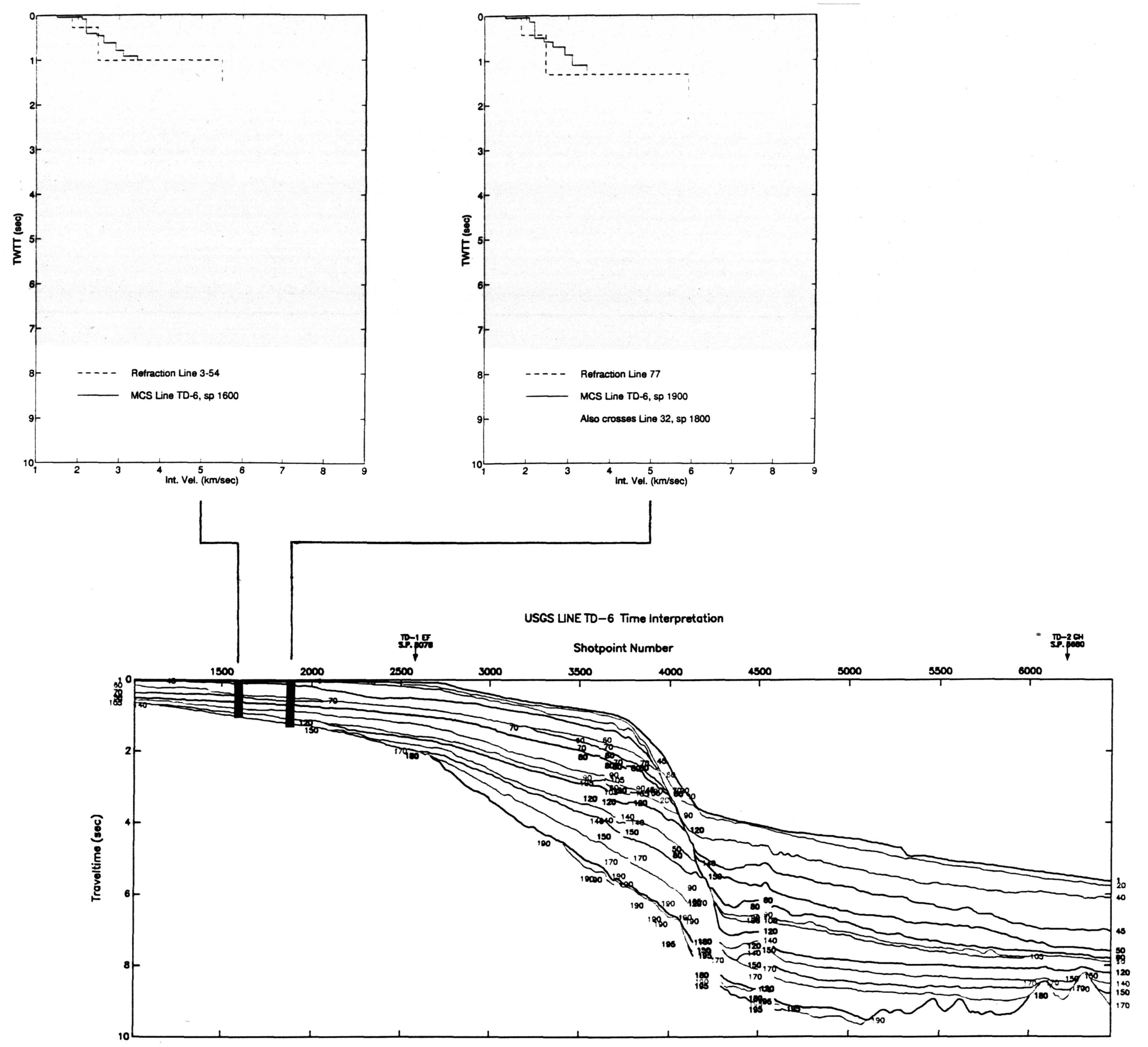




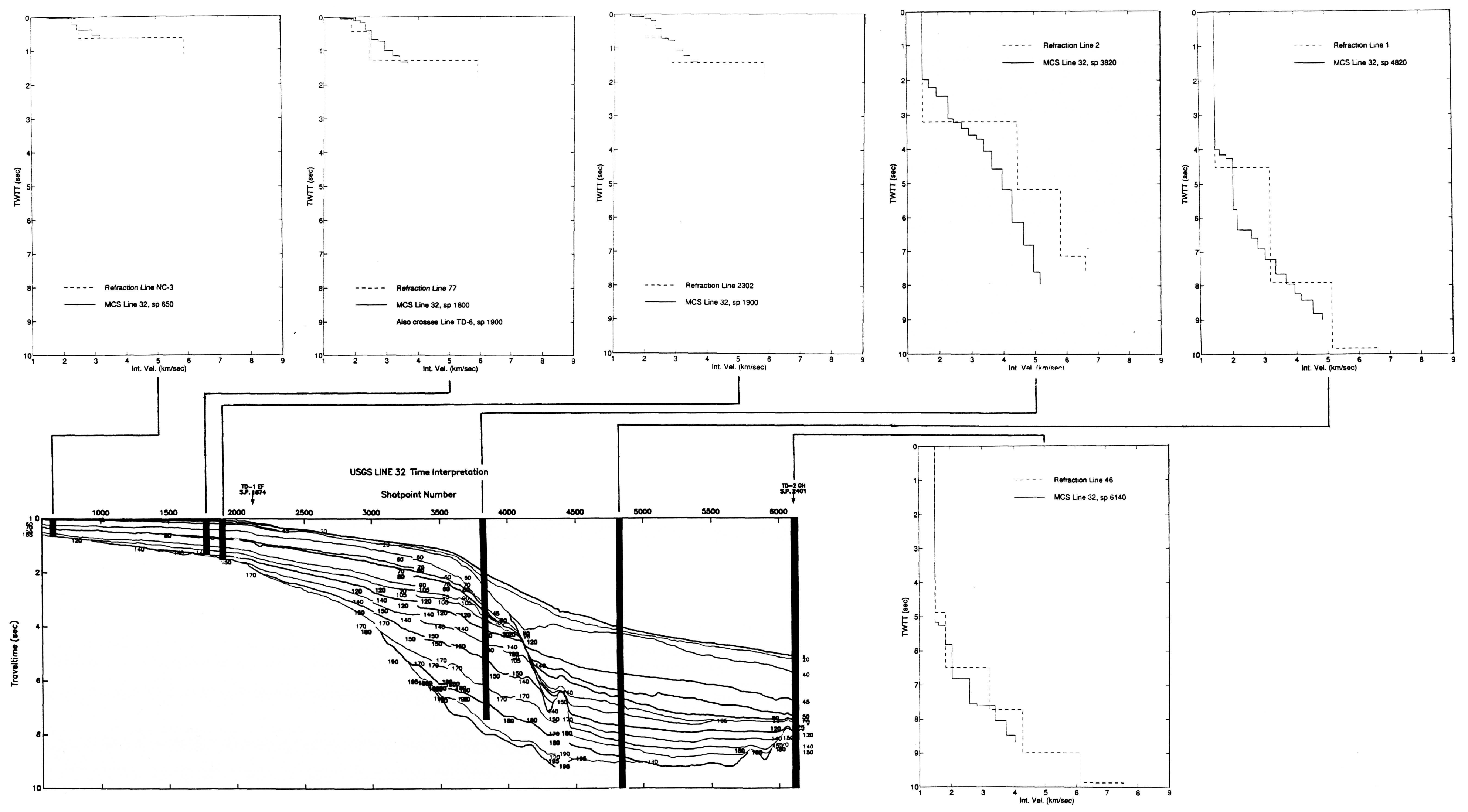




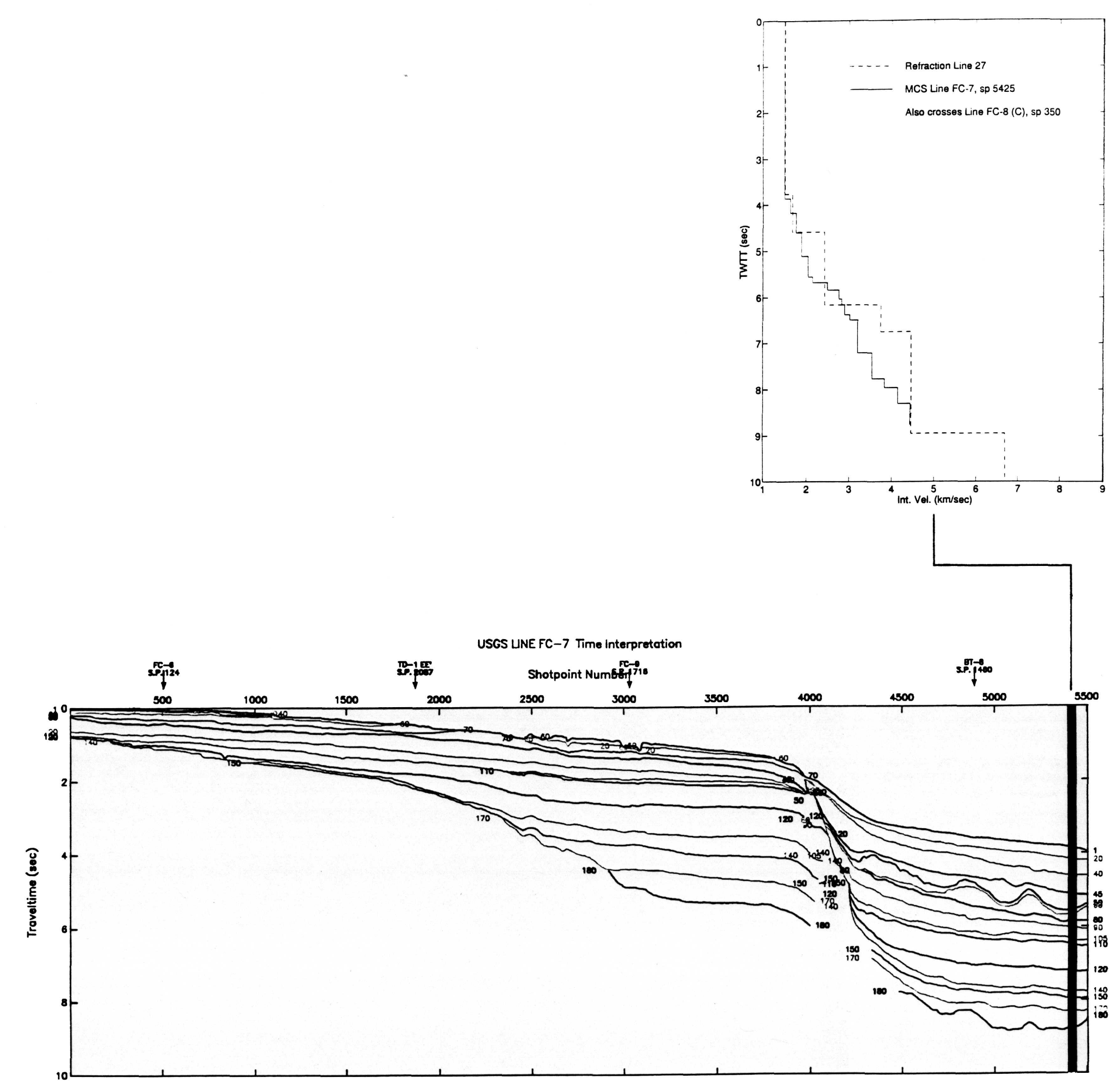




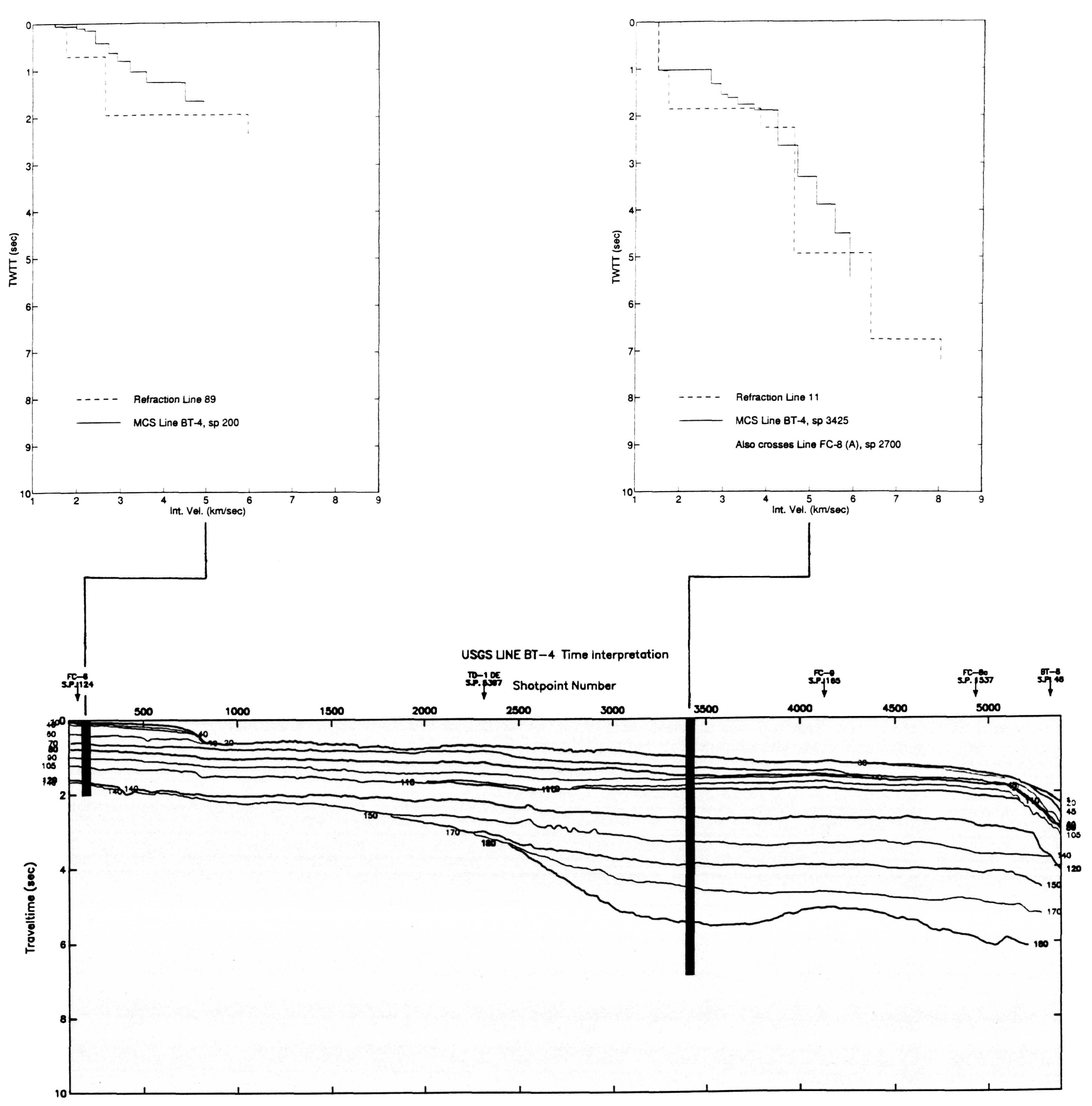



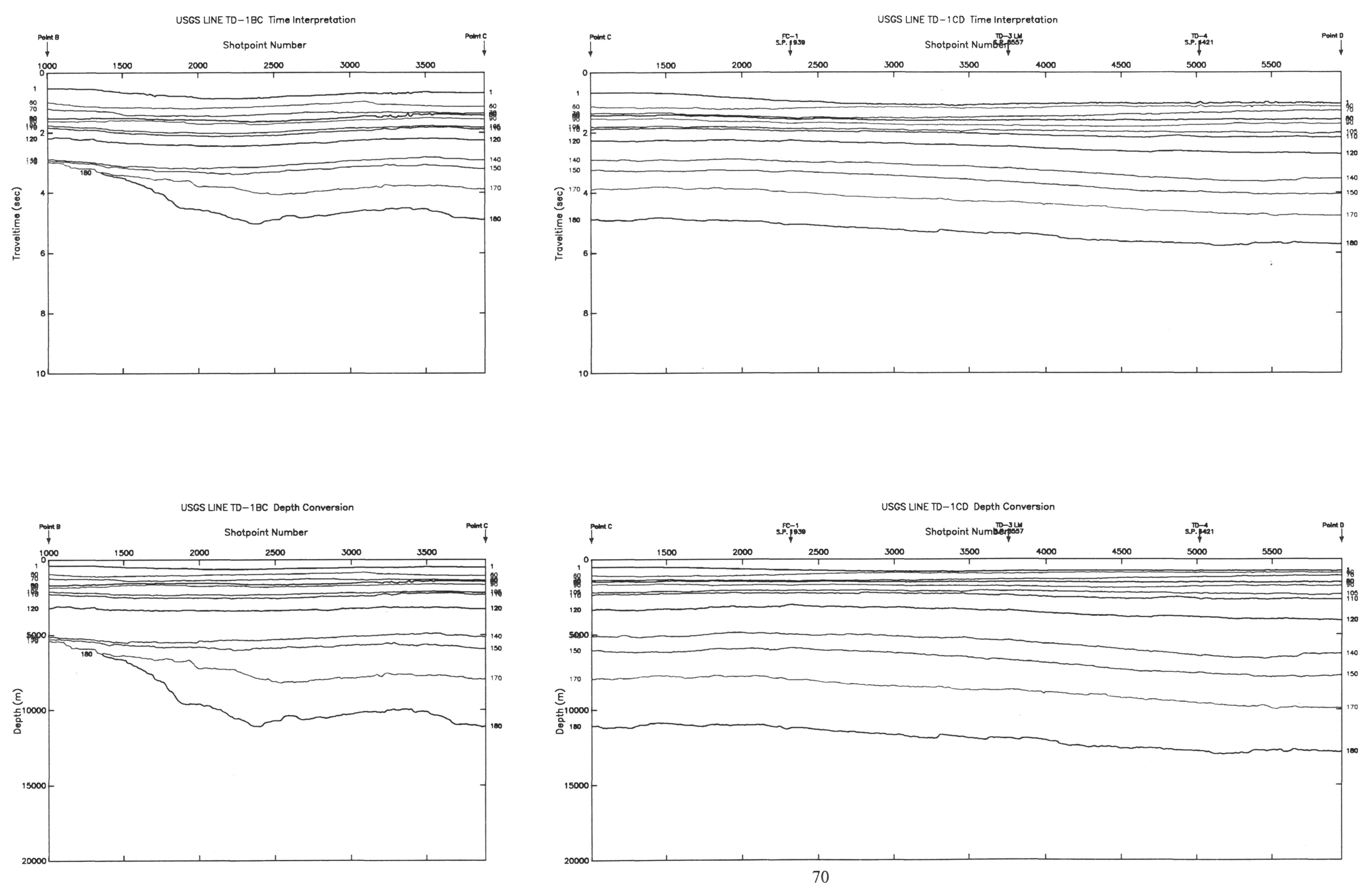

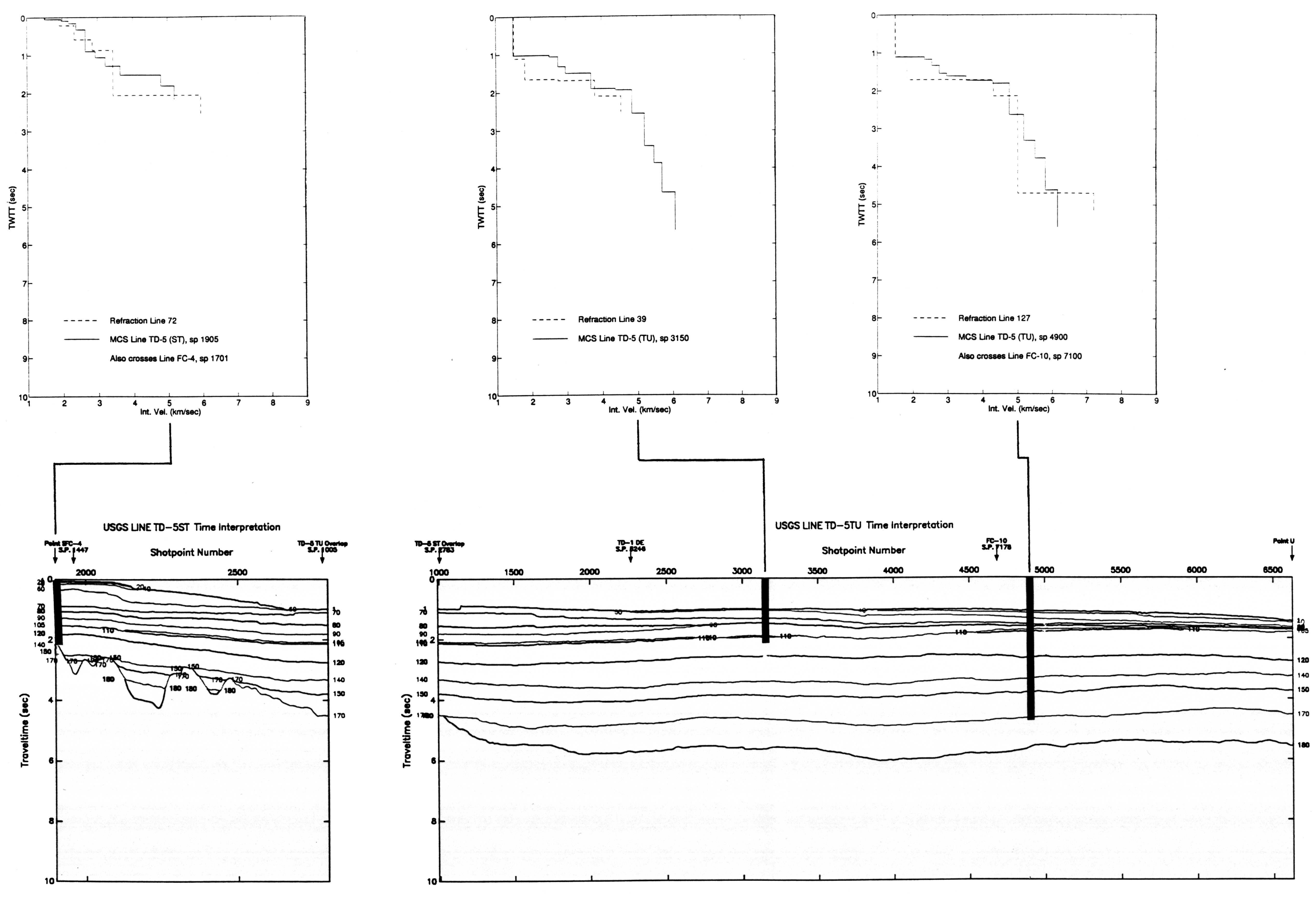

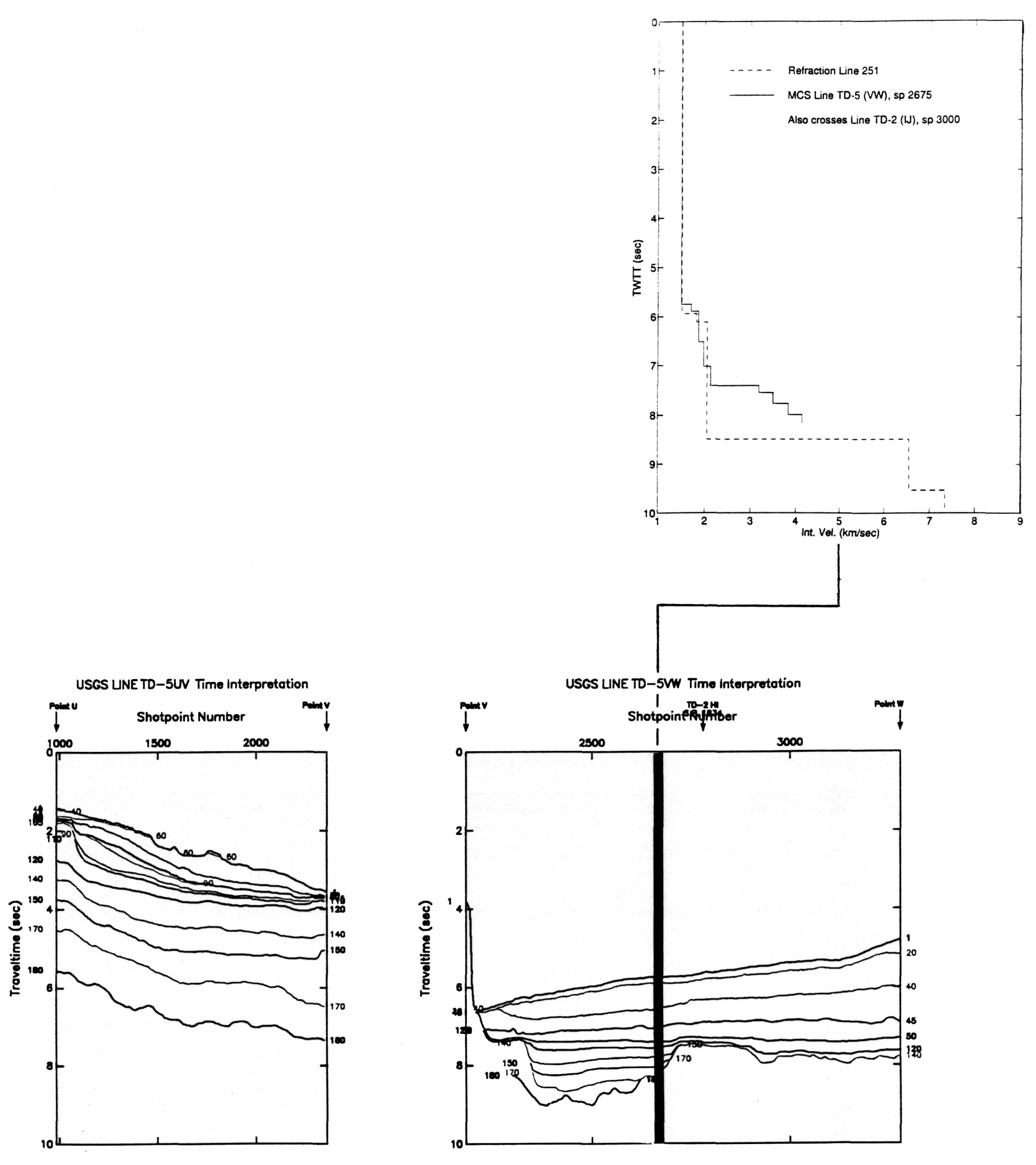

172 

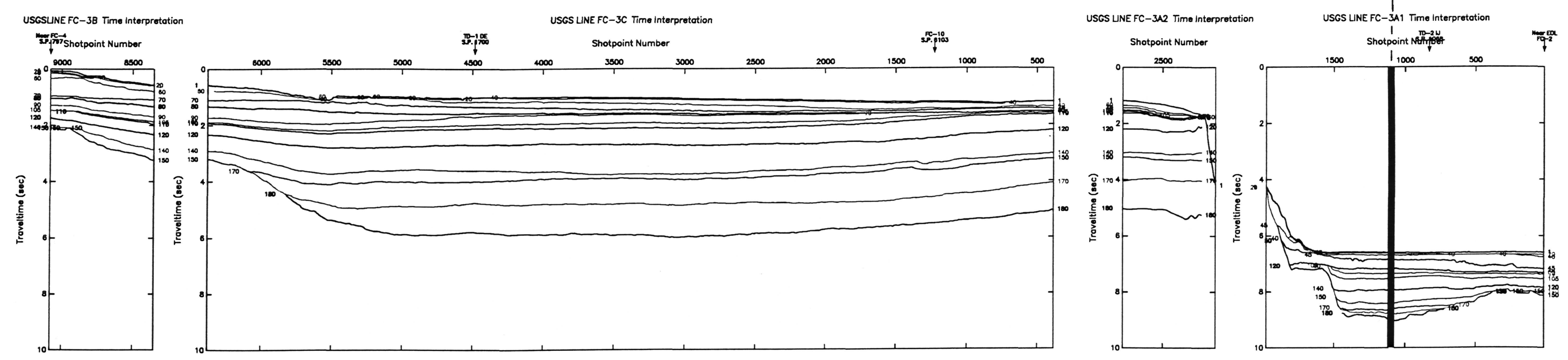


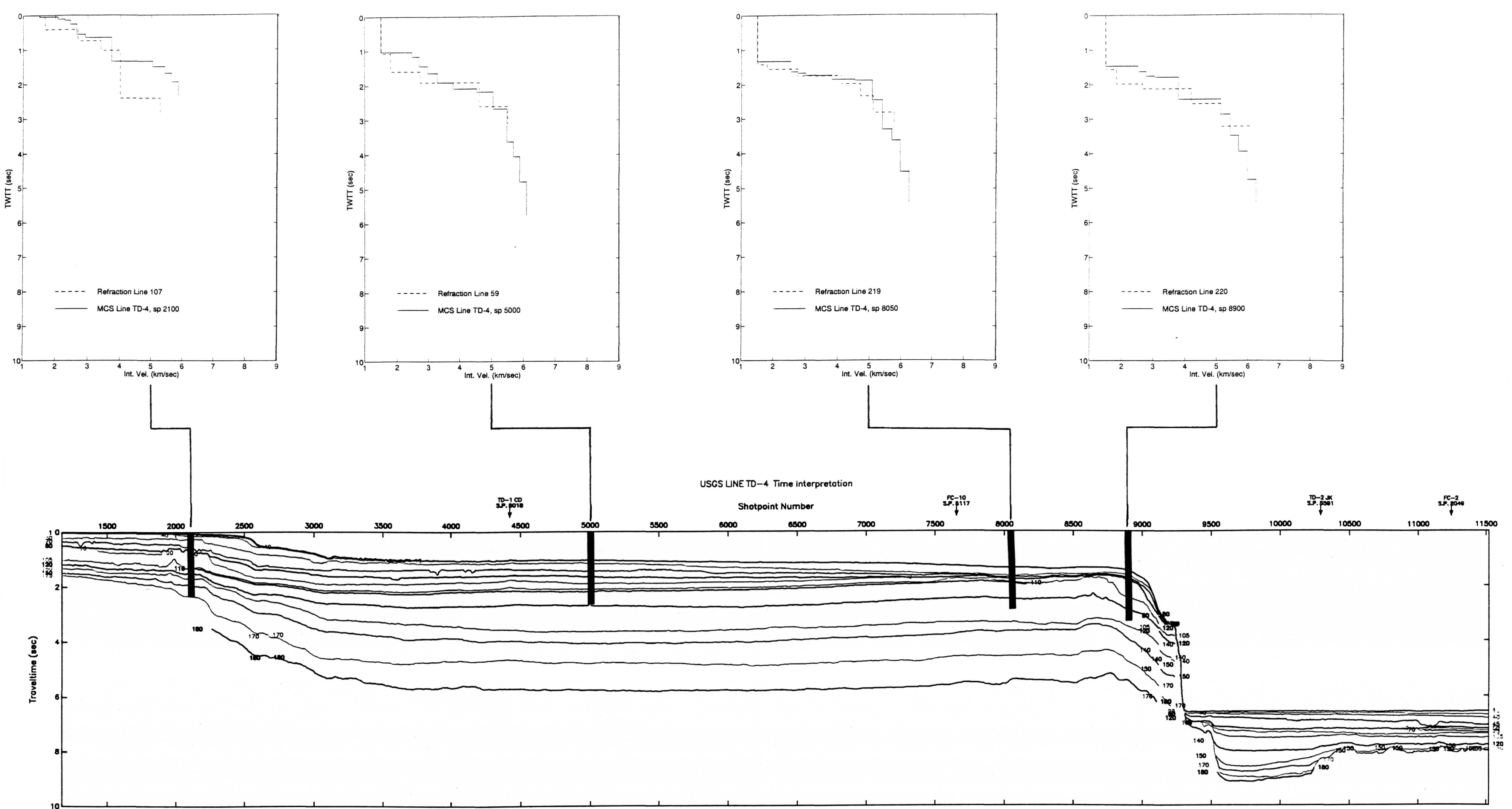




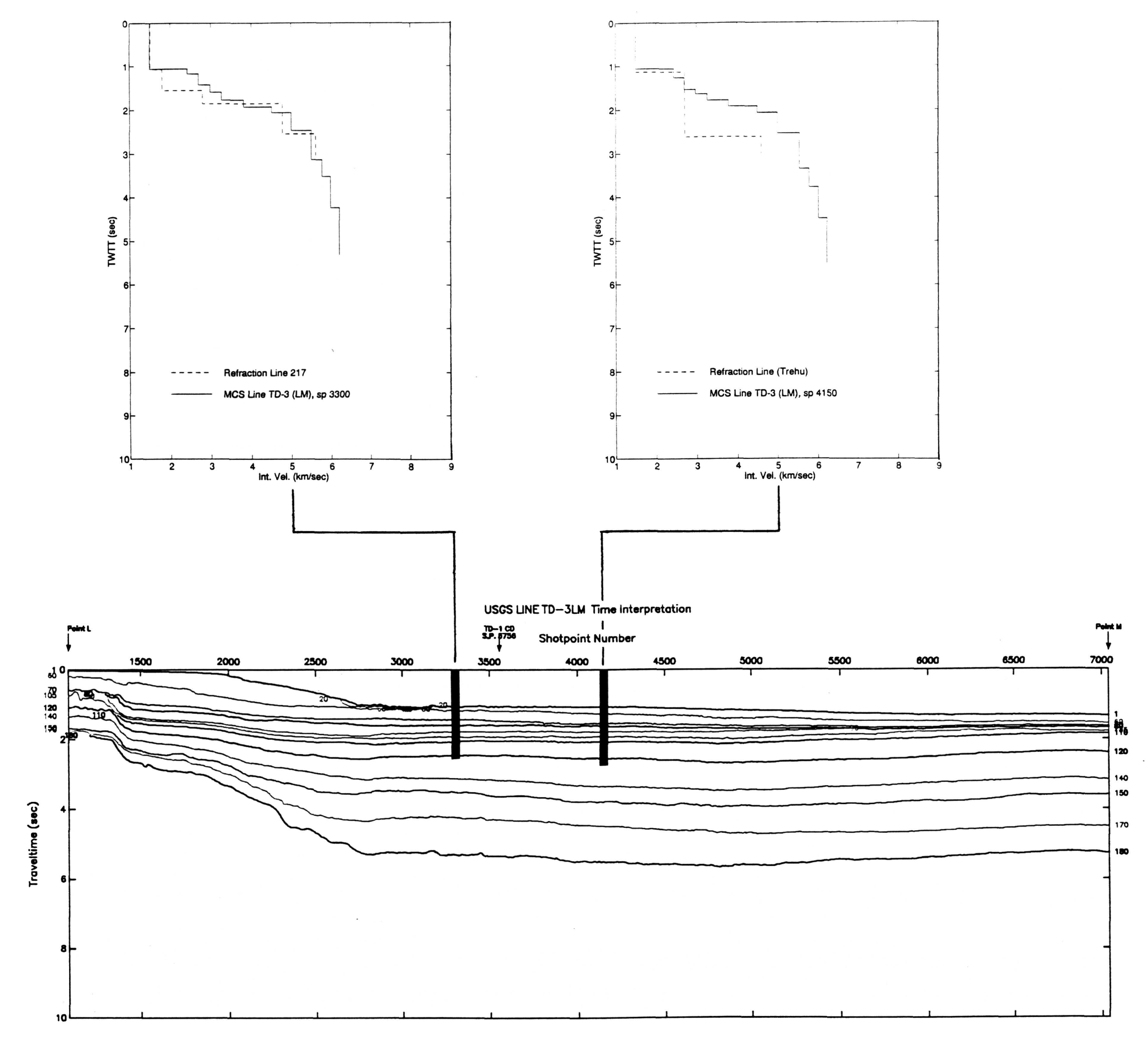




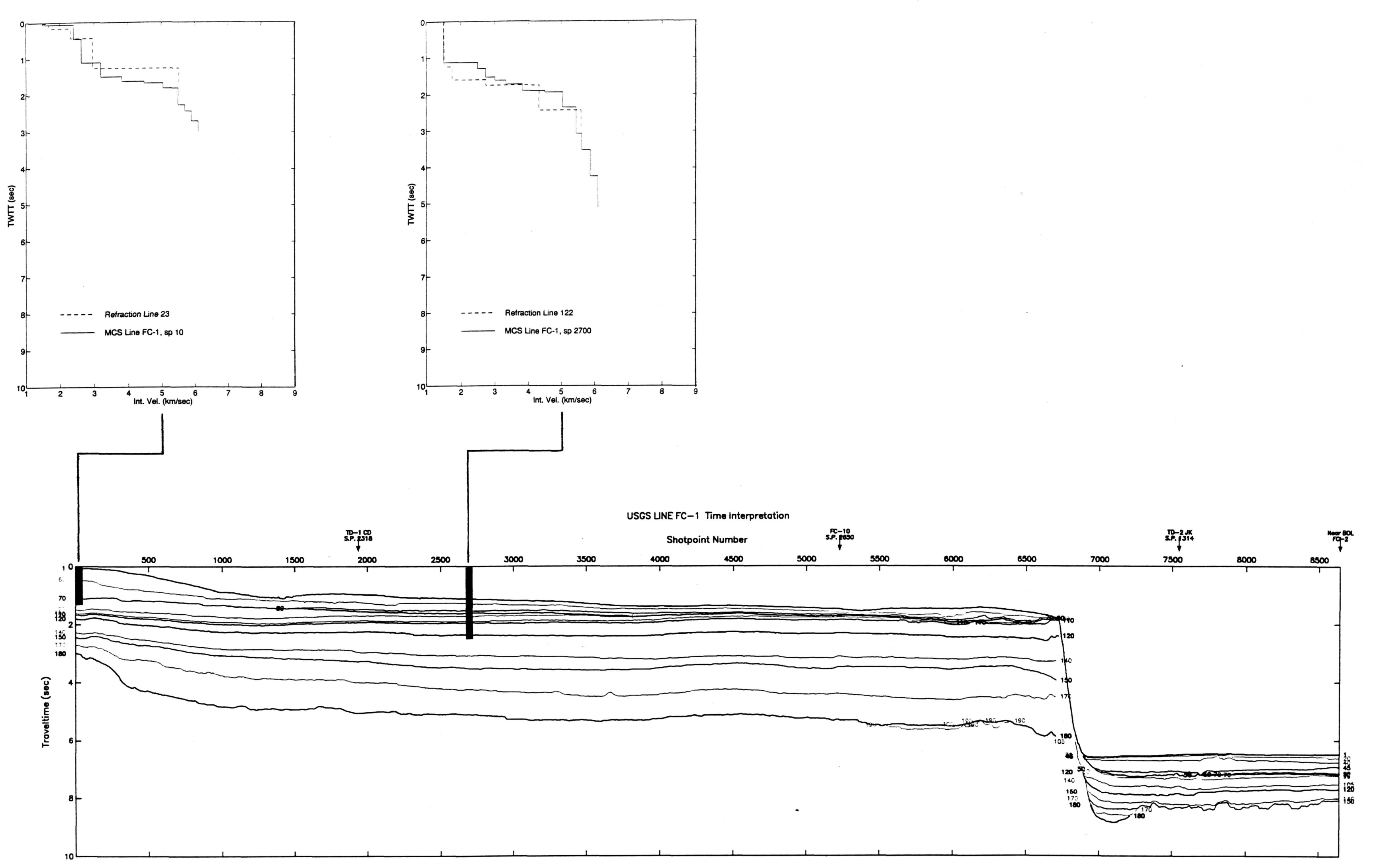

